\title{
Results of the Technical and Economic Feasibility Analysis for a Novel Biomass Gasification-Based Power Generation System for the Forest Products Industry
}

\author{
Phase 1 Pre-Design Evaluation Final Report
}

REPORTING PERIOD:

From: September 2001

To: August 2003

\section{PRINCIPAL AUTHORS:}

Bruce Bryan, GTI

Joseph Rabovitser, GTI

Sunil Ghose, Nexant

Jim Patel, Carbona Corporation

November 2003

DE-FC26-01NT41108

\section{COOPERATIVE AGREEMENT:}

\section{SUBMITTING ORGANIZATION:}

Gas Technology Institute

1700 South Mount Prospect Road

Des Plaines, IL 60018-1804 


\section{DISCLAIMER}

This report was prepared as an account of work sponsored by an agency of the United States Government. Neither the Unites States Government nor any agency thereof, nor any of their employees, makes any warranty, express or implied, or assumes any legal liability or responsibility for the accuracy, completeness, or usefulness of any information, apparatus, product, or process disclosed, or represents that its use would not infringe privately owned rights. Reference herein to any specific commercial product, process, or service by trade name, trademark, manufacturer, or otherwise does not necessarily constitute or imply its endorsement, recommendation, or favoring by the United States Government or any agency thereof. The views and opinions of authors expressed herein do not necessarily state or reflect those of the United States Government or any agency thereof. 


\section{ABSTRACT}

In 2001, the Gas Technology Institute (GTI) entered into Cooperative Agreement DE-FC2601NT41108 with the U.S. Department of Energy (DOE) for an Agenda 2020 project to develop an advanced biomass gasification-based power generation system for near-term deployment in the Forest Products Industry (FPI). The advanced power system combines three advanced components, including biomass gasification, 3-stage stoker-fired combustion for biomass conversion, and externally recuperated gas turbines (ERGTs) for power generation.

The primary performance goals for the advanced power system are to provide increased selfgenerated power production for the mill and to increase wastewood utilization while decreasing fossil fuel use. Additional goals are to reduce boiler $\mathrm{NOx}$ and $\mathrm{CO}_{2}$ emissions. The current study was conducted to determine the technical and economic feasibility of an Advanced Power Generation System capable of meeting these goals so that a capital investment decision can be made regarding its implementation at a paper mill demonstration site in DeRidder, LA.

Preliminary designs and cost estimates were developed for all major equipment, boiler modifications and balance of plant requirements including all utilities required for the project. A three-step implementation plan was developed to reduce technology risk. The plant design was found to meet the primary objectives of the project for increased bark utilization, decreased fossil fuel use, and increased self-generated power in the mill. Bark utilization for the modified plant is significantly higher (90-130\%) than current operation compared to the $50 \%$ design goal. For equivalent steam production, the total gas usage for the fully implemented plant is $29 \%$ lower than current operation. While the current average steam production from No. 2 Boiler is about $213,000 \mathrm{lb} / \mathrm{h}$, the total steam production from the modified plant is $379,000 \mathrm{lb} / \mathrm{h}$. This steam production increase will be accomplished at a grate heat release rate (GHRR) equal to the original boiler design. Boiler efficiencies (cogeneration-steam plus air) is increased from the original design value of $70 \%$ to $78.9 \%$ due to a combination of improved burnout, operation with lower excess air, and drier fuel. For the fully implemented plant, the thermal efficiency of fuel to electricity conversion is $79.8 \%$ in the cogeneration mode, $5 \%$ above the design goal. Finally, self-generated electricity will be increased from the $10.8 \mathrm{MW}$ currently attributable to No.2 Boiler to $46.7 \mathrm{MW}$, an increase of $332 \%$.

Environmental benefits derived from the system include a reduction in NOx emissions from the boiler of about $30-50 \%$ (90-130 tons/year) through syngas reburning, improved carbon burnout and lower excess air. This does not count NOx reduction that may be associated with replacement of purchased electricity. The project would reduce $\mathrm{CO}_{2}$ emissions from the generation of electricity to meet the mill's power requirements, including 50,000 tons/yr from a net reduction in gas usage in the mill and an additional 410,000 tons/yr reduction in $\mathrm{CO}_{2}$ emissions due to a $34 \mathrm{MW}$ reduction of purchased electricity. The total $\mathrm{CO}_{2}$ reduction amounts to about $33 \%$ of the $\mathrm{CO}_{2}$ currently generated to meet the mills electricity requirement.

The overall conclusion of the study is that while significant engineering challenges are presented by the proposed system, they can be met with operationally acceptable and cost effective solutions. The benefits of the system can be realized in an economic manner, with a simple payback period on the order of 6 years. The results of the study are applicable to many paper mills in the U.S. firing woodwastes and other solid fuels for steam and power production. 


\section{TABLE OF CONTENTS}

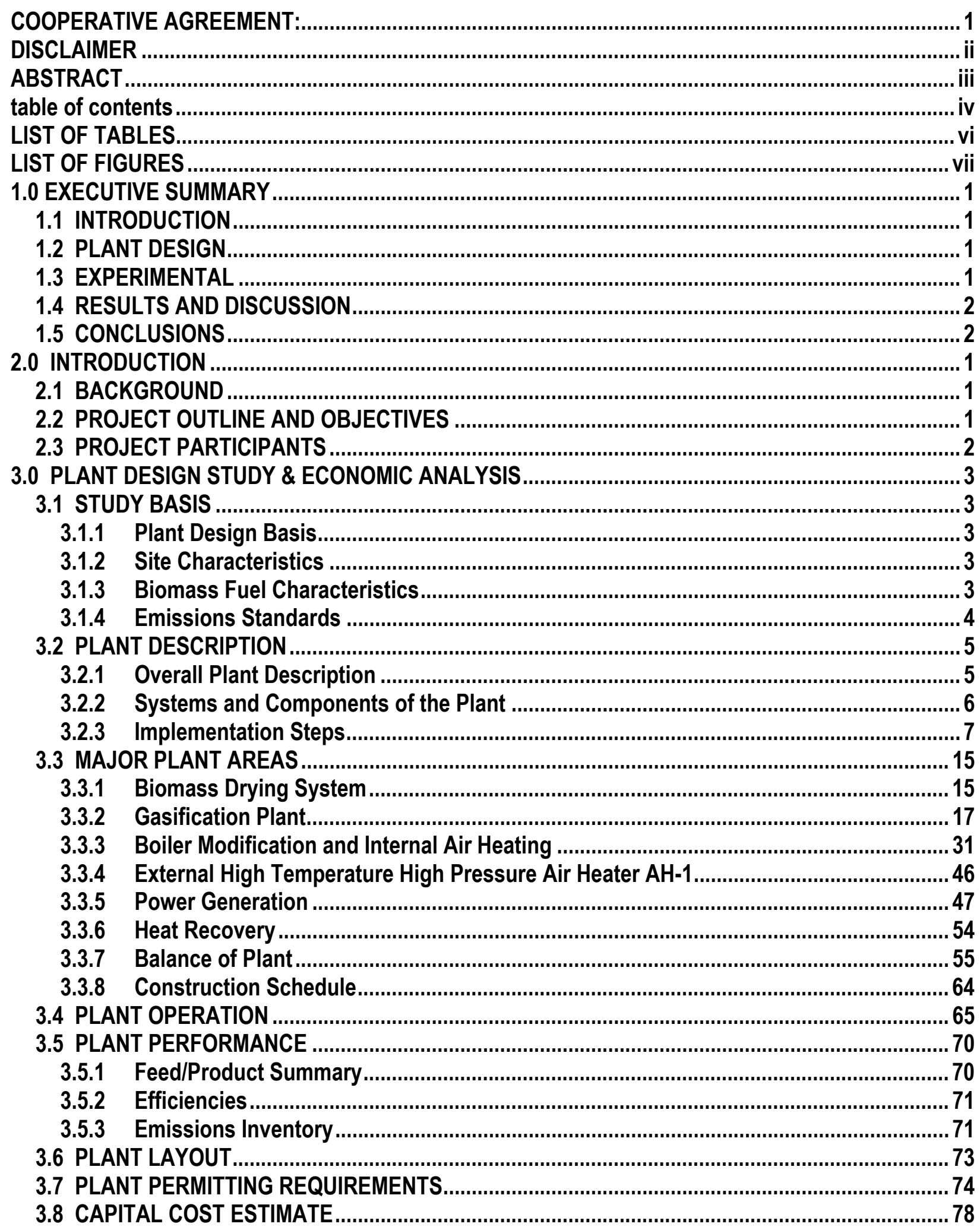




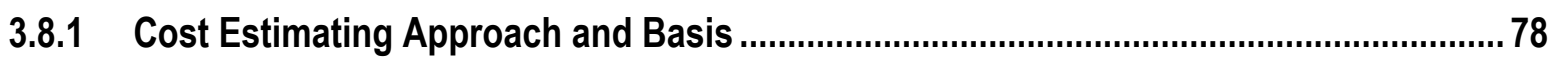

3.8.2 Data Source for the Estimate ............................................................................

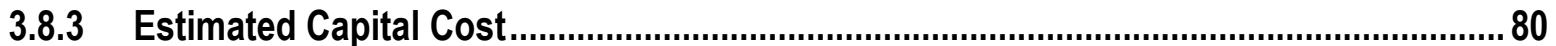

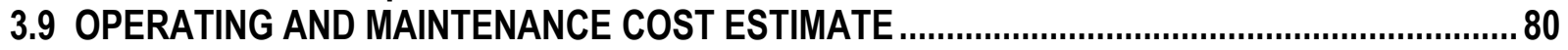

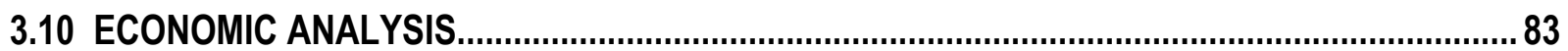

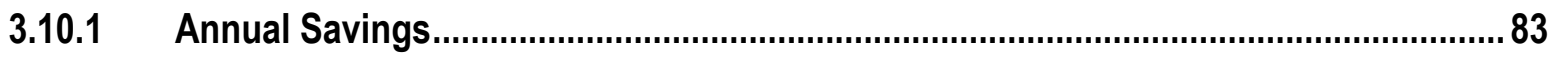

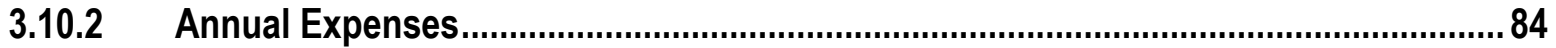

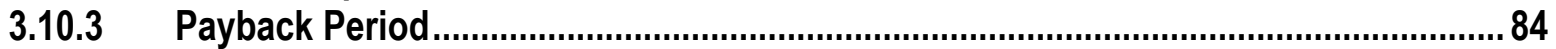

3.10.4 Demonstration vs. Commercial Plant Economics .................................................. 84

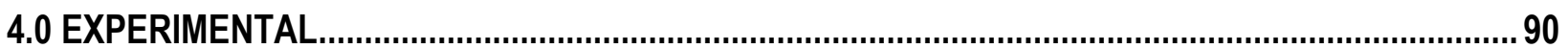

4.1 INSTITUTE OF PAPER SCIENCE AND TECHNOLOGY BARK DRYING VOC STUDY ................90

4.2 HIGH-TEMPERATURE HIGH-PRESSURE AIR HEATER MATERIALS TESTING .......................97

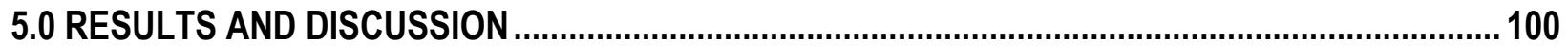

5.1 FINDINGS FOR THE DERIDDER MILL...................................................................... 100

5.2 APPLICATION OF THE TECHNOLOGY TO OTHER MILLS................................................ 102

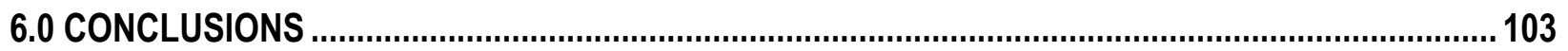

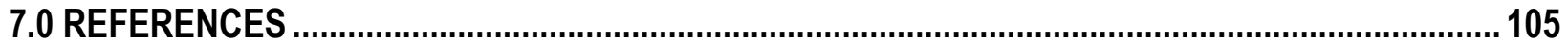

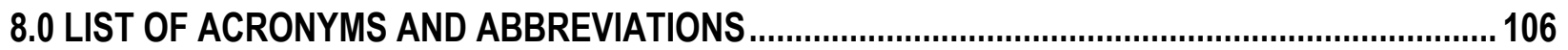

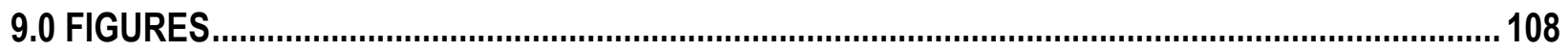

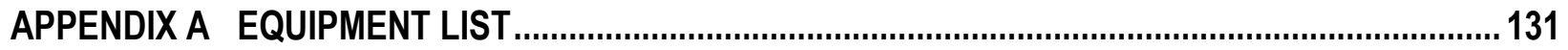

APPENDIX B SOLAR TURBINES INCORPORATED Final Report .................................................. 136 


\section{LIST OF TABLES}

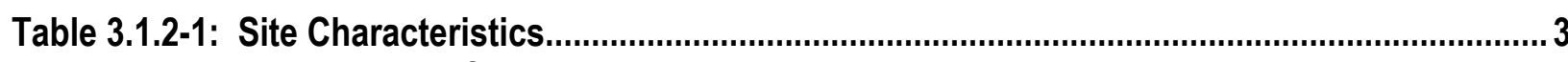

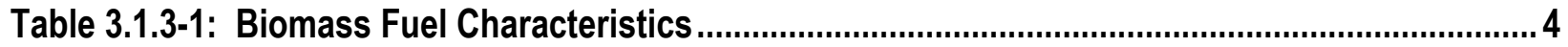

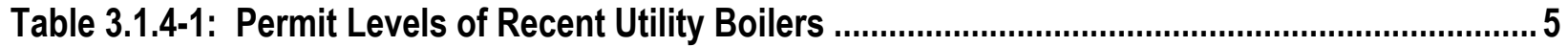

Table 3.2.3-1 Heat and Material Balance for Implementation Step 1 ..............................................

Table 3.2.3-2 Heat and Material Balance for Implementation Step 2 .................................................11

Table 3.2.3-3 Heat and Material Balance for Implementation Step 3 ..............................................13

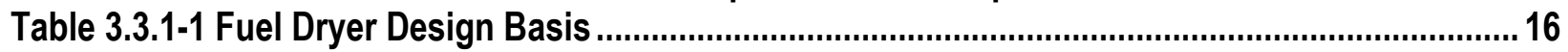

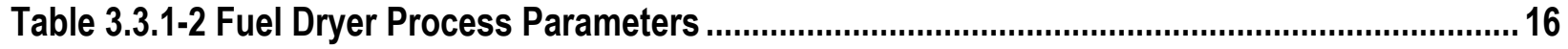

Table 3.3.2-1. Fuel Specification.......................................................................................... 18

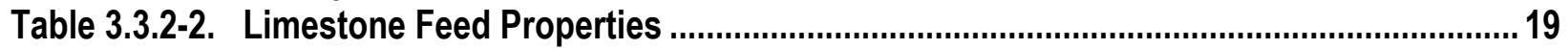

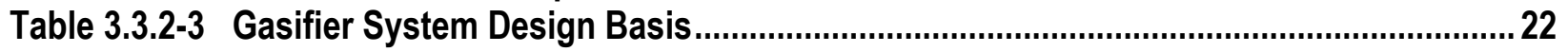

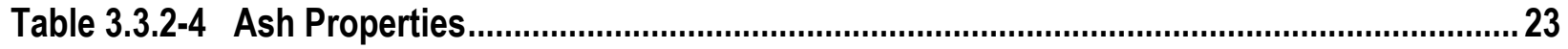

Table 3.3.2-5 Process Air Compressor Design Parameters ............................................................. 24

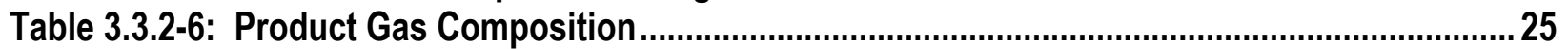

Table 3.3.2-7: Product Gas Properties After Partial Combustion ..................................................... 26

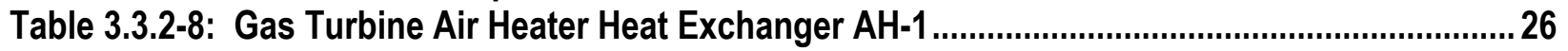

Table 3.3.2-9: Design Parameters of Emergency Spraying Nozzle .....................................................2

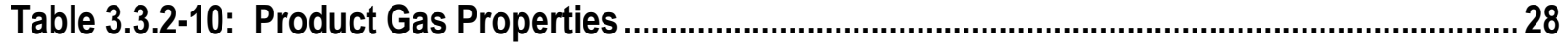

Table 3.3.2-11 Flare Design Parameters ..................................................................................29

Table 3.3.2-12: Nitrogen Generation System Process Design Parameters..................................... 31

Table 3.3.3-1: Boiler Performance - Original Design and 2001 Upgrade ............................................... 34

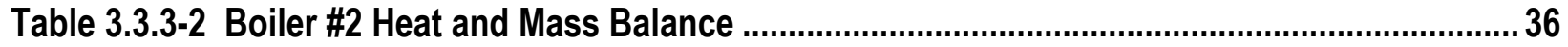

Table 3.3.3-3: Circulation Study Results ............................................................................... 42

Table 3.3.3-4: FD Fan and ID Fan Performance................................................................. 45

Table 3.3.6-1 HRSG Performance ....................................................................................... 54

Table 3.5.1-1 Baseline and Modified Plant Performance Comparison ................................................70

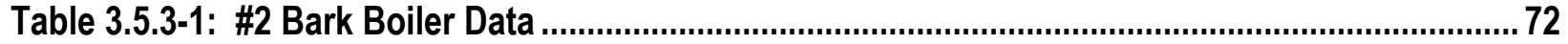

Table 3.8-1: Estimated Capital Cost - Direct Cost....................................................................... 81

Table 3.10-1: Input Parameters for Economic Analysis ............................................................... 83

Table 3.10-2a: Economic Analysis - Energy Consumption and Saving .............................................. 86

Table 3.10-2b: Economic Analysis - Cost Savings and Payback Period) ...........................................8

Table 3.10-3a: Economic Analysis - Alternative - Energy Consumption and Saving..........................88

Table 3.10-3b: Economic Analysis - Alternative - Cost Savings and Payback Period .........................89 


\section{LIST OF FIGURES}

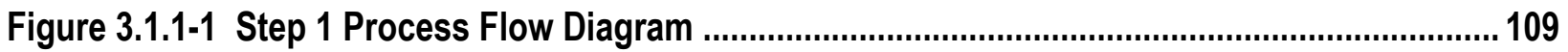

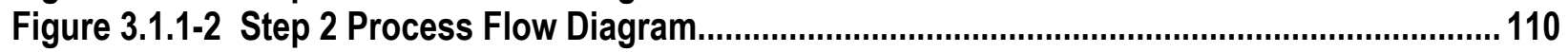

Figure 3.1.1-3 Step 3 and Overall Plant Process Flow Diagram ...................................................111

Figure 3.3.1-1: Biomass Dryer Process Flow Diagram ........................................................112

Figure 3.3.2-1: Gasification Process Flow Diagram - Step 3 ......................................................113

Figure 3.3.3-1 Internal High Temperature High Pressure Air Heater .................................................114

Figure 3.3.3-2 Internal HTHP Air Heater - Selected View 1 .........................................................115

Figure 3.3.3-3 Internal HTHP Air Heater - Selected View 2 .........................................................116

Figure 3.3.3-4 Metal Study for Internal HTHP Air Heater - No Air Imbalance .................................117

Figure 3.3.3-5 Metal Study for Internal HTHP Air Heater - With Air Imbalance ...............................118

Figure 3.3.4-1 External High Temperature High Pressure Air Heater-Design 1................................ 119

Figure 3.3.6-1 HRSG Arrangement and Performance ….......................................................... 120

Figure 3.3.7-1 Cooling Water System................................................................................ 121

Figure 3.3.7-2 Compressed Air System ............................................................................ 122

Figure 3.3.7-3 Electrical Single Line Diagram ................................................................... 123

Figure 3.3.7-4 Bark Conveying and Delivery System ............................................................... 124

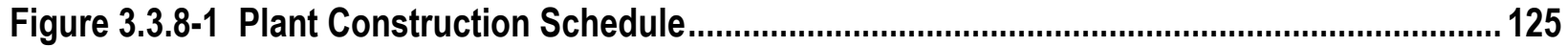

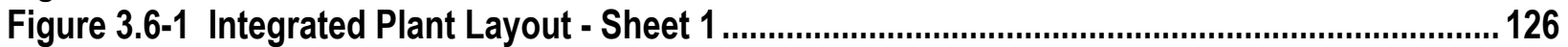

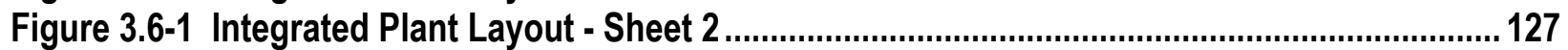

Figure 3.6-1 Integrated Plant Layout - Sheet 3 …................................................................... 128

Figure 4.2-1. Locations of Tube Samples in No. 2 Bark Boiler at Boise DeRidder .........................129

Figure 4.2-2 Test Assemblies for Tube Testing in No. 2 Bark Boiler DeRidder...............................129

Figure 4.2-3. Typical Temperature Profile for Test Tube Coupons with air temperature control (800

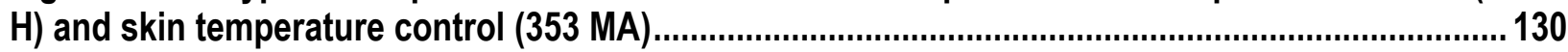




\subsection{EXECUTIVE SUMMARY}

\subsection{INTRODUCTION}

Paper mills use stoker boilers extensively to recover energy from wastewood, bark, and sludge. Because of the variability of feedstock moisture and ash content, the steam generation capacity of these boilers is generally limited by the ability to burn fuel on the grate. This limitation can be overcome by fuel and air staging, which improve combustion, reduce NOx emissions, and increase boiler efficiency through improved carbon burnout and operation at reduced excess air.

In 2001, the Gas Technology Institute (GTI) entered into Cooperative Agreement DE-FC2601NT41108 with the U.S. Department of Energy (DOE) for an Agenda 2020 project to develop an advanced biomass gasification-based power generation system for near-term deployment in the Forest Products Industry (FPI). The advanced power system will be used in conjunction with existing wood waste fired boilers and flue gas cleanup systems. It combines three advanced components, including biomass gasification, 3-stage stoker-fired combustion for biomass conversion, and externally recuperated gas turbines (ERGTs) for power generation.

The primary performance goals for the advanced power system are to provide increased selfgenerated power production for the mill and to increase wastewood utilization while decreasing fossil fuel use. Additional goals are to reduce boiler $\mathrm{NOx}$ and $\mathrm{CO}_{2}$ emissions. The objective of the current study is to determine the technical and economic feasibility of an Advanced Power Generation System capable of meeting these goals so that a capital investment decision can be made regarding its implementation at a paper mill demonstration site in DeRidder, LA.

\subsection{PLANT DESIGN}

The study revealed that the original system configuration, with all high-pressure air heated in the bark boiler, was not feasible due to space and heat limitations. An alternate design was developed using chemical and sensible heat in the gasifier syngas stream to heat air in a second, external heat exchanger between the gasifier and the boiler. Bark dryers were added to insure gasifier feed reliability and to make more high-level heat in the furnace available for air heating.

Preliminary designs and cost estimates were developed for all major equipment, boiler modifications and balance of plant requirements. All utilities are produced by the project. An implementation plan was developed to reduce technology risk. In implementation Step 1 the gasification island, the external air heater, one turbine, one HRSG and one bark dryer will be installed. In Step 2, the second bark dryer will be installed to dry bark for the boiler and in Step 3 , the internal air heater will be installed in No. 2 Boiler with the second turbine and HRSG.

\subsection{EXPERIMENTAL}

A study was conducted with bark from the DeRidder mill to determine VOC emissions from drying bark in a low temperature dryer with flue gas exhausted through the boiler flue gas cleaning system. VOCs were found to be in the expected range and calculated emissions from the dryer are expected to be within permitted limits. An experimental study was conducted to test candidate air heater tube materials inside the furnace of No. 2 Boiler. Tube samples were placed in the boiler to test performance under both oxidizing and reducing conditions. Several of the materials tested have survived for several thousand hours and exposure is continuing. 


\subsection{RESULTS AND DISCUSSION}

The modified plant design meets the primary objectives of the project for increased bark utilization, decreased fossil fuel use, and increased self-generated power in the mill. Bark utilization for the modified plant is significantly higher (90-130\%) than current operation compared to the $50 \%$ design goal. For equivalent steam production, the total gas usage for the modified plant lower than current operation. For Implementation Steps 1 and 2, gas usage is reduced by $45-47 \%$ and for Step 3 by $29 \%$. While the current average steam production from No. 2 Boiler is about $213,000 \mathrm{lb} / \mathrm{h}$, the combined steam production from the boiler and HRSGs will be about 315,000 lb/h for Steps 1 and 2 and 379,000 lb/h in Step 3. In Step 3 this steam production increase will be accomplished at a grate heat release rate (GHRR) equal to the original boiler design. Boiler efficiencies for Steps 1 and 2 (steam) and Step 3 (cogenerationsteam plus air) are increased from the original design value of $70 \%$ to $74.2,79.4$ and 78.9 , respectively, due to a combination of improved burnout, operation with lower excess air, and drier fuel. For the fully implemented case in Step 3, the thermal efficiency of fuel to electricity conversion is $79.8 \%$ in the cogeneration mode, $5 \%$ above the design goal. Finally, selfgenerated electricity will be increased from the $10.8 \mathrm{MW}$ currently attributable to No.2 Boiler to 29.7MW in Steps 1 and 2 and 46.7MW in Step 3, increases of $175 \%$ and 332\%, respectively.

Environmental benefits derived from the system include a reduction in NOx emissions from the boiler of about $30-50 \%$ (90-130 tons/year) through syngas reburning, improved carbon burnout and lower excess air. This does not count NOx reduction that may be associated with replacement of purchased electricity. The project would reduce $\mathrm{CO}_{2}$ emissions from the generation of electricity to meet the mill's power requirements, including 50,000 tons/yr from a net reduction in gas usage in the mill and an additional 410,000 tons/yr reduction in $\mathrm{CO}_{2}$ emissions due to a $34 \mathrm{MW}$ reduction of purchased electricity. The total $\mathrm{CO}_{2}$ reduction amounts to about $33 \%$ of the $\mathrm{CO}_{2}$ currently generated to meet the mills electricity requirement.

\subsection{CONCLUSIONS}

The overall conclusion of the study is that while significant engineering challenges are presented by the proposed system, they can be met with operationally acceptable and cost effective solutions. The benefits of increased wastewood utilization, reduced fossil fuel usage and increased self-generated electric power can be realized in an economic manner, with a simple payback period on the order of 6 years. Environmental benefits will also be realized in the form of reduced emissions of $\mathrm{NOx}$ and $\mathrm{CO}_{2}$.

The results of the study for the DeRidder site are applicable to many paper mills in the U.S. firing woodwastes for steam and power production. These materials can all be gasified and utilized for electric power generation with less technology risk and with equipment more consistent with current pulp and paper mill powerhouse operations than typical IGCC. If the advanced power system were applied to $20 \%$ of the FPI woodwaste-fired boiler capacity in a similar manner to the current study, the increase in self-generated power would be over 8,000 million $\mathrm{kWh} / \mathrm{yr}$, or about $13 \%$ of the total power purchased by the industry. Assuming purchased electricity is generated from coal and considering woodwaste fuel as $\mathrm{CO}_{2}$ neutral, substituting self-generated biomass power for coal-based purchased power in $20 \%$ of the industry's woodwaste-fired boiler capacity would reduce $\mathrm{CO}_{2}$ emissions to the environment by over 10 million tons/yr. With an average NOx production of about $0.25 \mathrm{lb}$ NOx/MMBtu from woodwaste combustion, application of the technology to $20 \%$ of the industry's woodwaste boiler capacity has the potential to reduce NOx emissions by over 10,000 tons/yr. 


\subsection{INTRODUCTION}

\subsection{BACKGROUND}

Paper mills use stoker boilers extensively to recover energy from wastewood, bark, and sludge. Because of the variability of feedstock moisture and ash, the steam generation capacity of these boilers is generally limited by the ability to burn fuel on the grate, or, in other words, the boiler capacity is underutilized because of combustion limitations. It has been demonstrated conclusively that this limitation can be overcome by the application of fuel staging (reburning) and air staging, which improves combustion on the grate, reduces NOx emissions by up to $50 \%$, and increases boiler efficiency through operation at reduced excess air and improved carbon burnout. The successful application of a 3-stage reburning combustion system was demonstrated in 1999 on a bark- and sludge-fired boiler using natural gas as the reburn fuel in an Agenda 2020 project sponsored by the U.S. Department of Energy (DOE) ${ }^{1}$.

Agenda 2020 is the joint federal-industry program executed by DOE and the AF\&PA in 1994. The overall objective of this project is to demonstrate the commercial applicability of a technology that advances the goals of Agenda 2020, providing new technology that will enable industry to achieve several important goals of Agenda 2020, namely to:

- Build technology leadership to advance United States global competitiveness

- Build energy self-sufficiency by taking advantage of biomass

- Meet demanding new environmental standards and requirements without incurring the predicted increases in cost for additional capital equipment, operations and energy consumption

- Protect the industry's most valuable resource (the forest) through sustainable management

- Continue providing high quality product

- Improve safety (an overarching goal of both industry and government)

In 2001, the Gas Technology Institute (GTI) entered into a Cooperative Agreement (DE-FC2601NT41108) with DOE for another Agenda 2020 project to develop, demonstrate, and place in continuous operation an advanced biomass gasification-based power generation system suitable for near-term commercial deployment in the Forest Products Industry. The advanced power system is to be used in conjunction with, rather than in place of, existing wood waste fired boilers and flue gas cleanup systems and combines three advanced technological components including biomass gasification and 3-stage stoker-fired combustion for biomass conversion, and externally recuperated gas turbines for power generation. The system concept is intended to avoid the major hurdles of high-pressure gasification, i.e., high-pressure fuel feeding and ash removal, and hot gas cleaning that are typical for conventional IGCC power generation. It aims to also minimize capital intensity and technology risks in the initial demonstration and is intended to meet the immediate needs of the Forest Products Industry for highly efficient and environmentally friendly electricity and steam generation systems utilizing existing wood waste as the fuel resource.

\subsection{PROJECT OUTLINE AND OBJECTIVES}

The project is being conducted in four phases with the technical and economic feasibility of the proposed biomass gasification-based power generation approach verified in Phase 1 and detailed design, construction and demonstration operations to be completed in subsequent phases, contingent on a decision to proceed by the demonstration host site. 
The overall objectives of this development project are:

- Development and field testing of the advanced system to increase utilization of the available wood waste fuels in the forest products industry

- Demonstration of stable and reliable operation along with the economic and environmental benefits of the biomass gasification-based power and steam generation system at full commercial scale

- Plant acceptance in continuous use within 6 years of project start

- Promotion and acceleration of the near-term acceptance of the developed and demonstrated technology in the Forest Products Industry

The major activities of Phase 1 include:

- Determining the information necessary to describe and quantify all anticipated environmental impacts of the project.

- Evaluating and selecting a paper mill as host site for the demonstration.

- Developing the preliminary design for the plant's Gasification Island

- Developing the preliminary design for the Indirect Air Heaters

- Evaluating the requirements for modifications to the existing bark-fired stoker boiler to accommodate an internal high pressure high temperature air heater (HTHP AH) and the addition of syngas reburn injection nozzles

- Evaluating and selecting an externally recuperated gas turbine (ERGT) and heat recovery steam generator (HRSG) for the plant's power island

- Evaluating the requirements for successful integration of the new power system into existing mill steam and electricity production and distribution systems

- Determining the balance-of-plant equipment requirements and the overall plant capital and operating costs

Specific energy and environmental performance goals for the advanced power system include:

- $50 \%$ or greater increase in wood waste usage for electricity and steam generation with a corresponding decrease in fossil fuel usage and/or purchased electricity

- Increased thermal efficiency of fuel to electricity conversion: up to $75 \%$ in cogeneration mode with $70 \%$ of energy utilized for electric power production, and up to $58 \%$ for electricity production only

- $50 \%$ or greater reduction in $\mathrm{NO}_{\mathrm{x}}$ emissions $\left(\mathrm{NO}_{\mathrm{X}}\right.$ below 70 ppmvd at $\left.3 \% \mathrm{O}_{2}\right)$

- $40 \%$ reduction in $\mathrm{CO}_{2}$ emissions

\subsection{PROJECT PARTICIPANTS}

The Phase 1 evaluation effort was led by the GTI. The project team for the evaluation included Babcock Power Inc. (BPI) for the air heater and boiler modifications studies, Solar Turbines Inc for the gas turbine portion of the power island study, Carbona Corporation for the gasification island study, Nexant LLC, a Bechtel technology and consulting company, for the plant integration and economic evaluations, and Boise Cascade Corporation as the demonstration plant host site.

The Cooperative Agreement for the project was executed by DOE in August 2001. In September 2001, Boise Cascade Corporation agreed to provide a host site for the demonstration at their pulp and paper mill in DeRidder, Louisiana. This report discusses the results of the Phase 1 technical and economic evaluation study for the DeRidder host site. 


\subsection{PLANT DESIGN STUDY \& ECONOMIC ANALYSIS}

\subsection{STUDY BASIS}

\subsubsection{Plant Design Basis}

The following energy and environmental goals provide the basis for plant design:

- Goal 1: Increase wood waste usage for electricity and steam generation resulting in a corresponding decrease in fossil fuel usage and/or purchased electricity. This is accomplished by converting a portion of the wood waste normally burned in the stoker into syngas in a biomass gasifier, then using the syngas as reburning fuel in the stoker.

- Goal 2: Increase self-generation of electrical power thus reducing dependence on grid power. This is accomplished by employing an advanced gas turbine in a recuperative manner. The combustion air for the gas turbine is preheated by utilizing the excess sensible heat from the wood waste gasification and stoker combustion processes mentioned in Goal 1 above.

- Goal 3: Reduce plant NOx emission by using syngas as a reburning fuel in the stoker boiler as indicated in Goal 1 above.

- Goal 4: Reduce $\mathrm{CO}_{2}$ emissions by increasing the utilization of biomass fuels and reducing the use of fossil fuel used for electricity and steam production.

\subsubsection{Site Characteristics}

The proposed project is envisaged to be a part of and located within the premises of the Pulp and Paper Mill owned by Boise Cascade Corporation Southern Operations and located at DeRidder, Louisiana. The project equipment is proposed to be located near \#2 Bark Boiler. The characteristics of the site are shown in Table 3.1.2-1.

Table 3.1.2-1: Site Characteristics

Elevation:

Minimum average daily temperature:

Maximum average daily temperature:

Relative humidity:

Annual rainfall:

Maximum wind velocity:

Seismic zone:
$207 \mathrm{ft}$. above mean sea level

$45.8^{\circ} \mathrm{F}$ (occurs in January)

$81.2^{\circ} \mathrm{F}$ (occurs in July)

Between 50 and 95 ; annual average $71.5 \%$

78.6 in. (2001 total)

$--$

Zone III

\subsubsection{Biomass Fuel Characteristics}

The average characteristics of the biomass fuel are presented in Table 3.1.3-1. 


\section{Table 3.1.3-1: Biomass Fuel Characteristics}

\begin{tabular}{lc} 
Composition & wt $\%($ dry $)$ \\
\cline { 2 - 2 } Carbon & 54.0 \\
Hydrogen & 6.4 \\
Oxygen & 21.5 \\
Nitrogen & 0.2 \\
Sulfur & 0.0 \\
Ash & 5.5 \\
Moisture, wt \% & 52.5 \\
Fuel Consumption & \\
$\quad$ On-site generated & $34.0 \%$ (by energy content) \\
$\quad$ Purchased & $66.0 \%$ (by energy content) \\
Size Consistency & \\
$\quad$ Fines & $17.7 \%$ \\
$\quad 1 / 8$ in. & $20.2 \%$ \\
$\quad$ 1/4 in. & $38.6 \%$ \\
$\quad 7 / 8$ in. & $11.0 \%$ \\
$\quad 11 / 2$ in. & $4.7 \%$ \\
HHV (wet), Btu/lb & $7.8 \%$ \\
& 4526
\end{tabular}

\subsubsection{Emissions Standards}

EPA guidelines for a site that has the potential to emit more than 100 tons per year of regulated criteria air pollutants, more than 10 tons per year of a single hazardous air pollutant (HAP), and more than 25 tons per year of combined HAPs are presented below. The State of Louisiana is required to follow these guidelines or have separate but equivalent or more stringent regulations. The thrust for these guidelines and regulations is derived from prevention of significant deterioration (PSD) of the environment, that is, a site or a facility has a potential to emit more than 100 tons of a regulated criteria air pollutant.

Even though a facility may have been grand fathered and follow the pre 1979 regulations, future modification and upgrades will have to meet or exceed the above requirements. Under new guidelines EPA is requiring that facilities constructed before the Clean Air regulations of 1971, should implement a continuous emission monitoring system for accurate emission data.

Table 3.1.4-1 lists the most recent permitted utility boilers and their permit levels (boilers constructed between 1995-and 2000). The primary fuel is coal, but these regulations are also applied to coke, lignite and wood fired boilers. MSW and other hazardous waste burning facilities fall under separate category and are not addressed here. 
Table 3.1.4-1: Permit Levels of Recent Utility Boilers

\begin{tabular}{|l|l|l}
\hline $\begin{array}{l}\text { Boiler Sizes } \\
\text { (Minimum Heat } \\
\text { Input Capacity) }\end{array}$ & Fuel Types & $\begin{array}{l}\text { Pollutants and } \\
\text { Guidelines Limits } \\
\text { (Lbs/MMBtu) }\end{array}$ \\
\hline$>250 \mathrm{MMBtu} / \mathrm{hr}$ & $\begin{array}{l}\text { Primary }- \text { Coal } \\
\text { or other solid } \\
\text { fuel }\end{array}$ & $\mathrm{SO}_{2}=0.10$ \\
\hline & & $\mathrm{PM}=0.025$ \\
\hline $\begin{array}{l}\text { Monitoring } \\
\text { Equipment }\end{array}$ & & $\mathrm{NO}_{\mathrm{X}}=0.1 \sim 0.2$ \\
\hline
\end{tabular}

Details on emission regulations for stationary gas turbines are provided in 10CFR60 sub part GG.

Since primary fuel for the gas turbine system is natural gas, $\mathrm{SO}_{2}$ and PM10 are not an issue and normally not specified.

\subsection{PLANT DESCRIPTION}

\subsubsection{Overall Plant Description}

A summary of the systems and equipment required to meet the objectives of the project is described in this section. A process flow diagram of the fully implemented gasification-based power generation system is presented in Figure 3.1.1-1. In the fully implemented system, an airblown low-pressure fluidized bed gasifier is used to generate syngas from wood waste for use as reburn fuel in the existing bark-fired No. 2 Power Boiler. About one-third of the stoker's design fuel input is converted to syngas in the gasifier while the remaining two thirds is fed to the stoker.

Some of the air from the gasification air compressor is used into burn a portion of the syngas as it leaves the gasifier to increase its temperature from $850^{\circ} \mathrm{C}\left(1562^{\circ} \mathrm{F}\right)$ to $1204^{\circ} \mathrm{C}\left(2200^{\circ} \mathrm{F}\right)$ prior to entering the high-temperature high-pressure air heater $\mathrm{AH}-1$. Heat is exchanged with a portion of a pressurized air stream from the compressor of an externally recuperated gas turbine (ERGT) generator, GT-1, preheating the air to about $760^{\circ} \mathrm{C}\left(1400^{\circ} \mathrm{F}\right)$ prior to the turbine combustor and cooling the syngas to $344^{\circ} \mathrm{C}\left(650^{\circ} \mathrm{F}\right)$ prior to entering the stoker boiler. The preheated air is further heated in the combustor to $852^{\circ} \mathrm{C}\left(1565^{\circ} \mathrm{F}\right)$ by combustion of natural gas prior to entering GT-1.

As the hot high-pressure air expands and cools through GT-1, 17 MWe of self-generated electric power is produced to displace power currently purchased from the grid. Vitiated air at about $18 \% \mathrm{O}_{2}$ is exhausted from GT-1 through a gasification air heater $\mathrm{AH}-2$ and then to a heat recovery steam generator HRSG-1, where about $50,000 \mathrm{lb} / \mathrm{h}$ of additional $250 \mathrm{psig}$ steam is 
generated for process use in the mill. A portion of the vitiated exhaust air from the HRSG is routed through a booster fan for use as undergrate and overfire (staged) combustion air in the boiler and the balance is discharged to the atmosphere through a stack.

The gasifier syngas is introduced through reburners into the stoker's primary combustion zone, creating a reducing zone immediately above the grate that destroys $\mathrm{NO}_{\mathrm{x}}$ precursors and significantly reduces $\mathrm{NO}_{\mathrm{x}}$ formation. The added gas flow also increases both heat release and mixing in the area immediately above the grate to greatly improve combustion stability and the ability to maintain boiler load through periods of increased fuel moisture. The syngas reburn staged-combustion arrangement eliminates the need to cofire fossil fuels continuously through auxiliary burners for this purpose. This allows low cost or negative cost $\mathrm{CO}_{2}$-neutral biomass waste fuel to replace higher cost, $\mathrm{CO}_{2}$-producing fossil fuels. Fuel- and air-staged combustion will also improve boiler efficiency through increased carbon burnout and reduced excess air at the boiler exit.

A second high-temperature high-pressure air heater, AH-3, is located in the upper furnace of the stoker boiler just below the furnace arch tip. Heat is exchanged with a portion of the pressurized air from a second externally recuperated gas turbine generator, GT-2, preheating the air prior to the turbine combustor. Air is further heated in the combustor in the same manner as GT-1, and an additional $17 \mathrm{MWe}$ of self-generated electric power is produced. Vitiated air is exhausted from GT-2 to a second heat recovery steam generator, HRSG-2, where an additional 50,000 lb/h of 250 psig steam is generated for use in the mill. The exhaust air from HRSG-2 combines with the exhaust air from HRSG-1 prior to the combustion air booster fan.

Heat in the flue gas leaving the boiler economizer is used to dry the wet bark fuel from $52.5 \%$ to $20 \%$ moisture upstream of the gasifier and stoker feeding systems. The boiler flue gas bypasses the existing tubular air heater and enters the bark dryers at about $318^{\circ} \mathrm{C}\left(605^{\circ} \mathrm{F}\right)$. The flue gas and evaporated moisture from the bark leave the dryer at a relatively low temperature of about $80^{\circ} \mathrm{C}\left(175^{\circ} \mathrm{F}\right)$, which limits volatile organic compounds (VOC) in the dryer exhaust. The dryer exhaust is returned to the boiler flue gas duct ahead of the dust collector for discharge through the existing ID fan, scrubber and stack.

Wet, hogged bark from the woodyard is diverted from the boiler bark conveyor to the dryers by a junction box and about two thirds of the dried bark is returned to the boiler conveyor in the same manner. The remaining bark is conveyed to a screening/sizing machine to reduce the fuel size sufficient for feeding through the gasifier feed lockhoppers.

\subsubsection{Systems and Components of the Plant}

The following systems and components are provided to accomplish the above functions:

- Biomass drying system with two dryers

- Gasification system

- Fuel (dried bark) feeding

- Limestone feeding

- Gasifier

- Gas feeding

- Ash removal

- Gasification process air supply

- Product gas heating and cooling

- Flaring 
- Product gas ducting

- Nitrogen generation

- Gas turbine air preheating with external heat exchangers

- Boiler modification

- Gas turbine air pre-heating in furnace with internal heat exchanger

- Syngas injection to boiler

- Power generation with two externally recuperated gas turbine generators

- Heat recovery with two heat recovery steam generators (HRSG)

- Balance of plant

- Cooling water supply

- Compressed air supply

- Fire protection

- Electrical distribution

- Bark conveying, screening/sizing and delivery

- Natural gas supply

\subsubsection{Implementation Steps}

The implementation of the plant is envisaged to be in three successive steps, the basic elements and main features of which are summarized below:

Step 1: Installation of the gasification section, one of the two bark dryers and the first of two recuperated gas turbines. The process flow diagram for this step is shown in Figure 3.1.1-1. In this step:

- About one-third of the total wet wood waste is dried in a bark dryer and fed to the gasifier. The un-dried (wet) two-thirds is fed directly to the boiler.

- Heat for drying is provided by burning natural gas in the bark dryer.

- Exhaust gas from the dryer is routed to the boiler flue gas exhaust at the inlet to the dust collector.

- One externally recuperated $17 \mathrm{MWe}$ gas turbine generator system (GT-1) is used to generate electricity.

- A portion of the combustion air for GT-1 is preheated in a syngas-to-air heat exchanger (AH-1).

- The air temperature to GT-1 is boosted in the turbine combustor by combustion of natural gas.

- The vitiated air (about 17.8\% oxygen) exhaust from GT-1 is fed into a heat recovery steam generator (HRSG-1).

- Gasification air is preheated in an air-to-air heat exchanger (AH-2) between the GT-1 exhaust and HRSG-1

- About 65,000 lb/h of additional steam is generated in HRSG-1 for process use in the mill.

- Vitiated air exhaust from HRSG-1 is discharged to the atmosphere through a stack.

The Heat and Material Balance for the plant after Step 1 implementation is shown in Table 3.2.3-1 
Step 2: Bypassing the tubular air heater to use boiler flue gas for bark drying. The process flow diagram for this step is shown in Figure 3.1.1-2. In this step:

- All wet wood waste to the gasifier and boiler are now dried. A second dryer is added to handle the full drying load. About one-third of the dried wood waste is fed to the gasifier, and two-thirds fed to the boiler.

- 17 MWe of electrical power continues to be generated via AH-1 and GT-1 along with about $65,000 \mathrm{lb} / \mathrm{h}$ of steam from HRSG-1.

- The boiler's tubular air heater is bypassed such that most or all of the flue gas from the economizer is used in the bark dryer.

- Exhaust gas from the dryer is routed into the boiler flue gas exhaust at the outlet of the economizer (at the inlet to the dust collector).

- Part of the vitiated air exhaust from HRSG-1 is used in the boiler as undergrate and overfire combustion air. The rest is discharged into the atmosphere through a stack.

The Heat and Material Balance for the plant after Step 2 implementation is shown in Table 3.2.3-2

Step 3: Installation of the second bark dryer, a second air heat exchanger, and the second recuperated gas turbine. The process flow diagram for this step is shown in Figure 3.1.1-3. In this step:

- A second externally recuperated 17 MWe gas turbine generator system (GT-2) is added for additional electricity generation.

- A portion of the combustion air for GT-2 is preheated in a platen heat exchanger inside the boiler (AH-3).

- The air temperature to GT-2 is boosted in the turbine combustor by combustion of natural gas.

- The vitiated air (about 18.1\% oxygen) exhaust from GT-2 is fed into a heat recovery steam generator (HRSG-2).

- Part of the flue gas exhaust from HRSG-2 is used in the boiler as combustion air and over-fire air. The rest is discharged into the atmosphere through a stack.

The Heat and Material Balance for the plant after Step 3 implementation is shown in Table 3.2.3-3 
Table 3.2.3-1 Heat and Material Balance for Implementation Step 1

\begin{tabular}{|c|c|c|c|c|c|c|c|c|c|c|c|c|c|c|}
\hline English Units & & & & & & & & & & & & & & \\
\hline & & 1 & 2 & 3 & 4 & 5 & 6 & 7 & 8 & 9 & 10 & 11 & 12 & 13 \\
\hline & & $\begin{array}{c}\text { Woodwaste } \\
\text { to Gasifier }\end{array}$ & $\begin{array}{c}\text { Air to } \\
\text { Gasifier }\end{array}$ & $\begin{array}{l}\text { Limestone } \\
\text { to Gasifier }\end{array}$ & $\begin{array}{c}\text { Purge } \\
\text { Nitrogen }\end{array}$ & $\begin{array}{c}\text { Ash from } \\
\text { Gasifier }\end{array}$ & $\begin{array}{c}\text { Raw Prod. } \\
\text { Gas }\end{array}$ & $\begin{array}{c}\text { Combustor } \\
\text { Air }\end{array}$ & $\begin{array}{c}\text { Heated } \\
\text { Prod. Gas } \\
\end{array}$ & $\begin{array}{c}\text { Cooled } \\
\text { Prod. Gas }\end{array}$ & $\begin{array}{c}\text { Reburn } \\
\text { Prod. Gas } \\
\end{array}$ & \begin{tabular}{|c|}
$\begin{array}{c}\text { Gasification } \\
\text { Air }\end{array}$ \\
\end{tabular} & $\begin{array}{c}\text { GT-1 Air to HE- } \\
1\end{array}$ & $\begin{array}{c}\text { Hot Air to } \\
\text { Combustor }\end{array}$ \\
\hline mass flow & Ib/h & 23621 & 40460 & 238 & 389 & 810 & 63422 & 14238 & 77660 & 77660 & 77660 & 54698 & 234389 & 234389 \\
\hline pressure & psia & 14.7 & 43.5 & 14.7 & 43.5 & 14.7 & 29.0 & 177.9 & 26.1 & 23.2 & 15.2 & 43.5 & 194.0 & 178.0 \\
\hline temperature & ${ }^{\circ} \mathrm{F}$ & 80 & 515 & 80 & 104 & 1472 & 1562 & 515 & 2199 & 651 & 651 & 285 & 661 & 1400 \\
\hline heat flow (HHV) & MMEtu/h & 180.5 & 4.8 & 0.0 & 0.0 & 0.5 & 183.9 & 1.7 & 186.1 & 150.1 & 144.4 & 3.3 & 33.8 & 79.8 \\
\hline electric power & Mwe & & & & & & & & & & & & & \\
\hline & & & & & & & & & & & & & & \\
\hline c & \%w (dry) & 54.00 & & & & 1.8 & & & & & & & & \\
\hline $\mathrm{H}$ & \%w (dry) & 6.40 & & & & & & & & & & & & \\
\hline N & \%w (dry) & 0.21 & & & & & & & & & & & & \\
\hline 0 & \%w (dry) & 33.85 & & & & & & & & & & & & \\
\hline $\mathrm{s}$ & \%w (dry) & 0.00 & & & & & & & & & & & & \\
\hline ash & \%w (dry) & 5.54 & & & & 98.2 & & & & & & & & \\
\hline moisture & $\% w$ & 20.00 & & & & & & & & & & & & \\
\hline $\mathrm{HHV}$ & Btu/lb (dy) & 9528 & & & & & & & & & & & & \\
\hline LHV & Btu/lb (dry) & 8923 & & & & & & & & & & & & \\
\hline & & 4724 & & & & & & & & & & & & \\
\hline $\mathrm{CaCO} 3$ & \%w & & & 77.0 & & & & & & & & & & \\
\hline $\mathrm{MgCO} 3$ & $\% w$ & & & 14.0 & & & & & & & & & & \\
\hline $\mathrm{SiO} 2$ & Kow & & & 8.0 & & & & & & & & & & \\
\hline Other inert material & \%ow & & & 1.0 & & & & & & & & & & \\
\hline & & & & & & & & & & & & & & \\
\hline $\mathrm{CO}$ & $\% 4$ & & & & & & 16.94 & & 14.66 & 14.66 & 14.66 & & & \\
\hline $\mathrm{CO} 2$ & $\% \mathrm{~V}$ & & & & & & 10.75 & & 9.56 & 9.56 & 9.56 & & & \\
\hline $\mathrm{H} 2$ & $\% \mathrm{~V}$ & & & & & & 14.74 & & 6.55 & 6.55 & 6.55 & & & \\
\hline $\mathrm{H} 2 \mathrm{O}$ & $\% v$ & & & & & & 10.33 & & 15.46 & 15.46 & 15.46 & & & \\
\hline $\mathrm{CH}_{4}$ & $\% 4$ & & & & & & 4.06 & & 3.52 & 3.52 & 3.52 & & & \\
\hline N2 & $\% \mathrm{~V}$ & & 79.0 & & 98.0 & & 42.93 & 79.00 & 50.08 & 50.08 & 50.08 & 79.0 & 79.0 & 79.0 \\
\hline $\mathrm{C} 2 \mathrm{H} 4$ & $\% \%$ & & & & & & 0.04 & & 0.021 & 0.021 & 0.021 & & & \\
\hline $\mathrm{C}_{6} \mathrm{H}_{6}$ & $\% \mathrm{~V}$ & & & & & & 0.11 & & 0.054 & 0.054 & 0.054 & & & \\
\hline $\mathrm{H} 2 \mathrm{~S}+\mathrm{COS}$ & $\% \mathrm{~V}$ & & & & & & 0 & & 0 & 0 & 0 & & & \\
\hline $\mathrm{NH} 3+\mathrm{HCN}$ & $\% \mathrm{~V}$ & & & & & & 0.11 & & 0.09 & 0.09 & 0.09 & & & \\
\hline 02 & $\% 0$ & & 21.0 & & 2.0 & & & 21 & & & & 21.0 & 21.0 & 21.0 \\
\hline $\mathrm{HHV}$ & Btu/scf (wet) & & & & & & 149 & & 107 & 107 & 107 & & & \\
\hline LHV & Btu/scf (wet) & & & & & & 137 & & 100 & 100 & 100 & & & \\
\hline density & lbiscf & & & & & & 0.068 & & 0.072 & 0.072 & 0.072 & & & \\
\hline & & & & & & & & & & & & & & \\
\hline & & & & & & & & & & & & & & \\
\hline & & & & & & & & & & & & & & \\
\hline & & & & & & & & & & & & & & \\
\hline & & & & & & & & & & & & & & \\
\hline & & & & & & & & & & & & & & \\
\hline SI Units & & & & & & & & & & & & & & \\
\hline & & 1 & 2 & 3 & 4 & 5 & 6 & 7 & 8 & 9 & 10 & 11 & 12 & 13 \\
\hline & & $\begin{array}{r}\text { Woodwaste } \\
\text { to Gasifier }\end{array}$ & $\begin{array}{l}\text { Air to } \\
\text { Gasifier }\end{array}$ & $\begin{array}{l}\text { Limestone } \\
\text { to Gasifier }\end{array}$ & $\begin{array}{c}\text { Purge } \\
\text { Nitrogen }\end{array}$ & $\begin{array}{l}\text { Ash from } \\
\text { Gasifier }\end{array}$ & $\begin{array}{c}\text { Raw Prod. } \\
\text { Gas }\end{array}$ & $\begin{array}{c}\text { Combustor } \\
\text { Air }\end{array}$ & $\begin{array}{c}\text { Heated } \\
\text { Prod. Gas }\end{array}$ & $\begin{array}{c}\text { Cooled } \\
\text { Prod. Gas }\end{array}$ & $\begin{array}{c}\text { Reburn } \\
\text { Prod. Gas } \\
\end{array}$ & $\begin{array}{c}\text { Gasification } \\
\text { Air }\end{array}$ & $\begin{array}{c}\text { GT- } 1 \text { Air to } \mathrm{HE} \text { - } \\
1\end{array}$ & $\begin{array}{c}\text { Hot Air to } \\
\text { Combustor }\end{array}$ \\
\hline mass flow & $\mathrm{kg} / \mathrm{s}$ & 2.98 & 5.10 & 0.03 & 0.05 & 0.10 & 7.99 & 1.79 & 9.79 & 9.79 & 9.79 & 6.89 & 29.53 & 29.53 \\
\hline pressure & bara & 1.013 & 3 & 1.013 & 3 & 1.013 & 2 & 12.28 & 1.8 & 1.6 & 1.05 & 3 & 13.38 & 12.28 \\
\hline temperature & ${ }^{\circ} \mathrm{C}$ & 27 & 268 & 27 & 40 & 800 & 850 & 268 & 1204 & 472 & 344 & 140.6 & 349 & 760 \\
\hline heat flow (HHV) & MJis & 52.9 & 1.4 & 0.0 & 0.0 & 0.1 & 53.9 & 0.5 & 54.6 & 44.0 & 42.3 & 1.0 & 9.9 & 23.4 \\
\hline electric power & Mwe & & & & & & & & & & & & & \\
\hline & & & & & & & & & & & & & & \\
\hline c & Ww $(d \mathrm{dy} y)$ & 54.00 & & & & 1.8 & & & & & & & & \\
\hline $\mathrm{H}$ & \%w (dry) & 6.40 & & & & & & & & & & & & \\
\hline N & Ww (dry) & 0.21 & & & & & & & & & & & & \\
\hline 0 & \%w (dry) & 33.85 & & & & & & & & & & & & \\
\hline$s$ & \%w (dry) & 0.00 & & & & & & & & & & & & \\
\hline ash & \%w (dry) & 5.54 & & & & 98.2 & & & & & & & & \\
\hline moisture (as fed) & \%w & 20 & & & & & & & & & & & & \\
\hline $\mathrm{HHV}$ & kJ/kg (dry) & 22163 & & & & & & & & & & & & \\
\hline LHV dry base & kJj/kg (dry) & 20754 & & & & & & & & & & & & \\
\hline & & & & & & & & & & & & & & \\
\hline $\mathrm{CaCO} 3$ & \%w & & & 77.0 & & & & & & & & & & \\
\hline $\mathrm{MgCO} 3$ & \%w & & & 14.0 & & & & & & & & & & \\
\hline $\mathrm{SiO} 2$ & \%w & & & 8.0 & & & & & & & & & & \\
\hline Other inert material & $\% w$ & & & 1.0 & & & & & & & & & & \\
\hline & & & & & & & & & & & & & & \\
\hline $\mathrm{CO}$ & $\% \mathrm{~V}$ & & & & & & 16.94 & & 14.66 & 14.66 & 14.66 & & & \\
\hline $\mathrm{CO} 2$ & $\% v$ & & & & & & 10.75 & & 9.56 & 9.56 & 9.56 & & & \\
\hline $\mathrm{H} 2$ & $\% \mathrm{~V}$ & & & & & & 14.74 & & 6.55 & 6.55 & 6.55 & & & \\
\hline $\mathrm{H} 2 \mathrm{O}$ & $\% \mathrm{~V}$ & & & & & & 10.33 & & 15.46 & 15.46 & 15.46 & & & \\
\hline $\mathrm{CH}_{4}$ & $\% \mathrm{~V}$ & & & & & & 4.06 & & 3.52 & 3.52 & 3.52 & & & \\
\hline N2 & $\% \mathrm{v}$ & & 79.0 & & 98.0 & & 42.93 & 79.0 & 50.08 & 50.08 & 50.08 & 79.0 & 79.0 & 79.0 \\
\hline $\mathrm{C} 2 \mathrm{H} 4$ & $\% 4$ & & & & & & 0.039 & & 0.021 & 0.021 & 0.021 & & & \\
\hline $\mathrm{C}_{6} \mathrm{H}_{6}$ & $\% \mathrm{~V}$ & & & & & & 0.106 & & 0.054 & 0.054 & 0.054 & & & \\
\hline $\mathrm{H} 2 \mathrm{~S}+\mathrm{COS}$ & $\% \mathrm{~V}$ & & & & & & 0 & & 0 & 0.00 & 0.00 & & & \\
\hline $\mathrm{NH} 3+\mathrm{HCN}$ & $\% \mathrm{~V}$ & & & & & & 0.1091 & & 0.094 & 0.09 & 0.09 & & & \\
\hline $\mathrm{O} 2$ & $\% \mathrm{~V}$ & & 21.0 & & 2.0 & & & 21.0 & & & & 21.0 & 21.0 & 21.0 \\
\hline HHV wet base & $\mathrm{kJ} / \mathrm{m}^{3} \mathrm{n}$ (wet) & & & & & & 5833 & & 4193 & 4193 & 4193 & & & \\
\hline LHV wet base & $\mathrm{kJ} / \mathrm{m}^{3} \mathrm{n}$ (wet) & & & & & & 5369 & & 3920 & 3920 & 3920 & & & \\
\hline density & $\mathrm{kg}^{\prime} \mathrm{m}^{3} \mathrm{n}$ & & & & & & 1.090 & & 1.156 & 1.156 & 1.156 & & & \\
\hline & & & & & & & & & & & & & & \\
\hline${ }^{1}$ Includes cooling & & & & & & & & & & & & & & \\
\hline
\end{tabular}


Table 3.2.3-1 Heat and Material Balance for Implementation Step 1 Continued

\begin{tabular}{|c|c|c|c|c|c|c|c|c|c|c|c|c|c|c|c|}
\hline English Units & & & & & & & & & & & & & & & \\
\hline & & 14 & 15 & 16 & 17 & 18 & 19 & 20 & 21 & 22 & 24 & 25 & 26 & 37 & 40 \\
\hline & & $\begin{array}{c}\text { GT-1 Bypass } \\
\text { Air }\end{array}$ & $\begin{array}{l}\text { Gas to GT-1 } \\
\text { Combustor }\end{array}$ & $\begin{array}{c}\text { Total Air to GT- } \\
11\end{array}$ & GT-1 Output & $\begin{array}{c}\text { HSRG-1 } \\
\text { Exhaust Air }\end{array}$ & $\begin{array}{c}\text { Stoker } \\
\text { Overfire Air }\end{array}$ & Undergrate Air & $\begin{array}{c}\text { Woodwaste } \\
\text { to Stoker }\end{array}$ & $\begin{array}{c}\text { Stoker } \\
\text { Bottom Ash }\end{array}$ & $\begin{array}{c}\text { Wet } \\
\text { Woodwaste }\end{array}$ & $\begin{array}{l}\text { Gas to } \\
\text { Dryer }\end{array}$ & $\begin{array}{c}\text { Flue Gas to } \\
\text { DC }\end{array}$ & $\begin{array}{l}\text { Export } \\
\text { Steam }\end{array}$ & $\begin{array}{c}\text { Superheated } \\
\text { Steam }\end{array}$ \\
\hline mass flow & lbih & \begin{tabular}{|l|}
456260 \\
\end{tabular} & 5997 & 732996 & 732996 & 732996 & 126824 & 167133 & 51750 & 641 & 91532 & 950 & 485759 & 57210 & 250000 \\
\hline pressure & psia & 194.0 & 194.0 & 178.0 & 14.9 & 14.7 & 15.6 & 14.8 & 14.7 & 14.7 & 14.7 & 14.7 & 14.3 & 274.7 & 865 \\
\hline temperature & ${ }^{\circ} \mathrm{F}$ & 661 & 80 & 1520 & 707 & 382 & 375 & 375 & 80 & 1004 & 80 & 80 & 336 & 409 & 825 \\
\hline heat flow (HHV) & MMBtu/h & 65.7 & 143.3 & 294 & 130.4 & 69.5 & 11.1 & 14.6 & 234.3 & 1.5 & 414.3 & 22.7 & 117.2 & 68.8 & 351.1 \\
\hline electric power & Mwe & & & & 17.0 & & & & & & & & & & \\
\hline & & & & & & & & & & & & & & & \\
\hline c & Ww (dy) & & & & & & & & 54.00 & 15.00 & 54.00 & & & & \\
\hline H & \%w (dy) & & & & & & & & 6.40 & & 6.40 & & & & \\
\hline N & \%w (dy $)$ & & & & & & & & 0.21 & & 0.21 & & & & \\
\hline 0 & \%w (dry) & & & & & & & & 33.85 & & 33.85 & & & & \\
\hline 8 & \%ow (dry) & & & & & & & & 0.00 & & 0.00 & & & & \\
\hline ash & \%w (dy) & & & & & & & & 5.54 & 85.00 & 5.54 & & & & \\
\hline moisture & \%ow & & & & & & & & 52.50 & & 52.5 & & & & \\
\hline $\mathrm{HHV}$ & Btulb (dry) & & & & & & & & 9528 & & 9528 & & & & \\
\hline LHV & Btu/b (dry) & & & & & & & & 8923 & & 8923 & & & & \\
\hline & & & & & & & & & & & & & & & \\
\hline $\mathrm{CaCO} 3$ & Kow & & & & & & & & & & & & & & \\
\hline $\mathrm{MgCO}$ & \%w & & & & & & & & & & & & & & \\
\hline $\mathrm{SiO} 2$ & \%ow & & & & & & & & & & & & & & \\
\hline Other inert material & \%ow & & & & & & & & & & & & & & \\
\hline & & & & & & & & & & & & & & & \\
\hline $\mathrm{CO}$ & \%v & & & & & & & & & & & & & & \\
\hline $\mathrm{CO} 2$ & $\% \mathrm{~V}$ & & & 1.46 & 1.46 & 1.46 & 0.03 & 0.03 & & & & & 11.22 & & \\
\hline $\mathrm{H} 2$ & $\% \mathrm{~V}$ & & & & & & & & & & & & & & \\
\hline $\mathrm{H} 2 \mathrm{O}$ & $\% y$ & & & 2.92 & 2.92 & 2.92 & 2.05 & 2.05 & & & & & 24.85 & 100 & 100 \\
\hline $\mathrm{CH}_{4}$ & $\% \mathrm{~V}$ & & 100 & & & & & & & & & 100 & & & \\
\hline $\mathrm{N} 2$ & $\% \mathrm{~V}$ & 79.0 & & 77.85 & 77.85 & 77.85 & 77.40 & 77.40 & & & & & 60.69 & & \\
\hline $\mathrm{C} 2 \mathrm{H} 4$ & \%v & & & & & & & & & & & & & & \\
\hline $\mathrm{C}_{6} \mathrm{H}_{6}$ & \%V & & & & & & & & & & & & & & \\
\hline $\mathrm{H} 2 \mathrm{~S}+\mathrm{COS}$ & $\% v$ & & & & & & & & & & & & & & \\
\hline $\mathrm{NH} 3+\mathrm{HCN}$ & $\% v$ & & & & & & & & & & & & & & \\
\hline 02 & \%ov & 21.0 & & 17.77 & 17.77 & 17.77 & 20.52 & 20.52 & & & & & 3.25 & & \\
\hline HHV & Btu/scf (wet) & & & & & & & & & & & & & & \\
\hline LHV & Btu/scf (wet) & & & & & & & & & & & & & & \\
\hline density & Ibiscf & & & & & & & & & & & & & & \\
\hline & & & & & & & & & & & & & & & \\
\hline & & & & & & & & & & & & & & & \\
\hline & & & & & & & & & & & & & & & \\
\hline & & & & & & & & & & & & & & & \\
\hline & & & & & & & & & & & & & & & \\
\hline & & & & & & & & & & & & 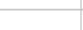 & & & \\
\hline SI Units & & & & & & & & & & & & & & & \\
\hline & & 14 & 15 & 16 & 17 & 18 & 19 & 20 & 21 & 22 & 24 & 25 & 26 & 37 & 40 \\
\hline & & $\begin{array}{c}\text { GT-1 } 1 \text { Bypass } \\
\text { Air }\end{array}$ & $\begin{array}{l}\text { Gas to GT-1 } \\
\text { Combustor }\end{array}$ & $\begin{array}{c}\text { Total Air to GT- } \\
1^{1}\end{array}$ & GT-1 Output & $\begin{array}{c}\text { HSRG-1 } \\
\text { Exhaust Air }\end{array}$ & $\begin{array}{c}\text { Stoker } \\
\text { Overfire Air }\end{array}$ & Undergrate Air & $\begin{array}{c}\text { Woodwaste } \\
\text { to Stoker }\end{array}$ & $\begin{array}{c}\text { Stoker } \\
\text { Bottom Ash }\end{array}$ & $\begin{array}{c}\text { Wet } \\
\text { Woodwaste }\end{array}$ & $\begin{array}{l}\text { Gas to } \\
\text { Dryer }\end{array}$ & $\begin{array}{c}\text { Flue Gas to } \\
D C\end{array}$ & $\begin{array}{l}\text { Export } \\
\text { Steam }\end{array}$ & $\begin{array}{c}\text { Superheated } \\
\text { Steam }\end{array}$ \\
\hline mass flow & $\mathrm{kg} / \mathrm{s}$ & \begin{tabular}{|l|}
57.49 \\
\end{tabular} & 0.76 & 92.36 & 92.36 & 92.36 & 15.98 & 21.06 & 6.52 & 0.08 & 11.53 & 0.12 & 61.21 & 7.21 & $1 \quad 31.50$ \\
\hline pressure & bara & 13.38 & 13.38 & 12.28 & 1.03 & 1.01 & 1.08 & 1.02 & 1.01 & 1.01 & 1.01 & 1.01 & 0.99 & 18.94 & 59.66 \\
\hline temperature & ${ }^{\circ} \mathrm{C}$ & 349 & 27 & 827 & 375 & 194 & 191 & 191 & 27 & 540 & 27 & 27 & 169 & 209 & 441 \\
\hline heat flow (HHV) & Muis & 19.3 & 42.0 & 86.2 & 38.2 & 20.4 & 3.2 & 4.3 & 68.7 & 0.5 & 121.4 & 6.7 & 34.4 & 20.2 & 101.6 \\
\hline electric power & Mwe & & & & 17.0 & & & & & & & & & & \\
\hline & & & & & & & & & & & 0.00 & & & & \\
\hline c & \%w (dry) & & & & & & & & 54.00 & 15.00 & 54.00 & & & & \\
\hline $\mathrm{H}$ & \%w (dry) & & & & & & & & 6.40 & & 6.40 & & & & \\
\hline$N$ & \%w (dry) & & & & & & & & 0.21 & & 0.21 & & & & \\
\hline 0 & \%w (dry) & & & & & & & & 33.85 & & 33.85 & & & & \\
\hline$s$ & \%w (dyy) & & & & & & & & 0.00 & & 0.00 & & & & \\
\hline ash & \%w (dry) & & & & & & & & 5.54 & 85.00 & 5.54 & & & & \\
\hline moisture (as fed) & \%ow & & & & & & & & 52.50 & & 52.50 & & & & \\
\hline HHV & $\mathrm{kJ} / \mathrm{kg}$ (dry) & & & & & & & & 22163 & & 22163 & & & & \\
\hline LHV dry base & $\mathrm{kJ} J \mathrm{~kg}(\mathrm{dry})$ & & & & & & & & 20754 & & 20754 & & & & \\
\hline & & & & & & & & & & & & & & & \\
\hline $\mathrm{CaCO} 3$ & \%ow & & & & & & & & & & & & & & \\
\hline $\mathrm{MgCO} 3$ & \%ow & & & & & & & & & & & & & & \\
\hline $\mathrm{SiO} 2$ & Kow & & & & & & & & & & & & & & \\
\hline Other inert material & \%w & & & & & & & & & & & & & & \\
\hline & & & & & & & & & & & & & & & \\
\hline $\mathrm{co}$ & $\% \mathrm{~V}$ & & & & & & & & & & & & & & \\
\hline $\mathrm{CO} 2$ & $\% \mathrm{~V}$ & & & 1.46 & 1.46 & 1.46 & 0.03 & 0.03 & & & & & 11.22 & & \\
\hline $\mathrm{H} 2$ & $\% v$ & & & & & & & & & & & & & & \\
\hline $\mathrm{H} 2 \mathrm{O}$ & $\% \mathrm{~V}$ & & & 2.92 & 2.92 & 2.92 & 2.05 & 2.05 & & & & & 24.85 & 100.00 & 100.00 \\
\hline $\mathrm{CH} 4$ & $\% \mathrm{~V}$ & & 100 & & & & & & & & & 100.00 & & & \\
\hline N2 & $\% \mathrm{~V}$ & 79.0 & & 77.85 & 77.85 & 77.85 & 77.40 & 77.40 & & & & & 60.69 & & \\
\hline $\mathrm{C} 2 \mathrm{H} 4$ & $\% \mathrm{~V}$ & & & & & & & & & & & & & & \\
\hline $\mathrm{C} 6 \mathrm{H} 6$ & $\% \mathrm{~V}$ & & & & & & & & & & & & & & \\
\hline $\mathrm{H} 2 \mathrm{~S}+\mathrm{COS}$ & $\% \mathrm{v}$ & & & & & & & & & & & & & & \\
\hline $\mathrm{NH} 3+\mathrm{HCN}$ & \%V & & & & & & & & & & & & & & \\
\hline 02 & \%ov & 21.0 & & 17.77 & 17.77 & 17.77 & 20.52 & 20.52 & & & & & 3.25 & & \\
\hline HHV wet base & $\mathrm{kJ} / \mathrm{m}^{3} \mathrm{n}$ (wet) & & & & & & & & & & & & & & \\
\hline LHV wet base & $\mathrm{kJ} / \mathrm{m}^{3} \mathrm{n}$ (wet) & & & & & & & & & & & & & & \\
\hline density & $\mathrm{kg}^{\prime} / \mathrm{m}^{3} \mathrm{n}$ & & & & & & & & & & & & & & \\
\hline & & & & & & & & & & & & & & & \\
\hline
\end{tabular}


Table 3.2.3-2 Heat and Material Balance for Implementation Step 2

\begin{tabular}{|c|c|c|c|c|c|c|c|c|c|c|c|c|c|}
\hline & & & & & & & & & & & & & \\
\hline English Units & & & & & & & & & & & & & \\
\hline & & 1 & 2 & 3 & 4 & 5 & 6 & 7 & 8 & 9 & 10 & 11 & 12 \\
\hline & & $\begin{array}{c}\text { Woodwaste } \\
\text { to Gasifier }\end{array}$ & $\begin{array}{c}\text { Air to } \\
\text { Gasifier }\end{array}$ & $\begin{array}{l}\text { Limestone } \\
\text { to Gasifier }\end{array}$ & $\begin{array}{l}\text { Purge } \\
\text { Nitrogen }\end{array}$ & $\begin{array}{l}\text { Ash from } \\
\text { Gasifier }\end{array}$ & $\begin{array}{c}\text { Raw Prod. } \\
\text { Gas }\end{array}$ & $\begin{array}{c}\text { Combustor } \\
\text { Air }\end{array}$ & $\begin{array}{c}\text { Heated } \\
\text { Prod. Gas }\end{array}$ & $\begin{array}{c}\text { Cooled } \\
\text { Prod. Gas }\end{array}$ & \begin{tabular}{l|} 
Reburn \\
Prod. Gas
\end{tabular} & $\begin{array}{c}\text { Gasification } \\
\text { Air }\end{array}$ & $\begin{array}{c}\text { GT-1 Air to HE- } \\
1\end{array}$ \\
\hline mass flow & $\mathrm{Ib} / \mathrm{h}$ & 23621 & 40460 & 238 & 389 & 810 & 63422 & 14238 & 77660 & 77660 & 77660 & 54698 & 234389 \\
\hline pressure & psia & 14.7 & 43.5 & 14.7 & 43.5 & 14.7 & 29.0 & 177.9 & 26.1 & 23.2 & 15.2 & 43.5 & 194.0 \\
\hline temperature & ${ }^{\circ} \mathrm{F}$ & 80 & 515 & 80 & 104 & 1472 & 1562 & 515 & 2199 & 882 & 651 & 285 & 661 \\
\hline heat flow (HHV) & MMBtu'h & 180.5 & 4.8 & 0.0 & 0.0 & 0.5 & 183.9 & 1.7 & 186.1 & 150.1 & 144.4 & 3.3 & 33.8 \\
\hline electric power & MWe & & & & & & & & & & & & \\
\hline & & & & & & & & & & & & & \\
\hline c & Kw (dry) & 54.00 & & & & 1.8 & & & & & & & \\
\hline $\mathrm{H}$ & \%w (dry) & 6.40 & & & & & & & & & & & \\
\hline N & \%w (dry) & 0.21 & & & & & & & & & & & \\
\hline 0 & \%w (dry) & 33.85 & & & & & & & & & & & \\
\hline s & \%w (dry) & 0.00 & & & & & & & & & & & \\
\hline ash & Sw (dry) & 5.54 & & & & 98.2 & & & & & & & \\
\hline moisture & Sow & 20.00 & & & & & & & & & & & \\
\hline $\mathrm{HHV}$ & Btu/lb (dry) & 9528 & & & & & & & & & & & \\
\hline LHV & Btu/lb (dry) & 8923 & & & & & & & & & & & \\
\hline & & 4724 & & & & & & & & & & & \\
\hline $\mathrm{CaCO} 3$ & \%w & & & 77.0 & & & & & & & & & \\
\hline $\mathrm{MgCO} 3$ & \%w & & & 14.0 & & & & & & & & & \\
\hline $\mathrm{SiO} 2$ & \%w & & & 8.0 & & & & & & & & & \\
\hline Other inert material & \%w & & & 1.0 & & & & & & & & & \\
\hline & & & & & & & & & & & & & \\
\hline $\mathrm{CO}$ & $\% \mathrm{~V}$ & & & & & & 16.94 & & 14.66 & 14.66 & 14.66 & & \\
\hline $\mathrm{CO} 2$ & $\% \mathrm{~V}$ & & & & & & 10.75 & & 9.56 & 9.56 & 9.56 & & \\
\hline $\mathrm{H} 2$ & $\% \mathrm{v}$ & & & & & & 14.74 & & 6.55 & 6.55 & 6.55 & & \\
\hline $\mathrm{H} 2 \mathrm{O}$ & $\% \mathrm{~V}$ & & & & & & 10.33 & & 15.46 & 15.46 & 15.46 & & \\
\hline $\mathrm{CH} 4$ & $\% \mathrm{~V}$ & & & & & & 4.06 & & 3.52 & 3.52 & 3.52 & & \\
\hline N2 & $\% \mathrm{~V}$ & & 79.0 & & 98.0 & & 42.93 & 79.00 & 50.08 & 50.08 & 50.08 & 79.0 & 79.0 \\
\hline $\mathrm{C} 2 \mathrm{H} 4$ & $\% \mathrm{~V}$ & & & & & & 0.04 & & 0.021 & 0.021 & 0.021 & & \\
\hline $\mathrm{C} 6 \mathrm{H} 6$ & $\% \mathrm{~V}$ & & & & & & 0.11 & & 0.054 & 0.054 & 0.054 & & \\
\hline $\mathrm{H} 2 \mathrm{~S}+\mathrm{COS}$ & $\% \mathrm{~V}$ & & & & & & 0 & & 0 & 0 & 0 & & \\
\hline $\mathrm{NH}_{3}+\mathrm{HCN}$ & $\% v$ & & & & & & 0.11 & & 0.09 & 0.09 & 0.09 & & \\
\hline 02 & $\% 4$ & & 21.0 & & 2.0 & & & 21 & & & & 21.0 & 21.0 \\
\hline $\mathrm{HHV}$ & Btu/scf (wet) & & & & & & 149 & & 107 & 107 & 107 & & \\
\hline LHV & Btu'scf (wet) & & & & & & 137 & & 100 & 100 & 100 & & \\
\hline density & lbiscf & & & & & & 0.068 & & 0.072 & 0.072 & 0.072 & & \\
\hline & & & & & & & & & & & & & \\
\hline & & & & & & & & & & & & & \\
\hline & & & & & & & & & & & & & \\
\hline & & & & & & & & & & & & & \\
\hline & & & & & & & & & & & & & \\
\hline & & & & & & & & & & & & & \\
\hline SI Units & & & & & & & & & & & & & \\
\hline & & 1 & 2 & 3 & 4 & 5 & 6 & 7 & 8 & 9 & 10 & 11 & 12 \\
\hline & & $\begin{array}{c}\text { Woodwaste } \\
\text { to Gasifier }\end{array}$ & $\begin{array}{l}\text { Air to } \\
\text { Gasifier }\end{array}$ & $\begin{array}{l}\text { Limestone } \\
\text { to Gasifier }\end{array}$ & $\begin{array}{l}\text { Purge } \\
\text { Nitrogen }\end{array}$ & $\begin{array}{l}\text { Ash from } \\
\text { Gasifier }\end{array}$ & $\begin{array}{c}\text { Raw Prod. } \\
\text { Gas }\end{array}$ & $\underset{\text { Cir }}{\text { Combustor }}$ & $\begin{array}{l}\text { Heated } \\
\text { Prod. Gas }\end{array}$ & $\begin{array}{c}\text { Cooled } \\
\text { Prod. Gas }\end{array}$ & $\begin{array}{l}\text { Reburn } \\
\text { Prod. Gas }\end{array}$ & $\begin{array}{c}\text { Gasification } \\
\text { Air }\end{array}$ & GT-1 Air to HE- \\
\hline mass flow & $\mathrm{kg} / \mathrm{s}$ & 2.98 & 5.10 & 0.03 & 0.05 & 0.10 & 7.99 & 1.79 & 9.79 & 9.79 & 9.79 & 6.89 & 29.53 \\
\hline pressure & bara & 1.013 & 3 & 1.013 & 3 & 1.013 & 2 & 12.28 & 1.8 & 1.6 & 1.05 & 3 & 13.38 \\
\hline temperature & ${ }^{\circ} \mathrm{C}$ & 27 & 268 & 27 & 40 & 800 & 850 & 268 & 1204 & 472 & 344 & 140.6 & 349 \\
\hline heat flow ( $\mathrm{HHV}$ ) & Mujis & 52.9 & 1.4 & 0.0 & 0.0 & 0.1 & 53.9 & 0.5 & 54.6 & 44.0 & 42.3 & 1.0 & 9.9 \\
\hline electric power & MWe & & & & & & & & & & & & \\
\hline & & & & & & & & & & & & & \\
\hline c & \%w (dy) & 54.00 & & & & 1.8 & & & & & & & \\
\hline $\mathrm{H}$ & \%w (dry) & 6.40 & & & & & & & & & & & \\
\hline $\mathrm{N}$ & \%w (dry) & 0.21 & & & & & & & & & & & \\
\hline 0 & Kw (dy) & 33.85 & & & & & & & & & & & \\
\hline 8 & \%w (dry) & 0.00 & & & & & & & & & & & \\
\hline ash & \%w (dry) & 5.54 & & & & 98.2 & & & & & & & \\
\hline moisture (as fed) & Sw & 20 & & & & & & & & & & & \\
\hline $\mathrm{HHV}$ & $\mathrm{kJjkg}(\mathrm{dry})$ & 22163 & & & & & & & & & & & \\
\hline LHV dry base & $\mathrm{kJ} J \mathrm{~kg}(\mathrm{dry})$ & 20754 & & & & & & & & & & & \\
\hline & & & & & & & & & & & & & \\
\hline $\mathrm{CaCO} 3$ & \%ow & & & 77.0 & & & & & & & & & \\
\hline $\mathrm{MgCO}$ & \%w & & & 14.0 & & & & & & & & & \\
\hline $\mathrm{SiO} 2$ & \%w & & & 8.0 & & & & & & & & & \\
\hline Other inert material & \%ow & & & 1.0 & & & & & & & & & \\
\hline & & & & & & & & & & & & & \\
\hline $\mathrm{CO}$ & $\% \mathrm{~V}$ & & & & & & 16.94 & & 14.66 & 14.66 & 14.66 & & \\
\hline $\mathrm{CO} 2$ & $\% \mathrm{~V}$ & & & & & & 10.75 & & 9.56 & 9.56 & 9.56 & & \\
\hline $\mathrm{H} 2$ & $\% \mathrm{~V}$ & & & & & & 14.74 & & 6.55 & 6.55 & 6.55 & & \\
\hline $\mathrm{H} 2 \mathrm{O}$ & $\% \mathrm{~V}$ & & & & & & 10.33 & & 15.46 & 15.46 & 15.46 & & \\
\hline $\mathrm{CH} 4$ & $\% \mathrm{v}$ & & & & & & 4.06 & & 3.52 & 3.52 & 3.52 & & \\
\hline N2 & $\% \mathrm{v}$ & & 79.0 & & 98.0 & & 42.93 & 79.0 & 50.08 & 50.08 & 50.08 & 79.0 & 79.0 \\
\hline $\mathrm{C} 2 \mathrm{H} 4$ & $\% \mathrm{~V}$ & & & & & & 0.039 & & 0.021 & 0.021 & 0.021 & & \\
\hline $\mathrm{C} 6 \mathrm{H} 6$ & $\% v$ & & & & & & 0.106 & & 0.054 & 0.054 & 0.054 & & \\
\hline $\mathrm{H} 2 \mathrm{~S}+\mathrm{COS}$ & \%V & & & & & & 0 & & 0 & 0.00 & 0.00 & & \\
\hline $\mathrm{NH} 3+\mathrm{HCN}$ & $\% \mathrm{~V}$ & & & & & & 0.1091 & & 0.094 & 0.09 & 0.09 & & \\
\hline 02 & Sov & & 21.0 & & 2.0 & & & 21.0 & & & & 21.0 & 21.0 \\
\hline $\mathrm{HHV}$ wet base & $\mathrm{kJ} / \mathrm{m}^{3} \mathrm{n}$ (wet) & & & & & & 5833 & & 4193 & 4193 & 4193 & & \\
\hline LHV wet base & $\mathrm{kJ} / \mathrm{m}^{3} \mathrm{n}$ (wet) & & & & & & 5369 & & 3920 & 3920 & 3920 & & \\
\hline density & $\mathrm{kg} / \mathrm{m}^{3} \mathrm{n}$ & & & & & & 1.090 & & 1.156 & 1.156 & 1.156 & & \\
\hline & & & & & & & & & & & & & \\
\hline${ }^{1}$ Includes cooling air & & & & & & & & & & & & & \\
\hline
\end{tabular}


Table 3.2.3-2 Heat and Material Balance for Implementation Step 2 Continued

\begin{tabular}{|c|c|c|c|c|c|c|c|c|c|c|c|c|c|}
\hline & & & & & & & & & & & & & \\
\hline English Units & & & & & & & & & & & & & \\
\hline & & 15 & 16 & 17 & 18 & 19 & 20 & 21 & 22 & 23 & 24 & 25 & 26 \\
\hline & & $\begin{array}{l}\text { Gas to GT-1 } \\
\text { Combustor }\end{array}$ & $\begin{array}{c}\text { Total Air to GT - } \\
11\end{array}$ & GT-1 Output & $\begin{array}{c}\text { HSRG-1 } \\
\text { Exhaust Air }\end{array}$ & $\begin{array}{c}\text { Stoker } \\
\text { Overfire Air }\end{array}$ & Undergrate Air & $\begin{array}{c}\text { Woodwaste } \\
\text { to Stoker }\end{array}$ & $\begin{array}{c}\text { Stoker } \\
\text { Bottom Ash }\end{array}$ & $\begin{array}{c}\text { Flue Gas } \\
\text { from Stoker }\end{array}$ & $\begin{array}{c}\text { Wet } \\
\text { Woodwaste }\end{array}$ & $\begin{array}{l}\text { Gas to } \\
\text { Dryer }\end{array}$ & $\begin{array}{c}\text { Flue Gas to } \\
\text { DC }\end{array}$ \\
\hline mass flow & Ibih & 5997 & 732996 & 732996 & 732996 & 165671 & 149582 & 27500 & 574 & 418926 & 86098 & 0 & 481321 \\
\hline pressure & psia & 194.0 & 178.0 & 14.9 & 14.7 & 15.6 & 14.8 & 14.7 & 14.7 & 14.5 & 14.7 & 14.7 & 14.3 \\
\hline temperature & ${ }^{\circ} \mathrm{F}$ & 80 & 1520 & 707 & 382 & 375 & 375 & 80 & 1004 & 572 & 80 & 80 & 209.5 \\
\hline heat flow (HHV) & MMEtu'h & 143.3 & 294 & 130.4 & 69.5 & 15.4 & 13.9 & 209.6 & 1.4 & 96.8 & 389.7 & 0.0 & 95.8 \\
\hline electric power & MWe & & & 17.0 & & & & & & & & & \\
\hline & & & & & & & & & & & & & \\
\hline c & \%w (dry) & & & & & & & 54.00 & 15.00 & & 54.00 & & \\
\hline H & \%w (dry) & & & & & & & 6.40 & & & 6.40 & & \\
\hline $\mathrm{N}$ & \%w (dry) & & & & & & & 0.21 & & & 0.21 & & \\
\hline 0 & \%w (dry) & & & & & & & 33.85 & & & 33.85 & & \\
\hline 8 & \%w (dry) & & & & & & & 0.00 & & & 0.00 & & \\
\hline ash & \%w (dry) & & & & & & & 5.54 & 85.00 & & 5.54 & & \\
\hline moisture & \%w & & & & & & & 20.00 & & & 52.5 & & \\
\hline HHV & Btulib (dry) & & & & & & & 9528 & & & 9528 & & \\
\hline LHV & Btuilb (dry) & & & & & & & 8923 & & & 8923 & & \\
\hline & & & & & & & & & & & & & \\
\hline $\mathrm{CaCO} 3$ & \%w & & & & & & & 5500 & & & & & \\
\hline $\mathrm{MgCO}$ & \%ow & & & & & & & & & & & & \\
\hline $\mathrm{Si} 02$ & \%ow & & & & & & & & & & & & \\
\hline Other inert material & \%ow & & & & & & & & & & & & \\
\hline & & & & & & & & & & & & & \\
\hline $\mathrm{CO}$ & $\% \mathrm{~V}$ & & & & & & & & & & & & \\
\hline $\mathrm{CO} 2$ & \%V & & 1.46 & 1.46 & 1.46 & 1.46 & 1.46 & & & 13.52 & & & 11.28 \\
\hline $\mathrm{H} 2$ & \%V & & & & & & & & & & & & \\
\hline $\mathrm{H} 2 \mathrm{O}$ & $\% 4$ & & 2.92 & 2.92 & 2.92 & 2.92 & 2.92 & & & 15.15 & & & 23.76 \\
\hline $\mathrm{CH}_{4}$ & \% V & 100 & & & & & & & & & & 100 & \\
\hline N2 & \%v & & 77.85 & 77.85 & 77.85 & 77.85 & 77.85 & & & 69.09 & & & 61.95 \\
\hline $\mathrm{C} 2 \mathrm{H}_{4}$ & \%y & & & & & & & & & & & & \\
\hline $\mathrm{C}_{6} \mathrm{H}_{6}$ & $\% \mathrm{~V}$ & & & & & & & & & & & & \\
\hline $\mathrm{H} 2 \mathrm{~S}+\mathrm{COS}$ & $\% \mathrm{~V}$ & & & & & & & & & & & & \\
\hline $\mathrm{NH} 3+\mathrm{HCN}$ & \%V & & & & & & & & & & & & \\
\hline 02 & $\% 4$ & & 17.77 & 17.77 & 17.77 & 17.77 & 17.77 & & & 2.24 & & & 3.01 \\
\hline HHV & Btu/scf (wet) & & & & & & & & & & & & \\
\hline LHV & Btu/scf (wet) & & & & & & & & & & & & \\
\hline density & Ib/scf & & & & & & & & & & & & \\
\hline & & & & & & & & & & & & & \\
\hline & & & & & & & & & & & & & \\
\hline & & & & & & & & & & & & & \\
\hline & & & & & & & & & & & & & \\
\hline & & & & & & & & & & & & & \\
\hline & & & & & & & & & & & & & \\
\hline & & & & & & & & & & & & & \\
\hline SIUnits & & & & & & & & & & & & & \\
\hline & & 15 & 16 & 17 & 18 & 19 & 20 & 21 & 22 & 23 & 24 & 25 & 26 \\
\hline & & $\begin{array}{l}\text { Gas to GT-1 } \\
\text { Combustor }\end{array}$ & $\begin{array}{c}\text { Total Air to GT- } \\
1^{1}\end{array}$ & GT-1 Output & $\begin{array}{l}\text { HSRG-1 } \\
\text { Exhaust Air }\end{array}$ & $\begin{array}{c}\text { Stoker } \\
\text { Overfire Air }\end{array}$ & Undergrate Air & $\begin{array}{c}\text { Woodwaste } \\
\text { to Stoker }\end{array}$ & $\begin{array}{c}\text { Stoker } \\
\text { Bottom Ash }\end{array}$ & $\begin{array}{c}\text { Flue Gas } \\
\text { from Stoker }\end{array}$ & $\begin{array}{c}\text { Wet } \\
\text { Woodwaste }\end{array}$ & $\begin{array}{l}\text { Gas to } \\
\text { Dryer }\end{array}$ & $\begin{array}{c}\text { Flue Gas to } \\
D C\end{array}$ \\
\hline mass flow & $\mathrm{kg} / \mathrm{s}$ & 0.76 & 92.36 & 92.36 & 92.36 & 20.87 & 18.85 & 3.47 & 0.07 & 52.78 & $\begin{array}{r}10.85 \\
\end{array}$ & 0.00 & 60.65 \\
\hline pressure & bara & 13.38 & 12.28 & 1.03 & 1.01 & 1.08 & 1.02 & 1.01 & 1.01 & 1.00 & 1.01 & 1.01 & 0.99 \\
\hline temperature & ${ }^{\circ} \mathrm{C}$ & 27 & 827 & 375 & 194 & 191 & 191 & 27 & 540 & 300 & 27 & 27 & 99 \\
\hline heat flow (HHV) & MJ/s & 42.0 & 86.2 & 38.2 & 20.4 & 4.5 & 4.1 & 61.4 & 0.4 & 28.4 & 114.2 & 0.0 & 28.1 \\
\hline electric power & MWe & & & 17.0 & & & & & & & & & \\
\hline & & & & & & & & & & & 0.00 & & \\
\hline c & Kw (dry) & & & & & & & 54.00 & 15.00 & & 54.00 & & \\
\hline $\mathrm{H}$ & \%w (dry) & & & & & & & 6.40 & & & 6.40 & & \\
\hline N & \%w (dry) & & & & & & & 0.21 & & & 0.21 & & \\
\hline 0 & \%w (dry) & & & & & & & 33.85 & & & 33.85 & & \\
\hline s & \%w (dry) & & & & & & & 0.00 & & & 0.00 & & \\
\hline ash & \%w (dry) & & & & & & & 5.54 & 85.00 & & 5.54 & & \\
\hline moisture (as fed) & \%W & & & & & & & 20.00 & & & 52.50 & & \\
\hline HHV & kJjikg (dry) & & & & & & & 22163 & & & 22163 & & \\
\hline LHV dry base & $\mathrm{kJj} / \mathrm{kg}(\mathrm{dry})$ & & & & & & & 20754 & & & 20754 & & \\
\hline & & & & & & & & & & & & & \\
\hline $\mathrm{CaCO}$ & \%ow & & & & & & & & & & & & \\
\hline $\mathrm{MgCO3}$ & \%w & & & & & & & & & & & & \\
\hline $\mathrm{SiO} 2$ & \%ow & & & & & & & & & & & & \\
\hline Other inert material & \%ow & & & & & & & & & & & & \\
\hline & & & & & & & & & & & & & \\
\hline $\mathrm{CO}$ & $\% \mathrm{~V}$ & & & & & & & & & & & & \\
\hline $\mathrm{CO} 2$ & $\% \mathrm{v}$ & & 1.46 & 1.46 & 1.46 & 1.46 & 1.46 & & & 13.52 & & & 11.28 \\
\hline $\mathrm{H} 2$ & \%V & & & & & & & & & & & & \\
\hline $\mathrm{H} 2 \mathrm{O}$ & $\% \mathrm{~V}$ & & 2.92 & 2.92 & 2.92 & 2.92 & 2.92 & & & 15.15 & & & 23.76 \\
\hline $\mathrm{CH} 4$ & $\% \mathrm{~V}$ & 100 & & & & & & & & & & 100.00 & \\
\hline N2 & \% V & & 77.85 & 77.85 & 77.85 & 77.85 & 77.85 & & & 69.09 & & & 61.95 \\
\hline $\mathrm{C} 2 \mathrm{H} 4$ & $\% y$ & & & & & & & & & & & & \\
\hline $\mathrm{C} 6 \mathrm{H} 6$ & \%V & & & & & & & & & & & & \\
\hline $\mathrm{H} 2 \mathrm{~S}+\mathrm{COS}$ & \%V & & & & & & & & & & & & \\
\hline $\mathrm{NH} 3+\mathrm{HCN}$ & $\% \mathrm{~V}$ & & & & & & & & & & & & \\
\hline 02 & 964 & & 17.77 & 17.77 & 17.77 & 17.77 & 17.77 & & & 2.24 & & & 3.01 \\
\hline HHV wet base & $\mathrm{kJJim}^{3} \mathrm{n}$ (wet) & & & & & & & & & & & & \\
\hline LHV wet base & $\mathrm{kJJm}^{3} \mathrm{n}$ (wet) & & & & & & & & & & & & \\
\hline density & $\mathrm{kg}^{3} \mathrm{~m}^{3} \mathrm{n}$ & & & & & & & & & & & & \\
\hline & & & & & & & & & & & & & \\
\hline
\end{tabular}


Table 3.2.3-3 Heat and Material Balance for Implementation Step 3

\begin{tabular}{|c|c|c|c|c|c|c|c|c|c|c|c|c|c|c|c|c|c|c|c|c|c|}
\hline \multicolumn{22}{|l|}{ English Units } \\
\hline & & 1 & $?$ & 3 & 4 & 5 & 6 & 7 & 8 & 9 & 10 & 11 & 12 & 13 & 14 & 15 & 16 & 17 & 18 & 19 & 20 \\
\hline & & $\begin{array}{l}\text { Woodwaste } \\
\text { to Gasifier }\end{array}$ & $\begin{array}{c}\text { Airto } \\
\text { Gasifier }\end{array}$ & $\begin{array}{l}\text { Limestone } \\
\text { to Gasififier }\end{array}$ & \begin{tabular}{|l} 
Purge \\
Nitrogen
\end{tabular} & $\begin{array}{l}\text { Assh from } \\
\text { Gasifier }\end{array}$ & $\begin{array}{c}\text { Raw Frod. } \\
\text { Gass }\end{array}$ & $\begin{array}{c}\text { Combustor } \\
\text { Air }\end{array}$ & $\begin{array}{c}\text { Heated } \\
\text { Frod. Gas }\end{array}$ & $\begin{array}{l}\text { Cooled } \\
\text { Plod. Gas }\end{array}$ & $\begin{array}{l}\text { Rebum } \\
\text { Prod. Gas }\end{array}$ & $\begin{array}{c}\text { Gasification } \\
\text { Air }\end{array}$ & $\begin{array}{c}\text { GT-1 Airto HE } \\
1\end{array}$ & 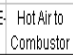 & $\begin{array}{l}\text { GT-1 Bypass } \\
\text { Air }\end{array}$ & $\begin{array}{l}\text { Gas to GT-1 } \\
\text { Combustor }\end{array}$ & $\begin{array}{c}\text { Total Air to GT- } \\
11\end{array}$ & GT-1 Output & $\begin{array}{c}\text { HBRG-1 } \\
\text { Exhaust Air }\end{array}$ & $\begin{array}{c}\text { Stoker } \\
\text { Overfive Air }\end{array}$ & Undergrate Air \\
\hline mass fow & loinh & 23621 & 40460 & 238 & 389 & 810 & ] $\quad 63422$ & $2 \quad 14238$ & 877660 & 77660 & 77660 & 54698 & $8 \quad 234389$ & $9 \quad 234389$ & $\begin{array}{l}9 \\
\end{array}$ & 5997 & $7 \quad 732996$ & 8732996 & 732996 & 184422 & $2 \quad 208055$ \\
\hline temperature & ${ }^{\circ F}$ & 80 & 515 & 80 & 104 & 1472 & 1562 & 515 & 2198 & 882 & 651 & 205 & 661 & 1400 & 661 & 80 & 1520 & 707 & 362 & 375 & 375 \\
\hline head flow (HHY) & MMElulih & 180.5 & 48 & 0.0 & 0.0 & 0.5 & 183.9 & 1.7 & 186.1 & 150.1 & 144.4 & 3.3 & 338 & 79.8 & 65.7 & 143.3 & 294 & 130.4 & 69.5 & 16.9 & 19.1 \\
\hline \multirow[t]{2}{*}{ electric power } & Millo & & & & & & & & & & & & & & & & & 17.0 & & & \\
\hline & & & & & & & & & & & & & & & & & & & & & \\
\hline c & $S_{W}(d y)$ & 54.00 & & & & 1.8 & & & & & & & & & & & & & & & \\
\hline H & $Y_{w}(d \mathrm{~d} Y y)$ & 6.40 & & & & & & & & & & & & & & & & & & & \\
\hline $\mathrm{N}$ & Yw $(d \mathrm{~d} y)$ & 0.21 & & & & & & & & & & & & & & & & & & & \\
\hline 0 & Sw $(d \mathrm{~d} y)$ & 33.85 & & & & & & & & & & & & & & & & & & & \\
\hline 8 & Sw $(d V y)$ & 0.00 & & & & & & & & & & & & & & & & & & & \\
\hline ash & Yw $(d \mathrm{~d} y)$ & 5.54 & & & & 98.2 & & & & & & & & & & & & & & & \\
\hline molisture & $8 \mathrm{~W}$ & 20.00 & & & & & & & & & & & & & & & & & & & \\
\hline HHV & Btullib (divin) & 9528 & & & & & & & & & & & & & & & & & & & \\
\hline \multirow[t]{2}{*}{ LHII } & Btullih (didy) & 8923 & & & & & & & & & & & & & & & & & & & \\
\hline & & 4724 & & & & & & & & & & & & & & & & & & & \\
\hline $\mathrm{CaCO3}$ & Sow & & & 77.0 & & & & & & & & & & & & & & & & & \\
\hline $\mathrm{MgCO}$ & \%ow & & & 14.0 & & & & & & & & & & & & & & & & & \\
\hline \multirow[t]{2}{*}{ Other ineit material } & \% & & & 1.0 & & & & & & & & & & & & & & & & & \\
\hline & & & & & & & & & & & & & & & & & & & & & \\
\hline$c 0$ & $\% \%$ & & & & & & 16.94 & & 14.66 & 14.66 & 14.66 & & & & & & & & & & \\
\hline $\mathrm{CO} 2$ & 84 & & & & & & 10.75 & & 9.56 & 9.56 & 9.56 & & & & & & & 1.46 & 1.46 & 1.36 & 1.36 \\
\hline $\mathrm{H} 2$ & $8 \%$ & & & & & & 14.74 & & 6.55 & 6.55 & 6.55 & & & & & & & & & & \\
\hline $\mathrm{H} 2 \mathrm{O}$ & $8 \%$ & & & & & & 10.33 & & 15.46 & 15.46 & 15.45 & & & & & & & 2.92 & 2.92 & 2.72 & 2.72 \\
\hline CH4 & 84 & & & & & & 4.06 & & 3.52 & 3.52 & 3.52 & & & & & 100 & & & & & \\
\hline $\mathrm{N} 2$ & \% & & 790 & & 98.0 & & 4293 & 79.00 & 50.08 & 50.00 & 50.08 & 79.0 & 790 & 79.0 & 79.0 & & & 77.85 & 77.85 & 77.92 & 77.92 \\
\hline $\mathrm{C} 2 \mathrm{H} 4$ & $8 \%$ & & & & & & 0.04 & & 0.021 & 0.021 & 0.021 & & & & & & & & & & \\
\hline CGH6 & 84 & & & & & & 0.11 & & 0.054 & 0.054 & 0.054 & & & & & & & & & & \\
\hline $\mathrm{H} 2 \mathrm{~B}+\mathrm{COS}$ & $8 \%$ & & & & & & 0 & & 0 & 0 & 0 & & & & & & & & & & \\
\hline $\mathrm{NH} 3+\mathrm{HCN}$ & $8 \%$ & & & & & & 0.11 & & 0.09 & 0.09 & 0.09 & & & & & & & & & & \\
\hline 02 & \%oy & & 21.0 & & 2.0 & & & 21 & & & & 21.0 & 21.0 & 21.0 & 21.0 & & & 17.77 & 17.77 & 17.99 & 17.99 \\
\hline HHV & Etujscc (wett) & & & & & & 149 & & 107 & 107 & 107 & & & & & & & & & & \\
\hline LHIV & Btussct (wet) & & & & & & 137 & & 100 & 100 & 100 & & & & & & & & & & \\
\hline density & lbiscli & & & & & & 0.068 & & 0.072 & 0.072 & 0.072 & & & & & & & & & & \\
\hline & & & & & & & & & & & & & & & & & & & & & \\
\hline
\end{tabular}

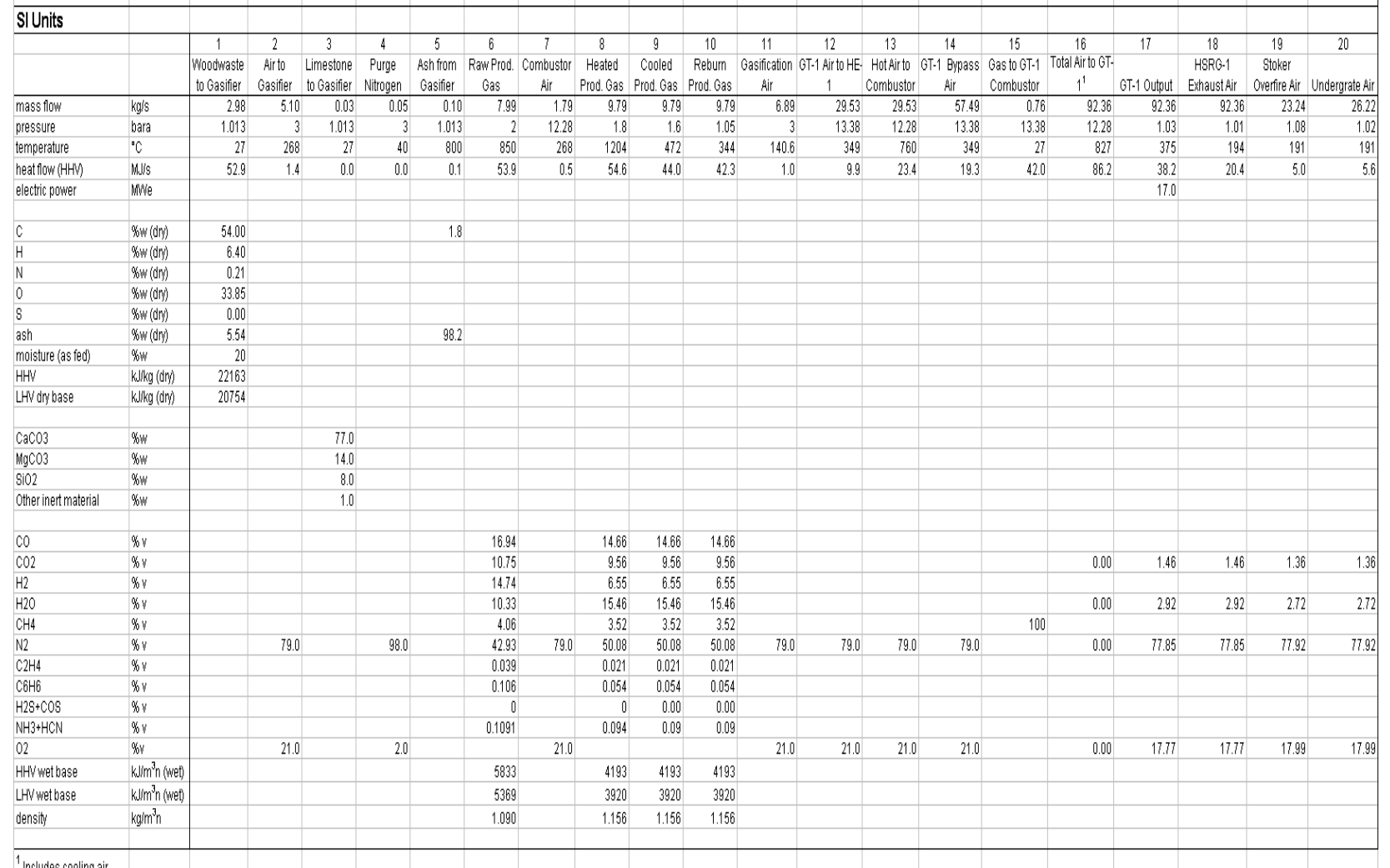


Table 3.2.3-1 Heat and Material Balance for Implementation Step 3 Continued

\begin{tabular}{|c|c|c|c|c|c|c|c|c|c|c|c|c|c|c|}
\hline English Units & & & & & & & & & & & & & & \\
\hline & & 21 & 22 & 23 & 24 & 25 & 26 & 27 & 28 & 29 & 30 & 31 & 32 & 33 \\
\hline & & $\begin{array}{c}\text { Woodwaste } \\
\text { to Stoker }\end{array}$ & $\begin{array}{c}\text { Stoker } \\
\text { Bottom Ash }\end{array}$ & $\begin{array}{l}\text { Flue Gas } \\
\text { from Stoker }\end{array}$ & $\begin{array}{c}\text { Wet } \\
\text { Moodwaste }\end{array}$ & $\begin{array}{l}\text { Gasto to } \\
\text { Dryer }\end{array}$ & $\begin{array}{c}\text { Flue Gas to } \\
\text { DC }\end{array}$ & $\begin{array}{c}\text { GT-2 Airto } \\
\text { HE-2 }\end{array}$ & $\begin{array}{c}\text { Hot Air to } \\
\text { Combustor }\end{array}$ & $\begin{array}{c}G T \cdot 2 \\
\text { Bipass Air }\end{array}$ & $\begin{array}{c}\begin{array}{c}\text { Gas to GT.2 } \\
\text { Combustor }\end{array} \\
\end{array}$ & $\begin{array}{c}\text { Total Airto } \\
\text { G-21 }\end{array}$ & GT-2 Output & $\begin{array}{c}\text { HSRG-2 } \\
\text { Ehanast Air }\end{array}$ \\
\hline mass flow & lbih & 38250 & 798 & 506318 & 104203 & 0 & 576069 & 320000 & 320000 & 370496 & 5158 & 732004 & 732004 & 732004 \\
\hline pressure & psia & 14.7 & 14.7 & 14.5 & 14.7 & 14.7 & 14.3 & 2080 & 178.0 & 194.0 & 194.0 & 178.0 & 14.9 & 14.7 \\
\hline temperature & ${ }^{\circ} \mathrm{F}$ & 80 & 1004 & 605 & 80 & 80 & 238 & 661 & 1400 & 661 & 80 & 1520 & 707 & 391 \\
\hline hest flow (HHV) & MMEtulh & 291.8 & 1.9 & 121.1 & 471.7 & 0.0 & 119.8 & 46.1 & 108.9 & 53.4 & 123.3 & 291 & 128.0 & 69.0 \\
\hline electric power & MNe & & & & & & & & & & & & 17.0 & \\
\hline & & & & & & & & & & & & & & \\
\hline C & Kow (dVh) & 54.00 & 15.00 & & 54.00 & & & & & & & & & \\
\hline $\mathrm{H}$ & Sw (dry) & 6.40 & & & 6.40 & & & & & & & & & \\
\hline N & $\operatorname{Sow}($ (dn) & 0.21 & & & 0.21 & & & & & & & & & \\
\hline 0 & Yw w (dry) & 33.85 & & & 33.85 & & & & & & & & & \\
\hline 8 & Sim (drn) & 0.00 & & & 0.00 & & & & & & & & & \\
\hline ash & Yw w (dry) & 5.54 & 85.00 & & 5.54 & & & & & & & & & \\
\hline moisture & Sow & 20.00 & & & 52.5 & & & & & & & & & \\
\hline$H H V$ & Ettullb (doy) & 9528 & & & 9528 & & & & & & & & & \\
\hline LHY & Etullh (dry) & 8923 & & & 8923 & & & & & & & & & \\
\hline & & & & & & & & & & & & & & \\
\hline $\mathrm{CaCO}$ & \%W & 7650 & & & & & & & & & & & & \\
\hline $\mathrm{MgCO}$ & \%iw & & & & & & & & & & & & & \\
\hline 5102 & $W_{W}$ & & & & & & & & & & & & & \\
\hline Other inert material & \%iw & & & & & & & & & & & & & \\
\hline Co & \%V & & & & & & & & & & & & & \\
\hline $\mathrm{CO2}$ & \%y & & & 13.48 & & & 11.36 & & & & & 1.26 & 1.26 & 1.26 \\
\hline $\mathrm{H} 2$ & $\% 4$ & & & & & & & & & & & & & \\
\hline H2O & $\% 4$ & & & 15.05 & & & 23.92 & & & & & 2.52 & 2.52 & 2.52 \\
\hline $\mathrm{CH} 4$ & $\% y$ & & & & & 100 & & & & & 100 & & & \\
\hline N2 & $\% 4$ & & & 69.13 & & & 61.81 & 79.0 & 79.0 & 79.0 & & 78.00 & 78.00 & 78.00 \\
\hline $\mathrm{C} 2 \mathrm{H} 4$ & कy & & & & & & & & & & & & & \\
\hline $\mathrm{C} 6 \mathrm{H} 6$ & $\%$ & & & & & & & & & & & & & \\
\hline $\mathrm{H} 2 \mathrm{~s}+\mathrm{COS}$ & $\phi_{4}$ & & & & & & & & & & & & & \\
\hline $\mathrm{NH} 3+\mathrm{HCN}$ & $\%$ & & & & & & & & & & & & & \\
\hline 02 & 864 & & & 2.33 & & & 2.91 & 21.0 & 21.0 & 21.0 & & 18.22 & 18.22 & 18.22 \\
\hline $\mathrm{HH} / \mathrm{H}$ & Btuscrf iwet) & & & & & & & & & & & & & \\
\hline LHY & Btuscfi wett & & & & & & & & & & & & & \\
\hline density & lbiscf & & & & & & & & & & & & & \\
\hline & & & & & & & & & & & & & & \\
\hline & & & & & & & & & & & & & & \\
\hline & & & & & & & & & & & & & & \\
\hline & & & & & & & & & & & & & & \\
\hline & & & & & & & & & & & & & & \\
\hline & & & & & & & & & & & & & & \\
\hline SIUnits & & & & & & & & & & & & & & \\
\hline pressure & bara & 1.01 & 1.01 & 1.00 & 1.01 & 1.01 & 0.99 & 14.34 & 12.28 & 13.38 & 13.38 & 12.28 & 1.09 & 1.01 \\
\hline temperature & ${ }^{\circ} \mathrm{C}$ & 27 & 540 & 318 & 27 & 27 & 114 & 349 & 760 & 349 & 27 & 827 & 375 & 199 \\
\hline heat flow (HHY) & MJ/s & 85.5 & $0 . \overline{6}$ & 35.5 & 138.2 & 0.0 & 35.1 & 13.5 & 31.9 & 15.6 & 36.1 & 85.2 & 37.5 & 20.2 \\
\hline electric power & Mwe & & & & & & & & & & & & 17.0 & \\
\hline & & & & & 0.00 & & & & & & & & & \\
\hline c & Sw (drn) & 54.00 & 15.00 & & 54.00 & & & & & & & & & \\
\hline $\mathrm{H}$ & Sow (drly) & 6.40 & & & 6.40 & & & & & & & & & \\
\hline $\mathrm{N}$ & Sow (dry) & 0.21 & & & 0.21 & & & & & & & & & \\
\hline 0 & Sow (dNh) & 33.85 & & & 33.85 & & & & & & & & & \\
\hline s & SW (drn) & 0.00 & & & 0.00 & & & & & & & & & \\
\hline ash & $\operatorname{Sow}(\mathrm{d} d \mathrm{~N})$ & 5.54 & 85.00 & & 5.54 & & & & & & & & & \\
\hline molisture (as fied) & SW & 20.00 & & & 52.50 & & & & & & & & & \\
\hline $\mathrm{HHY}$ & kJjlkg (ddy) & 22163 & & & 22163 & & & & & & & & & \\
\hline LHY dry base & k.Jilkg (dy) & 20754 & & & 20754 & & & & & & & & & \\
\hline & & & & & & & & & & & & & & \\
\hline $\mathrm{CaCO}_{3}$ & KW & & & & & & & & & & & & & \\
\hline $\mathrm{MgCO3}$ & sw & & & & & & & & & & & & & \\
\hline 5102 & \%iw & & & & & & & & & & & & & \\
\hline Other inert material & \% W & & & & & & & & & & & & & \\
\hline & & & & & & & & & & & & & & \\
\hline 60 & \%V & & & & & & & & & & & & & \\
\hline $\mathrm{CO} 2$ & $\% 6$ & & & 13.48 & & & 11.36 & & & & & 1.26 & 1.26 & 1.26 \\
\hline $\mathrm{H}_{2}$ & sy & & & & & & & & & & & & & \\
\hline $\mathrm{H} 2 \mathrm{O}$ & $\%$ & & & 15.05 & & & 23.92 & & & & & 2.52 & 2.52 & 2.52 \\
\hline $\mathrm{CH} 4$ & $\% 4$ & & & & & 100.00 & & & & & 100 & & & \\
\hline N2 & $\% 6$ & & & 69.13 & & & 61.81 & 79.00 & 79.00 & 79.00 & & 78.00 & 78.00 & 78.00 \\
\hline $\mathrm{C} 2 \mathrm{H} 4$ & \%4 & & & & & & & & & & & & & \\
\hline $\mathrm{CBH}$ & $g_{6}$ & & & & & & & & & & & & & \\
\hline $\mathrm{H} 2 \mathrm{~S}+\mathrm{COS}$ & \%y & & & & & & & & & & & & & \\
\hline $\mathrm{NH} 3+\mathrm{HCN}$ & $g_{4}$ & & & & & & & & & & & & & \\
\hline 02 & $96 \%$ & & & 2.33 & & & 2.92 & 21.00 & 21.00 & 21.00 & & 18.22 & 18.22 & 18.22 \\
\hline HH/ wet base & kJjimn n wet) & & & & & & & & & & & & & \\
\hline LHYwet base & kJum ${ }^{3} n$ iwett & & & & & & & & & & & & & \\
\hline density & $\operatorname{kggim}^{3} n$ & & & & & & & & & & & & & \\
\hline & & & & & & & & & & & & & & \\
\hline${ }^{1}$ Includes cooling air & & & & & & & & & & & & & & \\
\hline
\end{tabular}




\subsection{MAJOR PLANT AREAS}

Descriptions of the major plant areas, which include biomass drying, biomass gasification, modification of the existing biomass boiler, power generation, and preheating of gas turbine combustion air are given in this section.

\subsubsection{Biomass Drying System}

\section{System Description}

Preparation of fuel for gasifier includes the drying of bark fuel. The fuel drying system reduces fuel moisture content from $52.5 \%$ to $20 \%$. The dryer system includes two directly heated drum dryers. The drum dryers are of same size and capacity and will be installed in two steps. The dryers are integrated with the boiler flue gas system utilizing flue gas for the drying process and returning the exhaust gas to the dust removal system of the boiler. The dryer system is at negative pressure since it is upstream of the boiler's ID fan.

In the first implementation step the heat for drying is generated by burning natural gas and utilizing a small amount of recirculated flue gas from the boiler. Wet fuel is fed through an air lock (rotary feeder) at the inlet of the rotary drum. The drum is operated at negative pressure maintained by the ID fan of the boiler. Big particles of dried fuel drop out from the drum into a Drop-Out Box, which is equipped with a reversible screw conveyor to discharge the dried product. The small particles are conveyed with the gas flow to twin cyclones where the rest of dried fuel is separated from the gas stream. The cyclones are equipped with screw conveyors and airlock to remove the rest of dried fuel. The exhaust flange of the cyclone is connected to the dust removal system of the boiler, where the fine dust is removed from the gas flow.

In the second implementation step a second dryer will be installed. In this phase the two parallel dryers would provide dry feedstock to the gasifier and to the boiler. In this case both dryers would utilize flue gas from the boiler economizer as drying medium. Both dryers' exhausts are directed to the dust removal system of the boiler. The second dryer process is as described for the first dryer.

\section{Design Basis}

The design basis of the fuel dryers is summarized in Table 3.3.1-1.

\section{Process Parameters}

Technical and pricing information was received in quotations for the bark dryers from a U.S. (MEC) and a Swedish (Torkapparater) vendor. Process parameters for one (1) dryer are shown in the Table 3.3.1-2 below, based on MEC proposal data. Data shown for Step 1 is for base load operation of the Gasification Plant. Step 2 is $50 \%$ of the total requirement of the Gasification Plant and Stoker boiler at base load. 


\section{Table 3.3.1-1 Fuel Dryer Design Basis}

Fuel Dryers Design Basis for Steps $1 \& 2$

Material to be dried: bark

$\underline{\text { Bark size Fraction }}$

Size,

$1-1 / 2$ in $(38 \mathrm{~mm})$

$7 / 8$ in $(22.2 \mathrm{~mm})$

$5 / 8 \mathrm{in}(15.9 \mathrm{~mm})$

$1 / 4$ in $(6.35 \mathrm{~mm})$

$1 / 8$ in $(3.2 \mathrm{~mm})$

Fines
Wt $\%$

7.8

4.7

11.0

38.6

20.2

17.7

Product moisture into dryer, wet basis

Product moisture out of dryer, wet basis

Ambient air temperature at dryer air intake*

$52.5 \% \mathrm{~W}$

$20 \% \mathrm{~W}$

Product temperature at dryer air intake*

Bulk density for volumetric designs
A. Oven dry basis
B. Wet as fed basis

Wet fuel input, $\mathrm{lb} / \mathrm{h} / \mathrm{kg} / \mathrm{s}$

Available flue gas from boiler, $\mathrm{lb} / \mathrm{h} / \mathrm{kg} / \mathrm{s}$

Available boiler flue gas temperature, ${ }^{\circ} \mathrm{F} /{ }^{\circ} \mathrm{C}$

$59^{\circ} \mathrm{F}\left(15^{\circ} \mathrm{C}\right)$

$59^{\circ} \mathrm{F}\left(15^{\circ} \mathrm{C}\right)$

$10.0 \mathrm{lb} / \mathrm{ft}^{3}\left(160 \mathrm{~kg} / \mathrm{m}^{3}\right)$

$21.1 \mathrm{lb} / \mathrm{ft}^{3}\left(338 \mathrm{~kg} / \mathrm{m}^{3}\right)$

$\underline{\text { Step } 1 \quad \underline{\text { Step } 2}}$

$39685 / 5.0 \quad 54015 / 6.81$

$83351 / 10.5 \quad 555670 / 70.0$

$400 / 204 \quad 640 / 338$

Available boiler flue gas composition

$\begin{array}{lll}\mathrm{CO}_{2} & 17.6 & \% \mathrm{v} \\ \mathrm{O}_{2} & 4.3 & \% \mathrm{v} \\ \mathrm{H}_{2} \mathrm{O} & 16.3 & \% \mathrm{v} \\ \mathrm{N}_{2} & 61.8 & \% \mathrm{v}\end{array}$

* Based on vendor quotation, process ambient temperature is $66^{\circ} \mathrm{F}$

Table 3.3.1-2 Fuel Dryer Process Parameters

Dryer Process Parameters

Wet fuel input $\quad \mathrm{lb} / \mathrm{h} / \mathrm{kg} / \mathrm{s}$

Water evaporation rate, $\mathrm{lb} / \mathrm{h} / \mathrm{kg} / \mathrm{s}$

Dryer overall heat demand, MMBtu/h / MJ/s

Dried product mass flow rate, $\mathrm{lb} / \mathrm{h} / \mathrm{kg} / \mathrm{s}$

Dried product temperature, ${ }^{\circ} \mathrm{F} /{ }^{\circ} \mathrm{C}$

Exhaust gas flow, $\mathrm{lb} / \mathrm{h} / \mathrm{kg} / \mathrm{s}$

Estimated cool gas temp. at dryer outlet, ${ }^{\circ} \mathrm{F} /{ }^{\circ} \mathrm{C}$

Dust in exhaust gas, $\mathrm{lb} / \mathrm{scf} / \mathrm{g} / \mathrm{m}^{3} \mathrm{n}$

Expected uncontrolled VOC emission, $\mathrm{lb} / \mathrm{h} / \mathrm{kg} / \mathrm{h}$

Flue gas flow rate from boiler, $\mathrm{lb} / \mathrm{h} / \mathrm{kg} / \mathrm{s}$

Boiler flue gas temperature, ${ }^{\circ} \mathrm{F} /{ }^{\circ} \mathrm{C}$

Natural gas consumption, $\mathrm{lb} / \mathrm{h} / \mathrm{kg} / \mathrm{s}$

Total air supply to dryer, $\mathrm{lb} / \mathrm{h} / \mathrm{kg} / \mathrm{s}$

Estimated electric power demand, $\mathrm{kW} / \mathrm{kW}$

Pressure drop on dryer system, in. wg / mbar

\begin{tabular}{l}
\multicolumn{1}{c}{ Step 1 } \\
$39685 / 5.0$ \\
$16121 / 2.03$ \\
$2762 / 8.1$ \\
$3563 / 2.97$ \\
$154 / 68$
\end{tabular}

$271064 / 34.15$

$175 / 79$

$0.0028 / 45$

$41.0 / 18.6$

$82431 / 10.39$

$399 / 204$

$1074 / 0.135$

171437 / 21.6

$86 / 86$

$20 / 51$ $\underline{\text { Step } 2}$

$54015 / 6.81$

$21944 / 2.77$

$3475 / 10.18$

$32071 / 4.04$

$154 / 68$

$261490 / 32.95$

$175 / 79$

$0.0028 / 45$

$63.5 / 28.8$

$225700 / 28.44$

$640 / 338$

$0 / 0$

$13846 / 1.74$

82 / 82

$20 / 51$ 


\subsubsection{Gasification Plant}

\subsubsection{Fuel Feeding System}

The description of the Fuel Feeding System refers to the process flow diagram of the Gasification Plant (Figure 3.3.2-1). The two Fuel Feeding Systems A and B are identical, and note that limestone feeding occurs only in conjunction of Fuel Feeding System A.

\section{System Description}

The function of the Fuel Feeding System is to feed woodwaste fuel from atmospheric pressure to system pressure. The fuel is mainly bark of particle size smaller then $1.5 \mathrm{in} / 38 \mathrm{~mm}$. The mean particle size is about $0.25 \mathrm{in} / 6.5 \mathrm{~mm}$. The moisture content of biomass as fed is about $20 \%$.

The fuel feeding system is a rotary valve / surge hopper system. The feeding system includes two identical feeding lines of equal capacity. Each feeding line has a capacity of $80 \%$ of total fuel feed, i.e. providing a total feeding capacity of $2 \times 80 \%$. Each of the fuel feeding lines includes one Weigh Silo, one rotary valve feeding screw, one rotary valve, one surge hopper and one metering screw.

Fuel is conveyed from the weigh silo of the fuel feeding lines. The weigh silos are equipped with vent-filters to prevent dust emission. The fuel is discharged from the weigh silos with discharge devices (live bottom) and fed with the rotary valve feeding screw to surge hoppers through rotary valves and filling valves. The rotary valve feeding screw is equipped with variable speed drive and it can be operated in reverse direction when the weigh silo has to be emptied. The function of the rotary valve is to keep the pressure in the surge hopper.

The fuel filling sequence based on level measurement in the weigh silo and surge hopper operates the filling valves. The isolation valve operation is interlocked with gasifier/surge hopper pressure difference and feeding screw temperature.

From the surge hopper the fuel is discharged through a screw type live bottom to the metering screws and are fed to the gasifier through the feeding screws using inert gas purging. The metering screws are equipped with variable speed drive (gasifier fuel feed rate control). The feeding screw is equipped with constant speed drive and water-cooled shaft. The Fuel Feeding System can be isolated from the gasifier by an isolating valve upstream of the feeding screws.

\section{Design Basis}

The gasifier fuel specification at as fed conditions is shown in Table 3.3.2-1.

\subsubsection{Limestone Feeding System}

The description of the Limestone Feeding System refers to the process Flow Diagram of the Gasification Plant (Figure 3.3.2-1) 


\section{Table 3.3.2-1. Fuel Specification}

Fuel type: bark

Bark Size: Fraction

$7.8 \% \mathrm{w} \quad 1-1 / 2$ in $38 \quad \mathrm{~mm}$

$4.7 \% \mathrm{w} \quad 7 / 8$ in $22.2 \mathrm{~mm}$

$11.0 \% \mathrm{w} \quad 5 / 8$ in $\quad 15.9 \mathrm{~mm}$

$38.6 \% \mathrm{w} \quad 1 / 4$ in $6.35 \mathrm{~mm}$

$20.2 \% \mathrm{w} \quad 1 / 8$ in $3.2 \mathrm{~mm}$

$17.7 \% \mathrm{w}$ Fines Fines

As fed moisture content $20 \quad \% \mathrm{~W}$

Bulk density for volumetric designs $17.4-1 \mathrm{lb} / \mathrm{ft}^{3} \quad 280 \quad \mathrm{~kg} / \mathrm{m}^{3}$

Fuel temperature $\quad 154 \quad{ }^{\circ} \mathrm{F} \quad 68 \quad{ }^{\circ} \mathrm{C}$

Fuel mass flow rate $23620 \mathrm{lb} / \mathrm{h} \quad 2.98 \mathrm{~kg} / \mathrm{s}$

\section{Limestone System Description}

Limestone is used as bed material in the fluidized bed gasifier. Limestone is fed by a separate feeding line into the gasifier, through the feeding screw of fuel feeding line A. The function of the Limestone Feeding System is to pressurize limestone from atmospheric pressure to system pressure at low temperature and feed it into the fluidized bed of the gasifier.

The Limestone Feeding System includes limestone weigh silo, lock hopper, surge hopper and metering screw. Limestone is transported pneumatically to the weigh silo (DFS-SILO1), which is equipped with vent-filter (DFS-EXHHD1). The weigh silo is equipped with a bottom discharge system (DFS-CNV2, variable elevation cone, hydraulically operated, vendor specific), which controls the limestone feed to the lock-hopper (DFS-LH1). When the lock-hopper is filled, the filling valve will be closed. The lock-hopper will be pressurized up to surge hopper pressure using the nitrogen from the process nitrogen network. When the pressure of the lock-hopper is about the same as the pressure of the surge hopper (DFS-LH2), the pressure equalizing valve/line opens between these two hoppers and pressure will be equalized. The closing valve in the bottom of the lock-hopper will be opened and limestone drops by gravity into the surge hopper. When all the limestone is transferred from the lock-hopper into the surge hopper, the lock-hopper closing valve will close and the empty lock-hopper will be depressurized. The valves are operated automatically according the limestone filling sequence based on level measurements in the lock-hopper and the surge hopper.

The Limestone is fed by the variable speed limestone metering screw (DFS-CNV1) from the surge hopper to the fuel feeding screw A, where the limestone will be mixed with fuel and fed into the gasifier.

\section{Design Basis}

Limestone feed specification is shown in Table 3.3.2-2. 


\section{Table 3.3.2-2. Limestone Feed Properties}

\begin{tabular}{|c|c|c|c|c|c|c|}
\hline \multicolumn{7}{|l|}{ Composition: } \\
\hline $\mathrm{CaCO}_{3}$ & \multicolumn{6}{|c|}{$77 \% w$} \\
\hline $\mathrm{MgCO}_{3}$ & \multicolumn{6}{|c|}{$14 \% \mathrm{w}$} \\
\hline $\mathrm{SiO}_{2}$ & \multicolumn{6}{|c|}{$8 \% w$} \\
\hline Moisture & \multicolumn{6}{|c|}{ air dry } \\
\hline Other inert material & \multicolumn{6}{|c|}{$1 \% \mathrm{w}$} \\
\hline Bulk density & \multicolumn{2}{|c|}{$87 \mathrm{lb} / \mathrm{cf}$} & \multicolumn{4}{|c|}{$\left(1400 \mathrm{~kg} / \mathrm{m}^{3)}\right.$} \\
\hline \multicolumn{7}{|c|}{ Particle size distribution } \\
\hline Mesh $\quad-18$ & -30 & -40 & -50 & -70 & -100 & -140 \\
\hline$\% \mathrm{~W} \quad 100.0$ & 88.6 & 62.0 & 37.0 & 19.5 & 9.1 & 3.6 \\
\hline Limestone temperature & \multicolumn{6}{|c|}{$66^{\circ} \mathrm{F} \quad\left(19^{\circ} \mathrm{C}\right)$} \\
\hline Limestone feed rate & $2381 \mathrm{~b}$ & $\mathrm{~h}(0.03$ & $\mathrm{kg} / \mathrm{s})$ & & & \\
\hline
\end{tabular}

The Limestone Feeding System is designed for 15 min feeding time in an hour (no continuous feeding required due to small limestone mass flow) at the base load operation of the gasifier.

\subsubsection{Gasification System}

The description of the Gasification System refers to the process Flow Diagram of the Gasification Plant (Figure 3.3.2-1).

\section{System Description}

The Gasification System includes Gasifier reactor, Cyclone, Start-up Heater and the Gasifier Gas Feeding System. The function of the gasifier is to convert solid feedstock (bark and wood waste) to Low-Calorific Value (LCV) product gas. The gasifier is a low pressure, bubbling fluidized bed gasification system.

The feedstock fed into the gasifier will dry and de-volatilize in the fluidized bed, the remainder char is gasified and partly burnt to maintain sufficient gasification temperature. The product gas contains

- Combustible components including $\mathrm{CO}, \mathrm{H}_{2}$ and $\mathrm{CH}_{4}$

- Inert components including $\mathrm{N}_{2}, \mathrm{CO}_{2}$ and $\mathrm{H}_{2} \mathrm{O}$

- Trace contaminants including $\mathrm{H}_{2} \mathrm{~S}, \mathrm{COS}, \mathrm{NH}_{3}, \mathrm{HCN}, \mathrm{HCl}$, vapor phase alkalis.

The bulk (about 40\%) of the gas is nitrogen due to air blown gasification. The raw gas leaving the gasifier cyclone also contains entrained solid particles.

The Gasifier Reactor includes the following parts:

- Gasifier reactor pressure vessel with ports for gas and solids feed and removal, for measuring systems and manholes

- Gasifier reactor multi-component refractory lining of varying thickness along the height of the reactor

- Gas distributor system including the grid and ash removal pipe.

The Cyclone includes the following parts: 
- Cyclone pressure vessel with connection to gasifier

- Refractory lining inside the pressure vessel

- Dipleg from the cyclone bottom to the gasifier (external)

The Start-up Heater includes the following parts:

- Heater pressure vessel with connections to the gasifier and ports for gas feed and measuring systems

- Refractory lining of the heater

- Heater burner

The Gasifier Gas Feeding System includes the following parts:

- Air piping from the Process Air System to the gasifier

- Air distribution manifold

- Air control valve systems

- Steam piping from pressure reduction to gasifier

- Steam control valve system

- Nitrogen piping to from nitrogen manifold to gasifier

- Nitrogen valves.

\section{Gasifier Reactor}

The Gasifier Reactor accommodates the fluidized bed and the freeboard area. The fluidized bed area is a bubbling fluidized bed of inert bed material (limestone), char and ash. The disengaging/freeboard area is a suspension of char and ash elutriated from the fluidized bed. The gasifier operates at $1560^{\circ} \mathrm{F} / 850^{\circ} \mathrm{C}$ temperature and at $29.0 \mathrm{psia} / 2.0$ Bara pressure.

The reactor pressure vessel is of dual diameter. The refractory lining reduces the inside diameter of the reactor determining bed and freeboard diameters. The fluidized bed operates at between $3.0-4.3 \mathrm{ft} / \mathrm{s} / 1.0-1.3 \mathrm{~m} / \mathrm{s}$ superficial velocity while the gas velocity decreases in the freeboard, returning the bulk of the elutriated fine particles to the fluidized bed and providing longer residence time for gases and solids. The height (volume) of the fluidized bed is determined mainly by the reactivity of the fuel.

Biomass is fed by water-cooled feeding screws to the lower area of the fluidized bed from the surge hoppers of the feeding lines. The elutriated particles are separated from the product gas stream by the cyclone and are returned to the fluidized bed area. The limestone bed material is fed into the gasifier bed area through fuel feeding screw A.

The gasification air (and steam, if any) is fed by the Gasifier Gas Feeding system to the gasifier reactor through the gas distributor. The gas distributor includes the grid and the bed material discharge system. The grid is of conical design equipped with horizontal nozzles. The bottom of the conical grid is connected to the ash removal pipe/classifier (air flows in counter flow with ash in the ash removal pipe carrying back particles of smaller than a certain particle size to the fluidized bed) where the gasifier ash discharge takes place. The ash removal pipe/classifier connects the gasifier bed area to the ash discharge system. The bed material (limestone and ash) is removed from the gasifier through the ash removal pipe and classifier via the cooling screw. Product gas exits the gasifier through the top of the pressure vessel and enters the cyclone. 


\section{Cyclone}

The bulk of the elutriated particulate matter from the gasifier is separated from the raw gas flow in a cyclone separator. The separated dust is returned through the cyclone dipleg to the fluidized bed where the returned carbon will further gasify.

The cyclone is a refractory lined pressure vessel. The cyclone is connected to the top of the gasifier pressure vessel. The exit of the cyclone is connected through a refractory lined gas duct and air injection system to the gas cooler heat exchanger. The cyclone dipleg is arranged externally (outside gasifier pressure vessel) and connected to the gasifier pressure vessel at bottom of the bed area.

\section{Start-up Heater}

At startup the gasification system is heated-up by a start-up heater to sufficient temperature for the combustion of startup fuel and switchover gasification.

The start-up heater is a horizontal refractory lined pressure vessel equipped with the start-up burner. The start-up heater is connected to the ash removal pipe/classifier. The air introduced through the ash removal pipe is supplied through the start-up heater. The start-up burner is operated so that the heater exit temperature is controlled between $1470-1650{ }^{\circ} \mathrm{F} / 800-900{ }^{\circ} \mathrm{C}$. Once gasification temperature is achieved the startup burner is shut down and only air flows through the start-up heater at $635^{\circ} \mathrm{F} / 335^{\circ} \mathrm{C}$ temperature.

The start-up burner is located at one end of the horizontal pressure vessel. The other end is the gas exit connected to the ash removal pipe/classifier joint.

\section{Start-up Heater Burner}

The description of the Start-up Heater Burner refers to the process Flow Diagram of the Gasification Plant (Figure 3.3.2-1).

The start-up heater burner is a gas burner used for gasification system heat-up during plant startup. The start-up burner is connected to one end of the start-up burner chamber, which is a refractory lined, horizontal pressure vessel. The other end of the burner chamber is connected to the reactor ash discharge pipe of the gasifier.

The start-up burner is operated so that the heater exit temperature is controlled to $1470-1650^{\circ} \mathrm{F} /$ $800-900{ }^{\circ} \mathrm{C}$ with mixing air. The burner operates normally at atmospheric pressure, but it can be ignited and operated up to $29 \mathrm{psia} / 2$ Bara pressure. Since the heater vessel is connected to the gasifier reactor, ash removal air flows through the start-up heater at $635^{\circ} \mathrm{F} / 335^{\circ} \mathrm{C}$ temperature serving also as purge gas for the burner and the burner chamber. The ash removal air is fed through the mixing air nozzle.

\subsubsection{Gas Feeding System}

Gasification air is supplied at $43.5 \mathrm{psia} / 3$ Bara and $635^{\circ} \mathrm{F} / 335^{\circ} \mathrm{C}$. The airflow is divided in the following streams through the air distribution manifold:

- Grid air, which maintains fluidization in the bed. Grid air enters the fluidized bed through nozzles of the grid.

- Ash removal air which controls bed material and ash removal from the bed. The ash removal air is fed via the start-up heater, which is connected to the mid section of the ash 
removal pipe.

- Air for the partial combustion of product gas to maintain $2200{ }^{\circ} \mathrm{F} / 1204^{\circ} \mathrm{C}$ temperature before GT air heater. This airflow is fed through nozzles to the combustions section down stream gasifier cyclone.

- Air for the startup heater burner. This airflow is fed separately to the startup burner as combustion air when it is operated and purge air when it is out of operation.

All air feeding lines are equipped with flow control valves and check valves.

Steam of (at least) 58 psia / 4 bara pressure is fed to the grid air line in the case of excess grid temperature or fluidized bed temperature or during emergency shutdown of the gasifier. Steam is fed in mixture of the grid airflow. Steam flow is controlled in accordance with the grid airflow. The steam line is equipped with flow control valve, check valve and blow down line for condensate removal.

Nitrogen is fed to the gasifier during emergency shutdown or excess temperature in the ash removal pipe. Nitrogen is supplied to the air distribution manifold or directly to ash removal air line. The nitrogen lines are equipped with flow control valves and check valves.

\section{Design Basis}

The process design data for the Gasifier System is summarized in Table 3.3.2-3.

Table 3.3.2-3 Gasifier System Design Basis

$\begin{array}{lll}\text { Ambient temperature } & 66^{\circ} \mathrm{F} & 19^{\circ} \mathrm{C} \\ \text { Fuel feed rate (AF, 20\% moisture) } & 23621 \mathrm{lb} / \mathrm{h} & 2.98 \mathrm{~kg} / \mathrm{s} \\ \text { Fuel heat input } & 180.4 \mathrm{MMBtu} / \mathrm{h} & 52.8 \mathrm{MJ} / \mathrm{s} \\ \text { Product gas generation } & 63422 \mathrm{lb} / \mathrm{h} & 7.99 \mathrm{~kg} / \mathrm{s} \\ \text { Gasification temperature } & 1560^{\circ} \mathrm{F} & 850{ }^{\circ} \mathrm{C} \\ \text { Gasification pressure } & 29.0 \mathrm{psia} & 2.0 \mathrm{bara} \\ \text { Fluidization velocity } & 3.9 . \mathrm{ft} / \mathrm{s} & 1.2 \mathrm{~m} / \mathrm{s} \\ \text { Gasification air temperature } & 635^{\circ} \mathrm{F} & 335^{\circ} \mathrm{C}\end{array}$

\subsubsection{Ash Removal System}

The description of the Gasifier Ash Removal System refers to the Flow Diagram of the Gasification Plant (Figure 3.3.2-1).

\section{System Description}

The function of the Gasifier Ash Discharge System is to remove and cool the discharged solids (bed material consisting spent limestone and fuel ash) from the gasifier at system pressure and high temperature. The solids are removed through a water-cooled screw and lock-hoppers. The bed material (ash and spent limestone) is removed from the gasifier system through the ash discharge pipe at the bottom of the gasifier pressure vessel. Reliable and continuous gasifier ash removal is essential to ensure the stable operation of the gasifier. The gasifier ash removal system consists of one cooling screw, one surge-hopper and one lock-hopper system for depressurizing the ash. The cooling screw is cooled by cooling water. The lock hopper system is pressurized and made inert by using nitrogen. 
The bed material drops out from the gasifier fluidized bed through the ash removal pipe, in counter flow with a controlled airflow, into the ash cooling screw. The ash cooling screw is water-cooled, both shaft and jacket. In the cooling screw the bed material cools down from 1562 ${ }^{\circ} \mathrm{F} / 850{ }^{\circ} \mathrm{C}$ to $482{ }^{\circ} \mathrm{F} / 250^{\circ} \mathrm{C}$. The cooling screw is followed by the ash surge hopper, which enables the continuous operation of the cooling screw during ash depressurization. The isolation valves between the surge and lock-hopper opens after the lock-hopper is pressurized and the pressure is equalized. The ash drops from the buffer hopper into the lock-hopper. Then the isolation valve will close and the pressure of the lock-hopper will be let down to atmospheric pressure. After opening the valves between the lock-hopper and weigh silo, the ash drops into the weigh silo. After closing the valve between the lock-hopper and the weigh silo, the lock-hopper will be immediately pressurized and connected to the surge hopper. The ash removal sequence is operated based on level measurement in the lock-hopper.

\section{Design Basis}

The properties of reactor ash (mixture of bed material, ash and char) are shown in Table 3.3.2-4.

\section{Table 3.3.2-4 Ash Properties}

$\begin{array}{lll}\text { Density } & 62-75 \mathrm{lb} / \mathrm{cf} & 1000-1200 \mathrm{~kg} / \mathrm{m} 3 \\ \text { Moisture (less than) } & 1 \% \mathrm{w} & 1 \% \mathrm{w} \\ \text { Material temperature } & 1562{ }^{\circ} \mathrm{F} & 850^{\circ} \mathrm{C} \\ \text { Particle size } & 0.004-0.079 \text { in } & 0.1-2 \mathrm{~mm} \\ \text { Maximum particle size } 1.0 \mathrm{in} & 25 \mathrm{~mm} \\ \text { Ash discharge rate } & 810 \mathrm{lb} / \mathrm{h} & 0.1 \mathrm{~kg} / \mathrm{s}\end{array}$

The gasifier ash removal system includes one removal line of $120 \%$ base load capacity.

\subsubsection{Process Air System}

The description of the Process Air System refers to the process Flow Diagram of the Gasification Plant (Figure 3.3.2-1).

\section{System Description}

The function of the Process Air System is to provide air for the gasifier at required pressure.

The gasification air is taken from atmosphere and compressed in the process air compressor to $43.5 \mathrm{psia} / 3$ bara pressure to overcome the pressure drop of the gas feeding system, air preheater and the entire gasification system down to the gas injection system. A two stage intercooled centrifugal air compressor is applied. The compressor is equipped with air intake filter; blow down valve and silencer at discharge. The compressor is equipped with variable speed drive for part load control and surge protection performed by the control system based on the measurement of motor current, air flow and discharge pressure. The compressor has no after cooler therefore the supply temperature of air is about $217^{\circ} \mathrm{F} / 103^{\circ} \mathrm{C}$. The air is further heated to $635^{\circ} \mathrm{F} / 335^{\circ} \mathrm{C}$ in the last gas cooler $\mathrm{AH}-2$ heat exchanger by turbine exhaust gas. After the gas cooler the airflow is partly directed to the gasifier gas feeding system including air distribution and control valves and partly fed to the partial gas combustion nozzles.

\section{Design Basis}

The process air compressor is electric motor driven, two-stage, intercooled centrifugal 
compressor. The compressor has no aftercooling. The design parameters of the process air compressor (PAS-C1) are summarized in the Table 3.3.2-5.

Table 3.3.2-5 Process Air Compressor Design Parameters

$\begin{array}{lll}\text { Process medium } & \text { air } & \\ \text { Air relative humidity } & 60 \% \mathrm{RH} & \\ \text { Air mass flow rate } & & \\ \quad \text { @ } 66^{\circ} \mathrm{F} / 19^{\circ} \mathrm{C} & 57100 \mathrm{lb} / \mathrm{h} & 7.2 \mathrm{~kg} / \mathrm{s} \\ \text { Air inlet pressure } & 14.5 \mathrm{psia} & 1.0 \mathrm{bara} \\ \text { Max. air inlet temp } & 77^{\circ} \mathrm{F} & 25^{\circ} \mathrm{C} \\ \text { Air temp after inter cooler } & 104^{\circ} \mathrm{F} & 40^{\circ} \mathrm{C} \\ \text { Air outlet pressure } & 43.5 \mathrm{psia} & 3.0 \text { bara }\end{array}$

The compressor is equipped with an air intake filter blow down valve and a silencer at discharge.

\subsubsection{Product Gas Heating and Cooling}

The description of the product gas heating and cooling system refers to the Process Flow Diagram of the Gasification Plant (Figure 3.3.2-1).

\section{System Description}

The function of the Partial Gas Combustion Nozzle is to burn product gas to increase the gas temperature high enough $\left(2200^{\circ} \mathrm{F} / 1200^{\circ} \mathrm{C}\right)$ for heating of gas turbine air. The high gas temperatures also cause the tar content of the gas to decompose.

The function of the gas coolers is to heat high-pressure air for expansion through the gas turbine and to cool the product gas prior to injection to the boiler.

The product gas heating and cooling system includes the following process components:

- Partial gas combustion nozzle

- Syngas cooler heat exchanger which cools the syngas by heating gas turbine air

- Emergency Spraying Nozzle

The product gas leaves the cyclone of the gasifier at $1562{ }^{\circ} \mathrm{F} / 850^{\circ} \mathrm{C}$ temperature and $29 \mathrm{psia} /$ 2.0 bara pressure. In the partial combustion nozzles swirled airflow is injected in the gas stream maintaining good mixing and partial combustion of the product gas. The temperature of gas increases to $2200^{\circ} \mathrm{F} / 1204^{\circ} \mathrm{C}$. After partial combustion the product gas flows through the gas cooler heat exchanger $\mathrm{AH}-1$, which cools the syngas stream from $2200{ }^{\circ} \mathrm{F} / 1200^{\circ} \mathrm{C}$ temperature to about $670^{\circ} \mathrm{F} / 343{ }^{\circ} \mathrm{C}$.

The product gas is cooled in AH-1 by gas turbine air. The gas turbine air is extracted after the last stage of the compressor at $194 \mathrm{psia} / 13.4 \mathrm{bara}$ and $661^{\circ} \mathrm{F} / 349^{\circ} \mathrm{C}$ temperature and heated up to $1400^{\circ} \mathrm{F} / 760^{\circ} \mathrm{C}$ in $\mathrm{AH}-1$.

The gas cooler system is also equipped with Emergency Spraying Nozzle before the partial combustion nozzle. In an emergency situation when the gas coolers' capacity is not enough to cool the product gas to the required temperature, water is injected into the product gas flow through the spraying nozzles to cool the gas. 
The Emergency Spraying Nozzle is used to cool partly or entirely the hot product gas from $1562^{\circ} \mathrm{F} / 850^{\circ} \mathrm{C}$ to $650^{\circ} \mathrm{F} / 343^{\circ} \mathrm{C}$ in the case of malfunction of the gas cooler. The spray cooling nozzles are basically similar to steam attemperator nozzles. The preferred nozzle design is annular type, which is embedded in the refractory of the product gas duct. This arrangement causes no restrictions for the gas flow and protects the nozzles against erosion caused by the dust in the product gas.

\section{Partial Gas Combustor}

Partial Combustion Air Nozzle is used to inject hot air into the hot $\left(1562 \mathrm{~F} / 850^{\circ} \mathrm{C}\right)$ product gas stream so that the gas temperature is increased to $2200^{\circ} \mathrm{F} / 1204^{\circ} \mathrm{C}$ by partial combustion of product gas. The preferred nozzle design is an annular type nozzle, which is embedded in the refractory of the conical section of the product gas duct. This arrangement causes no restrictions for the gas flow and protects the nozzles against erosion caused by the dust in the product gas. The composition of the product gas from the gasifier is summarized in Table 3.3.2-6.

\section{Gas Turbine Air Heater}

Gas Turbine Air Heater AH-1 cools the product gas after partial combustion. The properties of product gas are shown in Table 3.3.2-7.

The gas turbine air heater design is very much vendor specific and it is not discussed here, only the process requirements are presented. The design parameters of the gas turbine air heater are summarized in Table 3.3.2-8.

\section{Table 3.3.2-6: Product Gas Composition}

Product gas at design conditions (Gasification Plant base load):

Composition:

Carbon monoxide (CO) $\quad 16.9 \%$-vol

Carbon dioxide $\left(\mathrm{CO}_{2}\right) \quad 10.8 \%$-vol

Hydrogen $\left(\mathrm{H}_{2}\right)$

$14.8 \%$-vol

Water vapor $\left(\mathrm{H}_{2} \mathrm{O}\right)$

$10.3 \%$-vol

Methane $\left(\mathrm{CH}_{4}\right)$

$4.1 \%$-vol

Higher hydrocarbons (CxHy)

Nitrogen $\left(\mathrm{N}_{2}\right)$

$0.1 \%$-vol

Oxygen $\left(\mathrm{O}_{2}\right)$

$42.9 \%$-vol

$0 \%$-vol

Sulfuric gases $\left(\mathrm{H}_{2} \mathrm{~S}+\mathrm{COS}\right) \quad 0$ ppmv

Nitrogenous gases $\left(\mathrm{NH}_{3}+\mathrm{HCN}\right) \quad 1091 \mathrm{ppmv}$

Hydrogen chloride $(\mathrm{HCl}) \quad 0$ ppmv

Heavy tars $(\mathrm{mw}>200 \mathrm{~g} / \mathrm{mol}) \quad<10 \mathrm{ppmv}$

Particulates

$50000 \mathrm{ppmv}$

Heating Value:

HHV (wet base)

Molecular weight

Gas flow rate in

$149 \mathrm{Btu} / \mathrm{scf}$

24.42

Gas inlet pressure

Gas inlet temperature

$63422 \mathrm{lb} / \mathrm{h}$

$28.3 \mathrm{psia}$

$1562^{\circ} \mathrm{F}$

$2200{ }^{\circ} \mathrm{F}$

$5833 \mathrm{~kJ} / \mathrm{m}^{3} \mathrm{n}$

Temp after partial combustion

Combustion air

Supply pressure

Supply temperature

36.3 psia $\quad 2.5$ bara

$635^{\circ} \mathrm{F} \quad 335^{\circ} \mathrm{C}$

Design flow rate

$14238 \mathrm{lb} / \mathrm{h} \quad 1.79 \mathrm{~kg} / \mathrm{s}$ 
Table 3.3.2-7: Product Gas Properties After Partial Combustion

Composition:

Carbon monoxide (CO)

Carbon dioxide $\left(\mathrm{CO}_{2}\right)$

Hydrogen $\left(\mathrm{H}_{2}\right)$

Water vapor $\left(\mathrm{H}_{2} \mathrm{O}\right)$

Methane $\left(\mathrm{CH}_{4}\right)$

Higher hydrocarbons (CxHy)

Nitrogen $\left(\mathrm{N}_{2}\right)$

Oxygen $\left(\mathrm{O}_{2}\right)$

Sulfuric gases $\left(\mathrm{H}_{2} \mathrm{~S}+\mathrm{COS}\right)$

Nitrogenous gases $\left(\mathrm{NH}_{3}+\mathrm{HCN}\right)$

Hydrogen chloride $(\mathrm{HCl})$

Heavy tars (mw>200 g/mol)

Particulates

Molecular Weight
$14.7 \%$-vol
$9.6 \%$-vol
$6.5 \%$-vol
$15.5 \%$-vol
$3.5 \%$-vol
$0.1 \%$-vol
$50.1 \%$-vol
$0 \%$-vol
$0 \mathrm{ppmv}$
940 ppmv
0 ppmv
$<10$ ppmv
50000 ppmv
25.9

Table 3.3.2-8: Gas Turbine Air Heater Heat Exchanger AH-1

Process Design Parameters

Design load (Gasification Plant base load)

Gas side

Gas mass flow

Gas inlet pressure

$77660 \mathrm{lb} / \mathrm{h} \quad 9.79 \mathrm{~kg} / \mathrm{s}$

Gas inlet temperature

27.6 psia $\quad 1.90$ bara

Gas outlet temperature

$2200^{\circ} \mathrm{F} \quad 1204{ }^{\circ} \mathrm{C}$

Air side

Air mass flow

$675^{\circ} \mathrm{F}$

$357^{\circ} \mathrm{C}$

Inlet pressure

$234389 \mathrm{lb} / \mathrm{h} \quad 29.53 \mathrm{~kg} / \mathrm{s}$

Inlet temperature

Outlet temperature (design)

Mechanical Design Parameters

194 psia $\quad 13.0$ bara

$661^{\circ} \mathrm{F} \quad 349^{\circ} \mathrm{C}$

$1400^{\circ} \mathrm{F} \quad 760^{\circ} \mathrm{C}$

Gas side

Mechanical design pressure

Air side

Mechanical design pressure

$29.0 \mathrm{psig} \quad 2.0 \mathrm{barg}$

319 psig 22 barg

\section{Emergency Water Injection}

Emergency Spraying Nozzle is used to cool partly or entirely the hot product gas from $1562{ }^{\circ} \mathrm{F} /$ $850^{\circ} \mathrm{C}$ to below $650^{\circ} \mathrm{F} / 343^{\circ} \mathrm{C}$ in the case of malfunction of the gas cooling. The spray cooling nozzle function is basically similar to steam attemperator nozzles. The preferred nozzle design is 
annular type, which is embedded in the refractory of the product gas duct. This arrangement causes no restrictions for the gas flow and protects the nozzles against erosion caused by the dust in the product gas. The internal diameter of the product gas duct is approx. $34.6 \mathrm{in} / 880 \mathrm{~mm}$. The design parameters of the spraying nozzles at base load are summarized in Table 3.3.2-9.

\subsubsection{Flare System}

The Flare System description refers to the process Flow Diagram of the Gasification Plant (Figure 3.3.2-1).

\section{System Description}

The primary function of the flare is to dispose of toxic and combustible gas components safely under relief conditions, by converting them into less objectionable products by combustion. Either elevated or ground flares can accomplish atmospheric discharge of toxic and combustible gases efficiently. An elevated flare has been selected for the project. Elevated flares are used mainly to safely dispose releases of large quantities of combustible gases.

\section{Table 3.3.2-9: Design Parameters of Emergency Spraying Nozzle}

Product gas (Gasification Plant base load)

Total gas flow rate

$77660 \mathrm{lb} / \mathrm{h}$

$9.79 \mathrm{~kg} / \mathrm{s}$

Inlet pressure

28.3 psia $\quad 1.95$ bara

Inlet temperature

$1562^{\circ} \mathrm{F} \quad 850^{\circ} \mathrm{C}$

Temperature after spray cooling

$650{ }^{\circ} \mathrm{F} 343{ }^{\circ} \mathrm{C}$

Spray cooling water (preliminary data)

Supply pressure

Supply temperature

58 psia

$59^{\circ} \mathrm{F}$

4.0* bara

Design water flow rate

$17780 \mathrm{lb} / \mathrm{h}$

$15{ }^{\circ} \mathrm{C}$

$2.24 \mathrm{~kg} / \mathrm{s}$

The flare system is an air-assisted flare located on the roof of the Gasification Plant building. The burner of the flare system (flare tip) is located on the top of the relief gas pipe. The flare tip is equipped with pilot burners. The pilot flame is continuously operated and ensures the safe ignition of the flare. For steady flare operation support fuel is required. The purpose of the support fuel is to maintain combustion temperature high enough to assure complete burning of all product gas compounds. Natural gas is used as support and pilot burner fuel.

Flare system will be operated at the start-up and shutdown of the gasifier and in the case of emergency shutdown or upset conditions. In those cases, the product gas is directed from the product gas line to the flare where the product gas is burnt off. The product gas is at max. $33.4 \mathrm{psia} / 2.3$ bara pressure and maximum $650^{\circ} \mathrm{F} / 343^{\circ} \mathrm{C}$ temperature when flare operation can occur. The pressure of the gas will be reduced in pressure control valves to near atmospheric level. The hot gas enters the combustor and will be ignited by the pilot flames.

During the start-up of the gasifier the product gas will be flared until the gasifier achieves adequate pressure and temperature at minimum load, which is about at the $50 \%$ capacity of the gasifier. Flaring starts when the heat-up of the gasification system starts. At the beginning only flue gas of natural gas combustion will be flared. After fuel feeding and ignition, the flue gas of 
biomass combustion is flared. After switching from combustion to gasification product gas of low quality will be flared until reaching the full parameter half load conditions.

In the shutdown sequence, the product gas will be flared after the gasifier capacity is reduced to minimum (50\% capacity) at full pressure and temperature. Before that the product gas is still burnt in the gas burner of the boiler. The flaring starts when the gasifier is separated from the boiler. Product gas quality decreases during the shut down period. Since nitrogen and steam is used for gasifier shutdown, the flared gas is a mixture of product gas, steam and inert gas.

In all emergency cases, fuel and air feed to the gasifier will stop first, and then the flare starts operating. Syngas injection to the boiler is stopped at the same time. Similar to the normal shutdown procedure, the role of flare is to let down pressure and reduce product gas injection to the boiler in a controlled manner.

\section{System Design}

The flare system is an air-assisted flare located on the roof of the Gasification Plant building. The burner of the flare system (flare tip) is located on the top of the relief gas pipe. The flare is used to burn cooled product gas at off design conditions before it is injected in the boiler. Gasification gas properties at design conditions (Gasification Plant base load) are shown in Table 3.3.2-10. The design parameters of the flare are summarized in Table 3.3.2-11.

Table 3.3.2-10: Product Gas Properties

Composition:

Carbon monoxide (CO) $1 \quad 4.7 \%$-vol

Carbon dioxide $\left(\mathrm{CO}_{2}\right) \quad 9.6 \%$-vol

Hydrogen $\left(\mathrm{H}_{2}\right)$

$6.5 \%$-vol

Water vapor $\left(\mathrm{H}_{2} \mathrm{O}\right)$

$15.5 \%$-vol

Methane $\left(\mathrm{CH}_{4}\right)$

$3.5 \%$-vol

Higher hydrocarbons (CxHy)

Nitrogen $\left(\mathrm{N}_{2}\right)$

$0.1 \%-\mathrm{vol}$

Oxygen $\left(\mathrm{O}_{2}\right)$

$50.1 \%$-vol

Sulfuric gases $\left(\mathrm{H}_{2} \mathrm{~S}+\mathrm{COS}\right) \quad 0 \mathrm{ppmv}$

Nitrogenous gases $\left(\mathrm{NH}_{3}+\mathrm{HCN}\right) 940 \mathrm{ppmv}$

Hydrogen chloride $(\mathrm{HCl}) \quad 0$ ppmv

Heavy tars $(\mathrm{mw}>200 \mathrm{~g} / \mathrm{mol}) \quad<10 \mathrm{ppmv}$

Particulates

50000 ppmv

Heating Value:

HHV (wet base)

Molecular weight

$107 \mathrm{Btu} / \mathrm{scf} \quad 4193 \mathrm{~kJ} / \mathrm{m}^{3} \mathrm{n}$

25.9 
Table 3.3.2-11 Flare Design Parameters

$\begin{array}{lll}\text { Maximum gasification gas flow } & 77660 \mathrm{~b} / \mathrm{h} & 9.79 \mathrm{~kg} / \mathrm{s} \\ \text { Maximum gasification gas temperature } & 6500^{\circ} \mathrm{F} & 343{ }^{\circ} \mathrm{C} \\ \text { Maximum gasification gas pressure } & 33.4 \mathrm{psia} & 2.3 \text { bara }\end{array}$

Support and pilot burner fuel natural gas (HHV=1000 Btu/scf)

The Flare System shall include the following components:

- Flare tip complete with combustor, burner shell, igniters, pilot burners, etc.

- Flare stack with tip connection

- Connections to gas inlet

- Connections for drain

- Flame front generator and ignition and control panel

The ignition and control system is coupled to the Gasification Plant control system, but the activation of manual ignition sequence should be also possible from the local control panel.

\subsubsection{Product Gas Ducting System}

The arrangement of the Product Gas Ducting is shown in the Process Flow Diagram of the Gasification Plant (Figure 3.3.2-1).

\section{System Description}

The function of the product gas ducting is to lead the product gas flow to the gas injectors via the gas coolers. The product gas ducting has to stand operating pressure (system pressure) and temperature with low heat loss and pressure drop.

The product gas ducting between the gasifier cyclone and gas injector including the following:

Section A: $\quad 1$ st cyclone - emergency spray nozzle

Section B: emergency spray nozzle - partial gas combustion nozzle

Section C: partial gas combustion nozzle - gas cooler inlet

Section D: gas cooler exit - gas cooler inlet

Section E: $\quad$ gas cooler bypass duct

Section F: $\quad$ line from Section A to rupture disc PSE569

Section G: gas cooler exit - gas injector

Section $\mathrm{H}$ : line from Section $\mathrm{G}$ to flare

\section{Design Basis}

The product gas ducting between the gasifier cyclone and gas injector at the boiler includes the following sections:

Section A: gasifier - 1st cyclone (refractory lined)

Section B: 1st cyclone - partial gas combustion (refractory lined)

Section C: partial gas combustion - gas turbine air heater (refractory lined)

Section D: GT air heater-gasification air pre-heater (refractory lined)

Section E: air pre-heaters by-pass line (refractory lined with valve)

Section F: branching line from Section B to rupture disc (double shell/insulated)

Section G: gasification air pre-heater - boiler (external insulation) 
Section $\mathrm{H}$ : branching line from Section $\mathrm{G}$ to flare (external insulation)

Section A, B, C, D and E are refractory lined ducts where the outer steel pipe holds the pressure and the inner refractory lining insulates the hot gas from the pressure vessel shell. The refractory lined product gas duct has no external insulation. The refractory lining has to protect against erosion (abrasive effect of fine dust) and corrosion (hot corrosion) and has to act as a thermal insulation as well.

The refractory lining includes two layers having different duties.

The inner layer (i.e. direct contact with the product gas) has to stand high temperatures, erosion, the effect of sintering (sinter may form on the refractory surface) and reducing atmosphere.

The outer layer of the refractory lining is between the inner layer and the pressure shell of the duct. The main task of this layer is thermal insulation to keep the temperature of the pressure shell at the designed value.

Product gas line section F (between Section B and rupture disc) has a double shell structure to ensure safe operation and relief of product gas to the rupture disc. This pipe is insulated with ceramic fiber (kaowool) between the two steel pipes.

Sections $\mathrm{G}$ and $\mathrm{H}$ are externally insulated ducts. A thin steel plate covers the insulation layer. The inner steel pipe holds the pressure and the insulation lining holds the surface temperature of the covering plate at the design value.

\subsubsection{Nitrogen Generation System}

The Nitrogen Distribution System description refers to the process Flow Diagram of the Gasification Plant (Figure 3.3.2-1).

\section{System Description}

Nitrogen is used in the Gasification Plant for inertization, pressurization and feeding of fuel and limestone, pressurization and inertization of ash discharge, as purge gas in the gasifier and flare, pressurizing the closed loop cooling water system and fluidizing gas during shutdown. Nitrogen is generated in an on-site nitrogen generation plant. Due to the small capacity of the nitrogen plant, the nitrogen generator is of membrane type.

Nitrogen plant comprises the following major equipment:

- Air compressor equipped with air intake filter and after cooler

- Air receiving tank

- Filter skid removing dust, water and oil from the air

- Air heater

- $\mathrm{N}_{2}$ generator unit (membrane packages)

- Nitrogen receiver tank

The air compressor supplies air of $188 \mathrm{psig} / 13$ barg pressure through an after cooler at $50-104 \mathrm{~F} / 10-40^{\circ} \mathrm{C}$ to the air receiver tank. Air is directed from the air receiver tank to the filter skid where dust, water and oil condensate is removed from the air. Following the filter unit the air is heated up by an electrical heater at least $7{ }^{\circ} \mathrm{C}$ above the dew point temperature. This ensures that no liquids are formed which can damage the membranes in the nitrogen generation system. In the membrane type nitrogen generator air is separated into product nitrogen stream 
and reject stream consisting of oxygen, nitrogen, argon, water vapor, carbon dioxide and other gases. The membrane packages are operated at $104-122^{\circ} \mathrm{F} / 40-50{ }^{\circ} \mathrm{C}$ temperature, the pressure of discharge nitrogen is $130-145 \mathrm{psig} / 9-10$ bara. The purity of the product nitrogen is $98 \%$-vol.

The generated nitrogen is stored in a nitrogen receiver tank at 87-145 psia / 6-10 bara pressure. The Nitrogen Distribution System distributes nitrogen from the nitrogen receiver tank to the consumers in the Gasification Plant.

\section{Design Basis}

The design parameters of the nitrogen generation system are shown in Table 3.3.2-12.

Table 3.3.2-12: Nitrogen Generation System Process Design Parameters

$\begin{array}{lll}\text { Required } \mathrm{N}_{2} \text { generation capacity } & 516 \mathrm{lb} / \mathrm{h} & 0.065 \mathrm{~kg} / \mathrm{s} \\ \text { Estimated normal } \mathrm{N}_{2} \text { consumption } & 357 \mathrm{lb} / \mathrm{h} & 0.045 \mathrm{~kg} / \mathrm{s} \\ \text { Peak } \mathrm{N}_{2} \text { consumption (from tank) } & 3800 \mathrm{lb} / \mathrm{h} & 0.48 \mathrm{~kg} / \mathrm{s} \\ \mathrm{N}_{2} \text { purity } & >98 \% \mathrm{vol} . & >98 \% \mathrm{vol} . \\ \mathrm{N}_{2} \text { supply pressure, approx. } & 145 \mathrm{psia} & 10 \mathrm{bara}\end{array}$

Available air for nitrogen generation is ambient air at $66^{\circ} \mathrm{F} / 19^{\circ} \mathrm{C}$ temperature and $70 \%$ relative humidity.

\subsubsection{Boiler Modification and Internal Air Heating Objectives}

The major objective of the Boiler Modification study is to develop a design for the in-furnace high temperature/high pressure air heater AH-3 for installation in \#2 Power Boiler at the DeRidder, Louisiana site. The following have also been performed:

- Determine furnace performance, steam temperature analysis, flue gas temperature analysis, boiler efficiency, fuel flow, and boiler system heat balance.

- Review grate size (capacity/turndown), over-fire air/under-grate air flow splits, combustion air temperature (under-grate air (UGA) limitations) and UGA tempering air system (if required).

- Circulation study for original $225,000 \mathrm{lb} / \mathrm{hr}$ steam flow and $250,000 \mathrm{Lb} / \mathrm{hr}$ steam flow (with syngas injection).

- Evaluate vibrations in the economizer

- Review boiler auxiliary systems (i.e., fans).

- Analyze the operational scenarios of the biomass gasifier and/or AH-3 off-line

\section{Findings and Conclusions}

Based on the above analyses, the following are findings and conclusions of the study:

- At $125 \%$ maximum continuous rating (MCR), 250,000 lb/hr steam flow, 320,000 lb/hr AH-3 air inlet flow, the AH-3 outlet temperature is $1400^{\circ} \mathrm{F}$. The superheater steam outlet pressure is $850 \mathrm{psig}$ and the $\mathrm{SH}$ steam outlet temperature is $825^{\circ} \mathrm{F}$. The syngas flow is $77,660 \mathrm{lb} / \mathrm{hr}$ and the dried bark (20\% moisture by weight) flow is $38,250 \mathrm{lb} / \mathrm{hr}$. 
- AH-3 consists of 18 assemblies with 2 tubes per assembly for a total of 36 air flow circuits. The design pressure is 300 psig. The tube size is 2.75 -inch OD and the wall thickness is 0.220 inch. The material selected is SB-407 $800 \mathrm{HT}$ with the exception that the final 7 tubes of each assembly will be Haynes 230 material.

- The results of the circulation study shows that no DNB is expected in the furnace waterwall with Boiler \#2 having the AH-3 in the furnace and operating at 250,000 lb/hr steam flow (125\% MCR) and 320,000 lb/hr HT HP AH air flow.

- The syngas injection system has 12 nozzles each at 6 in ID and located on the rear wall below the present HMZ OFA nozzles and above the furnace grate.

- There may be half standing wave frequency vibrations in the economizer due to coupling with the natural frequency of economizer duct plate.

- The UGA air temperature limitation is $480^{\circ} \mathrm{F}$ because there is an extensive fabric type grate seal.

- The FD fan and ID fan requirements will have to be reviewed as operation of the boiler above $225,000 \mathrm{lb} / \mathrm{h}$ may exceed the capacity of one or more of these fans.

- The system off line analysis indicates that air must be flowing to the AH-3 at all times when boiler \#2 is in operation.

\subsubsection{Description of \#2 Power Boiler}

The furnace water walls are 2.50 inch OD tubes, 0.188 -inch tube wall thickness, 3.0 inch spacing (centerline-to-centerline), and the tube material is SA 178-A. The furnace depth is $18 \mathrm{ft} 11$ inch and the furnace width is $18 \mathrm{ft} 11 \mathrm{inch}$. The furnace volume is $15633 \mathrm{ft}^{3}$ and the furnace projected water wall area including the exit plane is $3925 \mathrm{ft}^{2}$. The furnace is mounted over a traveling grate (forward direction from rear of furnace to front of furnace) and the effective grate area is $358 \mathrm{ft}^{2}$.

The furnace is fired by four pneumatic bark fuel distributors on the front wall. There are two auxiliary natural gas fired burners on the rear wall. Preheated air is supplied to the furnace via the UGA plenum and twelve (total) new HMZ over-fire air nozzles of which six are on the front wall and six are on the rear wall. The boiler has the capability for fly-ash/cinder re-injection and twelve re-injection nozzles are located on the rear wall. There is a pendant style radiant superheater (primary SH) in the upper portion of the furnace. The primary SH is composed of 18 platens at 12 inch spacing having two tubes per platen assembly for a total of 36 primary steam flow circuits. The tubes are 1.75 inch OD and the tube wall thickness is $0.149 \mathrm{inch}$. The tube material is SA 209-Tl. The radiant primary SH is supplied with saturated steam flow from the upper drum of the boiler and flows into primary steam outlet header for steam temperature control (if necessary) by spray water. The steam flows to the inlet header of the high temperature superheater (HTSH), a convection type secondary superheater and thence to the superheated steam outlet header. The HTSH tubes are 2.125 inch OD with 0.149-inch tube wall thickness and are made of SA 209-Tl material.

The boiler bank has a 60 -inch ID upper drum and 42 inch ID lower drum. The front tubes of the boiler bank are 2.0 inch OD and have a tube wall thickness of 0.148 inch. The. rear tubes of the boiler bank are 2.50 inch OD and the tube wall thickness is 0.148 inch. The boiler bank tube material is SA 178-A.

The economizer is a counter flow type having 2.0-inch OD tubes and tube wall thickness of 0.180 inch. The economizer tube material is SA 210-AI. 
The present air heater is a tubular type with flue gas flowing inside the tubes and air in counter cross flow on the outside of this two-pass system. The air heater tube size is 2.50 inch OD and the tube wall thickness is 10 gauge. The AH tubing material is reported to be SA 1015 (1) grade steel.

The dust collector was supplied by Gaines Equipment (Louisiana) and has 88 tubes that were changed from 9-inch diameter to 14-inch diameter.

The present forced draft fan on \#2 Power Boiler is by Chicago Blower Corp. (size 6000AF, D/1903, 91\% DWDI, N3, C/1200, W/IVC). The test block condition is 117,000 CFM at 17.2 in.w.c. outlet static pressure. For a steam flow of $225,000 \mathrm{lb} / \mathrm{hr}$, the predicted system resistance is 14 in.w.c. at 75,000 CFM (original FD fan sheet)

The present (original) ID fan is a Buffalo Forge $2715 \mathrm{H} 14$ and the test block conditions are 237128 ACFM@28.93 in.w.c. static suction, $445^{\circ} \mathrm{F}$, and 0.0439 lb/ $\mathrm{ft}^{3}$ density.

The original boiler performance design conditions for \#2 Power Boiler are 200,000 lb/hr steam flow at $100 \% \mathrm{MCR}, 825^{\circ} \mathrm{F} / 859 \mathrm{psig}, 350^{\circ} \mathrm{F}$ feedwater temperature, $30 \%$ excess air, and 4,500 $\mathrm{Btu} / \mathrm{lb} \mathrm{HHV} / 50 \%$ moisture by weight bark fuel. The 2001 upgrade design conditions for the boiler are $300,000 \mathrm{lb} / \mathrm{hr}$ steam flow $(150 \% \mathrm{MCR}), 825^{\circ} \mathrm{F} / 850 \mathrm{psig}, 360^{\circ} \mathrm{F}$ feedwater temperature $30 \%$ excess air, and 4,526 Btu/lb HHV/52.5\% moisture by weigh bark fuel. The original design conditions (100\% MCR; 112.4\% MCR by Combustion Engineering and upgrade design conditions by Alstom Power) are listed in Table 3.3.3-1.

The current design case of $250,000 \mathrm{lb} / \mathrm{hr}$ steam flow at $125 \% \mathrm{MCR}, 825^{\circ} \mathrm{F} / 850 \mathrm{psig} 353^{\circ} \mathrm{F}$ feedwater temperature, $30 \%$ excess air, and 4,526 Btu/lb/52.5\% moisture by weight bark fuel is also shown in Table 3.3.3-1.

\subsubsection{Implementation of Bark Boiler \#2 Modifications}

The major modifications to Boiler \#2 are the addition of wet bark dryer(s), bypassing of the present tubular air heater, injection of syngas for NOx reduction and combustion improvement, and the addition of a high temperature/high pressure air heater in the furnace. The purpose of the wood-waste dryer(s) is to remove moisture from $52.5 \%$ by weight wet bark. The dried bark moisture content will be $20 \%$ by weight.

The tubular air heater as presently installed, preheats the air for the under-grate air system, HMZ over-fire air system, and auxiliary natural gas burners (cooling air flow when not in use or natural gas combustion air when in use). Therefore, at present, all of the preheated combustion air flows through the tubular air heater. The preheated combustion air (after bypassing of the tubular air heater) will be supplied as exhaust air extracted from a HRSG at the same temperatures as normally supplied for UGA and OFA.

The high temperature/high pressure air heater is a parallel cross flow continuous radiant air heater that will be installed to fit above the top of the auxiliary natural gas burners and below the furnace arch tip. The air heater is composed of 18 assemblies, 2 air flow circuits per assembly for a total of 36 air flow circuits. The assemblies are on 12 -inch centers, $3 \%$ inch tube spacing, and the tube OD is $2 \%$ inches. The air enters through a lower header at $661^{\circ} \mathrm{F}, 180 \mathrm{psig}$, and exits through an upper header at $1400^{\circ} \mathrm{F}$. The design pressure is $300 \mathrm{psig}$. 
Table 3.3.3-1: Boiler Performance - Original Design and 2001 Upgrade

\begin{tabular}{|c|c|c|c|c|c|}
\hline Items & Units & \multicolumn{2}{|c|}{$\begin{array}{l}\text { Original Design } \\
\# 22378\end{array}$} & \multicolumn{2}{|c|}{\begin{tabular}{|c|l|}
$\begin{array}{c}\text { Adv. Power Sys. } \\
\text { Step } 3\end{array}$ & $\begin{array}{l}2001 \text { Upgrade. } \\
\text { Design }\end{array}$ \\
\end{tabular}} \\
\hline Steam Flow & lbs/hr & 200,000 & 225,000 & 250,000 & 300,000 \\
\hline Steam Temp/press & ${ }^{\circ} \mathrm{F} / \mathrm{psig}$ & $825 / 850$ & $825 / 850$ & $825 / 850$ & $825 / 850$ \\
\hline Feedwater Temp & ${ }^{\circ} \mathrm{F}$ & 350 & 350 & 350 & 360 \\
\hline Blowdown & $\mathrm{lbs} / \mathrm{hr}$ & 0 & 0 & 2,000 & 6,000 \\
\hline Bark Fuel Flow & lbs/hr & 69,310 & 78,090 & 64,421 & 106,980 \\
\hline Carbon Loss & $\%$ heat input & 1 & 1 & 1 & 2 \\
\hline Excess Air T AH In & $\%$ & 30 & 30 & 20 & 30 \\
\hline \multicolumn{6}{|l|}{ Air Temps } \\
\hline -to Fan & ${ }^{\circ} \mathrm{F}$ & 80 & 80 & 80 & 80 \\
\hline -to Furnace & ${ }^{\circ} \mathrm{F}$ & 352 & 383 & 375 & 430 \\
\hline Air thru FD Fan & lbs/hr & 293,000 & 330,000 & 392,477 & 441,800 \\
\hline Exit Gas Flow & lbs/hr & 362,000 & 407,000 & 506,318 & 558,200 \\
\hline Exit Gas Temp & ${ }^{\circ} \mathrm{F}$ & 352 & 366 & 238 & 439 \\
\hline GI (fuel) & MMBtu/hr & 311.9 & 351.4 & 436.0 & 484.2 \\
\hline GHRR & MMBtu/hr - ft2 & 813,000 & 915,000 & 814,500 & $1,262,100$ \\
\hline Thermal Efficiency & $\%$ & 70.25 & 69.89 & 78.9 & 66.88 \\
\hline \multicolumn{6}{|c|}{\begin{tabular}{|l|l} 
Bark Fuel Analysis(wet) \\
\end{tabular}} \\
\hline Carbon & $\% \mathrm{wt}$ & 26.15 & 26.15 & 25.65 & 25.65 \\
\hline Hydrogen & $\%$ wt & 3.15 & 3.15 & 3.04 & 3.04 \\
\hline Oxygen & $\%$ wt & 20.25 & 20.25 & 16.08 & 16.08 \\
\hline Nitrogen & $\%$ wt & 0.05 & 0.05 & 0.10 & 0.10 \\
\hline Sulfur & $\%$ wt & 0.00 & 0.00 & 0.00 & 0.00 \\
\hline Ash & $\%$ wt & 0.4 & 0.4 & 2.63 & 2.63 \\
\hline $\mathrm{H} 2 \mathrm{O}$ & $\%$ wt & 50.00 & 50.00 & 52.50 & 52.50 \\
\hline Total & $\%$ wt & 100.00 & 100.00 & 100.00 & 100.00 \\
\hline $\mathrm{HHV}$ & Btu/lb & 4500 & 4500 & 4526 & 4526 \\
\hline
\end{tabular}

\subsubsection{Bark Boiler \#2 Performance}

The boiler performance for implementation of Boiler \#2 modifications is shown in Table 3.3.3-2 Heat and Mass Balance. The three cases of implementation/modification are labeled as Step 1, Step 2, and Step 3. For Step 1, the boiler load is $125 \% \mathrm{MCR}$ at 250,000 Lb/hr steam flow. The fuel is wet bark $(52.5 \%$ moisture by weight $)$ and syngas $\left(670^{\circ} \mathrm{F}\right)$ and the excess air is $20 \%$. The present tubular air heater has not been removed from \#2 Boiler. AH-3 has not been installed in the furnace of \#2 Boiler.

For the Step 2, the boiler load is $125 \% \mathrm{MCR}$ at 250,000 Lb/hr steam flow, the fuel is dried bark ( $20 \%$ moisture by weight) and the syngas $\left(670^{\circ} \mathrm{F}\right)$ and the excess air is $20 \%$. The present tubular air heater is bypassed and the preheated combustion air for UGA and OFA will be extracted from HRSG-1. Air heater AH-3 has not been installed in \#2 Boiler. 
For the case Step 3, the boiler load is $125 \% \mathrm{MCR}$ at $250,000 \mathrm{Lb} / \mathrm{hr}$ steam flow. The fuel is dried bark $\left(20 \%\right.$ moisture by weight) and syngas $\left(670^{\circ} \mathrm{F}\right)$ and the excess air is $20 \%$. The present tubular air heater is bypassed. Combustion air for UGA and OFA is supplied by external HRSG1 and HRSG-2. Air heater AH-3 is installed in the furnace of \#2 Boiler.

In Step 1 (no heating surface modifications in Boiler \#2) bark is fed to the boiler at the asreceived moisture of $52.5 \mathrm{wt} \%$. Syngas from the gasifier enters the furnace at $670^{\circ} \mathrm{F}$ as the second fuel stream. The total fuel input to the boiler is $378.7 \mathrm{MMBtu} / \mathrm{h}$. The boiler produces $250,000 \mathrm{lb} / \mathrm{h}$ of superheated steam at $850 \mathrm{psig}$ and $825^{\circ} \mathrm{F}$. Usable heat output from the boiler is 281.1 MMBtu/h, for a boiler efficiency of $74.2 \%$

In Step 2 the tubular air heater is bypassed, all bark fuel to the gasifier and boiler is dried using waste heat in the boiler flue gas, and hot air is supplied heated air to the furnace (OFA and UGA from a portion of the hot vitiated air from the HRSG-1 exhaust. Bark is fed to the boiler from the dryers at a moisture of $20 \mathrm{wt} \%$. Syngas from the gasifier enters the furnace at $670^{\circ} \mathrm{F}$ as the second fuel stream. The total fuel input to the boiler is $354.0 \mathrm{MMBtu} / \mathrm{h}$. The boiler produces $250,000 \mathrm{lb} / \mathrm{h}$ of superheated steam at $850 \mathrm{psig}$ and $825^{\circ} \mathrm{F}$. Usable heat output from the boiler is 281.1 MMBtu/h and boiler efficiency is $79.4 \%$. Low-level waste heat from the boiler flue gas is used to perform the majority of the fuel drying rather than high-level heat in the furnace. This, plus the recovery of waste heat from HRSG-1 exhaust improves the overall boiler efficiency.

In Step 3 the tubular air heater remains bypassed, combustion air is supplied from the combined exhaust of HRSG-1 and HRSG -2 , and all bark is dried to $20-\mathrm{wt} \%$ with boiler flue gas. Syngas from the gasifier enters the furnace at $670^{\circ} \mathrm{F}$ as the second fuel stream. The internal air heater AH-3 is installed in the furnace, heating high-pressure air from the compressor of the second externally recuperated gas turbine, GT-2. The total fuel input to the boiler is now 436.0 $\mathrm{MMBtu} / \mathrm{h}$. The boiler again produces $250,000 \mathrm{lb} / \mathrm{h}$ of superheated steam at $850 \mathrm{psig}$ and $825^{\circ} \mathrm{F}$. The boiler now also produces $320,000 \mathrm{lb} / \mathrm{h}$ of high-pressure air at $1400^{\circ} \mathrm{F}$ and $178 \mathrm{psig}$ for expansion through GT-2. Usable heat output (steam plus air) from the boiler is $343.9 \mathrm{MMBtu} / \mathrm{h}$, for an effective boiler efficiency of $78.9 \%$. Low-level waste heat from the boiler flue gas is again used to perform the majority of the fuel drying, rather than high-level heat in the furnace. The high-level furnace heat is therefore available for heating air to the turbine, which produces $17 \mathrm{MW}$ of self-generated electricity. The overall system, including the external air heater AH-1 and its associated externally recuperated gas turbine provides $34 \mathrm{MW}$ of new self-generated electricity to the mill, plus $250,000 \mathrm{lb} / \mathrm{h}$ of $850 \mathrm{psig}$ superheated steam and about $129,000 \mathrm{lb} / \mathrm{h}$ of process steam including $100,000 \mathrm{lb} / \mathrm{h}$ of 250 psig steam from the HRSGs. 
Table 3.3.3-2 Boiler \#2 Heat and Mass Balance

(Sheet 1 of 3)

$\begin{array}{lrrr}\text { Units } & \text { Step 1 } & \text { Step 2 } & \text { Step 3 } \\ \% & 125 & 125 & 125\end{array}$

Load

Fuel Heat Input

Bark Fuel

$10^{6} \mathrm{Btu} / \mathrm{hr}$

234.3

209.6

291.6

Syn Gas

$10^{6} \mathrm{Btu} / \mathrm{hr}$

144.4

144.4

144.4

Total

$10^{6} \mathrm{Btu} / \mathrm{hr}$

378.7

354.0

436.0

Heat Output

SH Steam

$10^{6} \mathrm{Btu} / \mathrm{hr}$

281.1

281.1

281.1

HPHT Air Heater

$10^{6} \mathrm{Btu} / \mathrm{hr}$

NA

NA

62.8

Total

$10^{6} \mathrm{Btu} / \mathrm{hr}$

281.1

343.9

Efficiency (Steam + Air)

74.2

79.4

78.9

$\underline{\text { Water/Steam Flow }}$

Outlet SH Steam

Spray

Blowdown

Feedwater

$\mathrm{lb} / \mathrm{hr}$

$\mathrm{lb} / \mathrm{hr}$

250000

0

$\mathrm{lb} / \mathrm{hr}$

2000

252000

250000

250000

0

0

$\mathrm{lb} / \mathrm{hr}$

2000

2000

252000

252000

Water/Steam Pressure

Feedwater

Drum

SH Outlet

psia

1012

1012

1012

psia

962

962

962

psia

865

865

865

Fuel/Air/Flue Gas Flow

Excess Air

$\%$

20

20

20

Bark Fuel

$\mathrm{lb} / \mathrm{hr}$

51750

27500

38250

Syngas

$\mathrm{lb} / \mathrm{hr}$

77660

77660

77660

$\mathrm{lb} / \mathrm{hr}$

293957

392477

Flue Gas

$\mathrm{lb} / \mathrm{hr}$

421705

315253

506318 
Table 3.3.3-2 Boiler \#2 Heat and Mass Balance

(Sheet 2 of 3)

$\begin{array}{cccc}\text { Units } & \text { Step 1 } & \text { Step 2 } & \text { Step 3 } \\ \% & 125 & 125 & 125 \\ & & & \\ { }^{\circ} \mathrm{F} & 80 & 80 & 80 \\ { }^{\circ} \mathrm{F} & 670 & 670 & 670 \\ { }^{\circ} \mathrm{F} & 80 & 80 & 80 \\ { }^{\circ} \mathrm{F} & 375 & \mathrm{NA} & \mathrm{NA} \\ { }^{\circ} \mathrm{F} & \mathrm{NA} & 375 & 375\end{array}$

$\underline{\text { Bark Fuel (as fed) }}$

Water

wt. Dec. $\quad 0.5250$

$0.2000 \quad 0.2000$

Nitrogen

wt. Dec. $\quad 0.0010$

$0.0017 \quad 0.0017$

Hydrogen

wt. Dec.

0.0304

0.0512

0.0512

Oxygen

wt. Dec.

0.1608

0.2708

0.2708

Carbon

wt. Dec.

0.2565

0.4320

0.4320

Ash

wt. Dec.

0.0263

0.0443

0.0443

Total

wt. Dec.

1.0000

1.0000

1.0000

HHV

Btu/lb

4526

7622

7622

$\underline{\text { Syn Gas Fuel }}$

$\mathrm{CO}$

$\mathrm{CO} 2$

$\mathrm{H} 2$

$\mathrm{H} 2 \mathrm{O}$

$\mathrm{CH} 4$

N2

$\mathrm{C} 2 \mathrm{H} 4$

C6H6

$\mathrm{H} 2 \mathrm{~S}+\mathrm{COS}$

$\mathrm{NH} 3+\mathrm{HCN}$

$\mathrm{O} 2$

Total

Vol \%

14.626

14.626

14.626

Vol \%

9.542

9.542

9.542

Vol \%

6.410

6.410

6.410

Vol \%

15.545

15.545

15.545

Vol \%

3.505

3.505

3.505

Vol \%

50.204

50.204

50.204

Vol \%

0.021

0.021

0.021

Vol \%

0.053

Vol \%

0

Vol \%

0.094

Vol \%

0

0.053

0.053

Vol \%

100.00

0

0

HHV

$\mathrm{Btu} / \mathrm{SCF}$

105.608

0.094

0.094

0

0

$100.00 \quad 100.00$

$105.608 \quad 105.608$ 
Table 3.3.3-2 Boiler \#2 Heat and Mass Balance

(Sheet 3 of 3)

\begin{tabular}{lcccc} 
& Units & Step 1 & Step 2 & Step 3 \\
Load & $\%$ & 125 & 125 & 125 \\
HT HP Air Heater & & & & \\
\hline Air Flow & $1 \mathrm{~b} / \mathrm{hr}$ & NA & NA & 320000 \\
Air Inlet Pressure & $\mathrm{psia}$ & NA & NA & 208 \\
Air Outlet Pressure & psia & NA & NA & 178 \\
Air $\Delta$ P & psi & NA & NA & 30 \\
Air Inlet Temperature & ${ }^{\circ} \mathrm{F}$ & NA & NA & 661 \\
Air Outlet Temperature & ${ }^{\circ} \mathrm{F}$ & NA & NA & 1400 \\
Air $\Delta T$ & ${ }^{\circ} \mathrm{F}$ & NA & NA & 739 \\
Number of Circuits & -- & NA & NA & 36 \\
Tube OD & inch & NA & NA & 2.75 \\
Tube ID & inch & NA & NA & 2.31
\end{tabular}

\subsubsection{Internal High Temperature High Pressure Air Heater AH-3}

This section discusses the preliminary design developed for the internal air heater AH-3. The external air heater is discussed in Section 3.3.4. The design of the air heaters is determined in large part by the gas turbine to which they are coupled in the externally recuperated gas turbine (ERGT) cycle. Two gas turbines were considered during the evaluation. The first was a Titan 130 manufactured by Solar Turbines Inc. This turbine was used as the baseline for the study, and all heat exchanger designs, both internal and external, were based on inlet air conditions of $810^{\circ} \mathrm{F}$ and $250 \mathrm{psig}$. Later in the study, the Alstom GT 35 engine was selected as it is more readily adapted to the ERGT cycle and produces $20 \%$ more power $(17 \mathrm{MWe})$ than the Titan 130 . The GT 35 is a lower pressure machine with air leaving the turbine's compressor at 179 psig and $661^{\circ} \mathrm{F}$. The air heater designs based on the Titan 130 can be considered to be conservative from a mechanical design and cost estimating standpoint for the purposes of the current study. Designs specific to the GT 35 engine will be developed in the detailed design phase.

AH-3 is designed as a parallel cross-flow tube bundle to be located in the furnace above the top of the natural gas auxiliary burners are below the furnace arch tip. There are eighteen (18) assemblies at 12-inch spacing and two air flow circuits per assembly for a total of 36 air flow circuits. The tube OD is $2.75 \mathrm{inch}$ and the tube thickness is $0.220 \mathrm{inch}$. The air heater as located in the furnace is shown in Figure 3.3.3-1. Selected elevation views of the conceptual air heater are shown in Figures 3.3.3-2 and 3.3.3-3.

The air enters at $250 \mathrm{psig}$ and $810^{\circ} \mathrm{F}$ from the lower air header and leaves the tubes at $215 \mathrm{psig}$ and $1400^{\circ} \mathrm{F}$ to enter the upper air header. The design pressure was selected to be $300 \mathrm{psig}$ for the study. 
A metal study was conducted for the air heater tube bundle based on the air conditions discussed above. The metal study was completed for a case of $125 \% \mathrm{MCR}, 250,000 \mathrm{Lb} / \mathrm{hr}$ steam flow, $77,660 \mathrm{lb} / \mathrm{hr}$ syngas flow to the furnace, $35753 \mathrm{lb} / \mathrm{hr}$ dried bark flow at $20 \%$ moisture by weight, and $320,000 \mathrm{lb} / \mathrm{hr}$ HT HP air heater flow at $810^{\circ} \mathrm{F}, 250 \mathrm{psig}$ inlet conditions.

The first part of the metal study was done for the case of no air flow imbalance from tube circuit to tube circuit. The results of this part of the metal study are shown in Figure 3.3.3-4. The bulk air temperature and average tube metal temperature versus tube number is shown as a graph for individual continuous tube circuits. A sketch in the upper left portion of Figure 3.3.3-4 shows the continuity of each tube circuit. That is, tube circuit 1 is a continuum of tubes $1,4,5,8,9,12,13$, $16,17,20,21$, and 24 and tube circuit 2 is a continuum of tube $2,3,6,7,10,11,14,15,18,19$, 22, and 23. Maintaining a constant tube wall thickness along the tube circuit length will provide for minimum pressure drop. The average tube metal temperature at the outlet of tube 24 in circuit 1 is $1404^{\circ} \mathrm{F}$ and the bulk average air temperature with no air flow imbalance is $1378^{\circ} \mathrm{F}$. The ASME minimum tube wall thickness for SB-407 $800 \mathrm{HT}$ material at $300 \mathrm{psig} / 1404^{\circ} \mathrm{F}$ average metal temperature is 0.1318 inch (Le. 0.132 inch). The selected tube wall thickness of 0.220 -inch is greater than 0.132-inch and is acceptable. The average tube metal temperature at the outlet of tube 23 in circuit 2 is $1376^{\circ} \mathrm{F}$ and the bulk average air temperature with no air flow imbalance is $1352^{\circ} \mathrm{F}$. The ASME minimum tube wall thickness for SB-407 $800 \mathrm{HT}$ material at 300 $\mathrm{psig} / 1376^{\circ} \mathrm{F}$ is 0.1173 -inch (i.e. 0.118 inch). The selected tube wall thickness of 0.220 -inch is greater than 0.118 -inch and is acceptable.

Each of the thirty two (32) tube circuits will never have perfectly equal air flow. In practice, it is customary to allow for tube-to-tube flow imbalance at the design stage. The second part of the metal study was done for the case of air flow imbalance from tube circuit to tube circuit. The results of this part of the metal study are shown in Figure 3.3.3-5. The bulk air temperature, bulk air temperature plus air temperature imbalance, and average tube metal temperature versus tube number is shown as a graph for individual continuous tube circuits. A sketch in the upper left portion of Figure 3.3.3-5 shows the continuity of each tube circuits.

The average tube metal temperature at the outlet of tube 24 in circuit 1 is $1554^{\circ} \mathrm{F}$ and the bulk air flow temperature with imbalance is $1528^{\circ} \mathrm{F}$. The limiting metal temperature for SB-407 $800 \mathrm{HT}$ material is $1500^{\circ} \mathrm{F}$ for this condition, the minimum ASME wall thickness is 0.1893 inch $(0.189$ inch) for SB-407 $800 \mathrm{HT}$ material at 300 psig and $1500^{\circ} \mathrm{F}$ temperature limit. In this case, a new developmental material Haynes 230 (ASME CC2063) is selected to perform at $300 \mathrm{psig} / 1554^{\circ} \mathrm{F}$ and the minimum tube wall thickness for Haynes 230 material is 0.1229 -inch (0. 130-inch). Therefore, tube wall thickness of 0.220 inch is greater than $0.130 \mathrm{inch}$ and is acceptable. Tubes 20, 21, and 24 would be made of Haynes 230 material. The average tube metal temperature at the outlet of tube 23 in circuit 2 is $1500^{\circ} \mathrm{F}$. The limiting metal temperature for SB-407 $800 \mathrm{HT}$ material is $1500^{\circ} \mathrm{F}$. Again, for this condition, the minimum ASME wall thickness is 0.1893-inch (0. 189-inch) for SB-407 $800 \mathrm{HT}$ material at $300 \mathrm{psig}$ and $1500^{\circ} \mathrm{F}$ temperature limit. In this case again, the new developmental material Haynes 230 (ASME CC 2063) is selected to perform at $300 \mathrm{psig} / 1523^{\circ} \mathrm{F}$ and the minimum tube wall thickness for Haynes 230 material is 0.1088 -inch (0.109-inch). Therefore, a tube wall thickness of 0.220 -inch is greater than 0.109 -inch and is acceptable. Tube 22 and 23 would be made of Haynes 230 material. 


\subsubsection{Circulation Study}

A circulation study was done to estimate the circulation ratio for the case of $250,000 \mathrm{lb} / \mathrm{hr}$ steam flow, 30\% excess air, dried bark fuel and syngas fuel, no tubular air heater, and air heater AH-3 in the furnace (Case A). Also, a circulation study was done to estimate the circulation ratio for the case of $225,000 \mathrm{lb} / \mathrm{hr}$ steam flow, $30 \%$ excess air, wet bark fuel, and tubular air heater as presently installed in the boiler (Case B).

The circulation ratio is defined as the ratio of the total emulsion flow to the total steam generated.

For case A, the circulation ratio is 8.4 and the peak waterwall heat flux is $51,000 \mathrm{Btu} / \mathrm{hr}-\mathrm{ft}^{2}$ to the furnace waterwall. The average water wall tube metal temperature is $600^{\circ} \mathrm{F}$ and the calculated ASME minimum tube wall thickness is 0.1053 inch, which is less than the tube wall thickness of 0.188 -inch.

For case $\mathrm{B}$, the circulation ratio is 8.19 and the peak waterwall heat flux is $58,000 \mathrm{Btu} / \mathrm{hr} \mathrm{ft}^{2}$ to the furnace waterwall. The average waterwall tube metal temperature is $627^{\circ} \mathrm{F}$ and the calculated ASME minimum tube wall thickness is 0.1071-inch, which is less than the tube wall thickness of 0.188-inch.

For case $\mathrm{A}$, the inside tube wall temperature is $584.3^{\circ} \mathrm{F}$ at peak heat flux and the temperature difference $\Delta \mathrm{Tx}=\mathrm{Ti}$ - Tsat is $46.8^{\circ} \mathrm{F}$. The nucleate boiling regime is individual bubble regime.

For case $\mathrm{B}$, the inside tube wall temperature is $609.3^{\circ} \mathrm{F}$ and the temperature difference $\Delta \mathrm{Tx}=\mathrm{Ti}$

- Tsat is $69.4^{\circ} \mathrm{F}$. The nucleate boiling regime is individual bubble regime.

In general, the departure from nucleate boiling heat transfer regime, $\mathrm{DNB}$, occurs at $\Delta \mathrm{Tx}$ somewhat greater than $100^{\circ} \mathrm{F}$.

The excess temperature difference $\Delta \mathrm{Tx}$ is defined as the excess temperature above the boiling point. The maximum heat flux at the excess temperature $\Delta \mathrm{Tx}$ is of the order of approximately $500,000 \mathrm{Btu} / \mathrm{hr}^{2} \mathrm{f}^{2}$ and at this point DNB will begin as $\Delta \mathrm{Tx}$ increases. The maximum peak heat flux for case A and case B will not cause DNB.

The results are shown in Table 3.3.3-3.

\subsubsection{Furnace Syngas Injection}

The furnace cross-section dimensions are $18 \mathrm{ft} 11$-inch width and $18 \mathrm{ft} 11$-inch depth. The stoker floor is at elevation (relative to sea level) $227 \mathrm{ft} 0$-inch and the top of the stoker grate is approximately $231 \mathrm{ft} 0$-inch. The centerline elevation of four (4) pneumatic bark distributors are located on the front wall of the furnace and the bark is injected in a trajectory along the depth of the furnace toward the rear wall.

Twelve HMZ over-fire air nozzles are located at elevation $245 \mathrm{ft} 3$-inch on the rear wall. The centerline of the two auxiliary natural gas burners is at elevation $250 \mathrm{ft} 9$-inch and the natural gas burners are located on the rear wall. The location of the syngas injection ports will be at an approximate elevation of $235 \mathrm{ft}$ on the furnace rear wall using existing deactivated OFA nozzles and through new nozzles in the front wall of the boiler at an approximate elevation of $233 \mathrm{ft}$. The front nozzles will be located below the front header and no pressure parts will be modified. 
The nozzles will be sized to insure adequate velocity for uniform mixing in the furnace. A backup reburning fuel system using natural gas mixed with a small portion (10-15\%) of recirculated flue gas will be available to replace syngas in the event that the gasifier is off line.

\subsubsection{Vibrations in the Economizer}

The economizer tube bundle is located in the boiler back pass duct that is $17 \mathrm{ft} 101 / 2$ inch overall height, $18 \mathrm{ft} 10$ 1/4-inch wide and $8 \mathrm{ft} 0$-inch depth. The ductwork plate is 3/16-inch carbon steel. The economizer is a counterflow type having 24 circuits of 2 -inch OD tube. External plate stiffeners are arranged in a manner such that the basic plate sizes resulting are $2 \mathrm{ft}$ $\mathrm{x} 8 \mathrm{ft}, 2 \mathrm{ft} \times 1 \mathrm{ft} 81 / 8$-inch, and $2 \mathrm{ft} \times 7 \mathrm{ft} 9$-inch and the natural frequencies of these plates are $20.5 \mathrm{HZ}, 39 \mathrm{HZ}$, and $1.4 \mathrm{HZ}$ (resp.) as considered to be rigidly supported by the stiffener arrangement.

For the case of $125 \% \mathrm{MCR}$, steam flow $250,000 \mathrm{lb} / \mathrm{hr}$, dried bark (20\% moisture by weight) and syngas fuel input, flue gas flow of $525,709 \mathrm{lb} / \mathrm{hr}$ at $30 \%$ excess air, HT HP AH installed in furnace, $605^{\circ} \mathrm{F}$ economizer flue gas exit temperature, and no external original tubular air heater, the resulting Strouhal vortex shedding frequencies are $79 \mathrm{HZ}$ at the flue gas inlet to the economizer, $72 \mathrm{HZ}$ in the mid section of the economizer, and $65 \mathrm{HZ}$ at the flue gas exit of the economizer.

The flue gas standing half wave frequencies at the gas inlet to the economizer are $46 \mathrm{HZ}$ along the width and $108 \mathrm{HZ}$ along the depth. The flue gas standing half wave frequencies at the midsection of the economizer are $44 \mathrm{HZ}$ along the width and $103 \mathrm{HZ}$ along the depth. The flue gas standing half wave frequencies at the economizer gas exit are $42 \mathrm{HZ}$ along the width and 98 $\mathrm{HZ}$ along the depth. Standing half waves are opposite in phase of flue gas pressure pulsations.

The half standing wave frequency of $42 \mathrm{HZ}$ along the depth at the economizer exit is nearly synchronous with the natural frequency of the $2 \mathrm{ft} \times 1 \mathrm{ft} 81 / 2$ inch duct plate of $39 \mathrm{HZ}$. Therefore, a source frequency is nearly coupled with a natural frequency and vibration may occur.

\subsubsection{Combustion System}

The purpose of this section is to review grate capacity and turndown combustion air flow apportionment between over-fire air and under-grate air, combustion air temperatures and air tempering systems (if required).

The No. 2 boiler original performance design grate heat release rate for 200,000 lb/hr steam flow and $225,000 \mathrm{lb} / \mathrm{hr}$ steam flow and $30 \%$ excess air is $813,000 \mathrm{Btu} / \mathrm{hr}-\mathrm{ft}^{2}$ and 915,000 But/hr- $\mathrm{ft}^{2}$, respectively based on grate bark fuel heat input. The No. 2 boiler upgrade performance design grate heat release for $300,000 \mathrm{lb} / \mathrm{hr}$ steam flow and $30 \%$ excess air is $1,262,100 \mathrm{Btu} / \mathrm{hr}-\mathrm{ft}^{2}$ based on grate bark fuel heat input, which is higher than generally recommended.

For Step 3 of the current plant modifications, 250,000 Lb/hr steam flow, 20\% excess air the grate heat release rate is $762,000 \mathrm{Btu} / \mathrm{hr}^{-\mathrm{ft}^{2}}$ based on grate bark fuel heat input. The GHRR for Step 3 is equal to the GHRR of Bark boiler \#2 as originally designed and is far lower than the upgrade design heat release rate. An acceptable grate turndown is a four-to-one ratio and the purpose of limiting the turndown is to insure a bed of ash and fuel are on the grate at all times during operation. 
Table 3.3.3-3: Circulation Study Results

\begin{tabular}{|c|c|c|c|}
\hline Case & & $\mathrm{A}$ & $\mathrm{B}$ \\
\hline & Units & & \\
\hline Load & $\%$ & 112.5 & 125 \\
\hline Excess Air & $\%$ & 30 & 30 \\
\hline Fuel & Type & $\begin{array}{l}\text { Wet bark@50\% } \\
\text { moisture by weight }\end{array}$ & $\begin{array}{l}\text { Dried bark@20\% } \\
\text { moisture by weight }\end{array}$ \\
\hline Fuel & Type & NA & Syngas . \\
\hline Tubular Air heater & $\mathrm{Y} / \mathrm{N}$ & Yes & No \\
\hline HT HP Air heater AH-3 & $\mathrm{Y} / \mathrm{N}$ & No & Yes \\
\hline Steam flow & $\mathrm{Lb} / \mathrm{hr}$ & 225,000 & 250,000 \\
\hline Blowdown & $\mathrm{Lb} / \mathrm{hr}$ & 0 & 2000 \\
\hline FW Flow & $\mathrm{Lb} / \mathrm{hr}$ & 225,000 & 252,000 \\
\hline FW Pressure' & Psia & 993 & 1012 \\
\hline Drum Pressure & Psia & 943 & 962 \\
\hline SH Outlet Pressure & Psia & 865 & 865 \\
\hline FW Temp & ${ }^{\circ} \mathrm{F}$ & 350 & 353 \\
\hline Econ Outlet FW Temp & ${ }^{\circ} \mathrm{F}$ & 477 & 479 \\
\hline Drum Sat. Temp & ${ }^{\circ} \mathrm{F}$ & 537.5 & 539.9 \\
\hline $\begin{array}{l}\text { Peak Waterwall Heat } \\
\text { Flux }\end{array}$ & $\mathrm{Btu} / \mathrm{hr}-\mathrm{ft}^{2}$ & 51000 & 58000 \\
\hline $\begin{array}{l}\text { Waterwall A vg Tube } \\
\text { Temp }\end{array}$ & ${ }^{\circ} \mathrm{F}$ & 600 & 627 \\
\hline $\begin{array}{l}\text { Inside Tube Wall } \\
\text { Temp, Tt }\end{array}$ & ${ }^{\circ} \mathrm{F}$ & 584.3 & 609.3 \\
\hline$L \mid x=$ Tit - T sAT & ${ }^{\circ} \mathrm{F}$ & 46.8 & 69.4 \\
\hline Waterwall Tube OD & Inch & 2.5 & 2.5 \\
\hline Design Pressure & Psig & 1025 & 1025 \\
\hline $\begin{array}{l}\text { Waterwall Tube } \\
\text { Material }\end{array}$ & Type & SA-178A & SA-178A \\
\hline $\begin{array}{l}\text { Waterwall Tube } \\
\text { Thickness }\end{array}$ & Inch & 0.188 & 0.188 \\
\hline $\begin{array}{l}\text { ASME Tube } \\
\text { Minimum }\end{array}$ & Inch & 0.1053 & 0.1071 \\
\hline Circulation Ratio & $\mathrm{Lbm} / \mathrm{Lbm}$ & 8.40 & 8.19 \\
\hline
\end{tabular}


The path of combustion air to Bark boiler \#2 as originally designed and with the upgrade HMZ over-fire air system is as follows:

- The forced draft fan supplies air to the tubular air heat for combustion air heating.

- The heated air exits the tubular air heater in two paths: one path to the left side (west) of Bark boiler \#2 and one path to the right side (east) of Bark boiler \#2.

- The heated air takeoff for air supplied to the auxiliary natural gas burners is the juncture (both air paths).

- The air paths continue and have two more junctures apiece whereby each side path supplies over-fire air for $1 / 2$ of the furnace wall and $1 / 2$ of the front furnace wall OFA requirements.

- The air paths continue and deliver the under-grate air to the left side (west) and right side (east) of the under-grate air plenum of the stoker.

The grate seal (fabric belt type) has a temperature limitation of $480^{\circ} \mathrm{F}$ (maximum) and is designed for \pm 25 in. w.c.

With the introduction of syngas above the grate as approximately $1 / 3$ of the boiler fuel input, the OFA/UGA air flow split will be changed to accommodate an increase in OFA and decrease in UGA.

The combustion air temperature to the furnace (OFA/UGA) for the proposed modifications are in the range of $375^{\circ} \mathrm{F}$, well below the maximum of $480^{\circ} \mathrm{F}$ for the UGA limitation.

\subsubsection{Boiler Auxiliary Systems}

The purpose of this section is to evaluate the forced draft fan, induced draft fan, and overfire air fan.

\section{Forced Draft Fan}

The installed forced draft fan on Bark boiler \#2 is a Chicago Blower Corp. (size $6000 \mathrm{AF}$, D/1903, 91\% DWPI, A13, C/1200, VIVC) fan rated at 17.2 in.w.c. outlet static pressure, air flow of $117,000 \mathrm{CFM} / 110^{\circ} \mathrm{F}, 0.0707 \mathrm{lb} / \mathrm{ft}^{2}$ density. The air mass flow rate is $496,314 \mathrm{lb} / \mathrm{hr}$.

\section{Induced Draft Fan}

The installed (original) ID fan on Bark boiler \#2 is a Buffalo Forge $2715 \mathrm{H} 1 \mathrm{U}$ with a test block rating of 237128 ACFM@ 28.93 in.w.c. static suction at $445^{\circ} \mathrm{F}$ and $0.0439 \mathrm{Lb} / \mathrm{fl}^{2}$ density. The corresponding flue gas mass flow rate is $624,595 \mathrm{lb} / \mathrm{hr}$.

\section{Over-fire Air Fan}

There are no overfire air fans on Bark boiler \#2. The overfire air to the upgraded HMZ OFA system is supplied through the ductwork from the outlet(s) path(s) of the installed tubular air heater.

\section{Summary of FD Fan and ID Fan Performance}

A summary of FD fan and ID fan performance is listed in Table 3.3.3-4. The cases selected for comparison are the original design load of $200,000 \mathrm{lb} / \mathrm{hr}$ steam flow and 225,000 lb/hr steam flow, the Entec Study ${ }^{2}$ load of 250,000 lb/hr steam flow, and the Step 1, 2, and 3 loads of $250,000 \mathrm{lb} / \mathrm{hr}$ steam flow. 
In Implementation Step 1 woodwaste for the gasifier only is dried from $52.5 \%$ moisture by weight to $20 \%$ moisture by weight. As-received bark at $52.5 \%$ moisture is fed to the boiler. In this Step the dryer is fired with natural gas, the combustion products of which are mixed with a small amount of recirculated flue gas from the exit of the boiler ID fan. The dryer output is the dried woodwaste for the gasifier and the moist dryer exhaust gas. The exhaust gas is added to the boiler tubular air heater exit gas flow and the combined flow enters the dust collector.

In Step 2 and 3, the tubular air heater is bypassed. Flue gas from the economizer exit flows directly to the wood waste dryer to dry the moist bark fuel. A portion of the flue gas bypasses the dryer and recombines with the dryer exhaust at the dust collector inlet. This increases the flue gas temperature at the dust collector above the $175^{\circ} \mathrm{F}$ exhaust temperature of the dryer.

The primary benefit of the bark dryer(s) is that low-level waste heat from the boiler flue gas is used to dry the bark rather than high-level heat in the gasifier and stoker boiler. As a result, more high-level heat is available to drive the gasification reactions in the gasifier and to produce superheated steam and air in the boiler. An additional benefit is that the portion of bark moisture removed in the dryer bypasses the boilers upper furnace and goes directly to the dust collector. No. 2 boiler is already known to be operating at high velocity and pressure drop in the upper furnace. Bypassing a portion of the bark moisture directly to the dust collector significantly reduces the mass flow of water vapor in the upper furnace. Comparing the Entec case to the Step 3 case (both producing 250,000 lb/h of steam) in Table 3.3.3-4 shows that even though bark feed and feed moisture are higher in Step 3, water vapor from feed moisture in the upper furnace is significantly lower $(45,000 \mathrm{lb} / \mathrm{h}$ for the Entec case vs. only 12,374 lb/h for the Step 3 case.

Another advantage of the advanced power system is that a portion of the air required for combustion of the bark fuel is supplied by the gasification air compressor, which supplies air for partial combustion of a portion of the total system bark requirement in the gasifier. This air no longer needs to be supplied by the FD fan, extending its capacity to higher loads. Comparing the original boiler design cases producing 200,000 and 225,000 lb/h of steam to the Step 1 and 2 cases producing $250,000 \mathrm{lb} / \mathrm{h}$ shows that the additional steam production is accomplished with the same (Step 1) or lower (Step 2) FD air flow. For the 250,000 lb/h cases, the Step 3 boiler FD air flow is essentially the same as the Entec case despite producing a about $5 \mathrm{MW}$ of electricity from heated high pressure air in addition to the $250,000 \mathrm{lb} / \mathrm{h}$ of superheated steam.

Comparison of the total flue gas flow for the $250,000 \mathrm{lb} / \mathrm{h}$ cases shows that all of the advanced power system cases result in less or equal flue gas to the ID fan (including all bark moisture) than the Entec case. Again, Step 3 produces $5 \mathrm{MW}$ of electricity in addition to the steam with essentially the same flue gas flow to the ID fan.

\subsubsection{Systems Off-Line}

The purpose of this section is to analyze the operating methods and contingencies with either the Biomass Gasifier (Syngas) and/or the high temperature/high pressure air heater out of service.

\section{Biomass Gasifier Off-Line}

When the gasifier is off-line, a mixture of natural gas and recirculated boiler flue gas will be routed to the syngas reburn injection nozzles to maintain NOx reduction and combustion improvement through reburning and to keep the injection nozzle from overheating. GT-1 can be operated in a non-recuperated manner with natural gas until the gasifier is brought back online and gas can be reduced as air is again preheated with hot syngas in AH-1. 
Table 3.3.3-4: FD Fan and ID Fan Performance

\begin{tabular}{|c|c|c|c|c|c|c|c|}
\hline . Item & Units & $\begin{array}{c}\text { Original PB } \\
\text { Sheet }\end{array}$ & $\begin{array}{c}\text { Original PB } \\
\text { Sheet }\end{array}$ & Entec Study & Step 1 & Step 2 & Step 3 . \\
\hline Load & $\%$ & 100 & 112.5 & 125 & 125 & 125 & 125 \\
\hline Steam Flow & $\mathrm{lb} / \mathrm{hr}$ & 200,000 & 225,000 & 250,000 & 250,000 & 250,000 & 250,000 \\
\hline Gasifier Bark Feed, as fed & $\mathrm{lb} / \mathrm{h},(\%$ moisture $)$ & 0 & 0 & 0 & $23,621(20)$ & $23,621(20)$ & $23,621(20)$ \\
\hline Stoker Bark Feed, as fed & $\mathrm{lb} / \mathrm{h},(\%$ moisture $)$ & $69,310(50)$ & $78,090(50)$ & $90,000(50)$ & $51,750(52.5)$ & $27,500(20)$ & $38,250(20)$ \\
\hline Total System Bark Feed, as fed & $\mathrm{lb} / \mathrm{h},(\%$ moisture $)$ & $69,310(50)$ & $78,090(50)$ & $90,000(50)$ & $75,371(42.3)$ & $51,121(20)$ & $61,871(20)$ \\
\hline Total System Bark Feed, as rec'd & $\mathrm{lb} / \mathrm{h},(\%$ moisture $)$ & $69,310(50)$ & $78,090(50)$ & $90,000(50)$ & $91,532(52.5)$ & $86,098(52.5)$ & $104,203(52.5)$ \\
\hline Fuel Moisture through upper furnace & $\mathrm{lb} / \mathrm{h}$ & 34,655 & 39,045 & 45,000 & 31,893 & 10,224 & 12,374 \\
\hline \multicolumn{8}{|l|}{ FD Fan } \\
\hline Air Flow & $\mathrm{lb} / \mathrm{hr}$ & 293,000 & 330,000 & 316,724 & 293,957 & 315,253 & 392,477 \\
\hline Temperature & ${ }^{\circ} \mathrm{F}$ & 80 & 80 & 94 & 80 & 80 & 80 \\
\hline \multicolumn{8}{|l|}{ ID Fan } \\
\hline Flue Gas Flow & $\mathrm{lb} / \mathrm{hr}$ & 362,000 & 407,000 & 579,057 & 485,759 & 481,321 & 576,069 \\
\hline Temperature & ${ }^{\circ} \mathrm{F}$ & 352 & 366 & 367 & 336 & 210 & 238 \\
\hline
\end{tabular}


In Steps 2 and 3, the dryer can continue to dry bark for the boiler. In Step 1 the dryer would be idled or shut down until the gasifier was restarted.

\section{Externally Recuperated Gas Turbine GT-1 or GT-2 Off-Line}

The gas turbines are required to provide air to the external (AH-1) and internal (AH-3) air heaters. Air flow must be maintained to AH-1 at all times when the gasifier is running and to AH-3 whenever the No.2 Boiler is running. However, each of the turbines compresses enough air to supply both air heaters. Therefore, if one turbine is down, half of the operating turbines air can be routed through the off-line turbine's air heater and back to the operating turbines combustor, maintaining full power output from the remaining turbine while reducing its natural gas demand by about half.

\section{External Air Heater/Syngas Cooler AH-1 Off-Line}

If AH-1 is off-line, the gasifier must be shut down to avoid overheating $\mathrm{AH}-1$ and the syngas injection nozzles on No. 2 boiler.

\section{Internal Air Heater AH-3 Off-Line}

If AH-3 is off-line, No. 2 Boiler cannot be operated unless another means is available to cool the air heater tubes.

\section{No. 2 Boiler Off-Line (and Gasifier Off-Line)}

As currently designed, the gasifier cannot be operated when No. 2 Boiler is offline because the boiler is the only user for the syngas. However, both gas turbines can be operated on natural gas without external recuperation from the air heaters, with all turbine exhaust air routed through their respective HRSGs for 250-psig-steam production.

\subsubsection{External High Temperature High Pressure Air Heater AH-1}

This section discusses the preliminary design developed for the external air heater AH-1. The internal air heater design is discussed in Section 3.3.3.4.

Compressed combustion air to the externally recuperated gas turbine GT-1 combustor is preheated in an external heat exchanger using hot syngas from the gasifier. Three conceptual design approaches were developed for the external air heater including two with air on the tube side and one with syngas on the tube side (firetube design). All designs were based on the air conditions for the Titan 130 engine, with inlet air at 250 psig and $810^{\circ} \mathrm{F}$. In all cases syngas flow is 77,660 $\mathrm{lb} / \mathrm{hr}$ and 26-psia inlet pressure. Design 3 is used as the basis for the study cost estimate for AH1 .

\section{$\underline{\text { Design } 1}$}

In this design the external heat exchanger, $\mathrm{AH}-1$, is designed to have high-pressure air flowing inside the 2.50 -inch OD and $0.22 \mathrm{in}$. thick tubes. syngas at 77,660 lb/hr and 26-psia-inlet pressure flows across the outside of the tubes in a counterflow direction and is cooled from $2,200^{\circ} \mathrm{F}$ inlet temperature to $865^{\circ} \mathrm{F}$ outlet temperature. Air at $810^{\circ} \mathrm{F}$ inlet temperature and 265 psia inlet pressure flows inside the tubes. Air flow is $235,000 \mathrm{lb} / \mathrm{hr}$ with an outlet temperature of $1400^{\circ} \mathrm{F}$. Total outside surface area of the tubes is estimated to be $7,480 \mathrm{ft}^{2}$. The heat exchanger consists of 36 tube assemblies each with 2 tubes per assembly for a total of 72 circuits. The tube spacing is $\mathrm{ST}=3.50 \mathrm{in}$. and 56=3.75 in. The casing inside dimensions are $5 \mathrm{ft} .31 / 2 \mathrm{in}$. deep, 10 
ft. 7 in. wide, and $19 \mathrm{ft} .81 / 4$ in. high. A conceptual design of the heat exchanger is shown in Figure 3.3.4-1.

\section{Design 2}

In this design AH-1 will have hot syngas flowing inside the tubes and air flowing outside the tubes in a pure counterflow arrangement. The syngas conditions are the same as in Design 1. The tube OD is 2.50 inches arranged in a rectangular array of 8 tubes $\times 9$ tubes $=72$ tubes (circuits) on 3-inch centers. The shell side dimensions will be $24 \frac{1}{2}$-inch width $\times 27 \frac{1}{2}$-inch height and the exposed tubing length is to be $100 \mathrm{ft}$ having a total outside tube heat transfer area in excess of $4700 \mathrm{ft}^{2}$.

\section{$\underline{\text { Design } 3}$}

In this design AH-1 is designed as a shell and tube heat exchanger to have high pressure air flowing inside the 2.50 -inch OD and 0.22 in. thick tubes. Syngas at 77,660 lb/hr and 26-psia inlet pressure flows across the outside of the tubes in a counterflow direction and is cooled from $2,200^{\circ} \mathrm{F}$ inlet temperature to $865^{\circ} \mathrm{F}$ outlet temperature. Air at $810^{\circ} \mathrm{F}$ inlet temperature and 250 psig inlet pressure flows inside the tubes. Air flow is $235,000 \mathrm{lb} / \mathrm{hr}$ with an outlet temperature of $1400^{\circ} \mathrm{F}$. The total outside surface area of the tubes is estimated to be $8,000 \mathrm{ft}^{2}$. The heat exchanger consists of $171 \mathrm{U}$-shaped tubes each $65.1 \mathrm{ft}$. long. The inside diameter of the heat exchanger is $9.6 \mathrm{ft}$ and the overall length is $39.1 \mathrm{ft}$. Tube material is assumed to be high chrome nickel alloy HK-40.

\subsubsection{Power Generation}

\subsubsection{Power Island Design Evaluation}

Power generation for the plant will be accomplished by employing an externally recuperated gas turbine. The combustion air for the ERGT will be preheated by utilizing the excess sensible heat from the woodwaste gasification and stoker combustion processes. The following tasks were completed to define the most favorable power generation system configuration and system development path:

- Propose and analyze different candidate cycles for an ERGT

- Assess the viability of modifying existing Solar gas turbine designs to the ERGT cycle.

- Develop system installation, interconnection and commissioning requirements based on a standard Solar Titan 130 package to define layout and utilities requirements for the DeRidder site

- Assess the viability of gas turbines from other manufacturers for modification to the ERGT cycle

- Assess the market potential for an ERGT in the forest products industry from a turbine manufacturer's perspective

Six different ERGT cycles were considered for an ERGT system comprised of two Titan 130 sized turbines. Of these six options two were selected as the most suitable based on the practical operational constraints. These two options were thermodynamically analyzed over a range of operating parameters. Potential operating cost savings and mechanical design feasibility were also evaluated.

Three different ERGT development strategies were considered in defining the potential system configurations: 
- Development for a near-term application and requiring only moderate modification,

- A long-term engine development program requiring a significant developmental effort and considerable modification to the present engine designs.

- Modifications and developmental efforts required specifically for Solar engines to operate in the ERGT configuration with current operating constraints (temperatures and material considerations).

Information was provided by Solar on the layout, installation and commissioning of their standard Titan 130 gas turbine package. These data included the arrangement and layout drawings of a standard T130 package and information regarding its various pumps, compression systems and cooling systems. This information was used to help assess the feasibility and economics of modifying the existing Powerhouse at the DeRidder paper mill to accommodate the gasification-based power generation system.

Finally Solar assessed the market potential for an ERGT from a gas turbine manufacturer's perspective.

The following sections summarize the results of the power island design evaluation. The complete results are presented in Solar's final report in Appendix B.

\section{Proposed Cycle Concepts}

The initial study was based on a power generation turbine system that provides $27 \mathrm{MW}$ of electrical energy output. Configurations based on two Titan 130 size gas turbines were therefore evaluated. Six different ERGT cycles for two Titan 130-sized turbines were considered. Two of the cycles included two independent turbines, each with its own air heater and gas combustor to boost the air temperature to the required turbine inlet temperature. In one of these cycles the air heater and combustor were in series (Option 1) and the other in parallel (Option 2). In the remaining cycles two turbines were combined with a single heat exchanger and various single or dual combustor arrangements. Cycle diagrams are presented in Appendix B.

Of these six cycle options the first two, with independent turbine-air heater/combustor combinations, were selected as the most suitable based on the practical operational and cost constraints. These two cycle options were thermodynamically analyzed over a range of operating parameters, including turbine rotor inlet temperature (TRIT), pressure drop across and exit temperature of the air heater, combustor and turbine cooling, and humidification of the air at the turbine compressor inlet. Power generation and cost performance were compared to a standard Titan 130 operating on natural gas at the turbine's baseline ISO conditions, which are detailed in Appendix B.

It was found that cycles based on Option 2 provide a slightly greater power output as compared to Option 1. However, their savings in fuel cost is small when compared to a standard gas turbine and much smaller than that of a cycle based on Option 1. Since the first demonstration of this technology will most likely be with air heater exhaust temperatures in the range of $1400^{\circ} \mathrm{F}$ to $1500^{\circ} \mathrm{F}$, Option 2 does not provide enough fuel cost savings to warrant development. Therefore, Option 1 was selected as the preferred cycle and the rest of the analysis that was conducted is based on this cycle option.

Detailed parametric, thermodynamic analyses of Option 1 were then conducted for two TRITs to determine the effect of $\mathrm{HP} / \mathrm{HT}$ air heater pressure drop and exit temperature on the net turbine power output, natural gas consumption, turbine exhaust temperature and fuel cost. In these 
simulations, compressed air was used as the cooling medium for the turbine. The results of these analyses were again compared with those of the baseline engine.

The TRITs chosen for comparison were $2100^{\circ} \mathrm{F}$ and $1900^{\circ} \mathrm{F}$. The TRIT of $2100^{\circ} \mathrm{F}$ is currently state of the art for industrial turbines. The lower TRIT was adopted based on the assumptions that mechanical design of some of the ERGT components (such as the scroll) might force the system to be designed for a lower TRIT and that operation at lower TIRT could be cost effective when natural gas costs rise.

The results indicate that increasing the heat exchanger exit temperature and lowering its pressure drop, while increasing the TRIT, will maximize the ERGT savings and make the cycle more attractive. Note that unless the TRIT is increased beyond the current standard engine TRIT level of $2100^{\circ} \mathrm{F}$, there will always be a small penalty on the net turbine KW by using an ERGT.

However, the ERGT will provide higher exhaust heat relative to the standard gas turbine when both are compared at the same TRIT.

Additional thermodynamic analysis of Option 1 was conducted to evaluate the effect of using steam as the cooling medium for the turbine. These simulations were performed for a TRIT of $2100^{\circ} \mathrm{F}$. The variables involved in this analysis were the HP/HT air heater pressure drop and exit temperature, while the parameters used for the comparison were the net turbine power output, natural gas consumption, turbine exhaust temperature, cost of fuel per KW-hr and the percentage of savings in fuel cost.

This analysis assumes that no steam enters into the turbine flow stream. However, it must be noted that with respect to the forest product industry application the analysis is not evaluating a combined cycle and that steam is assumed to be available in abundance. Therefore some leakage of steam can be permitted in the actual design. Thus the design constraints on the turbine cooling circuit can be made less restrictive and will hopefully have a small impact on the engine cost.

Due to the pressure drop across the HP/HT heat exchanger, an ERGT with an air-cooled turbine will always have a net electrical output lower than a standard gas turbine. However an ERGT with a steam-cooled turbine can provide an electrical output greater than that of a standard gas turbine for an added pressure drop of up to 20 psi. The results further show that an ERGT can produce an increase in electrical output of about $8 \%$ by switching the cooling medium of the turbine from compressed air to steam (comparisons being made for the same pressure drop across the HP/HT heat exchanger).

Along with a higher electrical output, the ERGT with steam-cooled turbine also provides a higher exhaust temperature that aids in co-generation. Further, the ERGT with a steam cooled turbine generates a fuel cost savings of at least $23 \%$ over a standard gas turbine, while an ERGT with compressed air cooled turbine blades generates a fuel cost savings of at least $18 \%$. Thus using steam as a turbine cooling medium results in an additional $5 \%$ of fuel cost savings.

Based on the above discussion, it can therefore be concluded that thermodynamically an ERGT with a steam-cooled turbine is a preferred option.

Thermodynamic analysis of the Option 1 cycle was extended to encompass the effects of using a fogger/humidifier at the inlet of the gas turbine. The use of the humidifier changed the inlet air condition from a temperature of $80^{\circ} \mathrm{F}$ and a $\mathrm{RH}$ of $60 \%$ to a temperature of $70^{\circ} \mathrm{F}$ and a $\mathrm{RH}$ of $100 \%$. The analysis was conducted to study the effect of the humidifier on an ERGT with an aircooled turbine and an ERGT with a steam-cooled turbine. The results indicate that installation of 
the humidifier at the inlet of the ERGT using an air-cooled turbine increases the electrical output by about $5 \%$, while the exhaust temperature is decreased by less than $1 \%$. In addition, the installation of the humidifier also increases the savings in fuel cost by an additional 3\%. All these comparisons are made for the same HP/HT heat exchanger pressure drop.

Similar comparisons made for an ERGT using a steam cooled turbine reveal that using a humidifier at the inlet of the ERGT increases the electrical output by 5\%, while the exhaust temperature drops by less than $1 \%$ and the fuel cost savings is increased by about $3 \%$.

Thus over all, installing a humidifier at the inlet of an ERGT and using steam as the turbine cooling medium increases the electrical output by at least $14 \%$ and the fuel cost savings by an additional 7\% when compared to an ERGT that uses air as a turbine cooling medium and does not have humidification equipment installed at the inlet. It can therefore be concluded that thermodynamically an ERGT with a steam-cooled turbine and a humidifier at the compressor inlet is a preferred option.

Based on the results of the thermodynamic analyses summarized above, the most favorable cycle configuration was determined to be Option 1, with air heater and combustor in series. Increasing the HP/HT Heat Exchanger exit temperature and reducing the pressure drop across the heat exchanger will help maximize the fuel cost savings. The reduction in pressure drop also increases the net electrical output, but an increase in the heat exchanger exit temperature causes the power output to reduce slightly. Of the various options considered, the most beneficial in terms of fuel cost savings and the net power output is the ERGT cycle that uses steam as the cooling medium for its turbine and has a humidifier installed at the inlet.

\section{Titan 130 Package}

Solar provided information regarding the T130 layout and installation and commissioning. These include arrangement and layout drawings of a standard T130 package and information regarding the various pumps, compression systems and cooling systems required. This information is presented in Appendix B, and was used to develop a preliminary layout (Figure 3.61) for the turbines and their utility and interface requirements in the DeRidder mill.

To minimize the time and cost required to develop an ERGT system based on the cycles discussed above, the ERGT should be developed by modifying an existing gas turbine rather than developing a completely new ERGT design. The suitability of the Titan 130 for modification to an externally recuperated configuration was therefore evaluated. Minimum modifications would include modifying the combustor and providing a passage for the airflow to and from the HP/HT heat exchanger. Candidate engines for such a modification include:

- A gas turbine that has a side mounted can combustor

- A gas turbine that has a silo combustor

- A gas turbine that has already been designed to run in a recuperated cycle

Each of these three configurations can easily support the airflow to and from the HP/HT heat exchanger. However, the present production Titan 130 gas turbine that Solar offers does not fit any of the above criteria and is unsuitable for the ERGT application in its present form. The effort required to modify the Titan 130 so that it can accommodate an ERGT cycle could be comparable to that of developing a new gas turbine. Further, given the present expected maximum heat exchanger exit temperature of $1450^{\circ} \mathrm{F}$, Solar's developmental cost to produce two turbines for the current project would more than offset any fuel cost savings. 


\section{Equipment Modifications}

An assessment was made of the state of the technologies involved in an ERGT cycle and what improvements are possible in the near term. The conclusions drawn from these assessments are presented below.

\section{Combustor}

For production engines at Solar, the combustor inlet temperatures range from approximately $690^{\circ} \mathrm{F}$ to $1250^{\circ} \mathrm{F}$. Present material and premixed combustion technology limitations hinder the design of gas turbine combustors with inlet temperatures greater than $1450^{\circ} \mathrm{F}$ and the design effort required to achieve higher inlet temperatures would be considerable.

\section{$\underline{\mathrm{HP} / \mathrm{HT} \text { Air Heater }}$}

The present study has assumed that the HP/HT air heater can be operated at a pressure drop of 30 psi and an exit air temperature of $1400^{\circ} \mathrm{F}$. With material evaluation and significant engineering effort the exit temperature most likely can be increased to $1500^{\circ} \mathrm{F}$ in the near term. However, the high pressure drop (30 psi) is incompatible with most modern gas turbines due to instability in compressor operation. To overcome this hurdle either a gas turbine that can accommodate the higher pressure drop needs to be identified or developed, or the heat exchanger pressure drop needs to be reduced below 15 psi.

Design of an entirely new gas turbine for an ERGT for the Forest Products Industry is presently not economically viable for Solar.

Reduction of the heat exchanger pressure drop poses technical, cost and practical challenges for the internal air heater in the stoker boiler, where there is normally a limited space within the furnace to fit the air heater. This is because both the surface area and volume of the air heater would have to be increased in order to reduce the airside pressure drop. This will reduce the airside velocity, which would adversely affect the convective heat transfer coefficient, causing the heat exchanger temperatures to rise. Higher metal temperatures will require improved materials to be used to maintain the useful life and operational safety of the heat exchanger.

The space constraint would be less of a problem for the external air heater, which will be a standalone heat exchanger between the gasifier and stoker boiler. There is also the option to use a firetube (hot syngas inside the tubes) design for this air heater, which would reduce the airside drop to well below 15 psi.

\section{$\underline{\text { Steam Cooled Turbine }}$}

Although the ERGT using a steam cooled turbine looks attractive, developing such a turbine cooling system was judged to be prohibitively expensive for Solar. Of particular concern for Solar were smaller gas turbines where first cost is a critical buying criterion. Solar felt the capital cost would be substantially higher than regular air-cooled gas turbines due to the complexities of the cooling circuits and control systems and that the high development and manufacturing cost of such a system would nullify the fuel cost savings seen in the cycle analysis, especially as the combustor and heat exchanger designs limit the combustor inlet temperature to $1450^{\circ} \mathrm{F}$.

This is not expected to be the case for all turbine designs and manufacturers. Steam-cooled turbines are already commercially available from several major turbine manufacturers, including GE. It should also be pointed out that steam cooling for this application could be applied to the combustor only and would be much simpler than if cooling of the vanes and blades were 
required. Finally, while steam cooling would increase the efficiency and reduce the cost of power generation, it is not a requirement for the ERGT particularly for the first demonstration engines.

\section{Alternate Turbine Selection}

The unsuitability of the Titan 130 and other Solar turbines for modification to the externally recuperated design resulted in the turbine study being expanded to include other candidate engines for development and demonstration of the ERGT. Discussions were conducted with six turbine manufacturers for this purpose, including GE, Rolls Royce, Pratt \& Whitney, Hitachi, Siemens-Westinghouse and Alstom-ABB. These discussions led to a letter of interest/proposal from Alstom Power's Industrial Turbine Division in Houston, Texas. Alstom is a global provider of advanced technology in energy and transport infrastructure and are well known for their turbine and boiler technology within the U.S. Pulp and Paper Industry.

The turbine proposed by Alstom is their GT35P, which was specifically developed for the capability to export and import combustion air and has already been applied in an externally recuperated mode. The GT35P can therefore be much more readily modified for the project than Solar's Titan 130, which has never been produced or envisioned for an externally recuperated arrangement.

Alstom's proposal was reviewed with Boise Paper Solutions to insure that the GT35P turbine would be acceptable for the DeRidder mill. With its lower turbine inlet air temperature requirement and higher power output, the GT 35P is a better match for both the project's as well as the DeRidder mill's needs. Two Alstom turbines would produce about $34 \mathrm{MW}$ of selfgenerated electrical power vs. about $28 \mathrm{MW}$ from two Solar engines. The GT 35P was therefore selected as the basis for the ERGT and power generation system development.

\subsubsection{Power Generation Process}

As discussed above, the final power generation system configuration generates $34 \mathrm{MW}$ of electrical power to increase the in-house generating capacity to approximately $82.5 \mathrm{MW}$. A simple cycle, externally recuperated gas turbine using natural gas as fuel with a heat recovery steam generator for cogeneration capability is found to be the most efficient power and steam generation system. The gas turbine parameters are:

$\begin{array}{ll}\text { No. of Gas Turbine Units } & 2 \\ \text { Type and Model } & \text { Alstom GT 35P } \\ \text { Gross Power } & 17 \mathrm{MWe} \text { each (17 MW nominal) } \\ \text { Station Auxiliary Power } & 581 \mathrm{~kW} \text { (including HRSG and GT auxiliary) } \\ \text { Net Power } & 16.42 \mathrm{MWe} \\ \text { Fuel Input } & \text { Natural Gas } \\ & 17 \mathrm{bar}(250 \mathrm{psia}) \\ & 3,972 \mathrm{~kg} / \mathrm{hr}(1.1 \mathrm{~kg} / \mathrm{sec}) \\ \text { Compressor Pressure Ratio } & 12 \\ \text { Compressor outlet temperature } & 380^{\circ} \mathrm{C}\left(661^{\circ} \mathrm{F}\right) \\ \text { Turbine inlet temperature } & 850^{\circ} \mathrm{C}\left(1562^{\circ} \mathrm{F}\right)\end{array}$


Brief descriptions of the gas turbine generator components are given in the following paragraphs.

\section{Externally Recuperated Gas Turbine}

The gas turbine is a single shaft machine and consists of an air inlet section, compressor section, combustion section and turbine section. The turbine is connected to a synchronous generator through a gear assembly.

\section{Air Inlet Section}

The amount of air intake required by a gas turbine generator is approximately 3 times that required by a reciprocating engine. The air entrance is designed to conduct incoming air to the compressor with minimum energy loss

\section{Compressor Section}

The primary function of the compressor section is to supply enough air to satisfy the requirements of the combustion burners at required pressure. The compressor must increase the pressure of the mass of air received from the air inlet duct and then discharge it to the burners in the required quantity and pressure.

A secondary function of the compressor is to supply bleed air for various purposes in the engine. The bleed air is taken from any of the various pressure stages of the compressor. The exact location of the bleed port will depend upon the external air heater pressure and temperature requirement. Varying degrees of pressure and heat are available simply by tapping into the appropriate stage.

\section{Combustion Section}

The combustion section contains the combustion chambers, igniter plugs, and fuel nozzle or fuel injectors. It is designed to burn a fuel-air mixture and to deliver combusted gases to the turbine at a temperature not exceeding the allowable limit at the turbine inlet. Theoretically, the compressor delivers 100 percent of its air by volume to the combustion chamber. However, the fuel-air mixture has a ratio of 15 parts air to 1 part fuel by weight. Approximately 25 percent of this air is used to attain the desired fuel-air ratio. The remaining 75 percent is used to form an air blanket around the burning gases and to dilute the temperature, which may reach over $2500^{\circ} \mathrm{F}$. This ensures that the turbine section will not be destroyed by excessive heat.

The air used for combustion is known as primary air; that used for cooling is secondary air. Secondary air is controlled and directed by holes and louvers in the combustion chamber liner. Igniter plugs function during starting only; they are shut off manually or automatically. Combustion is continuous and self-supporting. After engine shutdown or failure to start, a pressure-actuated valve automatically purges any remaining unburned fuel from the combustion chamber.

\section{Turbine Section}

The turbine section consists of multiple stages located immediately next to the engine burner section. Turbines extract kinetic energy from the expanding gases as the gases come from the burners. They convert this energy in to shaft horsepower to drive the compressor and the generator connected to the gas turbine through a gearbox. 


\section{Exhaust Section}

If the engine exhaust gases are discharged through an exhaust duct and expansion joint into a heat recovery steam generator. An exhaust duct is added to collect and straighten the gas flow as it comes from the turbine.

The expansion joint between the turbine exhaust duct and the HRSG relieves the stresses and prevents movement of the gas turbine or HRSG due to thermal expansion. Description of the heat recovery from the gas turbine exhaust is described in Section 3.3.6 Heat Recovery.

\subsubsection{Heat Recovery}

\subsubsection{Heat Recovery Steam Generators (HRSG)}

There will be two HRSGs, each connected to a GT35 gas turbine exhaust. Each HRSG will be an unfired, two-pressure, non-reheat, natural circulation, drum type with horizontal gas flow, complete with feedwater stop and check valves, relief valves, continuous and intermittent blowdown system, and economizer bypass. The medium pressure (MP), and the low-pressure (LP) sections will each consist of an economizer, evaporator, and superheater section.

The estimated duty of each HRSG is shown in Table 3.3.6-1.

Table 3.3.6-1 HRSG Performance

\begin{tabular}{|c|c|c|c|}
\hline Item & $\begin{array}{c}\text { Flow kg/hr } \\
\text { (lbs/hr) }\end{array}$ & $\begin{array}{c}\text { Temperature }{ }^{\mathbf{0}} \mathbf{C} \\
\left({ }^{\circ} \mathbf{F}\right)\end{array}$ & $\begin{array}{c}\text { Pressure bar } \\
(\mathbf{p s i g})\end{array}$ \\
\hline MP Steam & $23,400(51,600)$ & $369(695)$ & $18.3(250)$ \\
\hline LP Steam & $5,830(12,850)$ & $177(350)$ & $4.2(60)$ \\
\hline
\end{tabular}

The HRSGs will be designed and constructed to operate within the maximum exhaust gas flow and temperature ranges of the CGT. The HRSG will be designed for outdoor installation.

The HRSG drums and internals will be sized for the required steam separation (purity) at the predicted HRSG performance data for the minimum HRSG drum pressure. In addition, the steam drums will be designed to accommodate surges associated with startup, shutdown, and rapid load changes.

The HRSG low-pressure superheater section will be designed for "dry" operation during startup and when there is maximum low-pressure steam demand. No steam flow through the lowpressure superheater will be needed for internal cooling because the low-pressure superheater tubes will be designed for the maximum expected gas temperature.

The HRSG scope of supply includes a single $40 \mathrm{~m}(\sim 130 \mathrm{ft})$ high, $6.50 \mathrm{~m}(21.33 \mathrm{ft})$ diameter, A36 structural carbon steel stack with a divider plate at the base to accept gas flows from both HRSGs.

The HRSG will not have an integral deaerator. Steam cycle deaeration will be performed in a separate deaerator tank. The two HRSGs will share a common deaerator. 


\subsubsection{Modularization}

To reduce field erection costs, the HRSG will be modularized with the following features:

- HRSG and associated piping and platforms will be shop-fabricated to the maximum extent transportable via highway.

- The HRSG will have top-supported MP sections; the LP sections will be bottom supported.

- Gas path insulation will be ceramic fiber blanket.

Figure 3.3.6-1 provides a schematic and expected performance of a single HRSG.

\subsubsection{Balance of Plant}

Major balance-of-Plant (BOP) system required for the biomass gasification-Based Power Generation plant include:

- Cooling Water System

- Compressed Air System

- Fire Protection System

- Electrical Distribution System

- Bark Conveying and Delivery System

- Natural Gas Supply System

\subsubsection{Cooling Water System}

\section{Function and Description of the System}

The purpose of the Cooling Water System is to supply cooling water to the various plant systems. Major systems and equipment requiring cooling water include:

- Gas turbine systems components-primarily lube oil coolers

- Compressed air system components-primarily inter-cooler, after-cooler, and lube oil cooler

- Gasification system components

A schematic diagram of the Cooling Water System is shown in Figure 3.3.7-1. The cooling water system equipment will consist of an open cooling tower loop and a closed loop. The closed loop is intended for supplying cooling water to certain components requiring demineralized water. The open loop will consist of a cooling tower, circulation pumps, and associated piping and valves. The closed loop system is provided with a surge tank, cooling water pumps, heat exchanger, chemical treatment equipment, and associated piping, valves and instrumentation.

\section{Major Equipment}

\section{Cooling tower}

No. of cells -1

Type of construction - Mechanical Draft, wooden

Heat load $-4.5 \times 10^{6} \mathrm{~kJ} / \mathrm{hr}$

Circulating water $-55 \times 10^{3} \mathrm{~kg} / \mathrm{hr}, 45 \mathrm{C} / 25 \mathrm{C}$ 


\section{Cooling tower fans}

No. of fans -1

Rating - 2-speed, $25 \mathrm{~kW}, 380 \mathrm{~V}$

\section{Circulating Water Pumps}

No. of pumps - 2-100\%

Type - horizontal centrifugal

Rating $-22,500 \mathrm{~kg} / \mathrm{hr}$ at 3.5 bar of discharge pressure, each

Motor - $1500 \mathrm{rpm}, 5 \mathrm{~kW}, 380 \mathrm{~V}$ each

\section{Cooling Water Pumps}

No. of pumps $-2-100 \%$

Type - horizontal centrifugal

Rating $-22,500 \mathrm{~kg} / \mathrm{hr}$ at 7.0 bar of discharge pressure, each

Motor - $1500 \mathrm{rpm}, 10 \mathrm{~kW}, 380 \mathrm{~V}$ each

\section{Cooling Water Surge Tank}

No. of tanks - 1

Capacity $-4.5 \mathrm{~m}^{3}$

Material - carbon steel

\section{Cooling Water Heat Exchangers}

No. of heat exchangers $-2-100 \%$

Type - straight tube, double pass, shell and tube

Rating $-25,000 \mathrm{~kg} / \mathrm{hr}$ thru shell and $25,000 \mathrm{~kg} / \mathrm{hr}$ thru tubes, $2.25 \times 10^{6} \mathrm{~kJ} / \mathrm{hr}$, each

Shell side temp. and pressure $-25 \mathrm{C}$ inlet; $45 \mathrm{C}$ outlet; 2 bar

Tube side temp. and pressure $-49 \mathrm{C}$ inlet; 30C outlet; 7 bar

\subsubsection{Compressed Air System}

\section{Function and Description of the System}

The Compressed Air System supplies clean, dry, oil free compressed air for operation of the pneumatic instruments and controls. The system also supplies compressed air to the different parts of the proposed improvements for miscellaneous compressed air activities.

A schematic diagram of the Compressed Air System is shown in Figure 3.3.7-2. The compressed air system includes air compressors, air receiver, instrument air pre-filters and after filters, air dryers, air headers, control valves and instrumentation. The compressors operate on receiver air pressure signal and keep the receiver charged to $125 \mathrm{psig}$. The receiver supplies service air on demand to the service air header network throughout the plant. The instrument air from the receivers is routed through the pre-filters, air dryers and after-filters to the instrument air header network through the plant. Individual control valves and instruments, which use instrument air, include individual pressure control valves to reduce air pressure as required.

An instrument air accumulator is provided for the receiver system. This accumulator contains adequate inventory of air to operate receiver system valves and instruments up to 30 minutes. This accumulator is supplied by the instrument air header on the tower and the supply line includes a check valve to maintain sir pressure in the accumulator in the event of a loss of instrument air header pressure. 


\section{System Design Basis}

The Compressed Air System is designed to supply adequate amount of air for all the air-operated valves and instruments on a peak coincidental demand basis. The amount of service air is estimated based on the experience of this size plant.

\section{Major Equipment}

\section{Air compressor}

No. of compressors

Rating

Motor

\section{Instrument air receiver}

No. of receivers

Capacity

Design pressure

Material

\section{Instrument air accumulator}

No. of accumulators

Capacity

Design pressure

Material

\section{Instrument air pre-filter}

No. of units

Capacity

Design pressure

\section{Instrument air dryer}

No. of units

Capacity

Design pressure

Instrument air after-filter

No. of units

Capacity

Design pressure
$2-100 \%$ capacity

1,700 std. cu. m per hr, 7.0 bar each

$200 \mathrm{~kW}, 380 \mathrm{~V}$, each

1

$9.7 \mathrm{~m}^{3}$

7.0 bar, ASME Section VIII

carbon steel

1

$9.7 \mathrm{~m}^{3}$

7.0 bar, ASME Section VIII

carbon steel

$1-100 \%$ capacity set

1,700 std. cu. $\mathrm{m}$ per hr

7.0 bar, ASME Section VIII

2 - $100 \%$ capacity sets

1,700 std. cu. m per hr

7.0 bar, ASME Section VIII

$1-100 \%$ capacity set

1,700 std. cu. m per hr

7.0 bar, ASME Section VIII

\subsubsection{Fire Protection System}

\section{Function and Description of the System}

The fire protection system consists of a fire water system designed to fight both indoor and outdoor fires of a conventional nature and a FM-200 system, including FM-200 fire extinguishers, for electrical fires in enclosed areas. The entire system is designed in accordance with NFPA codes.

The fire water system is an extension of the existing fire water system at the Boise Cascade 
facility at DeRidder. It consists of a dedicated 8 inch underground main connected to the existing main and is routed throughout the proposed improvements. Off the main header, 6-inch headers are routed to the GT units, dryers, gasifier complex, and the cooling tower. The cooling tower is protected by an automatic deluge system. The gas turbine and compressor lube oil areas are protected by automatic sprinkler systems.

Fire hydrants are provided to ensure $100 \%$ fire hose (2 i inch and/or 1V2 inch) coverage of all areas with combustible material. In addition, sprinkler systems are provided to the lube oil systems areas and the cooling tower.

All electrical equipment rooms, remote electronic stations are provided with total flooding FM200 systems or FM-200 portable fire extinguishers. The FM-200 total flooding system in the equipment room is designed for concentration of 5 to 7 percent by equipment or sub-floor volume at $70^{\circ} \mathrm{F}$. The turbine generator enclosure is provided with an automatic high pressure $\mathrm{CO}_{2}$ system. This system is actuated by thermal detectors inside the generator enclosure.

\section{Major Equipment}

\section{Piping and Valves}

8 in. main header

6 in. sub-header

Stand pipes, fire hydrants, fire hose

Sprinklers

\section{Fire Suppression and Extinguishing System}

FM-200 total system or High pressure $\mathrm{CO}_{2}$ fire extinguisher system

\subsubsection{Electrical Distribution System}

This section describes the principal electrical equipment and systems, their functions, and the general criteria upon which the design will be based for the proposed Advanced GasificationBased Fuel Conversion and Electricity Production System.

\section{Interconnection to Utility}

The Boise Paper Solutions DeRidder facility is interconnected to CLECO utility transmission system through a switchyard. Currently, Boise facility does not export any power to the grid. With addition of two $17 \mathrm{MW} \mathrm{GTs,} \mathrm{there} \mathrm{is} \mathrm{potential} \mathrm{for} \mathrm{power} \mathrm{export} \mathrm{to} \mathrm{the} \mathrm{grid.} \mathrm{This} \mathrm{will}$ require additional metering, protection, and controls to the existing switchyard and electrical system.

The Electrical Single Line Diagram is shown in Figure 3.3.7-3. The main step-up transformers for the GTs will be added to the power block and connected to the switchyard HV power circuit breakers by overhead lines. The HV-side potential transformers (PTs) and current transformers (CTs) required for metering, protective relaying, and generator synchronizing will have to be installed as part of the requirement for the interconnection to the Utility.

\section{Gas Turbine System}

Electric power will be generated by two 17 MW GT 35 Alstom turbines with a rated voltage of $15 \mathrm{kV}$. Generator output will be connected to the step-up transformer by a $17.5 \mathrm{kV}$ isolated phase bus. Power will be transmitted to the plant utility system through the facility's HV switchyard. 
The switchyard HV circuit breakers will be controlled from the control room via the DCS. Utility dispatch control interfaces will be provided if required by CLECO.

\section{Auxiliary Power}

Per DeRidder Plant Operations, there is no spare power available from the station service transformer for the new gasification and gas turbine system. One two-winding wye-wye 132 $\mathrm{kV} / 4.16 \mathrm{kV}$ station service transformer will be provided rated to supply startup and normal operating power requirements to all new installations.

Distribution system power will be supplied from NEMA Class E2 $4.16 \mathrm{kV}$ latched contactors so that the electrical auxiliary power distribution system will not require operator intervention to restore power to the system in case of a system disturbance. LV switchgear will be fed from 4.16 $\mathrm{kV} / 480 \mathrm{~V}$ pad-mounted oil-filled transformers. Power circuit breakers will be used to supply $480 \mathrm{~V}$ motor control center (MCC) buses. All $480 \mathrm{~V}$ loads will be supplied from $480 \mathrm{~V} \mathrm{MCC}$ buses.

\section{Emergency Power}

In case of a total loss of auxiliary power, or in situations when the utility system is out of service, emergency power for generator critical loads such as the turbine lubricating oil system and for common critical loads such as the DCS will be supplied from a $125 \mathrm{~V}$ de stationary battery.

\section{Power Transformers}

The main step-up transformer of each generator will be a $15 \mathrm{kV} / 138 \mathrm{kV}$, two-winding, delta-wye $\mathrm{OA} / \mathrm{FA} / \mathrm{FA}$ transformer. The station service transformer will be a separate $3.3 \mathrm{kV} / 132 \mathrm{kV}$, twowinding, wye-wye, OA/FA transformer. Final HV nominal ratings for the transformers will be selected based on the specific utility system parameters. Each main transformer will be provided with metal oxide surge arresters located adjacent to the HV terminals. The main step-up transformers will be oil cooled and have an air cell conservator system. Accessories will include a magnetic liquid level gauge, dial thermometer, winding temperature equipment, pressure relief device, sudden pressure relay, and bushing-mounted current transformers. The rating of the main step-up transformer will not limit the respective GT 35 turbine generator rated output at 0.85 lagging and 0.9 leading power factors and design conditions.

\section{Medium and Low Voltage Switchgear and Motor Control Center (MCC)}

The $4.16 \mathrm{kV}$ switchgear/MCC assembly will be located indoors, will use vacuum interrupters, and will be rated to distribute the full output of the unit auxiliary transformer. The switchgear portion of the assembly will contain the incoming power circuit breaker and feeder breaker for the generator static start system. The switchgear circuit breakers will be electrically operated and have a stored energy mechanism. The switchgear will be bus-connected to the medium voltage MCC (MV-MCC) using a transition cubicle. Each HV compartment in the MV-MCC will contain an externally operated no-load isolating switch, current limiting fuses, slide-out contactor assembly with vacuum interrupters, and control power transformer.

The $480 \mathrm{~V}$ load centers will be single-ended, rated $480 \mathrm{~V}$, three-phase, three-wire. Each will be supplied from a solidly grounded delta-wye, $4.16 \mathrm{kV} / 480 \mathrm{~V}$, oil-cooled transformer. The load centers will use manually operated air-break power circuit breakers. Each power circuit breaker will have a solid-state trip device. Bus volts, incoming amperes, and individual feeder amperes will be displayed on analog meters mounted on the front of the load centers. The load centers will supply power to $480 \mathrm{~V}$ MCCs and $480 \mathrm{~V}$ panel boards. 


\section{Volt Motor Control Centers}

MCCs will be rated $480 \mathrm{~V}$, three-phase, three-wire and will supply $480 \mathrm{~V}$ non-motor loads, motors rated $480 \mathrm{~V}$ from $1 \mathrm{hp}$ up to and including $175 \mathrm{hp}$, and lighting and distribution panel transformers. Thermal-magnetic molded-case circuit breakers will be used for non-motor loads. Each motor starter will consist of a three-pole magnetic-only molded-case circuit breaker, threephase overload relay with heater elements, three-pole contactor, and control power transformer. Indicating lights will be mounted on the front of each motor starter compartment door. MCCmounted 480/220 V three-phase, four-wire panel boards will be used to supply power to space heaters and small power loads associated with facility power production processes. MCCs will consist of vertical sections joined together to form rigid, freestanding assemblies. MCCs located outdoors will be installed in supplemental weather-resistant enclosures.

\section{Volt DC System}

The $125 \mathrm{~V}$ dc system will consist of a bank of batteries with static battery chargers, a switchboard, and a panel board. This system will supply dc power to the generator, DCS, switchgear, protection relay panels, and other critical dc loads. DC power to the generator and its auxiliaries will be supplied from a battery and two chargers provided by the supplier as a part of the generator scope of supply.

\section{Uninterruptible Power Supply System}

One solid-state uninterruptible power supply (UPS) will supply $220 \mathrm{~V}$ ac single-phase critical AC loads. The DCS operator stations will be supplied UPS ac; the power requirements for the DCS controllers and I/O will be met using DC/AC/UPS power as required. The UPS system will include an inverter, constant voltage transformer (CVT), static transfer switch, manual bypass switch, and panel board and will be provided as part of the generator scope.

\section{Electrical Protection, Metering, and Controls}

Protective relaying, metering, and instruments will be provided for proper interface and operation and to monitor equipment performance.

Protective Relaying. Protective devices will be coordinated to the extent possible so that electrical disturbances (fault, overload, etc.) are interrupted at the point nearest the fault, with the next upstream protective device providing backup protection. Ground fault protective devices will trip the respective breaker or starter. Protective devices will operate through a lockout relay (86) or equivalent device or circuit to prevent automatic restart/reclose of the equipment.

Protective devices will be rated for the maximum available fault current.

Current sensing relays will be the drawout case type to permit testing and calibration without disrupting the current transformer secondary circuit.

Metering. Shorting-type terminal blocks will be provided to allow instruments to be removed without disrupting current transformer circuits.

Relaying class accuracy for voltage and current transformers will be considered adequate for panel meter applications.

Controls. The generator will be synchronized automatically through its synchronizing system, which is included as part of the generator package. The synchronizing system will control turbine speed/generator frequency, generator voltage, and breaker closure. 
The incoming and static start circuit breakers on the $4.16 \mathrm{kV}$ bus will be controlled through the DCS and by locally (switchgear) mounted, four-position, pull-to-lock hand switches.

Breakers and starters that control process loads will be controlled from the control room. Equipment such as HVAC, air compressor, sump pumps, CEMS, etc., will be locally controlled only, with no control room control. Only single composite equipment alarms are included.

The $4.16 \mathrm{kV}$ latched contactors to load center transformers will be controlled locally.

The distribution system control will be local and not expected to be operated from the control room. Should a breaker trip, the operator will go to the breaker front to identify the cause, correct the problem, and reset/reclose.

The $400 \mathrm{~V}$ load center incoming and feeder breakers to transformers, panels, and MCCs will be controlled locally at the breakers.

Motor feeders will be controlled either through the DCS or an independent process controller. No locally mounted control will be included at the starter or at the motor location. Motor running/stopped indication will be provided at the MCC.

\section{Electrical Design Criteria/General Requirements}

\section{General}

The electrical systems, equipment, materials, and their installation will be designed in accordance with applicable industry codes and standards; local, state, and federal regulations; project design criteria; and other requirements as specified in this section.

The following general criteria will be used in designing the electrical system:

- Utility voltage variation maximum is \pm 5 percent of nominal $\mathrm{kV}$.

- Utility frequency variation maximum is \pm 0.5 percent of $60 \mathrm{~Hz}$.

- Utility available short-circuit is "infinite" for auxiliary distribution system bus rating.

- Utility actual available short-circuit is used for ground grid sizing and HV equipment ratings.

- Phase rotation is A-B-C counterclockwise.

- Equipment short-circuit ratings are based on the maximum available under all operating conditions. No additional margin is provided unless inherent in the final equipment selection.

- Equipment basic insulation levels (BILs) will be ANSI standard:

- Electrical clearances are per the National Electrical Safety Code, ANSI C2.

No security system or equipment is provided.

\section{Motors}

Motors will be the squirrel-cage induction type suitable for full voltage, across-the-line starting. Enclosures will be weather-protected Type II (outdoor), open drip-proof (indoor), or totally enclosed fan cooled (TEFC), as required for the specific application. Motors will be rated to provide at least 5 percent margin between the required driven load brake horsepower (bhp) and motor rated horsepower at a service factor of 1.0. Where the 5 percent margin would require 
using the next larger size motor, an allowable option is to provide a 1.15 service factor motor. Credit will not be taken for service factor capability above 1.0 for steady-state operating conditions.

Motors rated 3/4 to $175 \mathrm{hp}$ and fractional horsepower reversing motors (e.g., motor-operated valves) will be rated $480 \mathrm{~V}$. Motors $1 / 2 \mathrm{hp}$ and smaller will be rated $220 \mathrm{~V}$ ac. DC motors will be rated for $220 \mathrm{~V}$ or $215 \mathrm{~V}$, as required by the specific application.

Motors rated $25 \mathrm{hp}$ and above for use in outdoor applications other than HVAC will be provided with space heaters to prevent condensation formation during nonoperational periods. The power for space heaters will be provided from MCC distribution panelboards or control power transformers rated for the space heater.

\section{Grounding, Cathodic Protection, and Lightning Protection}

The facility grounding system will consist of buried stranded copper conductors and ground rods, as required. The grounding system design will be based on a maximum available fault current of $20,000 \mathrm{~A}$ in the switchyard. Fault duration will be considered to be 20 cycles. Credit will be taken for parallel paths, for multiple connections to equipment, and for fault current returning to the remote sources via transmission line static wires. Compression-type connectors that meet the requirements of IEEE 837 will be used for the buried connections.

Equipment and electrical systems in the power block will be grounded in accordance with the National Electrical Code (NEC).

Equipment grounding is planned to be in accordance with the NEC. Cable tray will be grounded by the tray itself. RSG conduit is self-grounding, and duct banks/trench should use a single conductor per run. The DCS and its I/O cabinets are to have the equipment and the signal circuits grounded at the cabinet location. The use of data highway obviates the need for a "tree"-type grounding system.

Because of the potential hazard should a leak develop, cathodic protection will be provided for the buried coated carbon steel natural gas pipes. Cathodic protection will not be included for any other buried pipe. If the site's soil resistivity is less than $200 \mathrm{ohm}-\mathrm{meter}$; then, cathodic protection will be provided for all buried coated carbon steel pipes.

Lightning protection for buildings and structures will be generally in accordance with NFPA 780. Lightning protection will be provided by a single ionization-type preventor

\section{Lighting Systems}

The existing DeRidder plant Lighting system will be used.

\subsubsection{Bark Conveying and Delivery System}

\section{Function and Description of the System}

The bark conveying and delivery system is shown in Figure 3.3.7-4 and is described below. Bark is currently delivered from the woodyard to No. 2 Boiler via an existing conveyor. In the proposed design this conveyor will be integrated with additional conveying, drying and screening equipment in a stepwise fashion as follows:

Implementation Step 1 - In this step, only the bark for the gasifier is dried. Wet bark from storage is carried on the existing conveyor up to junction box \#14. The junction box separates the bark into two streams. One stream continues on the existing conveyor leading to No.2 boiler. The 
second stream transports the bark to be dried for the gasifier, with the help of a conveyor, to dryer \#1. Dried bark is then transported to junction box \#15 linking the existing conveyor leading to No. 2 boiler. This junction box is located downstream of junction box \#14. Junction box \#15 then separates the dried bark into two streams. Most of the dried bark is transported (on demand from the gasifier metering bin) to a screening and sizing machine, where it is first shredded for size reduction and then screened to separate out oversize and rejects unsuitable for the gasifier. The oversize bark is conveyed back to the existing conveyor leading to No.2 boiler. The oversize material may also be recycled back for re-shredding and re-screening. The dried, sized bark is fed to the gasifier metering bin. In the event that the gasifier metering bin is approaching a full condition, junction box 15 will divert the dried bark flow back to the existing conveyor leading to No. 2 boiler, and the dryer will be throttled back to minimum-throughput hot standby operation until demand for fuel from the gasifier system is restored..

Implementation Steps $2 \& 3$ - In these steps, the entire quantity of bark is dried using dryers \#1 and \#2. Wet bark from storage is carried on the existing conveyor up to junction box \#14. The junction box then diverts the entire quantity of bark to the dryers. Dried bark is then transported to junction box \#15, which splits the dried bark flow as necessary to meet the gasifier and boiler bark demands. Operation of the screening/sizing system and transport to the gasifier metering bin is as described in Step1. In the event that one dryer is out of service, the dried and wet bark streams will be routed as in Step 1. In the event that both dryers are out of service, bark to the gasifier metering bin is stopped and wet bark is routed through junction box 14 on the existing conveyor to No. 2 boiler.

Metering and Feeding to Gasifier. Bark for the gasifier is fed in to two vibrating hoppers each with a variable opening gate. The gates allow the bark to drop to two conveyor belts. The two conveyor belts transfer the bark to two metering bins for weighing and finally feeding the gasifier.

\subsubsection{Natural Gas Supply System}

\section{Function and Description of the System}

As described in Section 3.2, Plant Description, additional electricity is generated on-site using externally recuperated gas turbine generators. Natural gas provides about $2 / 3$ of the heat required for the gas turbine generators. Estimated gas requirement is approximately $80,000 \mathrm{cf} / \mathrm{hr}$ per gas turbine.

Pressurized natural gas is supplied to the gas turbines with the help two multi-stage compressors, one for each gas turbine. Supply of natural gas to the compressors is from an on-site metering station located approximately $1 \mathrm{~km}$ from the compressors. Gas would be supplied at 4.5 bar. through a $7.5 \mathrm{~cm}$ diameter pipeline.

\section{Design Conditions:}

Inlet Gas Pressure: 4.5 bar

Discharge Gas Pressure: 18 bar

\section{Natural Gas compressor}

No. of compressors

Type of compressor Equivalent of ARIEL JGH4 four throw double acting compressor with aircooled lubricated cylinders and packing.
Rating
6,000 std. cu. m per hr, $890 \mathrm{rpm}$, each
Motor
$350 \mathrm{~kW}, 4000 \mathrm{~V}$, each 


\section{Compressor Accessories}

Inlet scrubber with automatic liquid discharge controls, Lubrication system, variable volume clearance pockets, for the first stage cylinders, duplex oil filter, vibration transmitter, oil temperature RTD, and oil pressure transmitter.

Inter-stage scrubber with automatic liquid discharge controls

Air-cooled heat exchanger for inter-stage gas cooling, discharge gas cooling, and compressor oil cooling with electric motor driven fan, hot dip galvanized structure, and vibration transmitter.

Coalescing filter/discharge scrubber with automatic liquid discharge controls.

Fabricated steel skid base with 1/4' thick raised pattern floor plate, concrete fill beneath the compressor $\&$ driver, and machined mounting surfaces for the compressor $\&$ driver.

Piping assembly with welded \& flanged connections for 2" pipe size and larger per ASME/ANSI B 31.3. Piping 1-1/2" size and smaller would be XH A-106B threaded with 2000\# forged steel fittings. The piping assembly will include a class 150 cast steel gate valve inlet gas isolating valve, a Norriseal Controls cast steel Class 300 discharge piston check valve, a 1" manual blow down valve, a 1" Kimray 1400 SMT automatic discharge pressure control valve, and a class 300 cast steel discharge gate valve isolating valve.

PLC control panel with an Allen-Bradley SLC-500 PLC and PanelView 1000 HMI. The control panel would be mounted on the compressor skid and would be assembled from components UL Listed or CSA Certified for a Class 1, Division 2 hazardous area.

\subsubsection{Construction Schedule}

A preliminary plant construction schedule is developed and presented in Figure 3.3.8-1. The objective of the preliminary schedule is to:

- Estimate the total duration required for implementing the project

- Identify the long lead time items

The schedule shows the time needed for implementing Step 1 of the project. Schedules for Steps 2 and 3 are not shown as the initiation of these two steps are not known in relation to Step 1.

Since all the major equipment of Steps 2 and 3 are duplicates of those of Step 1, it may be stated with a first order approximation that construction schedule for Steps 2 and 3 equipment will be similar to that of Step 1 equipment.

The unique features of the construction schedule are discussed in the following paragraphs.

The overall schedule for the plant is estimated to be twenty-seven months including design, engineering, fabrication, procurement, installation, start-up, testing and commissioning. One notable exception is the time required for development of gas turbines. Development of turbines will necessarily have to precede the schedule indicated above. This development duration is not known yet. The schedule is somewhat conservative to ensure minimum interruption of the operation of the existing plant.

Gasification plant equipment items comprise the longest lead-time items. Design, engineering, fabrication, and procurement will require 18 months. Installation of this equipment will need 9 months. However, there will be an overlap of three months with fabrication schedule. Thus the effective schedule for the gasification equipment is 24 months. 
Schedule for all the remaining equipment is enveloped by the schedule for gasification plant equipment as shown in Figure 3.3.8-1.

Schedule for start-up, testing and commissioning is conservatively estimated to be three months. However, it is likely that this duration can be shortened somewhat.

\subsection{PLANT OPERATION}

The purpose of this section is to provide guidelines for the startup, operation, and shutdown and emergency steps during major upset conditions of major systems and components that will be installed at the DeRidder plant. These guidelines do not substitute for detailed operating procedures and required operator training to be conducted prior to commissioning of the facility.

The major systems and components of the proposed facility are:

- External Air Heater AH-1

- Internal Air Heater AH-3

- Bark Dryer System

- Gasifier

- Gas Turbine Generator

- Dual Pressure Heat Recovery Steam Generator System

- Plant Auxiliaries Systems

These systems will be integrated with the existing bark boiler, DeRidder plant steam and electrical systems. However, each of the dryer, gasifier, gas turbine and HRSG will have its own control systems and will be operated independently but in conjunction with the rest of facilities at DeRidder plant.

\section{Bark Dryer System}

The bark dryer system is described in Section 3.2.1. Specific dryer startup and operation will be per dryer vendor procedures.

\section{Gasification Plant Control And Operation}

Control Philosophy: The Gasification Plant will be operated on load control. The main control functions of the gasifier are described below.

\section{Gasifier Load Control}

The Gasification Plant load is controlled by changing fuel feed rate. The changing fuel feed rate will vary the airflow to the gasifier according to the preset fuel/air ratio.

\section{Gasifier Temperature Control}

The gasifier bed temperature indicates the fuel/air ratio in the gasifier. Increasing temperature in the fluidized bed indicates higher airflow than required, decreasing temperature indicates less airflow than required. The temperature control adjusts the gasification airflow to compensate the fluctuations of the fuel quality and to keep the set value of the bed temperature.

\section{Air Feed Control}

The gasifier control system calculates the set values for the total airflow based on the fuel/air ratio set value. The total airflow is distributed then to the grid and ash removal pipe. The grid airflow maintains fluidization; the ash removal airflow controls bed material and ash removal 
from the bed area. Mixed with the air supplies also steam can be fed to the gasifier through the grid and with the ash removal air in case of excess temperatures, but not required for operation at design conditions.

The ash removal airflow is calculated by the gasifier control system based on the bed conditions (bed height or density) and ash removal pipe temperature.

\section{Product Gas Pressure Control}

The pressure control valve before the product gas injection to the boiler controls the gasifier gas pressure. This valve will keep the pressure at the required 15.2 psia / 1.05 bara pressure. When load changes the airflow and gasifier pressure will vary accordingly.

\section{Product Gas Temperature Control}

Water injection in the product gas line or adjusting the combustion air floe to the syngas combustor are used to control the product gas temperature to $\mathrm{AH}-1$.

\section{Internal Air heater AH-3 Operation}

Air Flow will be started to AH-3 from the Gas Turbine GT-2 compressor by starting GT-2 on natural gas prior to starting No. 2 Power Boiler. As the boiler comes online and more heat is available from AH-3, natural gas flow to the GT-2 combustor will be reduced accordingly. In the event that GT-2 must be taken offline while the boiler is operating, sufficient air is available from GT-1 to satisfy the air requirements of both AH-1 and AH-3. In this event, the natural gas flow to the GT-1 combustor will be further reduced to maintain the required turbine inlet temperature.

\section{External Air Heater AH-1 Operation}

Air flow will be started to AH-1 from the Gas Turbine GT-1 compressor by starting GT-1 on natural gas prior to gasifier startup. As the gasifier comes online and more heat is available from AH-1, natural gas flow to the GT-1 combustor will be reduced accordingly. In the event that GT-1 must be taken offline while the gasifier is operating, sufficient air is available from GT-2 to satisfy the air requirements of both $\mathrm{AH}-3$ and $\mathrm{AH}-1$. In this event, the natural gas flow to the GT-2 combustor will be further reduced to maintain the required turbine inlet temperature.

\section{Gasification Plant Operation}

The Gasification Plant can be operated with all syngas to the flare for brief periods when the Stoker boiler goes off-line but must have air flow to AH-1. Gasification Plant operation also requires auxiliaries like electrical, power, cooling water, etc.

Gasification Plant operation includes the following procedures:

- Start-up

- Shutdown

- Full load operation

- Part load operation

- Load changes

\section{Gasification Plant Start-Up Sequence}

The Gasification Plant start-up sequence includes the following steps: 
- The gasifier is in cold, ready-to-start condition.

- Air will be supplied to the gasifier through the start-up heater pressure vessel.

- Gasifier start-up heater burning natural gas is in ready-to-start condition.

- Gas cooler air is supplied by the gas turbine.

- Start-up-heater start at 50\% capacity. The flue gas is flared.

- Start-up heater in continuous operation with increased capacity. Bed material will be fed to the gasifier.

- Gasifier temperature is raised to the level where fuel feed is reasonable. Fuel feed starts.

- Heating is continued. Ignition of fuel occurs.

- Shifting from combustion to gasification after fuel ignition. The product gas is flared.

- Start-up heater shutdown.

- Fuel feed is gradually increased.

- Gasifier operating at full pressure and temperature at minimum load.

- Gasifier load increased from minimum load to full load.

\section{Gasification Plant Shutdown Sequence}

The controlled shutdown of the Gasification Plant includes the following steps:

- Gasifier full load reduced to minimum load.

- At minimum load product gas will be switched from boiler to flare.

- Gasifier pressure and load reduced, sufficient bed removal established.

- Gasification air replaced with steam and inert gas. Continuous bed removal.

\section{Gasification Plant Base Load Operation}

At base load operation the Gasification Plant is operated according to load control.

\section{Gasification Plant Load Changes and Part Load Operation}

The fluidization velocity limits the part load operation of the Gasification Plant to a minimum gasifier load of about $50 \%$. When changing the load from full load to part load, the fuel input to the gasifier decreases proportionally with decreasing air feed, according to the product gas set point.

\section{Gas Turbine Operation}

The gas turbine generator startup operation is a single step operator initiated action. This can be achieved through a local start at the GT control panel or through control room DCS operation. The start command will work when all the required prerequisite, such as combustor temperature, lube oil pressure and temperature conditions, time delay since last start, HRSG drum level, feedwater pump operation, etc. are satisfied. The turbine will go through the normal purge, speedup, fuel injection and fire sequence and arrive at no load status. Once the gas turbine has achieved stable speed, it is ready for generator synchronization. This is also operator-initiated action, achieved through closure of the generator breaker. After generator synchronization, the gas turbine load can be increased manually or through a pre-set load curve to a desired level.

The two gas turbines are completely independent and have independent controls and startup system. Hence, the turbine operation described here is same for both turbines. 


\section{Operating Procedure For Abnormal Conditions}

No Start. If it is noted during a start procedure that a no light off is indicated within 10 seconds after fuel is applied, the start procedure should be discontinued.

Before attempting a second start, dry motor the turbine for 60 seconds for purging the engine.

If the second start attempt fails, no further start attempt should be made before the cause of the start failure has been determined and corrected.

If the failure to start is attributed to either ignition system, it should be recorded, investigated and remedied at the earliest opportunity.

Unsatisfactory Starts. If an unsatisfactory start should occur, it will most likely be accompanied by one of the following conditions:

A. Hot Starts. A potential hot start is indicated by an abnormally rapid exhaust gas temperature (EGT) rise after light off. By monitoring fuel flow and EGT, a hot start can be anticipated before the $725 \mathrm{C}$ limit is exceeded.

Hot Starts may be caused by:

- Inadequate starter air pressure, resulting in low compressor airflow.

- Faulty starter valve action, preventing proper operation of starter, with same result as item (a)

- Premature starter deactivation

- Incomplete purging of fuel in the combustion chamber from the previous start attempt. Faulty pressurizing valve (hung open) resulting in fuel, under low pressure.

- Faulty turbine control resulting in incorrect sequence scheduling.

- Incorrect scheduling of Inlet Vane Guide (IGV)

B. Hung Starts. A hung start is identified by light off followed by abnormally slow acceleration and rpm stabilization below idle. A hung start may be result of fuel scheduling being either too lean or too rich. A lean hung start is associated with low fuel flow and proportionally low EGT. A rich condition can be recognized by a high fuel flow and an EGT rise, which may tend to develop into an over-temperature condition and possible compressor stall.

Oil System Malfunction. Exercise caution when operating a turbine with oil pressure outside the normal pressure range. Oil pressure fluctuations, or pressure shifts exceeding $+/-5 \mathrm{psid}$ (69kpa diff.) is cause for investigation.

\section{Turbine Malfunction}

A. the turbine should be shutdown as soon as possible after discovery of a serious malfunction. Severe damage to the turbine can result if turbine operation is continued with a critical deficiency. The longer the delay between detection of a malfunction and turbine shutdown, the more severe will be the resulting damage.

B. The following indications should be recognized as symptoms of a serious turbine malfunction and/or impending failure:

- An increase in turbine vibration accompanied by higher than normal EGT or fuel flow.

- Repeated or uncontrollable turbine stalls.

- Loss of thrust. 
- A shift in turbine parameters, or in the relationship of one parameter to another during steady state operation.

- Oil pressure increase or decrease of $+/-5$ psi or more from the normal steady state operating pressure, and/or an increase in oil temperature, or indications of oil filter bypass.

- Any combination of the foregoing symptoms.

Emergency Operating Procedure

\section{Turbine fire}

Internal Turbine Fire. An internal turbine fire may be evidenced by failure of EGT to decrease after turning the fuel off (post shutdown burning). In such case, the turbine should be isolated from the fuel supply. If the fire cannot be extinguished by motoring the turbine or if motoring is not possible, close the fuel shutoff valve and extinguish the fire with fire fighting equipment.

External Turbine Fire: An external turbine fire will be indicated by the fire warning system. The automatic fire retardant system will be activated and the turbine will be shutdown.

\section{Turbine Failure/Malfunction}

A malfunctioning turbine is evidenced by abnormal turbine parameters, noise or vibration. Continued operation with a known turbine malfunction may lead to turbine failure. In the event of an actual or impending failure, the turbine should be shutdown by turning the fuel and ignition off. If the turbine operates normally at idle, it should be allowed to idle for 3 minutes prior to shutdown if practical. Restart attempts without through investigation are not advisable, as further damage may result.

\section{Heat Recovery Steam Generator Operation}

Heat recovery steam generator (HRSG) operates with the associated gas turbine. The standard boiler controls for feedwater, drum level and boiler pressure control the HRSG operation. The HRSGs are dual pressure/ dual drum. Medium and low-pressure steam generated in the HRSG is tied into respective steam headers in the plant.

During startup, HRSG drum level is kept at low level and vents are kept open. The heat from the GT exhaust is transferred in the HRSG to make steam. When drum pressure rises to 10-15 psig, high point vents on the HRSG and steam lines are closed and steam is fed to the steam headers.

When HRSG drum level falls below low-low level, the master control will trip the GT. Restart of the HRSG and GT is achieved by re-establishing the water level and going through the turbine start sequence as described above. 


\subsection{PLANT PERFORMANCE}

This section summarizes the overall plant performance of the advanced gasification-based power system.

\subsubsection{Feed/Product Summary}

The overall energy a performance of the modified plant is summarized in comparison to current mill operations in Table 3.5.1-1. The current mill case considers fuel feed to and products from No. 2 Boiler and other gas fired boilers on site as required to match the modified plant steam output. The Step 1, 2, and 3 cases consider fuel feed and products information for the modified plant, including the boiler, gasifier, dryer, ERGTs, and HRSGs. Current mill performance is derived from mill data for No. 2 boiler averaged over a one-year period ending in May 2003. Fuel and products/emissions data for the modified plant is given for all 3 implementation steps.

Table 3.5.1-1 Baseline and Modified Plant Performance Comparison

\begin{tabular}{|c|c|c|c|c|c|}
\hline \multirow[b]{2}{*}{ Input/Outputs } & \multirow[b]{2}{*}{ Units } & \multirow{2}{*}{$\begin{array}{c}\text { Current } \\
\text { No. } 2 \text { Boiler }\end{array}$} & \multicolumn{3}{|c|}{ Modified Plant } \\
\hline & & & Step 1 & Step 2 & Step 3 \\
\hline Heat Input to Gasifier & MMBtu/h & 0.0 & 180.5 & 180.5 & 180.5 \\
\hline Heat Input to Boiler & MMBtu/h & 313.0 & 378.7 & 354.0 & 436.0 \\
\hline Total Heat Input to Boiler + Gasifier & MMBtu/h & 313.0 & 414.8 & 390.1 & 472.1 \\
\hline Bark Heat Input to Gasifier & MMBtu/h & 0.0 & 180.5 & 180.5 & 180.5 \\
\hline Bark Heat Input to Boiler & MMBtu/h & 204.4 & 234.3 & 209.6 & 291.6 \\
\hline Total Bark Heat Input & MMBtu/h & 204.4 & 414.8 & 390.1 & 472.1 \\
\hline Natural Gas Heat Input to Boiler & MMBtu/h & 108.6 & 0 & 0 & 0 \\
\hline Natural Gas Heat Input to ERGT & MMBtu/h & 0.0 & 143.3 & 143.3 & 266.6 \\
\hline Nat. Gas Heat Input to Bark Dryer & MMBtu/h & 0.0 & 6.7 & 0.0 & 0.0 \\
\hline Nat. Gas Heat Input to Other Boilers & MMBtu/h & $* 164.0(267.4)$ & 0.0 & 0.0 & 0.0 \\
\hline Total Natural Gas Heat Input & MMBtu/h & $* 272.6(376.0)$ & 150.0 & 143.3 & 266.6 \\
\hline Steam Produced From No. 2 PB & $\mathrm{Klb} / \mathrm{h}$ & 212.5 & 250.0 & 250.0 & 250.0 \\
\hline Steam Produced from HRSGs & $\mathrm{Klb} / \mathrm{h}$ & 0.0 & 64.5 & 64.5 & 128.9 \\
\hline Steam Produced From Other PBs & $\mathrm{Klb} / \mathrm{h}$ & $* 102(166.5)$ & 0.0 & 0.0 & 0.0 \\
\hline Total Steam Produced & $\mathrm{Klb} / \mathrm{h}$ & $* 314.5(378.9)$ & 314.5 & 314.5 & 378.9 \\
\hline Electricity Produced from Bark Steam & MW & 7.5 & 12.7 & 12.7 & 12.7 \\
\hline Electricity Produced from Gas Steam & MW & 3.3 & 0.0 & 0.0 & 0.0 \\
\hline Electricity Produced from ERGT & MW & 0.0 & 17.0 & 17.0 & 34.0 \\
\hline Total Electricity Produced & MW & 10.8 & 29.7 & 29.7 & 46.7 \\
\hline
\end{tabular}

*For steam production equivalent to the modified plant in Steps 1\&2 (Step 3) 
The primary objectives of the project are to increase woodwaste (bark) utilization, decrease fossil fuel use, and increase self-generated power in the mill. It can be seen from Table 3.5.1-1 that bark utilization in all cases for the modified plant is significantly higher (90-130\%) than current operation. For equivalent steam production, the total natural gas usage for the modified plant is in all cases lower than current operation. For Implementation Steps 1 and 2 gas usage is reduced by $45-47 \%$ and for Step 3 by $29 \%$. While the current average steam production from No. 2 Boiler is about $213,000 \mathrm{lb} / \mathrm{h}$, the combined steam production from the boiler and HRSGs will be about 315,000 lb/h for Steps 1 and 2 and 472,000 lb/h in Step 3. In Step 3 this steam production increase will be accomplished at a GHRR equal to the original boiler design. Finally, Selfgenerated electricity will be increased from the $10.8 \mathrm{MW}$ currently attributable to No.2 Boiler to 29.7MW in Steps 1 and 2 and 46.7MW in Step 3, increases of 175\% and 332\%, respectively.

\subsubsection{Efficiencies}

The design efficiency of No. 2 Boiler (heat to generate and superheat steam $\div$ total heat input to the boiler) is $70 \%$. Calculated boiler efficiencies for the modified plant in Steps 1 and 2 (steam) and Step 3 (cogeneration-steam plus air) are 74.2, 79.4 and 78.9, respectively due to a combination of factors:

- improved carbon burnout in the boiler through partial combustion of a portion of the bark in the gasifier before the boiler, which reduces combustion at the grate back to below its original design value of $813,000 \mathrm{Btu} / \mathrm{hr}-\mathrm{ft}^{2}$

- operation of the boiler with lower excess air as a result of improved fuel and combustion air staging

- Feeding 20\% moisture bark to the boiler instead of $52.5 \%$, using more high level heat within the boiler for heating steam and air for power generation rather than vaporizing water from the fuel

For the fully implemented case in Step 3, the thermal efficiency of fuel to electricity conversion is $79.8 \%$ in the cogeneration mode, $5 \%$ above the project goal of $75 \%$.

\subsubsection{Emissions Inventory}

\subsubsection{Upgrading and Modifying the Existing \#2 Bark Boiler}

Under the proposed project the existing facility will be modified and or upgraded. Under the current regulations, a construction air permit will be required in accordance with 40 CFR Part 51 (Best Available Retrofit Technology, BART).

Also, the boiler may have to comply with the current limits as well as conduct a new source review/PSD review in order to determine if a net increase in emissions is significant; that is, above certain thresholds for any of the six criteria pollutants listed in the PSD rule. This option could trigger PSD permitting, which would require a Best Available Control Technology analysis to determine appropriate pollution control retrofits.

Table 3.5.3-1 lists existing permit conditions for the \#2 Bark Boiler. 
Table 3.5.3-1: \#2 Bark Boiler Data

\begin{tabular}{|l|c|c|}
\hline \multicolumn{1}{|c|}{ Item } & Units & \\
\hline Heat Input & MMBtu/hr & 454.29 \\
\hline Bark Input & MMBtu/hr & 454.29 \\
\hline Nat. Gas Input & MMBtu/hr & 262 \\
\hline Boiler Fuel & & Bark \\
\hline & & \\
\hline Stack Gas Flow & $\mathrm{Cu} . \mathrm{Ft} . / \mathrm{Min}$ & $198,000.00$ \\
\hline Stack Temp & Deg F & 155.90 \\
\hline Stack Exit Velocity & $\mathrm{ft} / \mathrm{sec}$ & 46.50 \\
\hline Stack Diameter & $\mathrm{Ft}$. & 9.50 \\
\hline Stack Height & $\mathrm{Ft}$ & 178.15 \\
\hline
\end{tabular}

Table 3.5.3-2: \#2 Bark Boiler Air Permit*

\begin{tabular}{|l|c|c|c|}
\hline & Average & Max & Avg. \\
\hline & lbs/hr & lbs/hr & lbs/MMBtu \\
\hline PM-10 & 26.20 & 26.20 & 0.06 \\
\hline SO2 & 138.88 & 148.37 & 0.31 \\
\hline NOx & 71.73 & 72.01 & 0.16 \\
\hline CO & 149.92 & 149.92 & 0.33 \\
\hline VOC & 43.36 & 43.49 & 0.10 \\
\hline Lead & 0.03 & 0.03 & 0.00 \\
\hline
\end{tabular}

* These emissions are based on the current maximum heat input capacity of the boilers and single point source permit for source ID 79-01 - \#2 Bark boiler.

\subsubsection{Co-Generation Facility at the DeRidder Plant}

The proposed cogeneration facility at the Boise DeRidder plant will have advanced gas turbines with external recuperation and heat recovery steam generators for cogeneration. The external recuperation of combustion air will increase the turbine efficiency and cogeneration will provide supplemental steam for the DeRidder plant operation.

For new cogeneration facilities to be installed/constructed, a construction air permit will be required. With improvement in combustor design, the expected NOx levels from the gas turbine will be less than 25 ppm @ 15\% $\mathrm{O}_{2}$. This NOx level can be further reduced to 9-15 ppm @ 15\% $\mathrm{O}_{2}$ using SCR with ammonia injection. This level of NOx meets the current emission standards set by EPA. Since NOx limits are also adjusted for the cycle efficiency, the proposed externally recuperated gas turbine with expected higher efficiency will meet the required emissions regulations. Details on emission regulations for stationary gas turbines are provided in 10CFR60 sub part GG.

Since natural gas is the only fuel whose combustion products will pass through the turbines, $\mathrm{SO}_{2}$ and PM10 are not an issue and are not addressed here.

\subsubsection{Gasifier and the Bark Dryer}

There is no emission from the gasifier and the bark dryer. The VOC exhaust from the bark dryer will be fed directly into the gasifier as part of the combustion air. The low Btu syngas from the 
gasifier will be used as the supplemental fuel in the No. 2 Bark Boiler. Hence, no air permits will be required.

\subsection{PLANT LAYOUT}

As mentioned earlier, the proposed project is envisaged to be an integral part of and located within the premises of the Pulp and Paper Mill owned by Boise Cascade Corporation Southern Operations and located at DeRidder, Louisiana. The project equipment is located near No. 2 Bark Boiler to facilitate close coordination of the proposed project operation in conjunction with the No. 2 Bark Boiler.

The configuration and location of the equipment is shown in the layout drawings, Figure 3.6-1 in 3 sheets. The drawings also show the relative locations of the existing pulp and paper mill equipment.

\section{Availability of space.}

The space at the mill is at a premium due to the compact arrangement of the existing equipment. For this reason, the proposed project equipment is located in a somewhat scattered manner to utilize whatever space is available in the vicinity of the No. 2 Bark Boiler. The spaces found to be adequate and suitable are generally located in areas north of the boiler. The general approach in locating the equipment was to minimize lengths of the various interconnecting piping, ducting, and bark conveyor belts.

Gasification Equipment and External Air Heater. Relative arrangement of this equipment is essentially same as that discussed in Section 3.3.2 with the exception of the combustor and the equipment downstream of the combustor. This latter equipment is somewhat rearranged to fit the available space and to minimize lengths of the various interconnecting pipes without altering the functionality of the system.

Gas Turbine Generator \#1 (GT-1). GT-1 and associated equipment are closely related to the gasifier because the gasifier thermal energy is utilized to preheat the combustion air supply to the gas turbine. It is desirable that the lengths of the high temperature air pipes be kept at a minimum to minimize heat loss and cost. Thus the GT-1 and the associated equipment are located in the close proximity to the gasifier.

Gas Turbine Generator \#2 (GT-2). GT-2 and associated equipment are closely related to the Bark Boiler \#2 because the boiler heat is utilized to preheat the combustion air supply to the gas turbine. It is desirable that the lengths of the high temperature air pipes be kept at a minimum to minimize heat loss and cost. Thus the GT-2 and the associated equipment are located in the close proximity to the bark boiler.

Wet Bark Dryers. These dryers are physically large and require a large amount of real estate. Moreover, the dryers are closely associated with the gasifier and the bark boiler because dried bark is supplied from the dryers to the gasifier as well as the bark boiler. In addition, the hot and cold flue gas from the boiler is ducted between the two. The most suitable place available is between the gasifier and the bark boiler.

The dryers are located on two connected elevated platforms approximately $25 \mathrm{ft}$. above ground level. This is done to avoid interference with the ground level equipment and to keep the roadway underneath free for vehicular traffic. 


\section{Piping, Ducting, and Conveyors}

Major piping, ducting, and conveyor belts shown in the layout drawings include:

- Hot and cold piping between GT-1 and air heater AH-1 (Nos. 12 and 13 on the layout drawings)

- Product gas piping from syngas cooler to bark boiler \#2 (Nos. 10 on the layout drawings)

- Conveyor from conveyor junction box (No. 14 on the layout drawings) to wet bark screening and sizing machine (No. 14 on the layout drawings)

- Conveyor from wet bark screening and sizing machine to dryers (No. 17 on the layout drawings)

- Conveyor (No. 18 on the layout drawings) from dryers to conveyor junction box (No. 15 on the layout drawings)

- Conveyor from junction box (No. 15 on the layout drawings) to the gasifier (No. 11 on the layout drawings)

- Cold and hot flue gas ducting between dryers and boiler \#2 (Nos. 19 and 20 on the layout drawings)

\subsection{PLANT PERMITTING REQUIREMENTS}

For new construction, the following regulatory and permitting requirements are identified:

- A land use permit

- Emission permit for new sources

- Water discharged permit

- Statement of solid and toxic waste generated and method of disposition

- Compliance with noise level at the site boundary

In addition to above, site construction permit, building permit and compliance with local fire code, state boiler code, etc. is required.

Since the Advanced Gasification-Based Power Generation project will be sited in an existing industrial site, some of these activity will require review under the existing permit, while the other activities may require new permitting.

Under the DOE's NEPA Implementing Procedures (10CFR102) a detailed questionnaire and environmental impact will be developed. Following is a brief overview of various permitting and environmental impact work that will be performed by the project.

\section{Land Use Permit}

Since the proposed facility will be build on the Boise Paper Solutions' existing DeRidder facility, no new land use permit will be required. Beauregard Parish, LA may require to update the existing permit to reflect changes in the existing facility.

\section{Emission Source Permit}

\section{Bark Boiler and Waste Wet Wood Dryer}

As stated in Section 3.2, Plant Description and Section 3.3, Major Plant Areas, the gasifier and waste wet wood dryer do not represent a new and continuous emitting source. Hence, no permit will be required. A special filing for flare operation during shutdown and emergency trip of the gasifier may be required. 
The existing \#2 bark boiler will be modified to accept low Btu syngas as reburn fuel from the gasifier. The design of the new syngas injection and staged combustion/reburning system will improve boiler energy performance and reduce boiler NOx emissions by 30-50\% (90-130 tons/year). This does not count NOx reduction that may be associated with the coal-fired purchased electricity that is replaced with biomass and gas-fired self-generated electricity. The project will be required to apply for modification of the boiler, but as it will be an emissions reduction project the Louisiana Department of Environmental Quality (LDEQ) is expected to maintain a positive opinion of the project.

\section{New Gas Turbines/HRSGs}

Construction of any new source is subject to New Source Review (NSR). If the source is located in an attainment area, it will also trigger Prevention of Significant Deterioration (PSD) permitting, as required by the Clean Air Act (CAA) for major stationary sources of air pollution in attainment areas.

A major source is any stationary source with the potential to emit more than 100 tons of pollutant per year. The GT35P gas turbines will fall into this category.

The PSD regulations require that new major stationary sources obtain a PSD permit prior to construction to ensure compliance with the applicable NAAQS. To obtain a PSD permit, several steps must be completed:

- Perform a Best Achievable Control Technology (BACT) analysis;

- Conduct an ambient air quality analysis;

- Perform an additional impacts analysis;

- Demonstrate that the project does not adversely impact a Class I area; and

- Undergo adequate public participation.

\section{Bact Requirements}

A BACT analysis is done on a pollutant-by-pollutant and unit-by-unit basis considering energy, environmental, and economic impacts to determine the maximum degree of emissions reduction achievable for the proposed source.

\section{Ambient Air Quality Analysis}

Since the new sources will be located within the DeRidder Facility, the current ambient air quality data available for this facility will be used.

\section{Additional Impacts Analysis}

An impacts analysis is performed to determine the potential effect on soils, vegetation, and visibility in the area surrounding the proposed facility. The direct effect of source emissions and the impacts from general commercial, residential, industrial, and other growth associated with the proposed source may have to be analyzed.

\section{Public Participation}

The air permitting process requires public participation, public notice and a public comment period before the reviewing agency takes final action on a PSD application.

\section{Toxics Permitting Requirements}

There are no new or additional toxic substances that will be generated from the proposed project. Hence, it is expected that no new toxic permitting will be required. 


\section{Liquid Wastes and Discharges}

The liquid waste streams expected from the Gasification Plant will include the following:

1. Condensate water from air supply system

2. Condensate water from steam supply in conjunction with air supply

3. Condensate water from nitrogen generation system

4. Floor and equipment drain wastewater

These will not require treatment before discharge.

The gas turbine plant will have HRSG blowdown, which will be collected and send to the existing blowdown collection tank.

The oily water collection system will collect any oil leakage and spill from the gas turbine and send to existing waste collection system at the DeRidder plant.

\section{Solid Wastes}

There is one solid waste streams from the Gasification Plant, the bottom ash from the gasifier. The amount of bottom ash is $810 \mathrm{lb} / \mathrm{h} / 0.1 \mathrm{~kg} / \mathrm{s}$

The ash generated during bark and wood waste gasification consists of bed material (spent limestone), some inorganic compounds of fuel ash, unburnt carbon and all impurities fed with feedstock in the gasifier. The carbon content of the ash is below $5 \% \mathrm{w}$.

The bottom ash is non-hazardous and will be disposed in the same manner and location as the bark boiler ash.

\section{Noise}

During gasification and gas turbine plant operation, there are noise sources from process and plant equipment.

The following noise sources emitting outside the gasification plant:

The flare system noise level will not exceed a value of $75 \mathrm{~dB}(\mathrm{~A})$ in 1-meter distance from the equipment. The typical noise levels of the flare at ground level are as follows:

- $0 \mathrm{~m}$ from flare (building) basis:

$72.75 \mathrm{~dB}(\mathrm{~A})$

- $10 \mathrm{~m}$ from flare (building) basis:

$72.57 \mathrm{~dB}(\mathrm{~A})$

- $100 \mathrm{~m}$ from flare (building) basis:

$65.76 \mathrm{~dB}(\mathrm{~A})$

- $1000 \mathrm{~m}$ from flare (building) basis:

$46.72 \mathrm{~dB}(\mathrm{~A})$

The following noise sources emitting from the gas turbine power plant:

- Gas Turbine Generator

- Boiler feed pump

The following noise sources emitting from the Balance of Plant Equipment:

- Cooling Tower

- Air Compressor

- Blow-off of air compressor 
Venting of depressurized nitrogen from fuel feeding and ash removal systems

- The blow-off noise levels will not exceed a value of $90 \mathrm{~dB}(\mathrm{~A})$ in 1-meter distance from the equipment.

- The venting noise levels will not exceed a value of $90 \mathrm{~dB}(\mathrm{~A})$ in 1-meter distance from the equipment.

All the noise sources inside the buildings are in soundproof enclosure, thus the sound power level inside all buildings will not exceed $80 \mathrm{~dB}(\mathrm{~A})$ at 1-meter distance from the equipment. The noise level will be reduced to $55 \mathrm{~dB}(\mathrm{~A})$ in special rooms (rooms with medium or low voltage equipment or with electronics and control room).

\section{Greenhouse Gas Emissions}

The project would result in a significant reduction in $\mathrm{CO}_{2}$ emissions resulting from the generation of electricity to meet the mill's power requirements. This may allow the mill to insulate themselves to some extent from future greenhouse gas regulations, which may be promulgated at the state or federal level. A reduction of up to 50,000 tons/yr of carbon dioxide emissions will result from a net reduction in gas usage in the mill as a result of the project. The project will reduce purchased electricity in the mill by $34 \mathrm{MW}$, resulting in an additional 410,000 tons/yr reduction in $\mathrm{CO}_{2}$ emissions due to reduction of purchase electricity compared to current operations. The total $\mathrm{CO}_{2}$ reduction amounts to about $33 \%$ of the $\mathrm{CO}_{2}$ generated to meet the mills purchased electricity requirement. In this analysis, the purchased electricity is assumed to be generated from coal and woodwaste fuel is considered to be $\mathrm{CO}_{2}$ neutral to the environment. 


\subsection{CAPITAL COST ESTIMATE}

The purpose of this section is to provide capital cost estimates of various systems and components comprising the biomass gasification-based power generation facility.

The costs presented here are preliminary estimates. They do not have the benefit of a detailed estimate due to the pre-design evaluation nature of the study.

\subsubsection{Cost Estimating Approach and Basis}

Due to the preliminary nature of the study, the capital costs developed here are only indicative of the actual costs that may be expected for implementation of the project. Thus the approach has been to rely on historical data as much as possible with adjustments and extrapolations for differences in size, capacity, and implementation timing. In some instances, budgetary price quotations from equipment manufacturers have also been used. These prices are budgetary because the information given to the manufacturers is preliminary.

The information developed as a part of the pre-design evaluation effort of this study formed the basis for adjustments and extrapolations applied to the historical cost data. In situations where historical data is not available, order-of-magnitude estimates are made based on preliminary equipment specifications generated during the pre-design process.

The format specified by Boise Cascade has been followed to develop the capital cost estimate. The format specifically identifies the various direct and indirect cost parameters that should be used in the estimate. Plant capital cost is comprised of two components:

Capital cost $=$ Direct cost + Indirect cost.

The direct cost of a system or equipment refers to all the costs that can be directly allocated to the system or equipment under consideration. The indirect costs are those that cannot be directly attributed to any specific system or equipment. These costs are applicable to the plant as a whole.

The direct cost, which is also sometimes referred to as construction cost, is determined as follows:

Direct cost $=$ installed equipment cost

+ support facilities applicable to the installed equipment

The installed equipment cost, in turn, is comprised of:

Installed cost $=$ cost of equipment at the manufacturer's plant

+ cost of shipment

+ cost of installation labor

+ cost of materials associated with field installation.

Cost of installation labor is estimated as the product of 'installation labor hours' and 'cost of labor per hour'. Installation labor hour is estimated based the experience of the equipment supplier for similar equipment. Information on hourly cost of labor is provided to the project by Boise Cascade. 
Support facilities consist of:

Support facilities $=$ site preparation and auxiliaries

+ buildings and services

+ equipment foundation

+ instrumentation, piping, and electrical.

+ piping

+ electrical.

Costs of support facilities are estimated as percentages of installed cost. Since every piece of equipment is different from the others, these percentages are also different for each equipment. There are no fixed set of percentage values applicable across the board.

The indirect costs are attributable over the entire plant and are discussed below. These costs are generally expressed as fixed percentages of total direct cost of the total plant. Percentage values used here are specified by Boise Cascade and are typical of power projects.

- Consultant's Engineering Services (8\%) - services of an architect-engineering firm retained by the owner for design, engineering, procurement, construction management, testing, start-up, and commissioning.

- Owner's Engineering Services (4\%) - services performed by the owner particularly related to preliminary assessments, site preparation, permitting, etc.

- Additional Engineering Services (0.5\%) - special services sometimes needed for activities, which may have been inadvertently left out of the consultant's engineering services.

- Environmental Engineering (0.5\%) - engineering activities related to environmental assessment of the facility construction.

- Capitalized Spares (5\%) - generally includes one year's supply of consumable materials and short life items.

- Sales tax is levied at $5 \%$ on the direct cost plus all the indirect costs discussed above. Builder's risk insurance is typically $1 \%$ of all of the costs above.

The sum of the total direct cost and all of the above indirect costs forms the basis for estimating contingency, which typically ranges from $25 \%$ to $30 \%$ for order-of-magnitude cost estimates. Boise Cascade specifies 10\% contingency based on a detailed cost estimate. Thus for a predesign evaluation such as the present study, contingency would be much higher. By

Nexant/Bechtel experience, even for a cost estimate based on a detailed design, contingency ranges from $25 \%$ to $30 \%$. A contingency of $25 \%$ is used in the estimate for the present study.

\subsubsection{Data Source for the Estimate}

The data source for the capital cost estimate is a combination of participants' in-house database and some manufacturers as follows:

Gasification system: Carbona Corporation

Steam generation system: Nexant, Inc.

Gas turbine air pre-heating: Babcock Power Services

Balance-of-plant systems: Nexant, Inc.

Gas turbine system: Alstom Power, Inc.

Biomass drying equipment: $\mathrm{AB}$ Torkapparater of Sweden 


\subsubsection{Estimated Capital Cost}

As discussed earlier (Section 2), the plant is envisaged to constructed in 3 steps. Capital cost at the completion of Step 3 represents the total investment required for the proposed plant. The estimated costs are presented in Table 3.8-1 in two sheets. Sheet 1 shows the direct costs, and Sheet 2 shows the indirect costs and the total capital investment. The final project cost at the completion of Step 3 is summarized below:

$\begin{array}{ll}\text { Direct cost } & \$ 46.0 \mathrm{M} \\ \text { Indirect cost } & \$ 10.3 \mathrm{M} \\ \text { Contingency } & \$ 14.1 \mathrm{M} \\ \text { Total Capital Cost } & \mathbf{\$ 7 0 . 4} \mathbf{M}\end{array}$

\subsection{OPERATING AND MAINTENANCE COST ESTIMATE}

It is necessary that annual operation and maintenance (O\&M) costs of the proposed plant be evaluated both 'before' and 'after' the implementation of the plant to facilitate an economic analysis of the costs and benefits of the plant. The difference between the two ('costs before' minus 'costs after' implementation) represents the cost saving or economic benefit.

The costs involved in operating and maintaining the proposed plant would consist of two components: purchased electricity and fuel; and non-fuel operation and maintenance.

Traditionally, the non-fuel operation and maintenance is generally referred to as O\&M. The 'before' and 'after' O\&M costs are discussed in the following paragraphs. The cost of purchased electricity and fuel is discussed in Section 3.10, Economic Analysis.

Non-fuel O\&M. Operation and maintenance of the gasifier and gas turbine plants are the primary contributors to the non-fuel O\&M costs. For other systems, these costs are much less and are assumed to be negligible.

O\&M costs of the gas turbine plant consist of three components: variable O\&M cost, fixed O\&M cost, and cost of electricity for supplying compressed gas. Typical industry-average values for variable O\&M cost is $\$ 2.2 / \mathrm{MWh}$ and that for fixed O\&M cost is $\$ 5.1 / \mathrm{kW} /$ year. Power requirement for natural gas compression is estimated to be $0.75 \mathrm{MW}$ per gas turbine unit. Cost of electricity is estimated by using the current price of electricity at $\$ 55 / \mathrm{MWh}$.

O\&M costs of the gasifier plant consist of three components: materials; labor; and electricity. A typical industry-average value for cost of materials is $2 \%$ of capital cost per year. Labor cost is estimated by the total fully-loaded annual salaries $(\$ 0.1 \mathrm{M}$ per operator) of the required number of operators. It is estimated that the plant would require 3 operators to operate the combined gasifier and the gas turbine plants. Considering the number of shifts, operator vacation, and unforeseen events, an industry average multiplier of 4.5 is applied to estimate the total number of operating personnel required. Thus, it is estimated that 14 operating personnel would be required.

Electricity usage is estimated to be $1,000 \mathrm{~kW}$, and the cost is estimated by using the current price of electricity at \$55/MWh. 
Table 3.8-1: Estimated Capital Cost - Direct Cost

(Sheet 1 of 2)

\begin{tabular}{|c|c|c|c|c|c|}
\hline \multicolumn{6}{|l|}{ DIRECT COST (2003 \$) } \\
\hline Direct Costs: & Step 1 & Step 2 & 2 Step 3 & Total & \\
\hline \multicolumn{6}{|l|}{ Gasifier plant equipment } \\
\hline Fuel Feeding & 1,417 & & & 1,417 & \begin{tabular}{l|l|l|}
7 & \$K \\
\end{tabular} \\
\hline Limestone Feeding & 194 & & & 194 & $\$ K$ \\
\hline Air System & 740 & & & 740 & $\$ K$ \\
\hline Gasification System & 1,770 & & & 1,770 & \begin{tabular}{l|l|}
0 & $\$ \mathrm{~K}$ \\
\end{tabular} \\
\hline Startup Heater & 187 & & & 187 & $\$ K$ \\
\hline Gas Cooling & 588 & & & 588 & $\$ K$ \\
\hline Flare System & 263 & & & 263 & $\$ K$ \\
\hline Ash Discharge & 287 & & & 287 & $\$ K$ \\
\hline Cooling Water & 32 & & & 32 & $\$ K$ \\
\hline Nitrogen System & 600 & & & 600 & $\$ K$ \\
\hline Vendor Engineering (not included in equipment cost) & 2,170 & & & 2,170 & 0 \$K \\
\hline G-T-1 + GT-2 equipment & 10,974 & & 10,974 & 21,948 & $48 \mathrm{KK}$ \\
\hline External air heater \#1 (AH-1) & 1,547 & & & 1,547 & \begin{tabular}{l|l|l|}
7 & $\$ K$ \\
\end{tabular} \\
\hline HRSG-1 \& HRSG-2 & 1,731 & & 1,731 & 3,463 & 3 \$K \\
\hline Bark boiler \#2 modification equipment & & & 2,500 & 2,500 & 0 \$K \\
\hline Dryer equipment & 1,317 & 1,317 & & 2,634 & $4 \$ \mathrm{~K}$ \\
\hline \multicolumn{6}{|l|}{ Balance-of-Plant Equipment } \\
\hline \begin{tabular}{|l|} 
HRSG \#1 outlet ducting \\
\end{tabular} & 70 & & & 70 & $\$ \mathrm{~K}$ \\
\hline HRSG \#2 outlet ducting & & & 88 & 88 & $\$ K$ \\
\hline G-T \#1 air pre-heating piping & 165 & & & 165 & $\$ \mathrm{~K}$ \\
\hline G-T \#2 air pre-heating piping & & & 105 & 105 & $\$ K$ \\
\hline G-T NG supply equipment & 809 & & 809 & 1,618 & 8 \$K \\
\hline Product gas supply piping & 210 & & & 210 & $\$ K$ \\
\hline Bark Conveying and Delivery System & 482 & 321 & & 804 & $\$ K$ \\
\hline Dryer inlet \& exhaust gas ducting & 88 & 81 & 0 & 169 & $\$ K$ \\
\hline Plant cooling water system equipment & 101 & & & 101 & $\$ K$ \\
\hline Compressed air system equipment & 493 & & & 493 & $\$ K$ \\
\hline Fire protection system equipment & 50 & & & 50 & $\$ \mathrm{~K}$ \\
\hline Plant electrical system equipment & 889 & 86 & 810 & 1,786 & \begin{tabular}{|l|l|}
6 & $\$ K$ \\
\end{tabular} \\
\hline Total Direct Cost (Construction Cost) & 27,176 & 1,806 & 17,018 & 46,000 & $0 \$ K$ \\
\hline
\end{tabular}


Table 3.8-1: Estimated Capital Cost (Sheet 2 of 2)

- Indirect Cost and Total Capital Cost -

TOTAL CAPITAL COST (2003 \$)

Indirect Cost Parameters (Boise Guide):

Consultant's Engineering Services

Owner's Engineering Services

Additional Engineering Services

Environmental Engineering

Capitalized Spares

Sales Tax

Builder's Risk Insurance

Contingency

\begin{tabular}{|c|c|}
\hline $8 \%$ & $\%$ of direct cost \\
\hline $4 \%$ & $\%$ of direct cost \\
\hline $0.5 \%$ & $\%$ of direct cost \\
\hline $0 \%$ & $\%$ of owner's eng. services \\
\hline $3 \%$ & $\%$ of direct cost \\
\hline $5 \%$ & $\%$ of direct cost + Spares + Svcs \\
\hline $1 \%$ & $\%$ of direct $\cos t+$ Spares + Svcs + Tax \\
\hline $25 \%$ & $\%$ of $($ direct + indirect $)$ cost \\
\hline
\end{tabular}

\begin{tabular}{|l|c|c|c|c|c|}
\hline Indirect Costs: & Step 1 & Step 2 & Step 3 & Total & \\
\hline Consultant's engineering & 2,174 & 144 & 1,361 & $\mathbf{3 , 6 8 0}$ & \$K \\
\hline Owner's engineering & 1,087 & 72 & 681 & $\mathbf{1 , 8 4 0}$ & \$K \\
\hline Additional engineering & 136 & 9 & 85 & $\mathbf{2 3 0}$ & \$K \\
\hline Environmental engineering & 0 & 0 & 0 & $\mathbf{0}$ & $\$ \mathrm{~K}$ \\
\hline Capitalized spares & 815 & 54 & 511 & $\mathbf{1 , 3 8 0}$ & \$K \\
\hline Sales tax & 1,569 & 104 & 983 & $\mathbf{2 , 6 5 6}$ & \$K \\
\hline Builder's risk insurance & 330 & 22 & 206 & $\mathbf{5 5 8}$ & \$K \\
\hline Total Indirect cost & $\mathbf{6 , 1 1 1}$ & $\mathbf{4 0 6}$ & $\mathbf{3 , 8 2 7}$ & $\mathbf{1 0 , 3 4 4}$ & \$K \\
\hline Total Direct + Indirect cost & $\mathbf{3 3 , 2 8 7}$ & $\mathbf{2 , 2 1 2}$ & $\mathbf{2 0 , 8 4 5}$ & $\mathbf{5 6 , 3 4 4}$ & $\mathbf{\$ K}$ \\
\hline Contingency & 8,322 & 553 & 5,211 & 14,086 & \$K \\
\hline Total Project Cost & $\mathbf{4 1 , 6 0 9}$ & $\mathbf{2 , 7 6 4}$ & $\mathbf{2 6 , 0 5 6}$ & $\mathbf{7 0 , 4 3 0}$ & $\mathbf{\$ K}$ \\
\hline
\end{tabular}




\subsection{ECONOMIC ANALYSIS}

An economic analysis, i.e., estimated costs and benefits of the proposed project to assess the economic viability of the project, is presented in this section. The approach taken to assess the economic viability is to estimate the simple payback period needed to recover the initial investment of the proposed improvements. A simple payback period is computed by dividing the total investment cost by net annual saving realized as a result of operating the proposed plant. Using the guideline suggested by Boise Cascade Corporation, the threshold payback period assumed is 6 years.

Net annual saving is estimated as the difference of total annual savings gained and total annual expenses incurred as a result of operating the proposed plant. A number of parameters are used for the analysis. These are presented in Table 3.10-1.

\section{Table 3.10-1: Input Parameters for Economic Analysis}

\begin{tabular}{|c|c|c|c|c|c|}
\hline Input Parameters & Step 1 & Step 2 & Step 3 & & \\
\hline Annual operating hours & 8,000 & 8,000 & 8,000 & \multicolumn{2}{|l|}{ Hrs } \\
\hline Biomass feed to gasifier & 180.5 & 180.5 & 180.5 & \multicolumn{2}{|l|}{ MMBtu/h } \\
\hline Biomass feed to Boiler \#2 & & & & \multicolumn{2}{|l|}{ MMBtu/h } \\
\hline GT35 power & 17 & 17 & 34 & \multicolumn{2}{|l|}{ MW } \\
\hline GT Plant auxiliary power & $1.5 \%$ & $1.5 \%$ & $1.5 \%$ & \multicolumn{2}{|c|}{ Percent of gross generation } \\
\hline Natural gas supply to GT \#1+ \#2 + Dryer & 150.0 & 143.3 & 266.6 & \multicolumn{2}{|c|}{ MMBtu/h } \\
\hline Natural Gas saving from PB \#1 and Gas Boilers & 4 & 103.4 & 206.8 & \multicolumn{2}{|l|}{ MMBtu/h } \\
\hline Natural Gas saving from PB \#2 & 169.2 & 169.2 & 169.2 & \multicolumn{2}{|l|}{ MMBtu/h } \\
\hline Purchase price of biomass & 1.77 & 1.77 & 1.77 & \multicolumn{2}{|l|}{ \$/MMBtu } \\
\hline Purchase price of electricity & 55.00 & 55.00 & 55.00 & \multicolumn{2}{|l|}{$\$ / \mathrm{MWh}$} \\
\hline Purchase price of natural gas & 4.50 & 4.50 & 4.50 & \multirow{3}{*}{\multicolumn{2}{|c|}{ \$/MMBtu }} \\
\hline Escalation of electricity price & $3 \%$ & $3 \%$ & $3 \%$ & & \\
\hline Escalation of natural gas price & $3 \%$ & $3 \%$ & $3 \%$ & & \\
\hline \multicolumn{6}{|l|}{ Gas Turbine O\&M Cost } \\
\hline 1. Variable & 2.2 & 2.2 & 2.2 & \multicolumn{2}{|l|}{$\$ / M W h$} \\
\hline 2. Fixed & 5.1 & 5.1 & 5.1 & \multicolumn{2}{|l|}{$\$ / k W / Y r$} \\
\hline 2. Electricity for Gas Compressor & & 0.75 & 1.5 & \multicolumn{2}{|l|}{ MW } \\
\hline \multicolumn{6}{|l|}{ Annual Gasifier System O\&M Cost } \\
\hline 1. Materials & & $2 \%$ & $2 \%$ & \multirow{3}{*}{\multicolumn{2}{|c|}{ Percent of Capital Cost }} \\
\hline 2. Labor & & & & & \\
\hline A. No. of Operators & 14 & 14 & 14 & & \\
\hline B. Annual Cost per Operator & 0.1 & 0.1 & 0.1 & \multirow{2}{*}{\multicolumn{2}{|c|}{$\begin{array}{l}\text { \$M/Op/Yr Includes salaries, additives and overhead } \\
\text { MW }\end{array}$}} \\
\hline 3. Consumption of electricity & 1.0 & 1.0 & 1.0 & & \\
\hline PB \#2 O\&M Cost (Incremental) & & 0 & 0 & $\$ / Y r$ & $\begin{array}{l}\text { Assumed no additional Matl or } \\
\text { Labor would be required }\end{array}$ \\
\hline Year of cost basis & 2,003 & 2,003 & 2,003 & & \\
\hline Year of construction & 2,006 & 2,006 & 2,006 & & \\
\hline
\end{tabular}

\subsubsection{Annual Savings}

Total annual savings gained consist of the following:

1. Saving from on-site electricity generation: On-site generation of electricity relieves the plant from buying electricity from grid at a higher cost. Two new gas turbine generating units generate electricity at $17 \mathrm{MW}$ each. 
The additional electricity generated on site with the help of the proposed gas turbine generators replaces the equivalent amount of electricity currently purchased from the grid. The cost of replaced electricity represents the cost saving on electricity. The saving is estimated by using the current price of electricity at $\$ 55 / \mathrm{MWh}$.

2. Saving from reduced natural gas consumption in Boilers \#1 and \#2: Auxiliary steam is generated from the exhaust heat of the gas turbine units. This steam supplements steam generation by Boiler \#1 (including other gas boilers) and Boiler \#2, thus reducing natural gas consumption by these boilers at the rate of 206.8 MMBtu/hr and 169.2 MMBtu/hr, respectively. Saving is estimated by using the current price of natural gas at $\$ 4.50 / \mathrm{MMBtu}$.

\subsubsection{Annual Expenses}

Total annual expenses incurred consist of the following:

1. Cost of natural gas for electricity generation: Natural gas is used to fuel either one (Step 1 and 2) or two (Step 3) gas turbine generator units and one bark dryer (Step1) after implementation of the project. This represents a net expense, as there is no gas turbine generator before implementation. Expense is estimated by using the current price of natural gas at $\$ 4.50 / \mathrm{MMBtu}$.

2. Cost of biomass fuel for gasifier: Biomass (wood waste) fuel is used to fuel the gasifier at the rate of $180 \mathrm{MMBtu} / \mathrm{hr}$ after implementation of the project. Since there is no biomass consumption in a gasifier before implementation, this represents a net expense. The cost of this biomass consumption is estimated by using the current price of $\$ 1.77 / \mathrm{MMBtu}$.

3. Gas turbine O\&M expenses: These are discussed in Section 3.9, O\&M Cost Estimate.

4. Gasifier O\&M expenses: These are discussed in Section 3.9, O\&M Cost Estimate.

\subsubsection{Payback Period}

The economic analysis results including total annual savings and expenses are presented in Table 3.10-2 in two sheets. Sheet 1 shows energy consumption and saving for the current and proposed situations. Sheet 2 presents the cost saving and the resulting payback period.

As discussed in Section 3.8, the total capital investment for the proposed plant is estimated to be $\$ 70.4$ million. This does not include any subsidy or cost share. From Table 3.10-2, it may be seen that the total annual saving is estimated to be $\$ 13.69$ million. This results in a simple payback period of 5.1 years.

Savings and payback period was also analyzed assuming an alternative set of natural gas and electricity purchase prices. The alternative prices assumed are $\$ 5.00$ per million Btu of natural gas and $\$ 42.00$ per MWh of electricity. The analysis results are presented in Table 3.10-3. As may be seen from the table, the payback period changed very slightly due the alternative set of prices. Simple payback period is increased from 5.1 years to 6.6 years.

\subsubsection{Demonstration vs. Commercial Plant Economics}

\subsubsection{Capital Cost}

A number of factors are involved in the costs of a demonstration plant and a commercial plant. The capital cost presented in the previous section is for a first-of-a-kind demonstration plant at a 
specific location, which, in this case, is the Boise Cascade pulp mill at DeRidder in the State of Louisiana. The cost of such a plant tends to be higher than that of a commercial plant because of the development costs associated with a number of key technologies. In this case, the key technologies include gas turbine technology and the external air preheater technology. According to the gas turbine manufacturer (Alstom), gas combustor would require some development effort to operate on externally preheated combustion air. Equipment design and operating parameter envelope need to be established before commercializing the gas turbine system. Similarly, the external air preheater is a novel equipment requiring demonstration of materials compatibility with producer gas, fabricability, heat transfer characteristics, safety characteristics, etc. Safety is particularly critical due to the potential for exothermic reaction and flammability caused by airgas mixing in case of a leakage. Double wall heat exchanger tubes may be needed to eliminate leakage potential.

An additional factor that would influence the cost is the site condition of the location of the commercial plants. The Boise Cascade DeRidder plant is highly congested requiring spread-out equipment placement and long lengths of high temperature piping, ducting, and conveyors. These have significant impact on the plant cost.

The cost of a commercial plant on the other hand, which could be located at any of the forest product industries facilities, could be potentially lower than that of the first-of-kind plant. These plants would have the benefit of development and operating experience of the first plant. Moreover, the sites may not be as congested as the first plant.

It is difficult to estimate the cost benefit of high temperature piping, ducting, and conveyors without identifying a specific location for a commercial plant. However, a 50 percent reduction may be judged to be appropriate considering the unusual congestion at the DeRidder plant. This would amount to a saving of approximately $\$ 1.6 \mathrm{M}$ in direct cost. The development cost benefits of gas turbine and external heat exchanger would be approximately $\$ 8 \mathrm{M}$ and $\$ 0.5 \mathrm{M}$ in direct costs, for gas turbine and external air heat exchanger, respectively. Thus, the cost of a commercial plant is expected to be as follows:

$\begin{array}{lc}\text { Direct cost } & \$ 35.9 \mathrm{M} \\ \text { Indirect cost } & \$ 8.1 \mathrm{M} \\ \text { Contingency } & \$ 11.0 \mathrm{M} \\ \text { Total Capital Cost } & \$ 55.0 \mathrm{M}(2003 \$)\end{array}$

\subsubsection{Annual Expenses and Payback Period}

It may be estimated that for a commercial plant the total annual saving would be approximately the same as the first plant at \$10-14 million depending on gas and electricity cost assumptions. Thus, with a $\$ 55.0$ million capital cost, the simple payback period for a commercial plant would be approximately 4 to 6 years. 
Table 3.10-2a: Economic Analysis - Energy Consumption and Saving

\begin{tabular}{|c|c|c|c|c|c|c|c|c|c|c|}
\hline & & \multicolumn{6}{|c|}{$\begin{array}{l}\text { Energy Consumption, } \\
\text { MWh/Yr or MMBtu/Yr }\end{array}$} & \multirow{2}{*}{\multicolumn{3}{|c|}{$\begin{array}{c}\text { Energy Saving, } \\
\text { MWh/Yr or MMBtu/Yr } \\
\text { Saving = Current - Proposed }\end{array}$}} \\
\hline & & \multicolumn{3}{|c|}{ Current Consumption } & \multicolumn{3}{|c|}{ Proposed Consumption } & & & \\
\hline & & Step 1 & Step 2 & Step 3 & Step 1 & Step 2 & Step 3 & Step 1 & Step 2 & Step 3 \\
\hline \multicolumn{11}{|l|}{ Electricity } \\
\hline $\begin{array}{l}\text { Annual Electricity Replaced } \\
\text { (see Note 1) }\end{array}$ & MWh & 133,960 & 133,960 & 267,920 & 0 & 0 & 0 & 133,960 & 133,960 & 267,920 \\
\hline \multicolumn{11}{|l|}{ Fuel } \\
\hline $\begin{array}{l}\text { Additional Annual Biomass Consumption in } \\
\text { Gasifier and Boiler \#2 (see Note 2) }\end{array}$ & MMBtu & 0 & 0 & 0 & $1,683,200$ & $1,485,600$ & $2,141,600$ & $(1,683,200)$ & $(1,485,600)$ & $(2,141,600)$ \\
\hline $\begin{array}{l}\text { Annual Natural gas consumption } \\
\text { for GT\#1 \& \#2 and Dryers (see Note 2) }\end{array}$ & MMBtu & 0 & 0 & 0 & $1,200,000$ & $1,146,400$ & $2,132,800$ & $(1,200,000)$ & $(1,146,400)$ & $(2,132,800)$ \\
\hline $\begin{array}{l}\text { Annual Natural Gas Consumption Replaced } \\
\text { for PB\#1 and Gas Boilers (see Note 2) }\end{array}$ & MMBtu & 827,200 & 827,200 & $1,654,400$ & 0 & 0 & 0 & 827,200 & 827,200 & $1,654,400$ \\
\hline $\begin{array}{l}\text { Annual Natural Gas Consumption Replaced } \\
\text { for PB\#2 (see Note } 2)\end{array}$ & MMBtu & $1,353,600$ & $1,353,600$ & $1,353,600$ & 0 & 0 & 0 & $1,353,600$ & $1,353,600$ & $1,353,600$ \\
\hline
\end{tabular}

Note 1: Annual Electricity Replaced = Note 2: Annual Fuel Consumption =
Gross GT output * Annual operating hours * (1 - GT plant auxiliary power in \% of gross output) Hourly consumption * Annual operating hours 
Table 3.10-2b: Economic Analysis - Cost Savings and Payback Period)

\begin{tabular}{|c|c|c|c|c|c|c|c|c|c|c|}
\hline \multirow[b]{3}{*}{ Project Implementation Step } & & \multicolumn{6}{|c|}{ Cost of Energy Consumption, $\$ \mathrm{M} / \mathrm{Yr}$} & & & \\
\hline & & \multicolumn{3}{|c|}{ Current Plant } & \multicolumn{3}{|c|}{ Proposed Plant } & \multicolumn{3}{|c|}{ Cost Saving, $\$ \mathbf{M} / \mathbf{Y r}$} \\
\hline & & Step 1 & Step 2 & Step 3 & Step 1 & Step 2 & Step 3 & Step 1 & Step 2 & Step 3 \\
\hline \multicolumn{11}{|l|}{ Electricity } \\
\hline Annual Electricity Replaced by GT & MWh & 8.05 & 8.05 & 16.10 & 0.00 & 0.00 & 0.00 & 8.05 & 8.05 & 16.10 \\
\hline \multicolumn{11}{|l|}{$\begin{array}{r}\text { Fuel } \\
\end{array}$} \\
\hline $\begin{array}{l}\text { Additional Annual Biomass } \\
\text { Consumption in Gasifier and Boiler \#2 }\end{array}$ & MMBtu & 0.00 & 0.00 & 0.00 & 2.98 & 2.63 & 3.79 & $(2.98)$ & $(2.63)$ & $(3.79)$ \\
\hline $\begin{array}{l}\text { Annual Natural gas consumption } \\
\text { for GT\#1 \& \#2 and Dryers }\end{array}$ & MMBtu & 0.00 & 0.00 & 0.00 & 5.90 & 5.64 & 10.49 & $(5.90)$ & $(5.64)$ & $(10.49)$ \\
\hline $\begin{array}{l}\text { Annual Natural gas consumption for } \\
\text { PB\#1 and Gas Boilers }\end{array}$ & MMBtu & 4.07 & 4.07 & 8.14 & 0.00 & 0.00 & 0.00 & 4.07 & 4.07 & 8.14 \\
\hline $\begin{array}{l}\text { Annual Natural gas consumption for } \\
\text { PB\#2 }\end{array}$ & MMBtu & 6.66 & 6.66 & 6.66 & 0.00 & 0.00 & 0.00 & 6.66 & 6.66 & 6.66 \\
\hline \multicolumn{11}{|l|}{ Operation and Maintenance } \\
\hline Annual Gas Turbine O\&M & $\$ \mathrm{M} / \mathrm{Yr}$ & 0.00 & 0.00 & 0.00 & 0.42 & 0.42 & 0.83 & $(0.42)$ & $(0.42)$ & $(0.83)$ \\
\hline Annual Gasifier System O\&M Cost & $\$ M / Y r$ & 0.00 & 0.00 & 0.00 & 2.09 & 2.09 & 2.09 & $(2.09)$ & $(2.09)$ & $(2.09)$ \\
\hline $\begin{array}{l}\text { Annual Power Boiler \#2 O\&M } \\
\text { (incremental) Cost }\end{array}$ & $\$ M / Y r$ & 0.00 & 0.00 & 0.00 & 0.00 & 0.00 & 0.00 & 0.00 & 0.00 & 0.00 \\
\hline \multicolumn{8}{|c|}{ Net Annual Saving, \$M/Yr. } & 7.39 & 8.00 & 13.69 \\
\hline \multicolumn{8}{|c|}{ Total Plant Capital Cost, \$M } & 41.6 & 44.4 & 70.4 \\
\hline \multicolumn{8}{|c|}{ Simple Payback Period, Years } & 5.6 & 5.5 & 5.1 \\
\hline
\end{tabular}


Table 3.10-3a: Economic Analysis - Alternative - Energy Consumption and Saving

\begin{tabular}{|c|c|c|c|c|c|c|c|c|c|c|}
\hline & & \multicolumn{6}{|c|}{$\begin{array}{l}\text { Energy Consumption, } \\
\text { MWh/Yr or MMBtu/Yr }\end{array}$} & \multirow{2}{*}{\multicolumn{3}{|c|}{$\begin{array}{c}\text { Energy Saving, } \\
\text { MWh/Yr or MMBtu/Yr } \\
\text { Saving = Current - Proposed }\end{array}$}} \\
\hline & & \multicolumn{3}{|c|}{ Current Consumption } & \multicolumn{3}{|c|}{ Proposed Consumption } & & & \\
\hline & & Step 1 & Step 2 & Step 3 & Step 1 & Step 2 & Step 3 & Step 1 & Step 2 & Step 3 \\
\hline \multicolumn{11}{|l|}{ Electricity } \\
\hline $\begin{array}{l}\text { Annual Electricity Replaced } \\
\text { (see Note 1) }\end{array}$ & MWh & 133,960 & 133,960 & 267,920 & 0 & 0 & 0 & 133,960 & 133,960 & 267,920 \\
\hline \multicolumn{11}{|l|}{ Fuel } \\
\hline $\begin{array}{l}\text { Additional Annual Biomass Consumption in } \\
\text { Gasifier and Boiler \#2 (see Note 2) }\end{array}$ & MMBtu & 0 & 0 & 0 & $1,683,200$ & $1,485,600$ & $2,141,600$ & $(1,683,200)$ & $(1,485,600)$ & $(2,141,600)$ \\
\hline $\begin{array}{l}\text { Annual Natural gas consumption } \\
\text { for GT\#1 \& \#2 and Dryers (see Note 2) }\end{array}$ & MMBtu & 0 & 0 & 0 & $1,200,000$ & $1,146,400$ & $2,132,800$ & $(1,200,000)$ & $(1,146,400)$ & $(2,132,800)$ \\
\hline $\begin{array}{l}\text { Annual Natural Gas Consumption Replaced } \\
\text { for PB\#1 and Gas Boilers (see Note 2) }\end{array}$ & MMBtu & 827,200 & 827,200 & $1,654,400$ & 0 & 0 & 0 & 827,200 & 827,200 & $1,654,400$ \\
\hline $\begin{array}{l}\text { Annual Natural Gas Consumption Replaced } \\
\text { for PB\#2 (see Note 2) }\end{array}$ & MMBtu & $1,353,600$ & $1,353,600$ & $1,353,600$ & 0 & 0 & 0 & $1,353,600$ & $1,353,600$ & $1,353,600$ \\
\hline
\end{tabular}


Table 3.10-3b: Economic Analysis - Alternative - Cost Savings and Payback Period

\begin{tabular}{|c|c|c|c|c|c|c|c|c|c|c|}
\hline \multirow[b]{3}{*}{ Project Implementation Step } & & \multicolumn{6}{|c|}{ Cost of Energy Consumption, \$M/Yr } & & & \\
\hline & & \multicolumn{3}{|c|}{ Current Plant } & \multicolumn{3}{|c|}{ Proposed Plant } & \multicolumn{3}{|c|}{ Cost Saving, \$M/Yr } \\
\hline & & Step 1 & Step 2 & Step 3 & Step 1 & Step 2 & Step 3 & Step 1 & Step 2 & Step 3 \\
\hline \multicolumn{11}{|l|}{ Electricity } \\
\hline Annual Electricity Replaced by GT & MWh & 6.15 & 6.15 & 12.30 & 0.00 & 0.00 & 0.00 & 6.15 & 6.15 & 12.30 \\
\hline \multicolumn{11}{|l|}{ Fuel } \\
\hline $\begin{array}{l}\text { Additional Annual Biomass } \\
\text { Consumption in Gasifier and Boiler \#2 }\end{array}$ & MMBtu & 0.00 & 0.00 & 0.00 & 2.98 & 2.63 & 3.79 & $(2.98)$ & $(2.63)$ & $(3.79)$ \\
\hline $\begin{array}{l}\text { Annual Natural gas consumption } \\
\text { for GT\#1 \& \#2 and Dryers }\end{array}$ & MMBtu & 0.00 & 0.00 & 0.00 & 6.56 & 6.26 & 11.65 & $(6.56)$ & $(6.26)$ & $(11.65)$ \\
\hline $\begin{array}{l}\text { Annual Natural gas consumption for } \\
\text { PB\#1 and Gas Boilers }\end{array}$ & MMBtu & 4.52 & 4.52 & 9.04 & 0.00 & 0.00 & 0.00 & 4.52 & 4.52 & 9.04 \\
\hline $\begin{array}{l}\text { Annual Natural gas consumption for } \\
\text { PB\#2 }\end{array}$ & MMBtu & 7.40 & 7.40 & 7.40 & 0.00 & 0.00 & 0.00 & 7.40 & 7.40 & 7.40 \\
\hline \multicolumn{11}{|l|}{ Operation and Maintenance } \\
\hline Annual Gas Turbine O\&M & $\$ M / Y r$ & 0.00 & 0.00 & 0.00 & 0.34 & 0.34 & 0.68 & $(0.34)$ & $(0.34)$ & $(0.68)$ \\
\hline Annual Gasifier System O\&M Cost & $\$ \mathrm{M} / \mathrm{Yr}$ & 0.00 & 0.00 & 0.00 & 1.99 & 1.74 & 1.99 & $(1.99)$ & $(1.74)$ & $(1.99)$ \\
\hline $\begin{array}{l}\text { Annual Power Boiler \#2 O\&M } \\
\text { (incremental) Cost }\end{array}$ & $\$ \mathrm{M} / \mathrm{Yr}$ & 0.00 & 0.00 & 0.00 & 0.00 & 0.00 & 0.00 & 0.00 & 0.00 & 0.00 \\
\hline & & & \multicolumn{5}{|c|}{ Net Annual Saving, \$M/Yr. } & 6.20 & 7.10 & 10.62 \\
\hline & & & \multicolumn{5}{|c|}{ Total Plant Capital Cost, \$M } & 41.6 & 44.4 & 70.4 \\
\hline & & & \multicolumn{5}{|c|}{ Simple Payback Period, Years } & 6.7 & 6.3 & 6.6 \\
\hline
\end{tabular}




\subsection{EXPERIMENTAL}

Two key technical questions arising from the study were the effect of bark drying on VOC emissions from the plant and material selection for the high-temperature high-pressure air heaters. An experimental evaluation of the VOC emissions from DeRidder bark samples under bark drying conditions was conducted by the Institute of Paper Science and Technology (IPST) at their facilities in Atlanta, GA ${ }^{3}$. The IPST work is discussed in Section 4.1 below.

An experimental evaluation of selected candidate tube materials for $\mathrm{AH}-1$ and $\mathrm{AH}-3$ was conducted by Oak Ridge National Laboratory (ORNL). Test coupons of four tube material were exposed in two different locations in the upper furnace of the DeRidder boiler. The ORNL work is discussed in Section 4.2 below.

\subsection{INSTITUTE OF PAPER SCIENCE AND TECHNOLOGY BARK DRYING VOC STUDY}

\section{Summary}

The VOC and HAP emissions during drying of fresh "bark" were found to be consistent with levels previously reported in the literature for related wood materials. This is not surprising given that the "bark" sample actually contained about $50 \%$ wood.

\section{Scope of Work}

Fresh "bark" from the Boise \#2 Power Boiler in DeRidder, LA was evaluated for Volatile Organic Carbon (VOC) and Hazardous Air Pollutant (HAP) emissions during drying at the Institute of Paper Science and Technology (IPST) in Atlanta, GA. The "bark" sample, shipped to IPST in a five gallon screw capped pail, was stored unopened at $4^{0} \mathrm{C}$ until analyzed. The "bark" sample, actually a mixture of pine bark and pine wood, contains only about $50 \%$ bark with the remainder of the material being wood. The sample material ranges in size from fine particles less than $1 \mathrm{~mm}$ in diameter to large pieces up to several inches in length. For the lab experiments, the "bark" sample was fractionated into three size categories: fine, medium and large. Total VOC (by EPA Method 25A) and HAP emissions (by Extractive FTIR Spectroscopy) were measured for each of the size fractions during drying to final moisture contents of 30,20 and $10 \%$ by weight.

\section{Apparatus and Experimental Conditions}

The hardware setup for measuring the VOC and HAP emissions in real-time during drying of the bark samples consisted of three main components: a heated tube furnace, a Fourier Transform Infrared (FTIR) spectrometer, and a hydrocarbon analyzer. The tube furnace, used to heat and dry the samples to the desired moisture endpoint, was a Thermo Pro, Inc. (Columbus, OH) Model TF12C tube furnace equipped with a hollow alumina sample chamber tube. This tube was heated to $198 \pm 2{ }^{\circ} \mathrm{C}$ and maintained at this temperature for the duration of the testing. An airflow of 2.55 liters per minute $\left(20^{\circ} \mathrm{C}\right.$ and $\left.1 \mathrm{~atm}\right)$, measured through a Gilmont Accucal 220 flow meter, was delivered through the heated tube and across the sample to sweep the VOC and HAP emissions to the detection instruments via heated stainless steel transfers lines. The heated gas exhaust from the tube furnace was routed into the heated 10-meter gas cell inlet of a MIDAC (Irvine, CA) Model I1106 FTIR Spectrometer. This instrument collects and records FTIR spectra of the gas cell contents every 53 seconds and enables the identification and quantification of 
individual gaseous components in the sample stream. During this testing the following compounds were detected and monitored:
Methanol
Formaldehyde
Acetaldehyde
Pinene

These additional compounds were not detected or monitored.

\section{Propionaldehyde \\ Acrolein}

The outlet from the FTIR gas cell was coupled to the inlet of a J.U.M. Engineering (Germany) Model VE-7 Hydrocarbon Analyzer using a heated stainless steel transfer line. This analyzer, equipped with a flame ionization detector, continuously measures the VOC concentration of the sample stream. An interfaced data system records a VOC concentration data point every 10 seconds.

\section{Sample Preparation and Initial \% Moisture Determinations}

The "bark" sample container was retrieved from cold storage and opened to remove a large representative grab sample from the center of the sample container. This grab sample was fractionated into three size categories: fine, medium and large. The fine fraction was collected by shaking the grab sample through a No. 6 USA Standard Testing Sieve conforming to ASTM E11 specifications. This sieve has openings of $3.35 \mathrm{~mm}(0.132 \mathrm{in}$.). This fine fraction was immediately placed and sealed in a clean polyethylene zip-lock bag and weighed. The medium and large fractions remaining in the sieve were quickly fractionated by hand. The large fraction was comprised of bark and wood pieces that had areas greater than approximately $1 \mathrm{in}^{2}$. The segregated medium and large fractions were immediately placed and sealed in separate, clean polyethylene bags and weighed. The fine, medium and large fractions constituted $37.35 \%$, $43.89 \%$ and $18.76 \%$ of the total weight of the grab sample respectively.

The initial percent moistures (wet weight basis) of each of the size fractions were determined by drying three representative aliquots of each fraction to a constant weight at $105^{\circ} \mathrm{C}$. The initial moisture content of each of the size fractions were above the $50 \%$ desired target moisture content. The initial moisture content of the fine fraction $(51.82 \%)$ was somewhat lower than that of the medium fraction (52.66\%) which was itself somewhat lower than that of the large fraction $(53.30 \%)$. A summary of the size fraction and percent moisture data appears in the following table. 


\begin{tabular}{|c|c|c|c|c|c|}
\hline & \multicolumn{5}{|c|}{$\begin{array}{c}\text { "Bark" Sample } \\
\text { Size and Moisture Distribution }\end{array}$} \\
\hline & $\begin{array}{c}\text { Wet } \\
\text { Weight } \\
(\mathrm{g})\end{array}$ & $\begin{array}{c}\text { Wet } \\
\text { Weight } \\
\text { (as \% of total) }\end{array}$ & $\begin{array}{c}\text { Initial } \\
\% \\
\text { Moisture } \\
\text { (wet basis) }\end{array}$ & $\begin{array}{c}\text { Dry } \\
\text { Weight } \\
\text { Equivalent } \\
(\mathrm{g}) \\
\end{array}$ & $\begin{array}{c}\text { Dry } \\
\text { Weight } \\
\text { (as \% of total) }\end{array}$ \\
\hline $\begin{array}{l}\text { Fine } \\
\text { Fraction }\end{array}$ & 217 & 37.35 & 51.82 & 104.6 & 37.87 \\
\hline $\begin{array}{l}\text { Medium } \\
\text { Fraction }\end{array}$ & 255 & 43.89 & 52.66 & 120.7 & 43.70 \\
\hline $\begin{array}{l}\text { Large } \\
\text { Fraction }\end{array}$ & 109 & 18.76 & 53.30 & 50.9 & 18.43 \\
\hline Total & 581 & 100.00 & & 276.2 & 100.00 \\
\hline
\end{tabular}

\section{Sample Drying Runs}

With the instrumentation stabilized, calibrated and operating in a continuous monitoring mode, the fine fraction was analyzed first. Approximately 10.0 grams of sample was weighed to the nearest 0.01 gram into a tubular sample boat constructed from stainless steel wire mesh (100 mesh). The loaded boat was immediately placed into the heated zone of the tube furnace; the airflow was re-established by reconnecting the gas line stopper to the cool inlet end of the furnace tube and a stopwatch was started to monitor elapsed time of the sample in the drying oven. Real-time emission data was monitored on both the FTIR spectrometer data system and the hydrocarbon analyzer data system. For each run, at the end of the drying period, the sample and boat were retrieved from the tube furnace and immediately weighed to the nearest 0.01 gram to determine the final $\%$ moisture content of the sample. When sufficient sample runs were collected for the fine fraction at 30\%,20\% and 10\% final moisture contents, testing of the medium and large fractions were performed. All of the drying tests were conducted over a threeday period.

The following table summarizes the drying times required for each of the three size fractions to each of the three target $\%$ moisture endpoints. In addition, the number of valid drying runs that were collected for each size fraction and target $\%$ moisture endpoint is presented. The quantitative data from each of these runs were used to arrive at the reported emission values for Total VOC and specific HAPs.

\begin{tabular}{|l|c|c|c|c|c|c|}
\cline { 2 - 7 } \multicolumn{1}{c|}{} & \multicolumn{2}{c|}{$\begin{array}{c}\text { Drying Time in } 198^{0} \mathrm{C} \text { Tube Furnace } \\
\text { to the Target \% Moisture } \\
\text { (minutes) }\end{array}$} & \multicolumn{2}{c|}{$\begin{array}{c}\text { Number of Replicate Drying Runs to } \\
\text { the Target \% Moisture } \\
\text { (number of averaged data points) }\end{array}$} \\
\cline { 2 - 7 } \multicolumn{1}{c|}{} & $30 \%$ & $20 \%$ & $10 \%$ & $30 \%$ & $20 \%$ & $10 \%$ \\
\hline Fine & 6 & 9 & 14 & 9 & 5 & 2 \\
\hline Medium & 7 & 11 & 15 & 7 & 4 & 2 \\
\hline Large & 9 & 13 & 25 & 8 & 5 & 3 \\
\hline
\end{tabular}




\section{Results}

The drying runs for each size fraction to target $\%$ moisture endpoints provided a significant volume of data. The FTIR spectroscopy system generated real-time concentration data points for each analyte every 53 seconds and the hydrocarbon analyzer generated VOC concentration data points every 10 seconds. Graphical plots of real-time concentration for Pinene (from the FTIR spectrometer) and Total VOC (from the hydrocarbon analyzer) for each drying run for each size fraction are provided at the end of the report. In addition, graphical plots from the FTIR spectrometer for two long drying runs for each size fraction are presented which show the realtime concentrations of each of the monitored analytes. For the duration of each valid drying run, the raw concentration data were integrated and processed along with airflow, sample weight and percent moisture values to provide final results in micrograms of target analyte emitted per oven dry gram ( $\mu \mathrm{g} / \mathrm{g}$ o.d.) of sample to each target $\%$ moisture endpoint. The results are summarized in the following tables.

\begin{tabular}{|l|c|c|c|c|c|c|}
\cline { 2 - 7 } \multicolumn{1}{c|}{} & \multicolumn{9}{c|}{ Pinene } \\
\cline { 2 - 7 } & \multicolumn{2}{|c|}{$30 \%$ Final Moisture } & \multicolumn{2}{c|}{$20 \%$ Final Moisture } & \multicolumn{2}{c|}{$10 \%$ Final Moisture } \\
\cline { 2 - 7 } & $\begin{array}{c}\text { Average } \\
\text { concentration } \\
\mu \mathrm{g} / \mathrm{g} \text { o.d. }\end{array}$ & $\begin{array}{r}\text { standard } \\
\text { deviation } \\
\mu \mathrm{g} / \mathrm{g} \text { o.d. }\end{array}$ & $\begin{array}{c}\text { Average } \\
\text { concentration } \\
\mu \mathrm{g} / \mathrm{g} \text { o.d. }\end{array}$ & $\begin{array}{c}\text { standard } \\
\text { deviation } \\
\mu \mathrm{g} / \mathrm{g} \text { o.d. }\end{array}$ & $\begin{array}{c}\text { Average } \\
\text { concentration } \\
\mu \mathrm{g} / \mathrm{g} \text { o.d. }\end{array}$ & $\begin{array}{c}\text { standard } \\
\text { deviation } \\
\mu \mathrm{g} / \mathrm{g} \text { o.d. }\end{array}$ \\
\hline $\begin{array}{l}\text { Fine } \\
\text { Fraction }\end{array}$ & 142.6 & 13.1 & 200.3 & 21.3 & 374.4 & 4.5 \\
\hline $\begin{array}{l}\text { Medium } \\
\text { Fraction }\end{array}$ & 82.1 & 9.7 & 141.2 & 8.9 & 182.1 & 17.8 \\
\hline $\begin{array}{l}\text { Large } \\
\text { Fraction }\end{array}$ & 52.9 & 19.5 & 77.5 & 14.5 & 179.8 & 42.0 \\
\hline
\end{tabular}

\begin{tabular}{|l|c|c|c|c|c|c|}
\cline { 2 - 7 } \multicolumn{1}{c|}{} & \multicolumn{6}{c|}{ Total VOC as $\mathbf{C}_{\mathbf{3}} \mathbf{H}_{\mathbf{8}}$ (Method 25A) } \\
\cline { 2 - 7 } & $30 \%$ Final Moisture & \multicolumn{2}{c|}{$20 \%$ Final Moisture } & \multicolumn{2}{c|}{$10 \%$ Final Moisture } \\
\cline { 2 - 7 } & $\begin{array}{c}\text { Average } \\
\text { concentration } \\
\mu \mathrm{g} / \mathrm{g} \text { o.d. }\end{array}$ & $\begin{array}{c}\text { standard } \\
\text { deviation } \\
\mu \mathrm{g} / \mathrm{g} \text { o.d. }\end{array}$ & $\begin{array}{c}\text { Average } \\
\text { concentration } \\
\mu \mathrm{g} / \mathrm{g} \text { o.d. }\end{array}$ & $\begin{array}{c}\text { standard } \\
\text { deviation } \\
\mu \mathrm{g} / \mathrm{g} \text { o.d. }\end{array}$ & $\begin{array}{c}\text { Average } \\
\text { concentration } \\
\mu \mathrm{g} / \mathrm{g} \text { o.d. }\end{array}$ & $\begin{array}{c}\text { standard } \\
\text { deviation } \\
\mu \mathrm{g} / \mathrm{g} \text { o.d. }\end{array}$ \\
\hline $\begin{array}{l}\text { Fine } \\
\text { Fraction }\end{array}$ & 265.7 & 23.1 & 357.2 & 28.0 & 625.7 & 0.4 \\
\hline $\begin{array}{l}\text { Medium } \\
\text { Fraction }\end{array}$ & 168.8 & 29.0 & 257.1 & 22.2 & 338.6 & 22.1 \\
\hline $\begin{array}{l}\text { Large } \\
\text { Fraction }\end{array}$ & 109.6 & 36.1 & 148.5 & 21.5 & 307.0 & 34.3 \\
\hline
\end{tabular}




\begin{tabular}{|l|c|c|c|c|c|c|}
\cline { 2 - 7 } \multicolumn{1}{c|}{} & \multicolumn{9}{c|}{ Methanol } \\
\cline { 2 - 7 } & \multicolumn{2}{|c|}{$30 \%$ Final Moisture } & \multicolumn{2}{c|}{$20 \%$ Final Moisture } & \multicolumn{2}{c|}{$10 \%$ Final Moisture } \\
\cline { 2 - 7 } & $\begin{array}{c}\text { Average } \\
\text { concentration } \\
\mu \mathrm{g} / \mathrm{g} \text { o.d. }\end{array}$ & $\begin{array}{c}\text { standard } \\
\text { deviation } \\
\mu \mathrm{g} / \mathrm{g} \text { o.d. }\end{array}$ & $\begin{array}{c}\text { Average } \\
\text { concentration } \\
\mu \mathrm{g} / \mathrm{g} \text { o.d. }\end{array}$ & $\begin{array}{c}\text { standard } \\
\text { deviation } \\
\mu \mathrm{g} / \mathrm{g} \text { o.d. }\end{array}$ & $\begin{array}{c}\text { Average } \\
\text { concentration } \\
\mu \mathrm{g} / \mathrm{g} \text { o.d. }\end{array}$ & $\begin{array}{c}\text { standard } \\
\text { deviation } \\
\mu \mathrm{g} / \mathrm{g} \text { o.d. }\end{array}$ \\
\hline $\begin{array}{l}\text { Fine } \\
\text { Fraction }\end{array}$ & 6.3 & 0.8 & 8.6 & 1.4 & 13.5 & 2.0 \\
\hline $\begin{array}{l}\text { Medium } \\
\text { Fraction }\end{array}$ & 2.9 & 0.2 & 5.5 & 0.7 & 8.1 & 0.1 \\
\hline $\begin{array}{l}\text { Large } \\
\text { Fraction }\end{array}$ & 4.6 & 1.0 & 7.9 & 0.6 & 23.6 & 4.2 \\
\hline
\end{tabular}

\begin{tabular}{|l|c|c|c|c|c|c|}
\cline { 2 - 7 } \multicolumn{1}{c|}{} & \multicolumn{9}{c|}{ Formaldehyde } \\
\cline { 2 - 7 } & \multicolumn{2}{|c|}{$30 \%$ Final Moisture } & \multicolumn{2}{c|}{$20 \%$ Final Moisture } & \multicolumn{2}{c|}{$10 \%$ Final Moisture } \\
\cline { 2 - 7 } & $\begin{array}{c}\text { Average } \\
\text { concentration } \\
\mu \mathrm{g} / \mathrm{g} \text { o.d. }\end{array}$ & $\begin{array}{r}\text { standard } \\
\text { deviation } \\
\mu \mathrm{g} / \mathrm{g} \text { o.d. }\end{array}$ & $\begin{array}{c}\text { Average } \\
\text { concentration } \\
\mu \mathrm{g} / \mathrm{g} \text { o.d. }\end{array}$ & $\begin{array}{c}\text { standard } \\
\text { deviation } \\
\mu \mathrm{g} / \mathrm{g} \text { o.d. }\end{array}$ & $\begin{array}{c}\text { Average } \\
\text { concentration } \\
\mu \mathrm{g} / \mathrm{g} \text { o.d. }\end{array}$ & $\begin{array}{c}\text { standard } \\
\text { deviation } \\
\mu \mathrm{g} / \mathrm{g} \text { o.d. }\end{array}$ \\
\hline $\begin{array}{l}\text { Fine } \\
\text { Fraction }\end{array}$ & 2.3 & 0.2 & 3.9 & 0.3 & 9.1 & 0.1 \\
\hline $\begin{array}{l}\text { Medium } \\
\text { Fraction }\end{array}$ & 4.4 & 0.7 & 7.0 & 1.7 & 10.5 & 0.2 \\
\hline $\begin{array}{l}\text { Large } \\
\text { Fraction }\end{array}$ & 2.9 & 1.8 & 3.2 & 1.0 & 11.2 & 5.9 \\
\hline
\end{tabular}

\begin{tabular}{|l|c|c|c|c|c|c|}
\cline { 2 - 7 } & \multicolumn{5}{c|}{ Acetaldehyde } \\
\cline { 2 - 7 } & \multicolumn{2}{|c|}{$30 \%$ Final Moisture } & \multicolumn{2}{c|}{$20 \%$ Final Moisture } & \multicolumn{2}{c|}{$10 \%$ Final Moisture } \\
\cline { 2 - 7 } & $\begin{array}{c}\text { Average } \\
\text { concentration } \\
\mu \mathrm{g} / \mathrm{g} \text { o.d. }\end{array}$ & $\begin{array}{r}\text { standard } \\
\text { deviation } \\
\mu \mathrm{g} / \mathrm{g} \text { o.d. }\end{array}$ & $\begin{array}{c}\text { Average } \\
\text { concentration } \\
\mu \mathrm{g} / \mathrm{g} \text { o.d. }\end{array}$ & $\begin{array}{c}\text { standard } \\
\text { deviation } \\
\mu \mathrm{g} / \mathrm{g} \text { o.d. }\end{array}$ & $\begin{array}{c}\text { Average } \\
\text { concentration } \\
\mu \mathrm{g} / \mathrm{g} \text { o.d. }\end{array}$ & $\begin{array}{c}\text { standard } \\
\text { deviation } \\
\mu \mathrm{g} / \mathrm{g} \text { o.d. }\end{array}$ \\
\hline $\begin{array}{l}\text { Fine } \\
\text { Fraction }\end{array}$ & 2.6 & 1.6 & 2.0 & 1.1 & 1.8 & 0.8 \\
\hline $\begin{array}{l}\text { Medium } \\
\text { Fraction }\end{array}$ & 0.2 & 0.4 & 0.4 & 0.5 & 0.8 & 0.5 \\
\hline $\begin{array}{l}\text { Large } \\
\text { Fraction }\end{array}$ & 0.0 & 0.0 & 0.0 & 0.0 & 0.0 & 0.0 \\
\hline
\end{tabular}




\section{Total VOC as $\mathrm{C}_{3} \mathrm{H}_{8}($ Method 25A)}

\begin{tabular}{|l|c|c|c|c|}
\cline { 3 - 5 } \multicolumn{2}{c|}{} & \multicolumn{3}{c|}{ Average Concentration of VOC $(\boldsymbol{\mu} / \mathbf{g}$ o.d.) } \\
\hline Fraction & Percent of Total & $\mathbf{3 0 \%}$ Moisture & $\mathbf{2 0 \%}$ Moisture & $\mathbf{1 0 \%}$ Moisture \\
\hline \hline Fine & 37.87 & 265.7 & 357.2 & 625.7 \\
\hline Medium & 43.70 & 168.8 & 257.1 & 338.6 \\
\hline Large & 18.43 & 109.6 & 148.5 & 307.0 \\
\hline Total & 100.00 & 194.6 & 275.0 & 441.5 \\
\hline
\end{tabular}

\section{Pinene}

\begin{tabular}{|l|c|c|c|c|}
\cline { 3 - 5 } \multicolumn{2}{c|}{} & \multicolumn{3}{c|}{ Average Concentration of VOC $(\boldsymbol{\mu} / \mathbf{g}$ o.d.) } \\
\hline Fraction & Percent of Total & $\mathbf{3 0 \%}$ Moisture & $\mathbf{2 0 \%}$ Moisture & $\mathbf{1 0 \%}$ Moisture \\
\hline \hline Fine & 37.87 & 142.6 & 200.3 & 374.4 \\
\hline Medium & 43.70 & 82.1 & 141.2 & 182.1 \\
\hline Large & 18.43 & 52.9 & 77.5 & 179.8 \\
\hline Total & 100.00 & 99.6 & 151.8 & 254.5 \\
\hline
\end{tabular}

\section{Methanol}

\begin{tabular}{|l|c|c|c|c|}
\cline { 3 - 5 } \multicolumn{1}{c|}{} & \multicolumn{3}{c|}{ Average Concentration of VOC $(\boldsymbol{\mu} / \mathbf{g}$ o.d.) } \\
\hline Fraction & Percent of Total & $\mathbf{3 0 \%}$ Moisture & $\mathbf{2 0 \%}$ Moisture & $\mathbf{1 0 \%}$ Moisture \\
\hline \hline Fine & 37.87 & 6.3 & 8.6 & 13.5 \\
\hline Medium & 43.70 & 2.9 & 5.5 & 8.1 \\
\hline Large & 18.43 & 4.6 & 7.9 & 23.6 \\
\hline Total & 100.00 & 4.5 & 7.1 & 13.0 \\
\hline
\end{tabular}

\section{Formaldehyde}

\begin{tabular}{|l|c|c|c|c|}
\cline { 3 - 5 } \multicolumn{1}{c|}{} & \multicolumn{3}{c|}{ Average Concentration of VOC $(\boldsymbol{\mu} / \mathbf{g}$ o.d.) } \\
\hline Fraction & Percent of Total & $\mathbf{3 0 \%}$ Moisture & $\mathbf{2 0 \%}$ Moisture & $\mathbf{1 0 \%}$ Moisture \\
\hline Fine & 37.87 & 2.3 & 3.9 & 9.1 \\
\hline Medium & 43.70 & 4.4 & 7.0 & 10.5 \\
\hline Large & 18.43 & 2.9 & 3.2 & 11.2 \\
\hline Total & 100.00 & 3.3 & 5.1 & 10.1 \\
\hline
\end{tabular}

\section{Acetaldehyde}

\begin{tabular}{|l|c|c|c|c|}
\cline { 3 - 5 } \multicolumn{1}{c|}{} & \multicolumn{3}{c|}{ Average Concentration of VOC $(\boldsymbol{\mu} / \mathbf{g}$ o.d.) } \\
\hline Fraction & Percent of Total & $\mathbf{3 0 \%}$ Moisture & $\mathbf{2 0 \%}$ Moisture & $\mathbf{1 0 \%}$ Moisture \\
\hline \hline Fine & 37.87 & 2.6 & 2.0 & 1.8 \\
\hline Medium & 43.70 & 0.2 & 0.4 & 0.8 \\
\hline Large & 18.43 & 0.0 & 0.0 & 0.0 \\
\hline Total & 100.00 & 1.1 & 0.9 & 1.0 \\
\hline
\end{tabular}




\section{Findings}

The following findings can be summarized from the data.

1. Total VOC and HAP emissions are influenced by both sample size fraction and final moisture levels.

2. The lower the final moisture level, the higher the Total VOC and Total HAP emissions. For example, Total VOC emissions in the fine size fraction are 1.3 times greater at $20 \%$ final moisture than at 30\% final moisture, and 2.4 times greater at $10 \%$ final moisture than at 30\% final moisture.

3. The finer the sample size fraction, the greater the VOC and Pinene emissions for a specific final moisture endpoint. For example, at 30\% final moisture content, the Total VOC emissions from the fine size fraction are 1.6 times greater than the emissions from the medium size fraction and 2.4 times greater than the emissions from the large size fraction.

4. Total VOC emission correlates directly with Pinene emission. As Pinene emissions increase, Total VOC emissions increase. Pinene is likely the major contributor to Total VOC.

5. The HAPs detected (in order of highest to lowest concentration) were Methanol, Formaldehyde and Acetaldehyde. Propionaldehyde, Acrolein and Phenol were not detected. In all but the fine size fraction, methanol and formaldehyde accounted for more than $90 \%$ of the Total HAP emissions. In the fine size fraction, acetaldehyde contributed to between 7 and $23 \%$ of the Total HAP emissions, depending on the final moisture endpoint.

6. As the sample size fraction increases, the data variability increases due to reduced sample homogeneity.

7. The larger the sample size fraction, the longer the drying period required to reach the target $\%$ moisture endpoint. For example, the $10 \mathrm{~g}$ fine size fraction test specimens took 14 minutes to reach $10 \%$ final moisture whereas the $10 \mathrm{~g}$ large size fraction specimens took 25 minutes to reach $10 \%$ final moisture.

8. The largest Methanol emission measured was from the large size fraction dried to $10 \%$ moisture. This probably occurred due to severe over drying along the wood chip edges and along the fibrous bark pieces as a result of the extended drying times required to reduce the bulk \% moisture down to $10 \%$.

9. Acetaldehyde was not detected in any of the large size fraction runs. Trace levels were detected in the medium size fraction and somewhat higher concentrations were detected in the fine size fraction.

10. The reported VOC and Pinene emissions are consistent with reported values for related wood materials. Refer to attached "Mechanisms of Terpene Release During Sawdust and Flake Drying” by Sujit Banerjee, 2001.

11. The reported HAP emissions are consistent with reported values for related wood materials ${ }^{4}$. 


\subsection{HIGH-TEMPERATURE HIGH-PRESSURE AIR HEATER MATERIALS TESTING}

\section{Summary}

Four different candidate tube materials, including SA-213P91, SA-213TP347H, SB-213-800H, and SS-353 were tested in oxidizing and reducing regions of the DeRidder No.2 Bark Boiler.

For reducing atmosphere application only $800 \mathrm{H}$ and $353 \mathrm{MA}$ materials appear to be suitable candidates for AH-1 based on the fact that these materials did not sag during the 3-month period (over $2000 \mathrm{hrs}$ ) of in-furnace testing.

In the oxidizing zone of the in-boiler testing all of the materials appeared to have held up during 2 separate series of tests.

Laboratory analysis will be performed on the surviving coupons to determine the final material selections

\section{Scope of Work}

Testing of candidate air heater tube materials was conducted in the No.2 Boiler in DeRidder, Louisiana. Tube coupons are located in two sections of the boiler representing conditions expected for the air heater tubes in AH-1 and AH-3. Erosion, corrosion, and fouling experience gained in testing these coupons will allow better material selections to be made for the demonstration plant air heaters. The following tasks comprise the tube material study.

1. Test condition definition and selection of coupon location

2. Selection of tube materials for coupon testing

3. Design of test coupons and modules

4. Development of I\&C and data collection system

5. Procurement and characterization of the selected tube materials

6. Fabrication of the test coupons and modules

7. Installation of the test modules at the selected locations

8. Short and long term testing

9. Characterization of coupon samples after exposure

10. Report and recommendations

Design, preparation and installation of the test coupon assemblies were done by the Oak Ridge National Laboratories (ORNL) with direction and support from DeRidder mill personnel and GTI.

\section{Design of Test Coupon Assemblies}

The separate air heaters will have their tubes exposed to different gas environments - oxidizing in the stoker and reducing after the gasifier. Anticipated flue gas and syngas temperatures for the air heaters are of the order of $2000-2200^{\circ} \mathrm{F}$. The target exit air temperature is $1400^{\circ} \mathrm{F}$ minimum with the eventual goal of air temperatures as high as $1800^{\circ} \mathrm{F}$. Sample tubes were therefore be tested in two different zones in the boiler: near the grate where fuel rich conditions simulate the reducing atmosphere after the gasifier, and at the top of the furnace in front of the existing superheater banks. The tube locations in No. 2 Boiler are shown in Figure 4.2-1. Four different 
materials, including SA-213P91, SA-213TP347H, SB-213-800H, and SS-353 were selected for testing in both locations. 3/4" pipe (1.05" OD) was selected for the test tube coupons based on the availability compressed air (total $200 \mathrm{scfm}$ ) for cooling at the mill.

\section{Test Condition Location and Tube Sample Configuration}

Based on the project requirements and available data from No. 2 Power bark firing boiler at Boise, two test locations of test tube coupons were identified; one location about $6 \mathrm{ft}$ above the grate considered as a reducing environment, the other location near the top of the boiler in an oxidizing environment as shown in Figure 4.2-1.

The first test panels provided for testing of 4 test samples per panel as shown in Figure 4.2-2 for both top and bottom test locations. ORNL purchased the $3 / 4$ " pipe and fabricated the bend on the $4 \frac{1}{2} \mathrm{ft}$ long samples. The bends faced opposite the direction of flue gas flow. ORNL assembled the samples in the test panels. The $2^{\text {nd }}$ test panels were designed and fabricated by GTI and provided for testing of 2 test samples per panel for the top location of the boiler.

\section{Measurement Schematics and Data Collection System}

To measure metal and air temperature five (5) thermocouples were installed by ONRL on each tube; four (4) of Type K 1/16" diameter with 310 SS sheath attached to the outside surface of the test tube coupon approximately every 14" along the length; and one (1) Type K 1/8" diameter with $310 \mathrm{SS}$ sheath to measure the air temperature on the inside of the tube at the exit of the tube. In the first series of tests the thermocouples were mounted on the topside of the tube and attached with 310 stainless shim stock bands. In the second series of tests, $1 / 8^{\prime \prime} \times 3 / 8^{\prime} \times 3 / 8^{\prime \prime}$ Stainless steel machined weld pads were employed to secure the tip of the thermocouple and along the length. In the second series the thermocouples were mounted on the bottom side of the tube facing the flue gas flow.

A control valve, pressure transducer, surge tank and pressure regulator (as shown in Figure 4) allowed automatic control of the compressed air flow to each individual test tube coupon. In some cases air flow control was based on air temperature and in others based on test tube coupon skin temperature. GTI assisted ORNL in selection of controls and instrumentation including pressure regulators, control valves and pressure transducers and piping/electrical configuration. ORNL assembled the piping/electrical for each test tube panel. Preliminary check out of the electrical operation and thermocouple recording/control in a data-logging computer with necessary Labview software was performed at ORNL.

Fabrication of the air heater tube testing assemblies was completed at ORNL including attachment and testing of thermocouples. The assemblies were transported to the DeRidder mill by ORNL personnel and installed through existing access doors on the West side of Level 2 and Level 5 on No. 2 Power Boiler on March 19, 2003. Identification of the tubes and their associated thermocouples and pressure transmitters is given below. 


\section{Lower Door}

\begin{tabular}{|c|c|c|c|c|}
\hline Tube \# & Material/Thk, in. & Skin T/C \# & Air T/C \# & Pressure \\
\hline 1 & $353 \mathrm{MA} / 0.12$ & $1,2,3,4$ & 5 & 1 \\
\hline 2 & $800 \mathrm{H} / 0.22$ & $6,7,8.9$ & 10 & 2 \\
\hline 3 & $\mathrm{P} 91 / 0.16$ & $11,12,13,14$ & 15 & 3 \\
\hline 4 & $347 \mathrm{H} / 0.22$ & $16,17,18,19$ & 20 & 4 \\
\hline
\end{tabular}

\section{Upper Door}

\begin{tabular}{|c|c|c|c|c|}
\hline Tube \# & Material/Thk, in. & Skin T/C \# & Air T/C \# & Pressure \\
\hline 5 & $353 \mathrm{MA} / 0.12$ & $21,22,23,24$ & 25 & 5 \\
\hline 6 & $347 \mathrm{H} / 0.22$ & $26,27,28,29$ & 30 & 6 \\
\hline 7 & $\mathrm{P} 91 / 0.16$ & $31,32,33,34$ & 35 & 7 \\
\hline 8 & $800 \mathrm{H} / 0.22$ & $36,37,38,39$ & 40 & 8 \\
\hline
\end{tabular}

\section{Installation of Test Tube Coupons in Boise's DeRidder No. 2 Bark Fired Power Boiler.}

The first series of test panels were installed on March 19, 2003 in the No. 2 Power Boiler. A cold test was performed with the plant compressed air to check out the instrumentation and measure the air pressures in each sample tube before inserting the test panels in the boiler. Once installed several issues arose. The test panel installed near the top of the boiler between the $1^{\text {st }}$ and $2^{\text {nd }}$ banks of superheater tubes was affected by the operation of the sootblower, which operated 8 to 10 times per day. As a result of sootblower operation, the tubes were bent and some thermocouples were detached. Another issue was that the thermocouples on the bottom panel failed prematurely. Nevertheless preliminary information indicated that the test samples in the bottom location experienced skin temperatures of the order of 1400 to $2000 \mathrm{~F}$ as shown in Figure 4.2-3. After 3 months of testing the samples were removed and it was noted that P91 steel sagged in the reducing atmosphere in the lower portion of the furnace.

A $2^{\text {nd }}$ series of new test tube coupons with thermocouples attached on the tubes under a pad welded to the tube was installed on June 23, 2003. For this $2^{\text {nd }}$ series of tests new test panels were made for the top of the boiler and contained two tubes per panel. The new test panels were installed in front of the steam superheater tubes where the soot blower would not affect them. After over two months of operation 12 of 35 thermocouples are still providing data. In this $2^{\text {nd }}$ series of tests, $347 \mathrm{H}$ stainless steel sagged in reducing atmosphere. Inspection of the $2^{\text {nd }}$ series of test tube coupons is scheduled for Nov. 3, 2003. At that time it is planned to remove the $2^{\text {nd }}$ set of test tube coupons for laboratory analysis.

\section{Findings to Date}

Although the target air temperatures of $1400^{\circ} \mathrm{F}$ were not achieved for the short tube samples in either test location because of insufficient length/surface area of the samples, the sample tube skin temperatures in the rich condition approached $1800^{\circ} \mathrm{F}$. Furthermore, the tube samples were exposed to flue gases from bark firing in the boiler for over $2000 \mathrm{hrs}$ under variable conditions. For reducing atmosphere application only $800 \mathrm{H}$ and $353 \mathrm{MA}$ materials appear to be suitable candidates for AH-1 based on the fact that these materials did not sag during the 3-month period (over $2000 \mathrm{hrs}$ ) of in-furnace testing. In the oxidizing zone of the in-boiler testing all of the materials appeared to have held up during both series of tests and accordingly further laboratory analysis is required to narrow down the selection for a oxidizing application. 


\subsection{RESULTS AND DISCUSSION}

The plant design study and economic analysis for the proposed Advanced Power Generation System was conducted to evaluate the technical and economic feasibility of the system for the DeRidder mill and other similar mills in the Forest Products Industry. The primary performance goals for the advanced system are to provide increased self-generated power production for the mill, and to increase wastewood utilization while decreasing fossil fuel use. Additional goals are to reduce boiler NOx and $\mathrm{CO}_{2}$ emissions. The objective of the current study is to determine the technical and economic feasibility of an Advanced Power Generation System capable of meeting these goals so that capital investment decision can be made regarding its implementation at the mill.

\subsection{FINDINGS FOR THE DERIDDER MILL}

The study revealed that the original system configuration, with all high-pressure air heated in an air heater located in the upper furnace of the bark boiler was not feasible due to the limited physical space and heat available in the furnace. An alternative design was developed utilizing the excess chemical and sensible heat in the gasifier syngas stream to heat additional highpressure air in a second, external heat exchanger/syngas cooler between the gasifier and the boiler. Each air heater will provide air to one of two ERGTs.

It was determined that the gasifier would require bark to be dried for reliable feeding and so a bark dryer was added to the design using waste heat from the boiler flue gas as the drying medium. A second dryer was then added to dry bark for the stoker boiler in order to make more high-level heat in the furnace available for air heating.

An experimental study was conducted with bark from the DeRidder mill to determine what VOC emissions might be expected from drying bark and exhausting the resulting moist flue gas to the atmosphere through the existing No. 2 Boiler flue gas cleaning system. VOC emissions from the DeRidder were found to be in the expected range for similar materials and the calculated emissions are expected to be within permitted limits.

The mill was found to be somewhat steam-limited during certain periods of the year and the target steam production from No. 2 Boiler was set at 250,000 lb/h for the new system, $125 \%$ of the original boiler MCR. HRSGs were added to the ERGT exhausts for about $129,000 \mathrm{lb} / \mathrm{h}$ of additional process steam generation including $100,000 \mathrm{lb} / \mathrm{h}$ of 250 -psig process steam.

It was determined that the internal air heater could be located in the upper furnace just below the arch tip and that, with dried bark as fuel, high pressure air could be heated to the required $1400^{\circ} \mathrm{F}$. It was also determined that the required syngas injection nozzles can be located at appropriate positions on the boiler. A circulation study for the modified boiler was found to be acceptable. It was determined that the boiler would operate at its design GHRR in spite of the increased steam and air production. The required FD fan flows will be similar to current operation at similar steam loads. ID fan capacity will also be similar and will be near its limit with the full system integration in Step 3.

The original gas turbine selected, the Titan 130 by Solar Turbines, proved to be too difficult to modify for externally recuperated operation. A suitable alternative was found in the Alstom GT $35 \mathrm{P}$, an engine that has already been used in a recuperated mode. The GT-35P has the added advantage of generating an additional $3 \mathrm{MW}$ (17MW vs. 14MW for the Titan). It also operates at a lower pressure ratio, so the pressure rating for the air heaters can be lowered. Finally, the 
GT 35P can provide and use the total amount of air heated in both air heaters, meaning that both air heaters can stay in service even with one turbine off-line.

It was determined that candidate air heater tube materials are available that should be suitable for operation at heated air discharge temperatures of $1400^{\circ} \mathrm{F}$ and possibly higher. It was further determined that a workable externally recuperated gas turbine cycle can be developed at this air temperature. An experimental study was conducted to test candidate air heater tube materials inside the furnace of No. 2 Boiler. Tube samples were positioned in the boiler to test performance under both oxidizing and reducing conditions. Several of the tested materials have survived for over several thousand hours and exposure of the surviving materials is continuing.

The mill was found to have limited but sufficient space in the vicinity of No. 2 Boiler to install the necessary plant equipment. A gasification plant design was developed for the system that provides sufficient syngas for the system and has an acceptable footprint. Integration of the gasifier and associated equipment into the overall operation of the No. 2 Boiler was determined to be feasible.

The modified plant design was found to meet the primary objectives of the project for increased bark utilization, decreased fossil fuel use, and increased self-generated power in the mill. Bark utilization in all cases for the modified plant is significantly higher (90-130\%) than current operation compared to the $50 \%$ design goal. For equivalent steam production, the total natural gas usage for the modified plant is in all cases lower than current operation. For Implementation Steps 1 and 2 gas usage is reduced by $45-47 \%$ and for Step 3 by $29 \%$. While the current average steam production from No.2 Boiler is about $213,000 \mathrm{lb} / \mathrm{h}$, the combined steam production from the boiler and HRSGs will be about 315,000 lb/h for Steps 1 and 2 and 379,000 $\mathrm{lb} / \mathrm{h}$ in Step 3. In Step 3 this steam production increase will be accomplished at a GHRR equal to the original boiler design. Calculated boiler efficiencies for Steps 1 and 2 (steam) and Step 3 (cogeneration-steam plus air) are increased from the original design value of $70 \%$ to $74.2,79.4$ and 78.9, respectively due to a combination of improved burnout, operation with lower excess air, and drier fuel. For the fully implemented case in Step 3, the thermal efficiency of fuel to electricity conversion is $79.8 \%$ in the cogeneration mode, $5 \%$ above the design goal. Finally, self-generated electricity will be increased from the $10.8 \mathrm{MW}$ currently attributable to No.2 Boiler to 29.7MW in Steps 1 and 2 and 46.7MW in Step 3, increases of 175\% and 332\%, respectively.

Environmental benefits derived from the system include a reduction in NOx emissions from the boiler of about $30-50 \%$ (90-130 tons/year) as a result of staged combustion (reburning) with syngas in the boiler, improved carbon burnout and operation at lower excess air. This does not count NOx reduction that may be associated with any coal-based purchased electricity that is replaced.

The project would provide a significant reduction in $\mathrm{CO}_{2}$ emissions from the generation of electricity to meet the mill's power requirements. This may allow the mill to insulate themselves to some extent from future greenhouse gas regulations, which may be promulgated at the state or federal level. A reduction of up to 50,000 tons/yr of carbon dioxide emissions will result from a net reduction in gas usage in the mill as a result of the project. The project will reduce purchased electricity in the mill by $34 \mathrm{MW}$, resulting in an additional 410,000 tons/yr reduction in $\mathrm{CO}_{2}$ emissions due to reduction of purchased electricity compared to current operations. The total $\mathrm{CO}_{2}$ reduction amounts to about $33 \%$ of the $\mathrm{CO}_{2}$ currently generated to meet the mills purchased 
electricity requirement. In this analysis, the purchased electricity is assumed to be generated from coal and woodwaste fuel is considered to be $\mathrm{CO}_{2}$ neutral to the environment.

The three-step implementation plan for installation of the modified plant was found to be an acceptable approach to reduce technology risk. The initial implementation step will install the gasification island, the external air heater, one turbine, one HRSG and one bark dryer. No.2 Boiler will not be dependent on these systems so that shakedown and debottlenecking will not jeopardize steam production. In Step 2, the second bark dryer will be installed once performance with the first dryer is judged to be acceptable. In Step 3, the internal air heater will be installed in No. 2 boiler and the second turbine and HRSG will be added only after all other new plant components have been successfully demonstrated.

A Systems Off-Line analysis of the proposed plant indicates that an acceptable means can be developed to deal with the loss of one of the major systems, including one of the ERGTs, which would put its associated air heater at risk for overheating. Since one GT 35P can supply enough air for both air heaters, the remaining turbine can utilize both air heaters with reduced natural gas firing rate until the other turbine is brought back on-line. As designed, the gasification plant and associated air heater and ERGT cannot be run unless No.2 boiler is on-line because the boiler is the only user for the syngas. However, if alternative uses for this fuel gas can be found in the mill, the gasification island and one ERGT producing $17 \mathrm{MW}$ of electricity could be operated independent of the boiler.

Preliminary designs were developed and equipment, materials and operating costs identified for all major plant systems and the Balance of Plant equipment. The resulting economic analysis was developed as a simple payback period computed by dividing the total investment cost by net annual savings realized as a result of plant operations. The total capital investment for the proposed plant is estimated to be $\$ 70.4$ million. This includes a relatively large $25 \%$ contingency and does not include any subsidy or cost share. The total annual saving is estimated to be $\$ 13.69$ million. This results in a simple payback period of 5.1 years. Savings and payback period was also analyzed assuming an alternative set of natural gas and electricity purchase prices. The alternative prices assumed are $\$ 5.00$ per million Btu of natural gas and $\$ 42.00$ per MWh of electricity. The analysis results are presented in Table 3.10-3. As may be seen from the table, the payback period changed very slightly due the alternative set of prices. Simple payback period is increased from 5.1 years to 6.6 years.

The overall construction schedule for the plant is estimated to be twenty-seven months including design, engineering, fabrication, procurement, installation start-up, testing and commissioning. This does not include development time for the turbines, which will have to commence before the rest of the project. The gasification plant equipment is expected to have the longest lead times at 18 months.

\subsection{APPLICATION OF THE TECHNOLOGY TO OTHER MILLS}

The results of the study for the DeRidder site are expected to be applicable to many paper mills in the U.S. firing wastewood, clarifier solids and other biosolids for steam and electric power production. These waste materials can all be successfully gasified and, with the proposed advanced power system configuration, utilized for electric power generation.

Approximately 3.2 quads $\left(3.2 \times 10^{15}\right.$ Btu $)$ of energy is consumed annually by the Forest Products Industry with the majority, about 2.7 quads, consumed by the Pulp and Paper Industry. ${ }^{5}$ Over half of this energy is derived from recovered biomass sources, including about $30 \%(0.41$ 
quad/yr) from bark and wood residues typically burned in stoker boilers. The balance of the industry's energy requirements are supplied primarily from fossil fuels and purchased electricity, including about 0.59 quads/yr of natural gas and 0.21 quads/yr of purchased electricity. Annual expenditures by the industry for gas and electricity are about $\$ 4.4$ billion, representing about $72 \%$ of total energy expenditures.

The advanced power system is designed to increase a mill's capacity to self-generate electrical power and steam from biomass while decreasing its dependence on fossil fuels for steam and power production. When applied to a gas-cofired boiler as in the DeRidder case, the technology can eliminate gas usage in the boiler by substituting biomass-derived syngas as reburn fuel. If the boiler is operating below its maximum steaming capacity due to biomass combustion limitations at the grate, the gasification of a portion of the biofuel outside the boiler followed by injection and combustion of the syngas in the boiler can restore its full steaming capacity. This can result in further reduction of gas (or other fossil fuel) usage by the mill as less gas will be used for steam and power generation from package boilers.

The energy and environmental impacts of the advanced power system on the DeRidder mill are discussed in the findings above. The impacts on other mills with woodwaste-fired boilers will depend on the boiler capacity, the extent to which it is cofired with gas or other fossil fuel, how much fossil fuel is used for steam and power generation in other boilers and the price and emissions associated with purchased power. We estimate that there are about 200 woodwaste boilers in the industry consuming about 245 million Btu/hr of bark and other woodwastes each. If the advanced power technology were applied to $20 \%$ of this boiler capacity using gas in a similar manner for cofiring and supplemental steam and power generation, the potential increase in self-generated power would be over 8,000 million $\mathrm{kWh} / \mathrm{yr}$, or about $13 \%$ of the total power purchased by the industry.

Assuming that purchased electricity is generated from coal and considering woodwaste fuel to be $\mathrm{CO}_{2}$ neutral to the environment, the substitution of self-generated biomass-based power for coal based purchased power in $20 \%$ of the industry's woodwaste-fired boiler capacity would reduce $\mathrm{CO}_{2}$ emissions to the environment by over 10 million tons/yr.

With an average NOx production of about $0.251 \mathrm{~b}$ NOx/MMBtu from woodwaste combustion, application of the technology to $20 \%$ of the industry's woodwaste boiler capacity has the potential to reduce NOx emissions by over 10,000 tons/yr.

\subsection{CONCLUSIONS}

The overall conclusion of the study is that while significant engineering challenges are presented by the advanced power system, particularly for the design and fabrication of the internal and external air heaters, these challenges can be met with operationally acceptable and cost effective solutions. The benefits of increased wastewood utilization, reduced fossil fuel usage and increased self-generated electric power can be realized in an economic manner, with a simple payback period on the order of 6 years. Significant environmental benefits will also be realized in the form of reduced emissions of $\mathrm{NOx}$ and $\mathrm{CO}_{2}$.

The results of the study for the DeRidder site are expected to be applicable to many paper mills in the U.S. firing biosolids for steam and electric power production. These waste materials can all be successfully gasified and utilized for electric power generation. The proposed system makes this feasible by significantly reducing the technology risk and cost of typical gasification- 
based power system using IGCC. IGCC technology hurdles, including the cost, complexity and reliability of key components are eliminated in the proposed system, which does not require high pressure gasifiers and biomass feeding systems to meet the gas turbines pressure ratio or hot gas cleanup systems to meet the turbines stringent inlet gas requirements. The proposed system, using a low pressure gasifier and feeding systems coupled with the use of high-pressure heated air as the working fluid in externally recuperated gas turbines, provides a system much more consistent with typical pulp and paper mill powerhouse operations. The advanced power system offers a near-term solution to the problems of applying advanced gasification-based technology to meet the energy needs and reduce the environmental impact of the U.S. Forest Products Industry. 


\subsection{REFERENCES}

1. H. Abbasi, J. Rabovitser, B. Bryan and S. Wohadlo, et. al., "Commercial Demonstration of METHANE de-NOX ${ }^{\circledR}$ Reburn on a Biomass-Fired Stoker Boiler,” paper presented at the International Gas Research Conference, Amsterdam, The Netherlands, November 58,2001

2. Engineering study by Entec Services, Inc., October 23-24, 2001, Boise internal document

3. M. Buchanan, Institute of Paper Science and Technology, "Total VOC and HAP Emissions from Fresh Bark," Report prepared for GTI, April 2003

4. Banerjee et al., "HAPs Release from Wood Drying," 2000.

5. MECS 1994-Manufacturing Energy Consumption Survey, Energy Information Administration, 1997 


\subsection{LIST OF ACRONYMS AND ABBREVIATIONS}

$\begin{array}{ll}\text { ACFM } & \text { Actual Cubic Feet per Minute } \\ \text { AH } & \text { Air Heater } \\ \text { ASME } & \text { American Society of Mechanical Engineers } \\ \text { ASTM } & \text { American Society for Testing Materials } \\ \text { BACT } & \text { Best Achievable Control Technology } \\ \text { BART } & \text { Best Available Retrofit Technology } \\ \text { BFD } & \text { Block Flow Diagram } \\ \text { BOP } & \text { Balance-of-Plant } \\ \text { CAA } & \text { Clean Air Act } \\ \text { CEM } & \text { Continuous Emissions Monitor } \\ \text { CFR } & \text { Code of Federal Regulation } \\ \text { CGT } & \text { Combustion Gas Turbine } \\ \text { CLECO } & \text { Central Louisiana Electric Company } \\ \text { DNB } & \text { Departure from Nucleate Boiling } \\ \text { DOE } & \text { U.S. Department of Energy } \\ \text { EGT } & \text { Exhaust Gas Temperature } \\ \text { EPA } & \text { Environmental Protection Agency } \\ \text { FD } & \text { Forced Draft } \\ \text { FGR } & \text { Flue Gas Recirculation } \\ \text { FPI } & \text { Forest Products Industry } \\ \text { FTIR } & \text { Fourier Transform Infrared } \\ \text { GHRR } & \text { Grate Heat Release Rate } \\ \text { GT } & \text { Gas Turbine } \\ \text { HAP } & \text { Hazardous Air Pollutant } \\ \text { HCV } & \text { High Calorific Value } \\ \text { HRSG } & \text { Heat Recovery Steam Generator } \\ \text { H\&MB } & \text { Heat \& Mass Balance } \\ \text { HMZ } & \text { Horizontal Mixing Zone } \\ \text { HTSH } & \text { High Temperature Superheater } \\ \text { ID } & \text { Inside Diameter } \\ \text { IGV } & \text { Induced Draft } \\ \text { LCV } & \text { Inlet Vane Guide } \\ \text { MCR } & \text { Low Calorific Value } \\ \text { MJ/hr } & \text { Maximum Continuous Rating } \\ \text { MMBtu/hr } & \text { Mega (Million) Joules per hour } \\ \text { MSW } & \text { Million Btu per hour } \\ \text { NEPA } & \text { National Environmental Policy Act } \\ \text { NSR } & \text { New Source Review } \\ \text { OD } & \text { Outside Diameter } \\ \text { OFA } & \text { Overfire Air } \\ \text { PM } & \text { Particulate Matter } \\ \text { SH } & \text { Superhention of Significant Deterioration } \\ & \end{array}$




\section{ACRONYMS AND ABBREVIATIONS - Continued}

UGA Undergrate Air

VOC Volatile Organic Carbon, Volatile Organic Compounds

$\mu \mathrm{g} / \mathrm{g}$ o.d. micrograms per gram on an oven dry weight basis

ug/g o.d. micrograms per gram on an oven dry weight basis

ppmv parts-per-million-volume

in. inches

in $^{2} \quad$ square inches

$\mathrm{mm} \quad$ millimeter

g grams 


\subsection{FIGURES}

The following figures are presented in this section:

Figure 3.1.1-1 Step 1 Process Flow Diagram

Figure 3.1.1-2 Step 2 Process Flow Diagram

Figure 3.1.1-3 Step 3 Process Flow Diagram

Figure 3.3.1-1 Biomass Dryer Process Flow Diagram

Figure 3.3.2-1 Gasification Plant Process Flow Diagram

Figure 3.3.3-1 Internal High Temperature High Pressure Air Heater

Figure 3.3.3-2 Internal HTHP Air Heater - Selected View 1

Figure 3.3.3-3 Internal HTHP Air Heater - Selected View 2

Figure 3.3.3-4 Results of Metal Study for Internal HTHP Air Heater - No Air Imbalance

Figure 3.3.3-5 Results of Metal Study for Internal HTHP Air Heater - With Air Imbalance

Figure 3.3.4-1 External High Temperature High Pressure Air Heater - Design 1

Figure 3.3.6-1 HRSG Arrangement and Performance

Figure 3.3.7-1 Cooling Water System

Figure 3.3.7-2 Compressed Air System

Figure 3.3.7-3 Electrical Single Line Diagram

Figure 3.3.7-4 Bark Conveying and Delivery System

Figure 3.3.8-1 Plant Construction Schedule

Figure 3.6-1 Integrated Plant Layout (3 sheets)

Figure 4.2-1 Locations of Test Tube Samples in No. 2 Bark Boiler at Boise DeRidder

Figure 4.2-2 Test Assemblies for Air Heater Tube Testing in No. 2 Bark Boiler DeRidder

Figure 4.2-3 Typical Temperature Profiles for Test Tube Coupons with air temperature control $(800 \mathrm{H})$ and skin temperature control $(353 \mathrm{MA})$ 


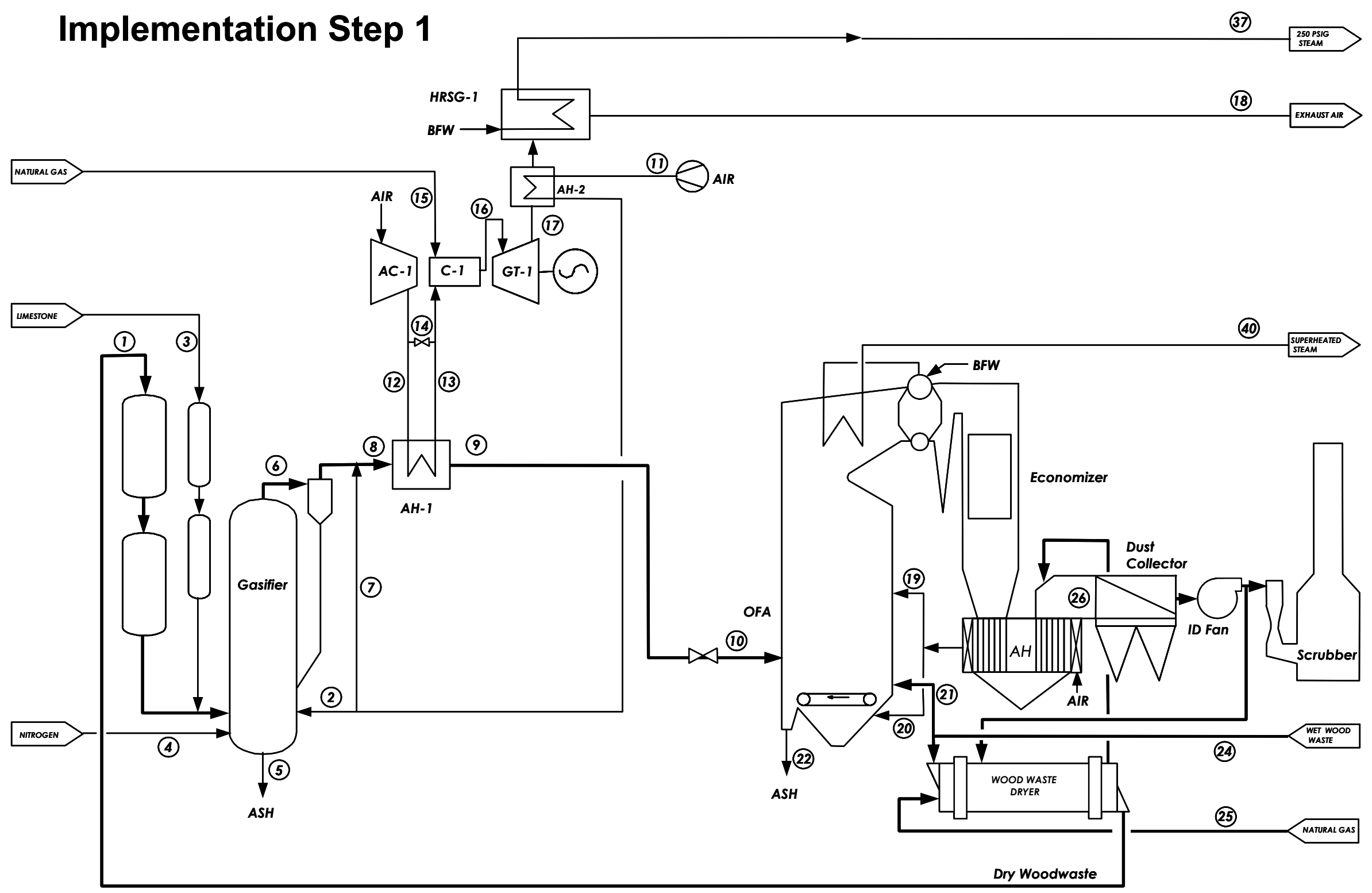

Figure 3.1.1-1 Step 1 Process Flow Diagram 


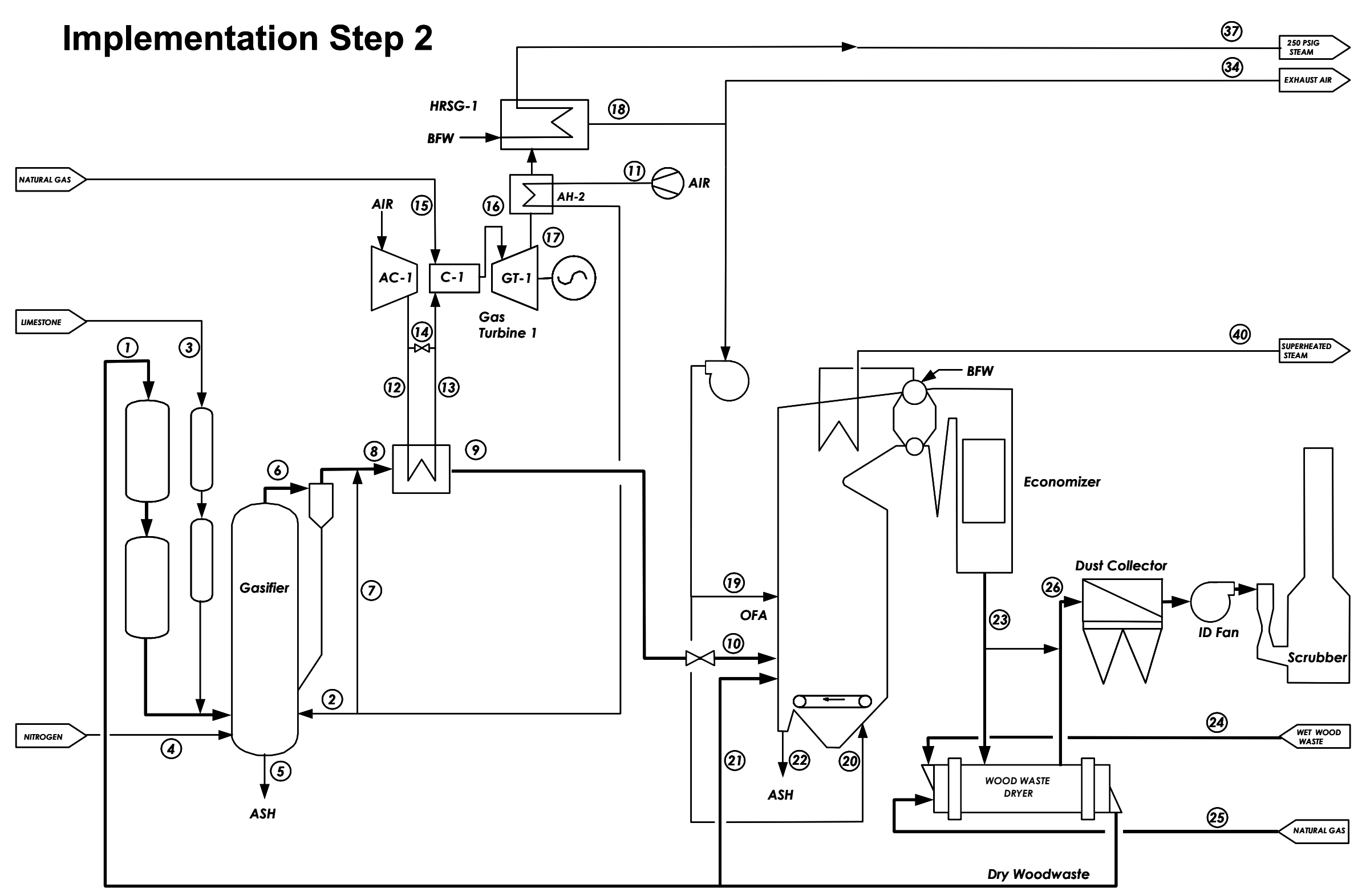

Figure 3.1.1-2 Step 2 Process Flow Diagram 


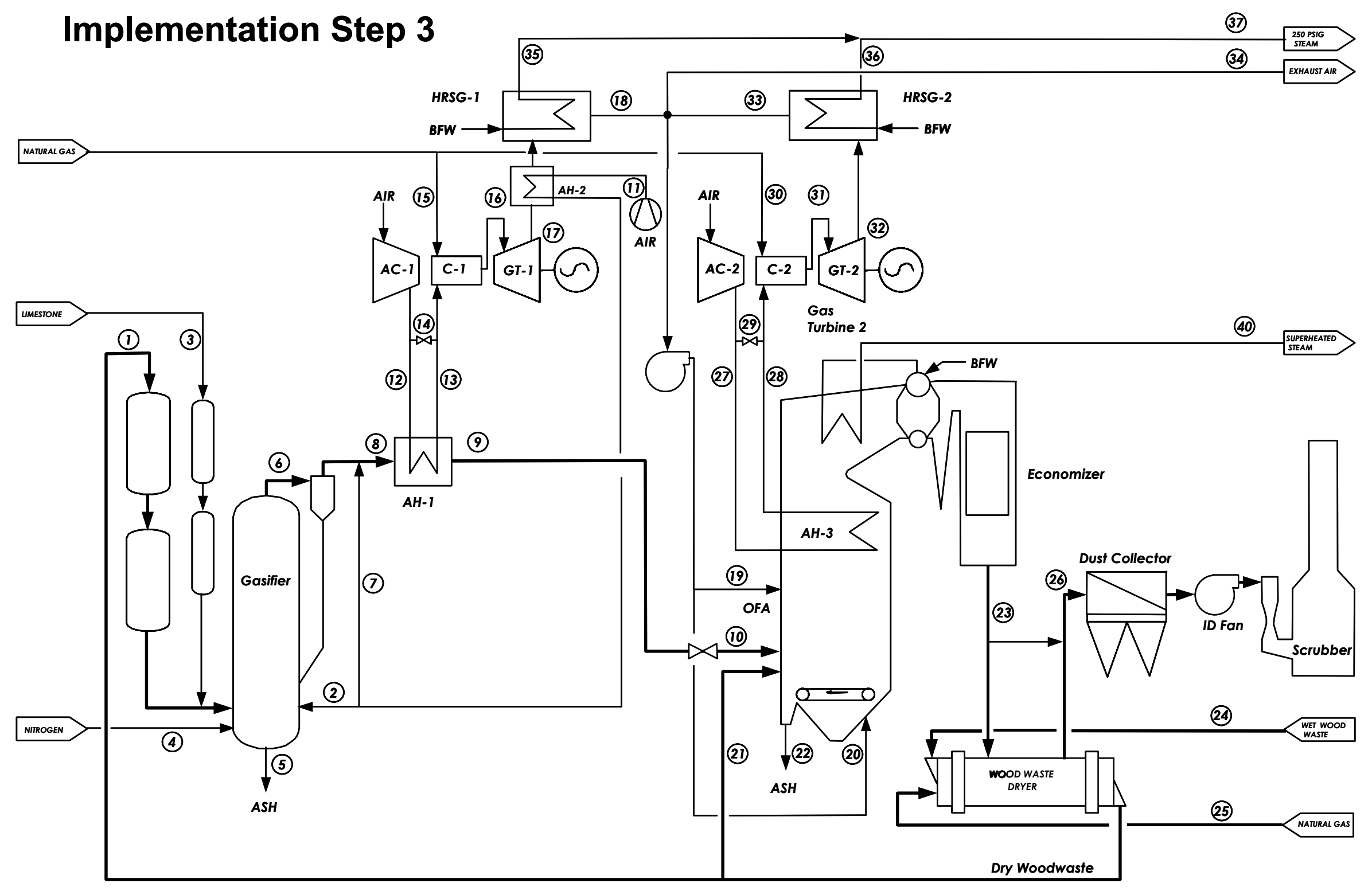

Figure 3.1.1-3 Step 3 and Overall Plant Process Flow Diagram 


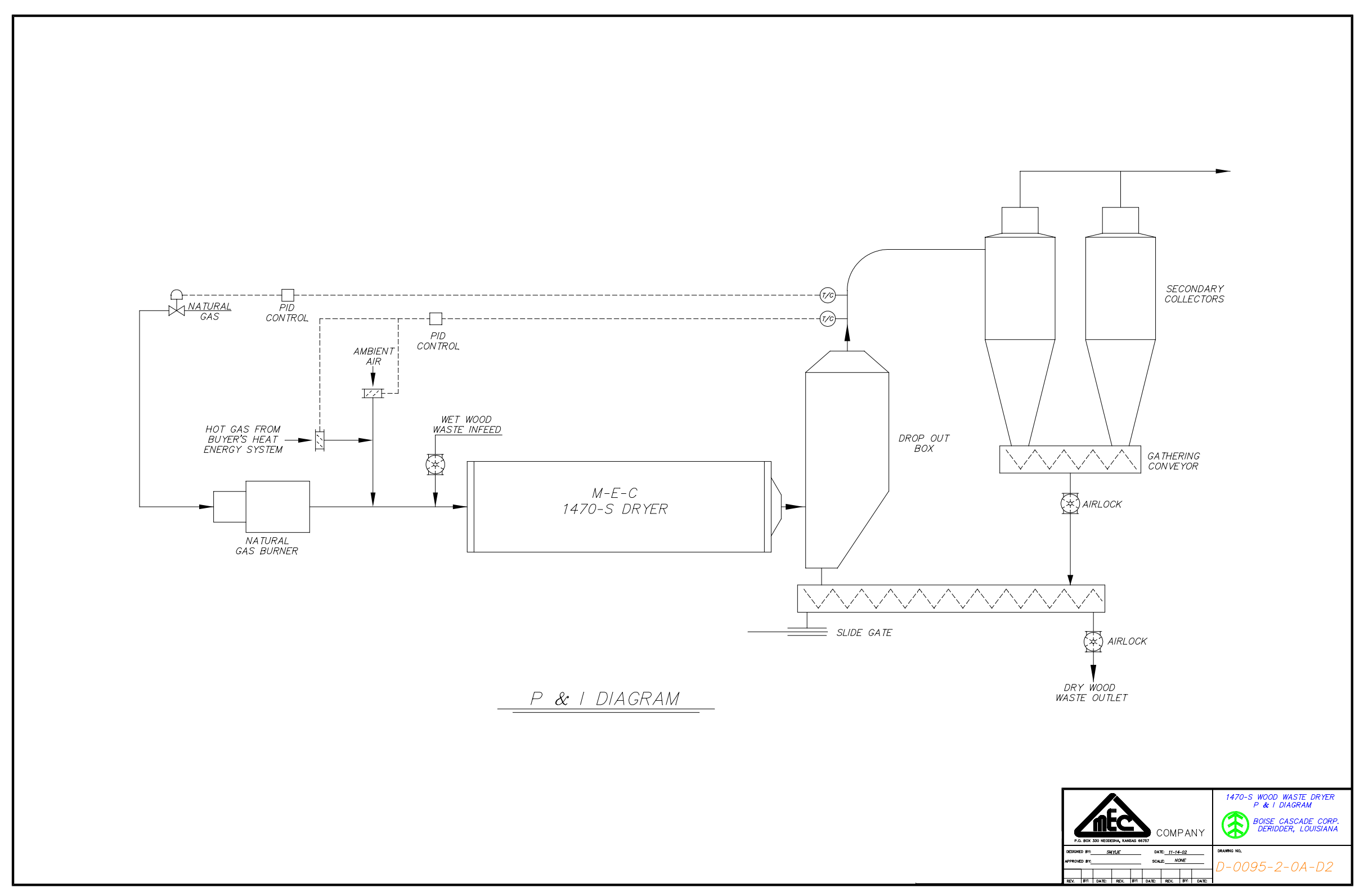

Figure 3.3.1-1: Biomass Dryer Process Flow Diagram 


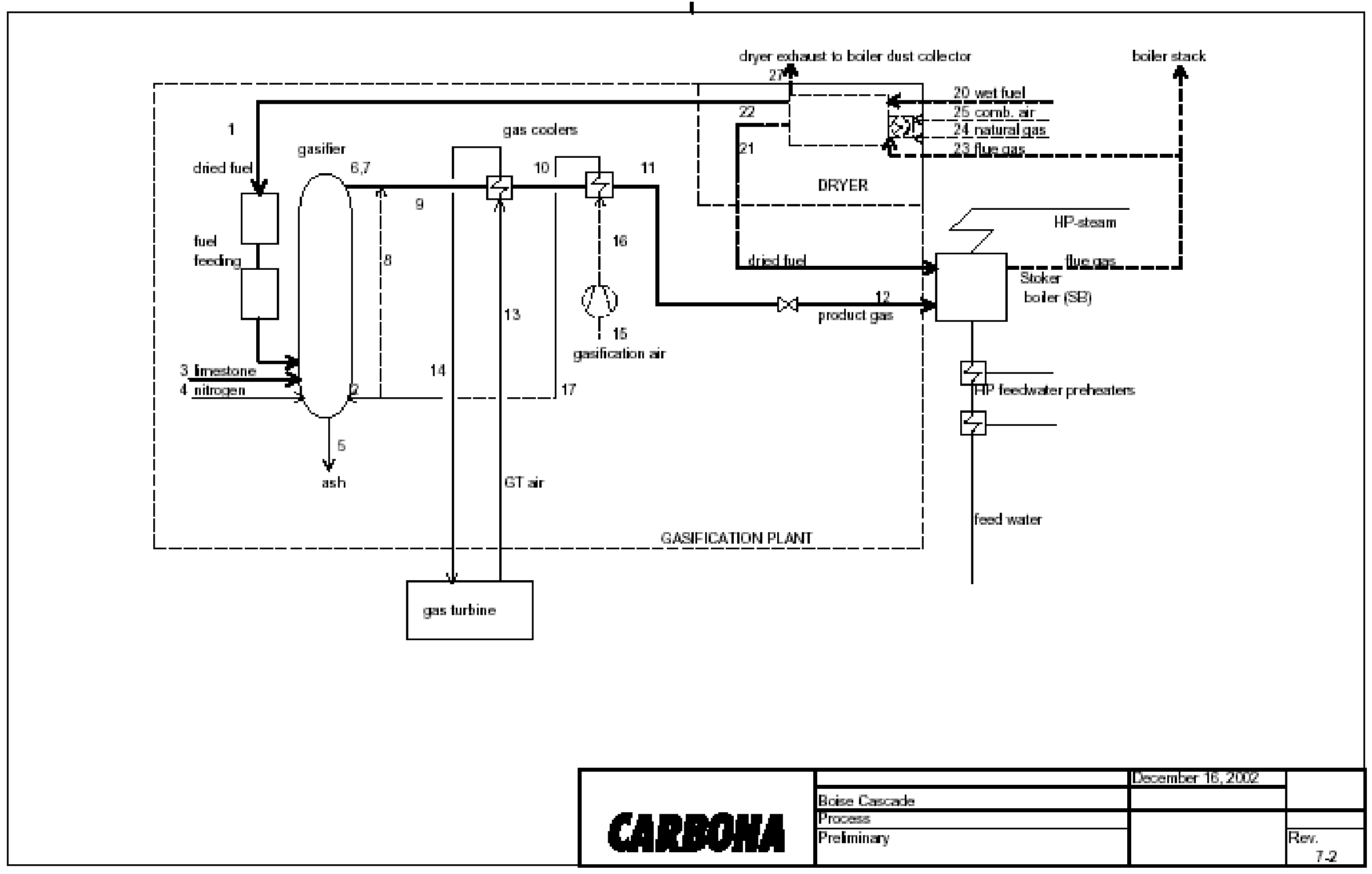

Figure 3.3.2-1: Gasification Process Flow Diagram - Step 3 


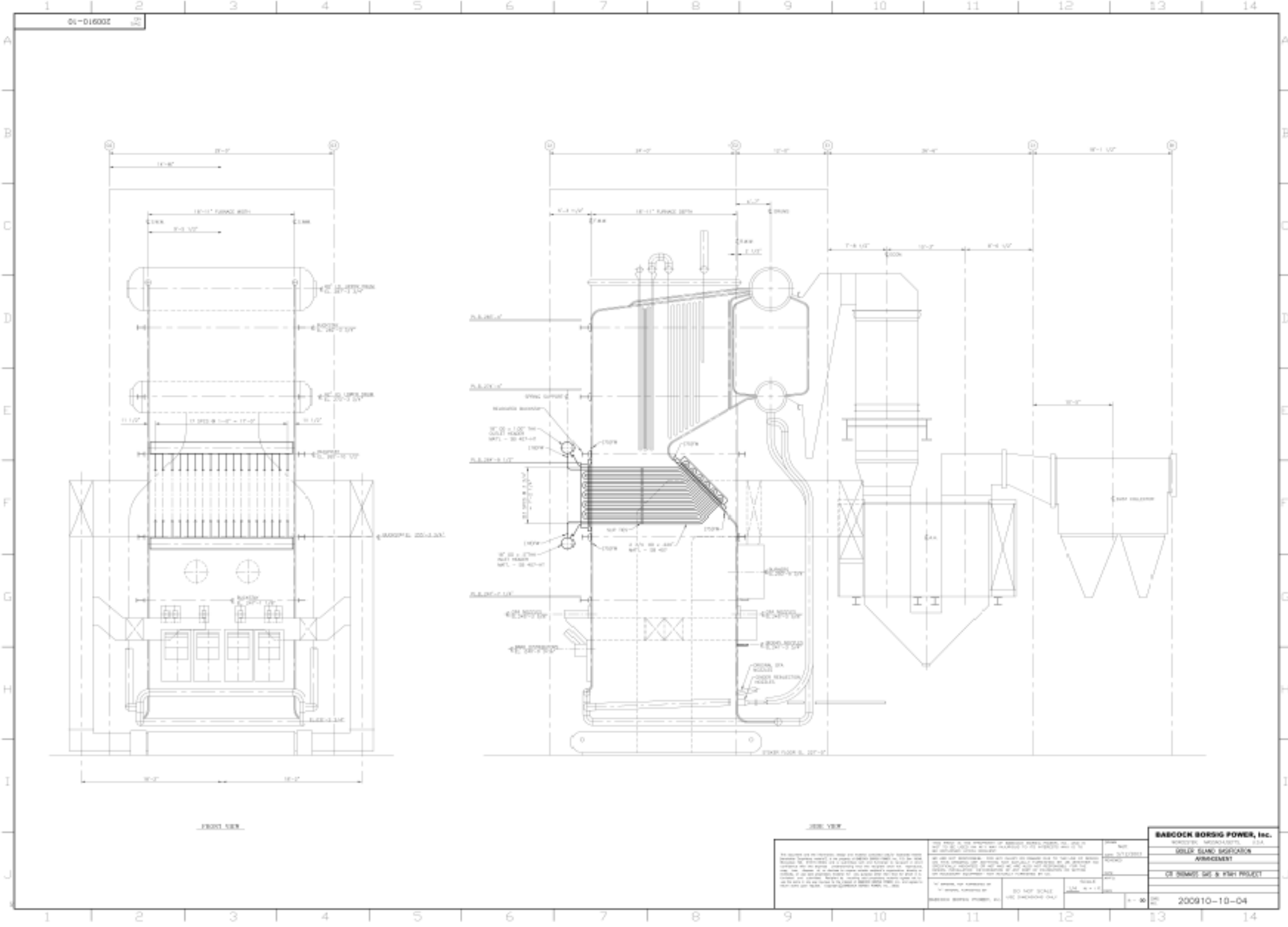

Figure 3.3.3-1 Internal High Temperature High Pressure Air Heater 


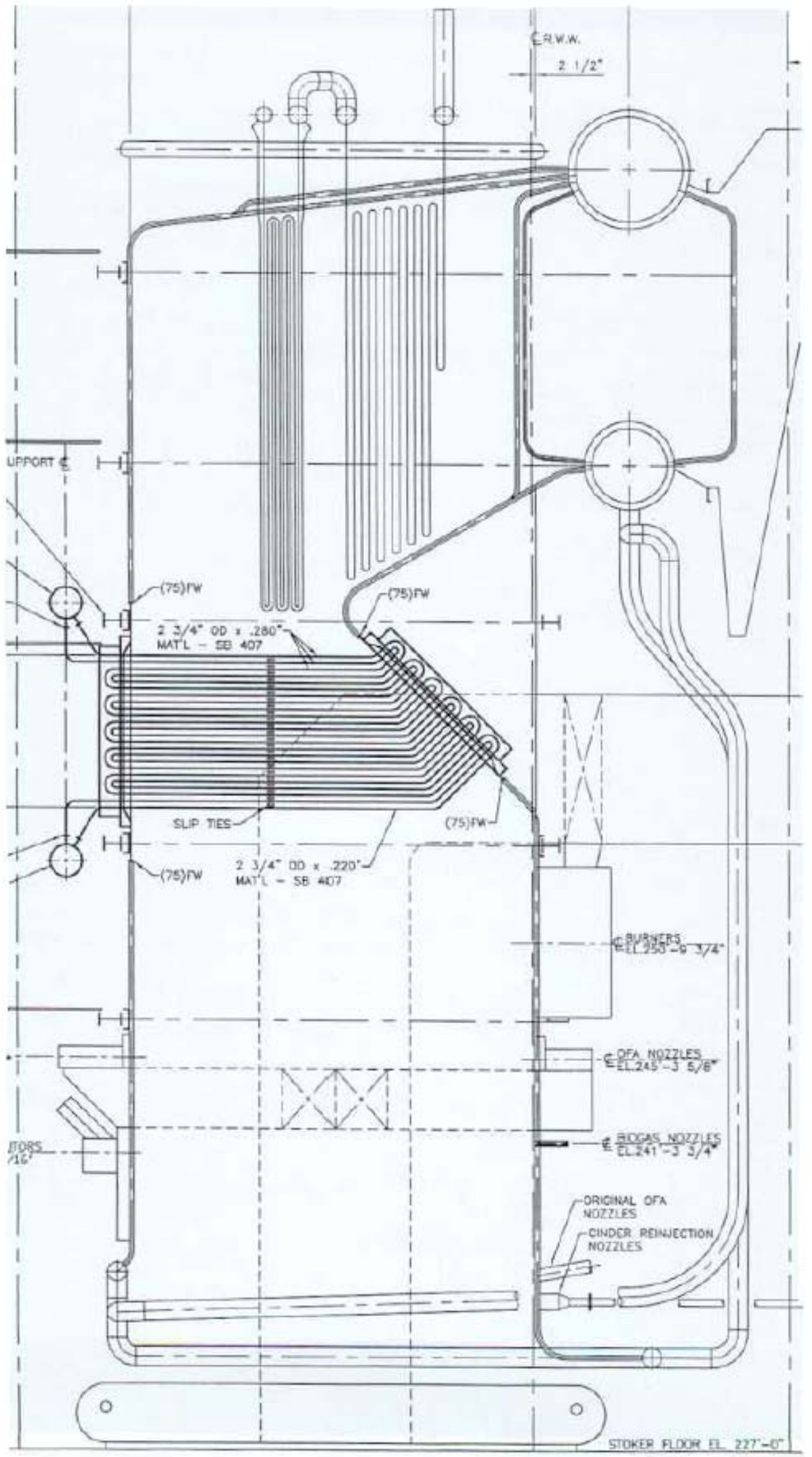

Figure 3.3.3-2 Internal HTHP Air Heater - Selected View 1 


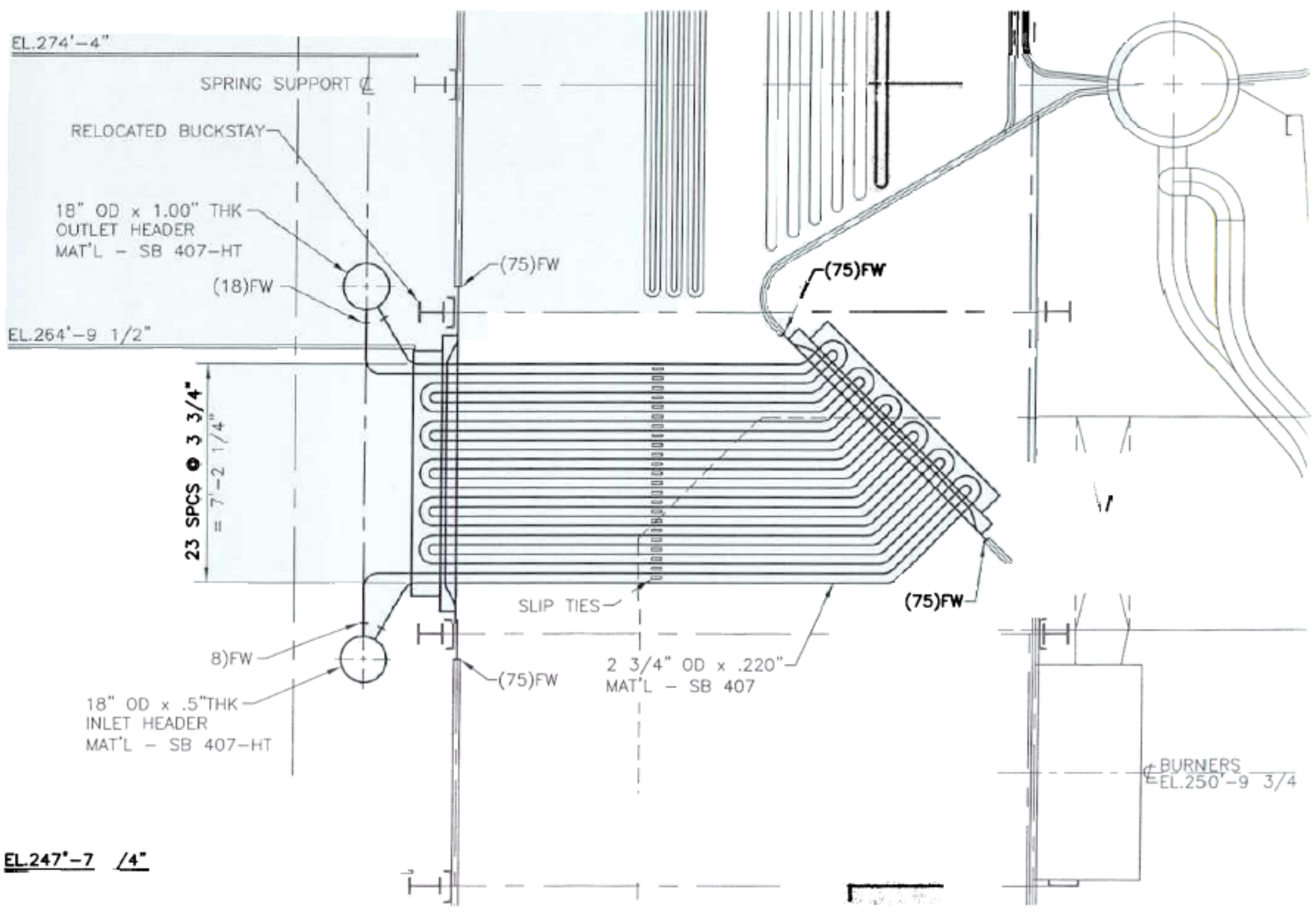

Figure 3.3.3-3 Internal HTHP Air Heater - Selected View 2 


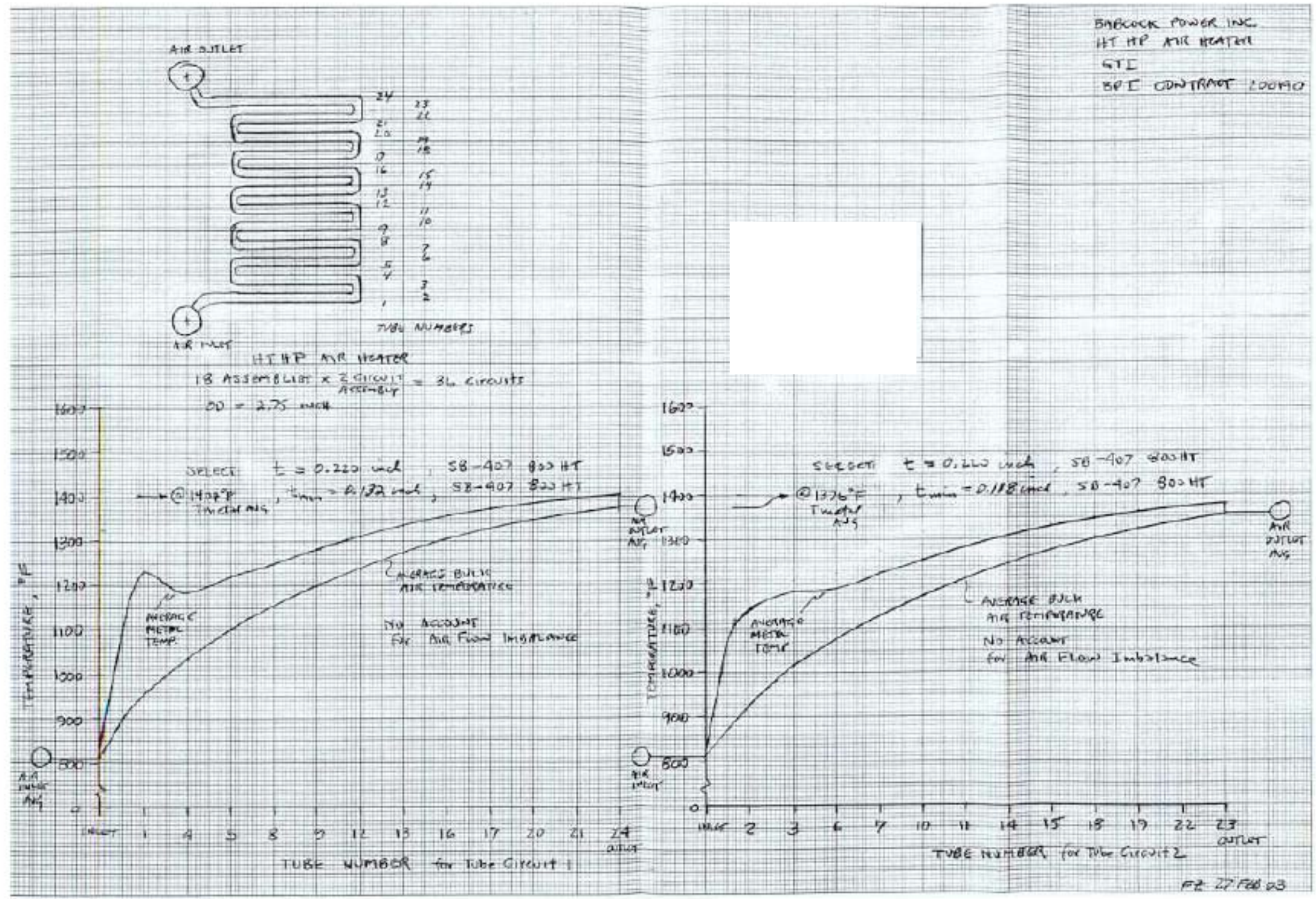

Figure 3.3.3-4 Metal Study for Internal HTHP Air Heater - No Air Imbalance 


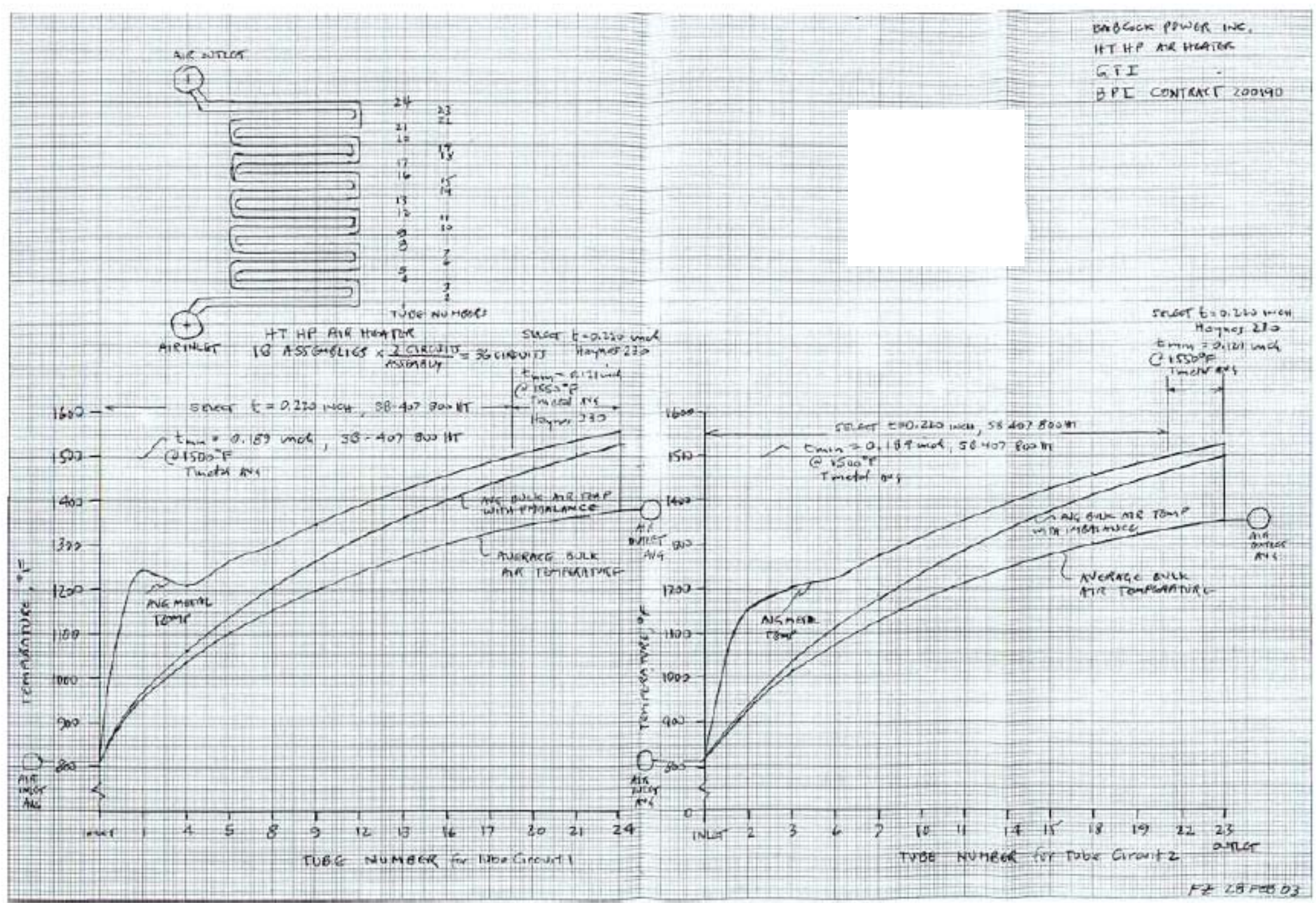

Figure 3.3.3-5 Metal Study for Internal HTHP Air Heater - With Air Imbalance 


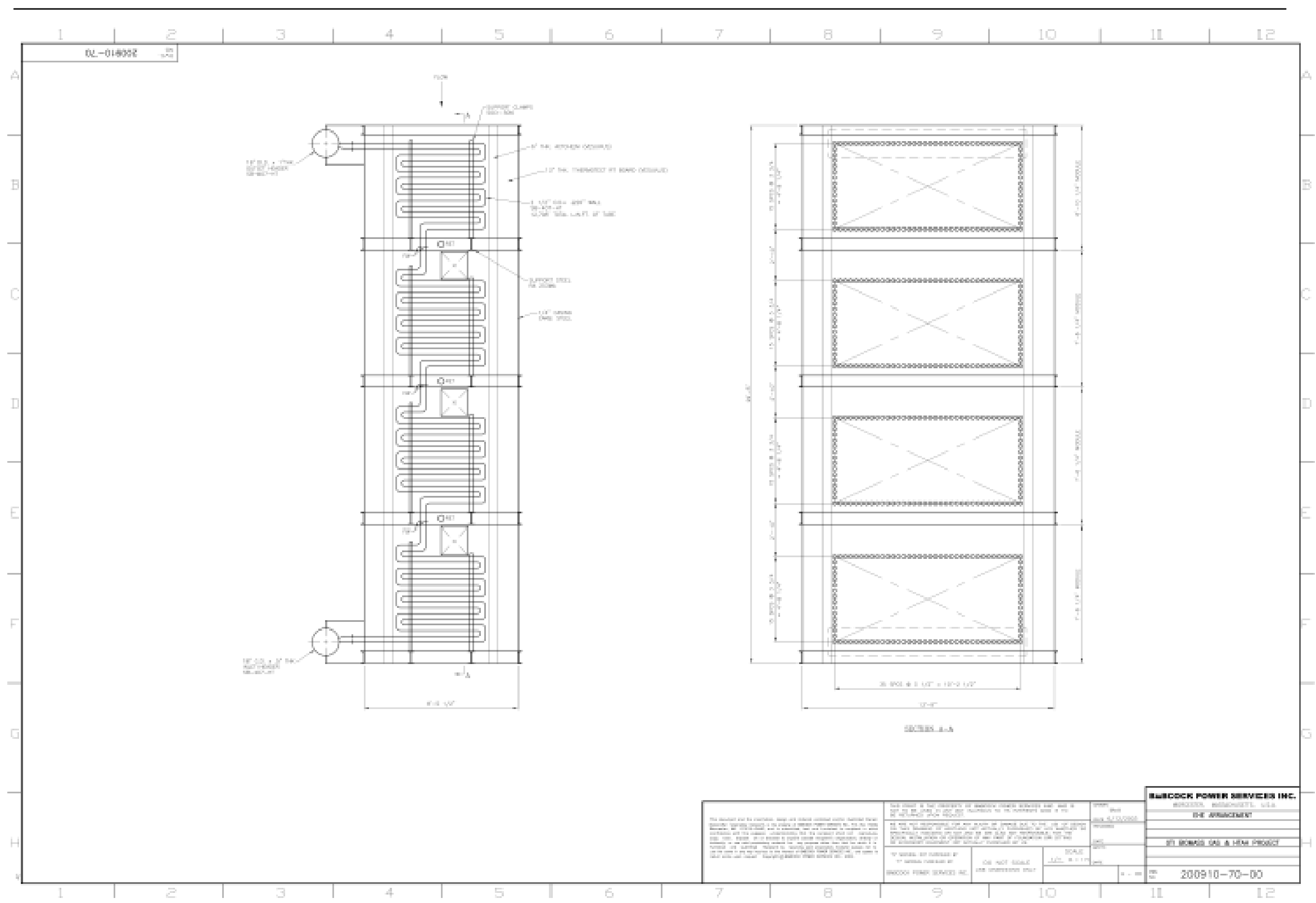

Figure 3.3.4-1 External High Temperature High Pressure Air Heater-Design 1 


\section{Single Train Dual Pressure HRSG}

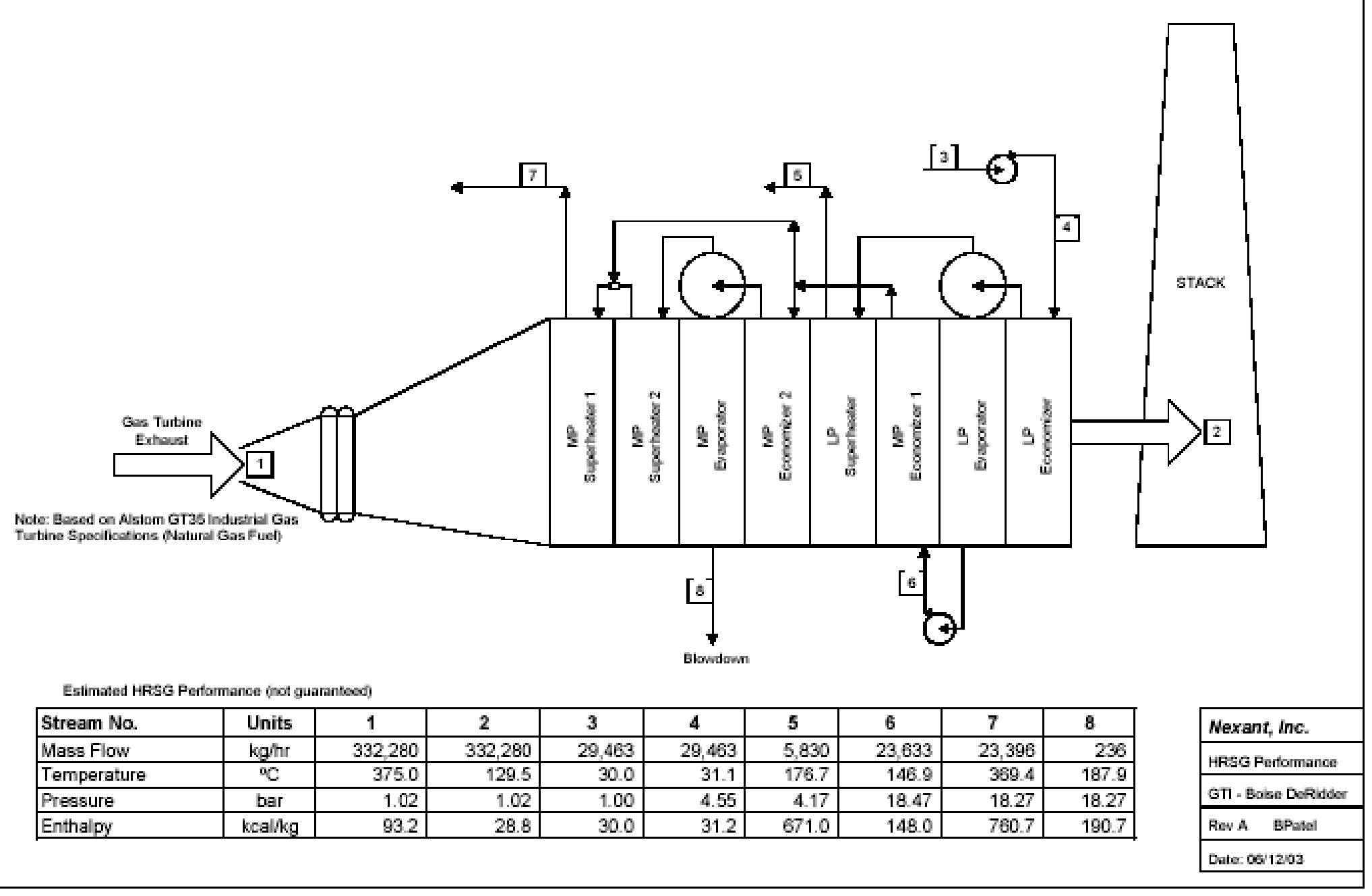

Figure 3.3.6-1 HRSG Arrangement and Performance 


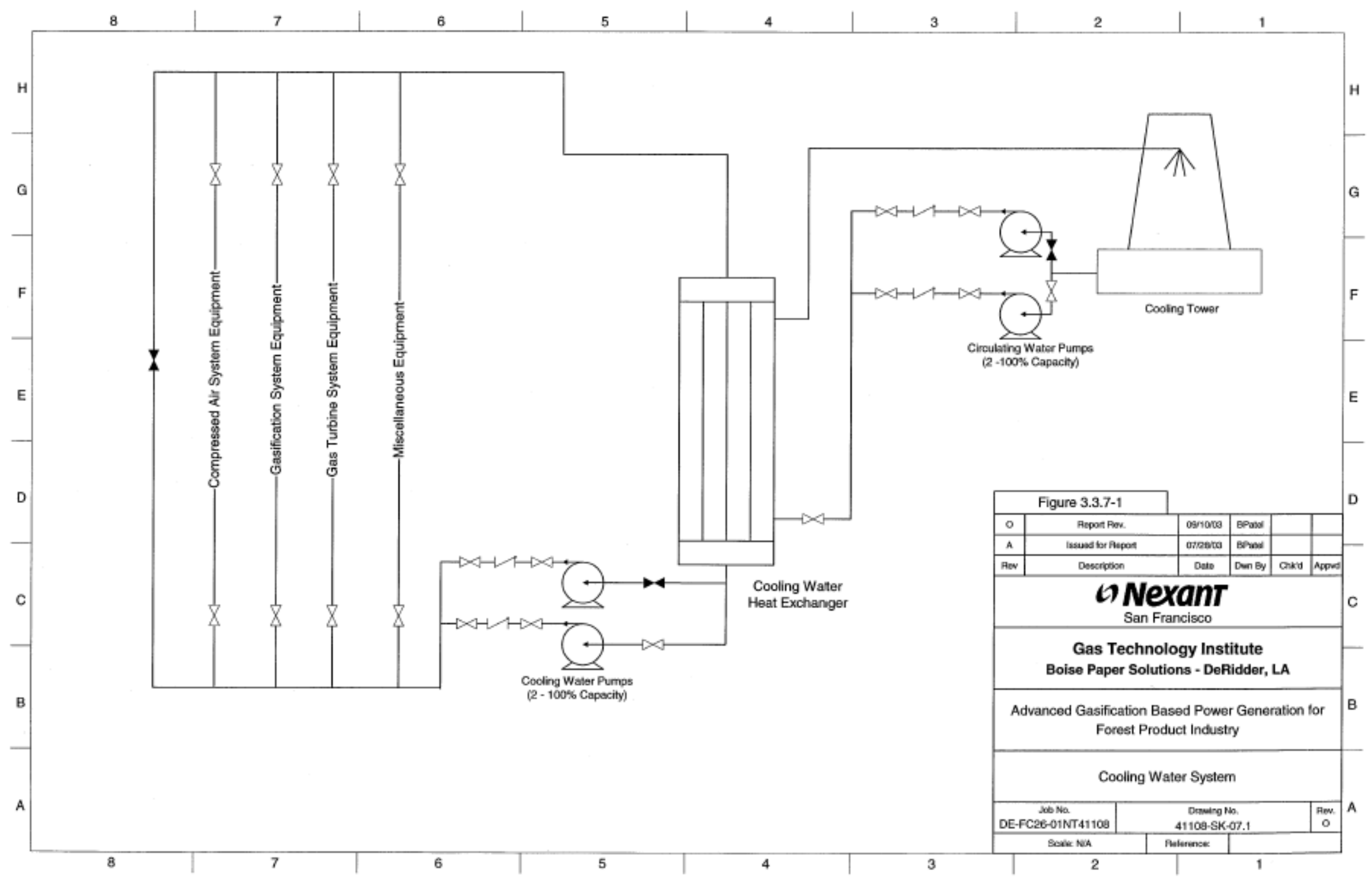

Figure 3.3.7-1 Cooling Water System 


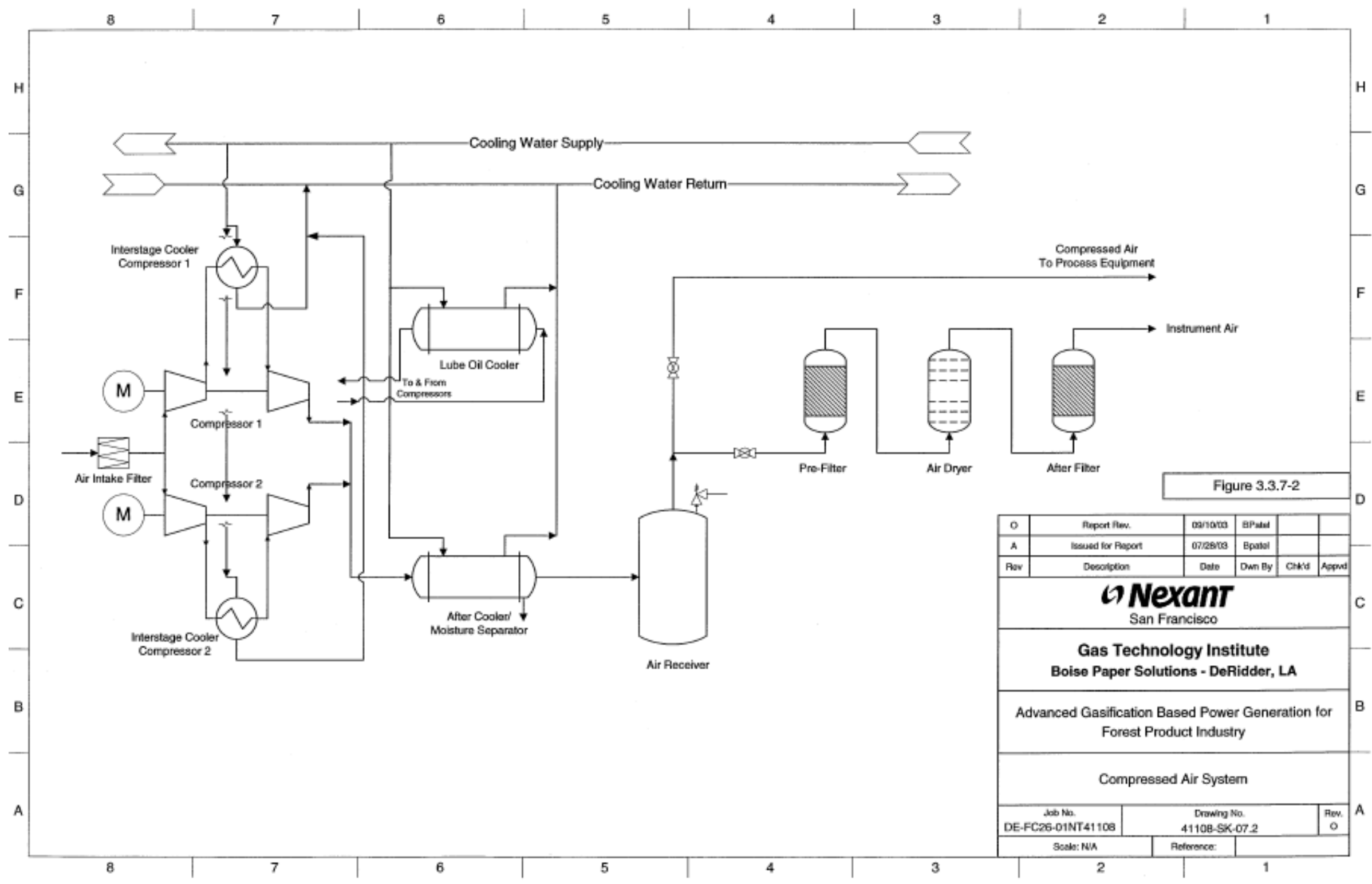

Figure 3.3.7-2 Compressed Air System 


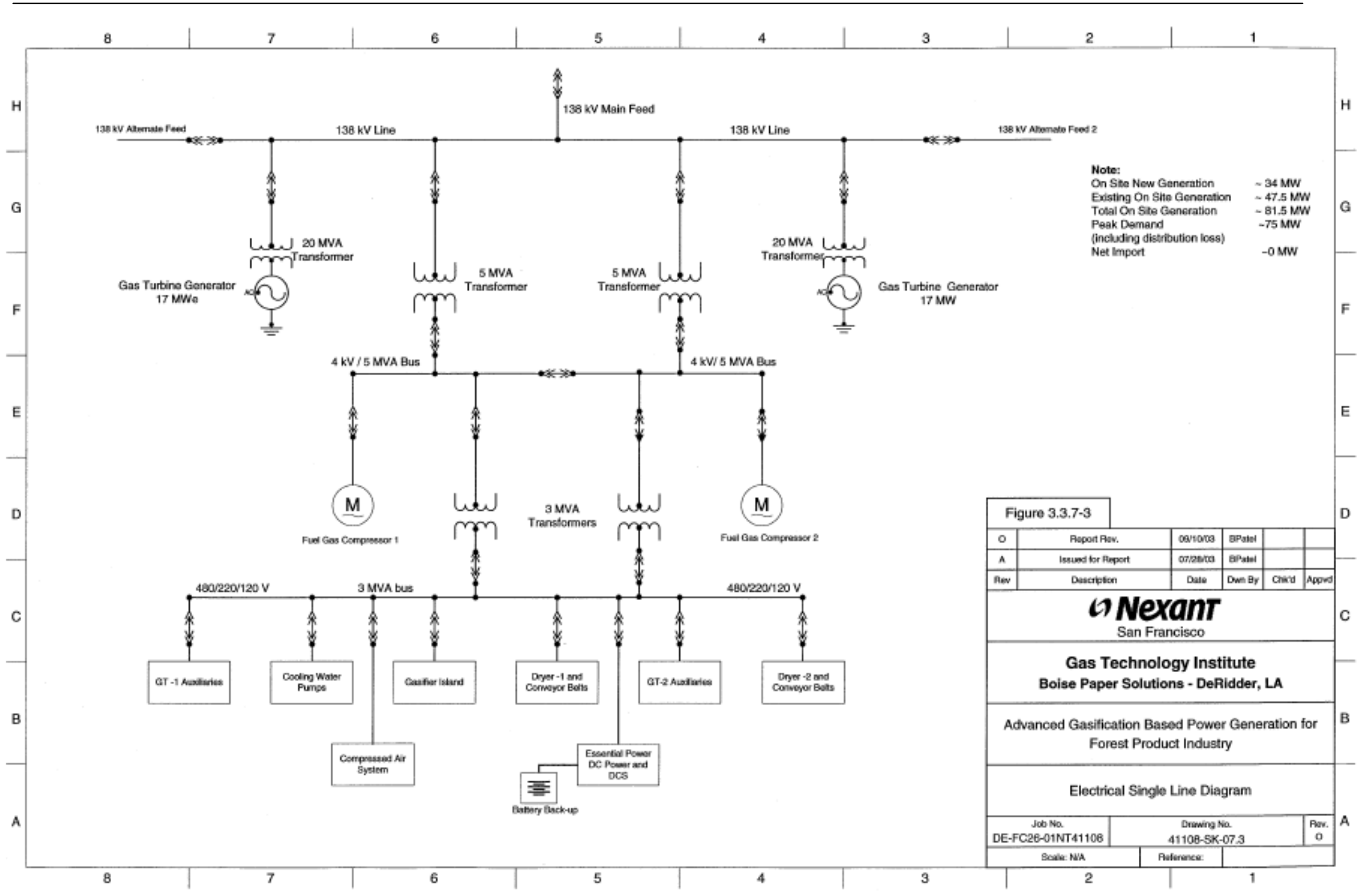

Figure 3.3.7-3 Electrical Single Line Diagram 


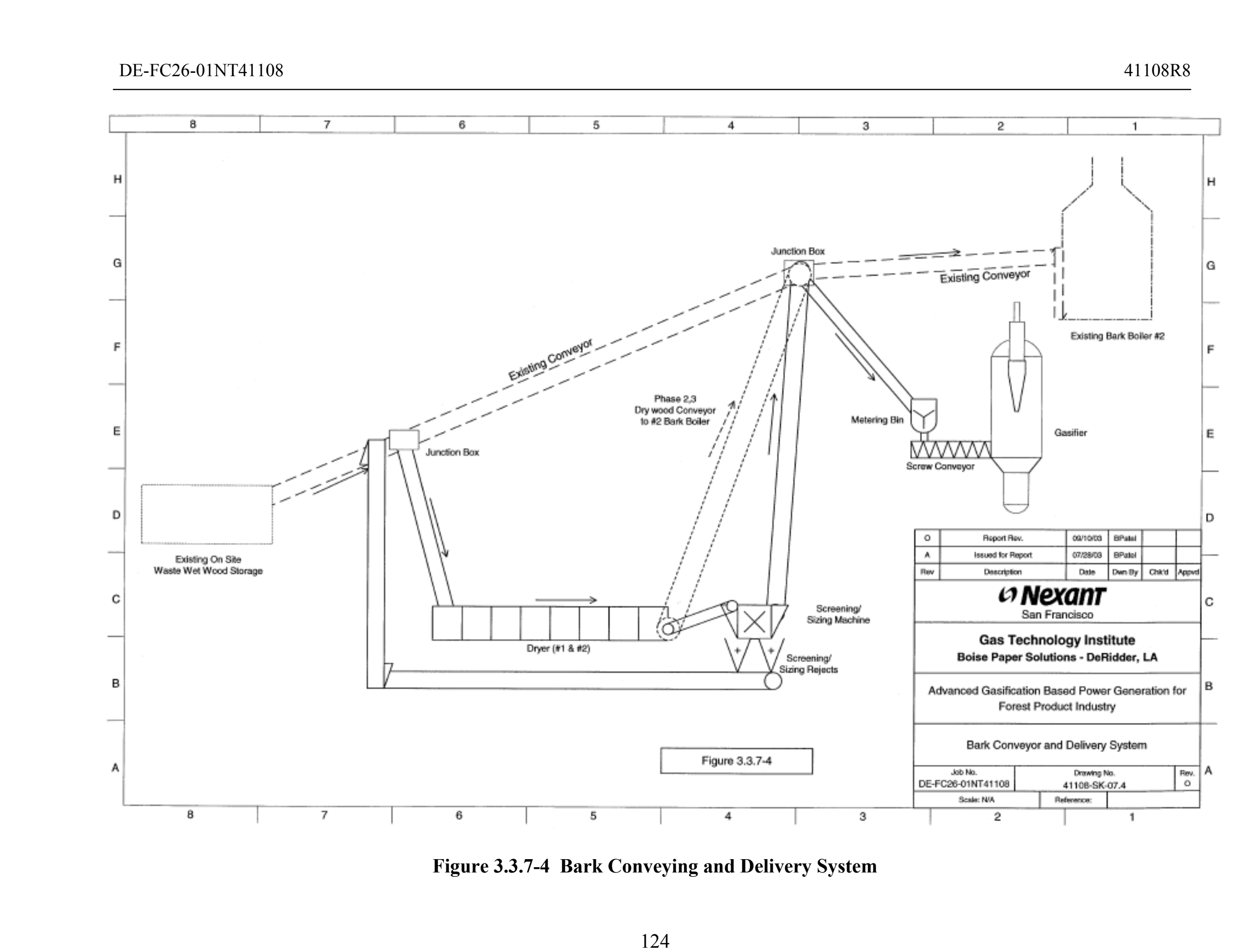




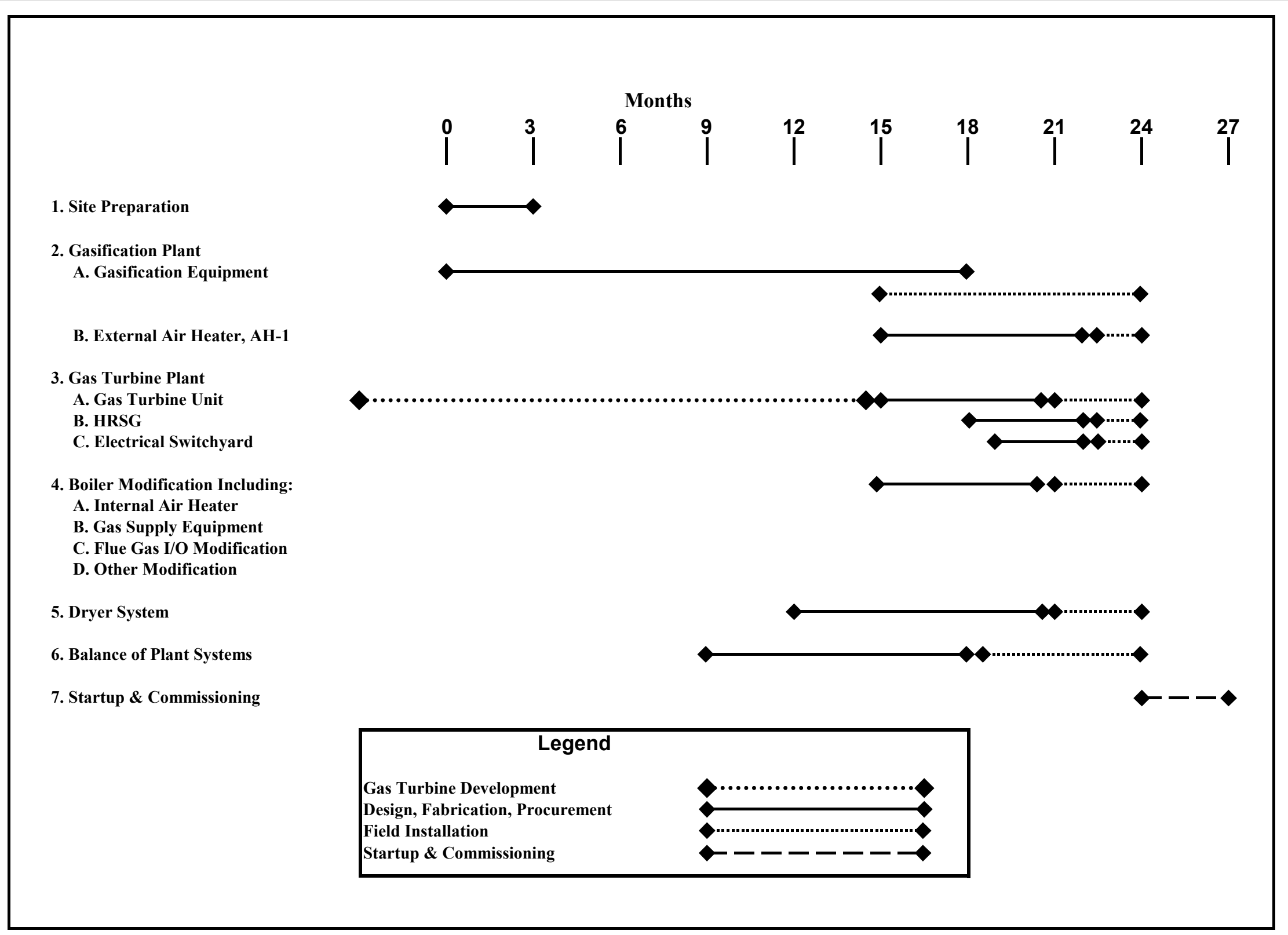

Figure 3.3.8-1 Plant Construction Schedule 


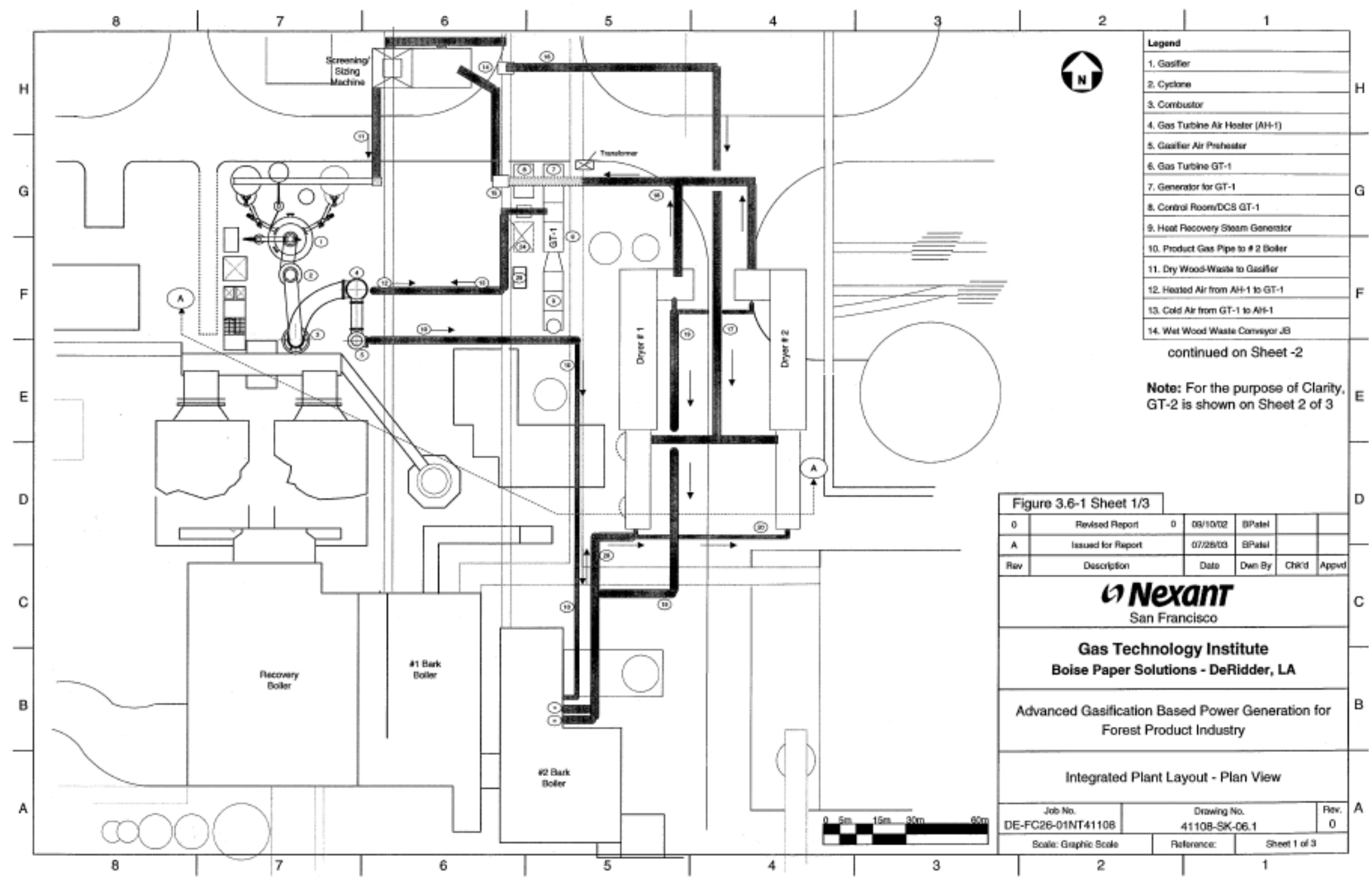

Figure 3.6-1 Integrated Plant Layout - Sheet 1 


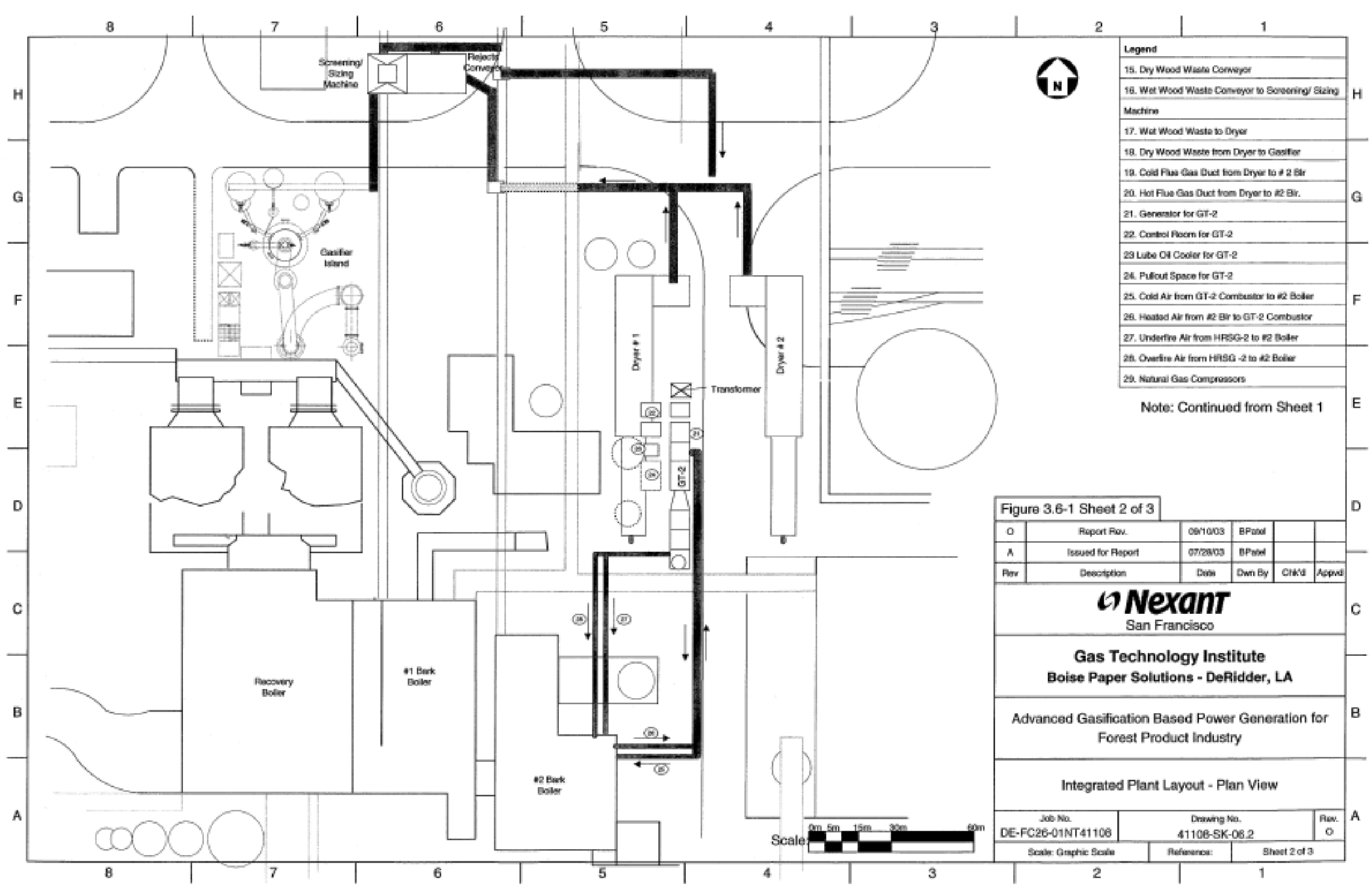

Figure 3.6-1 Integrated Plant Layout - Sheet 2 


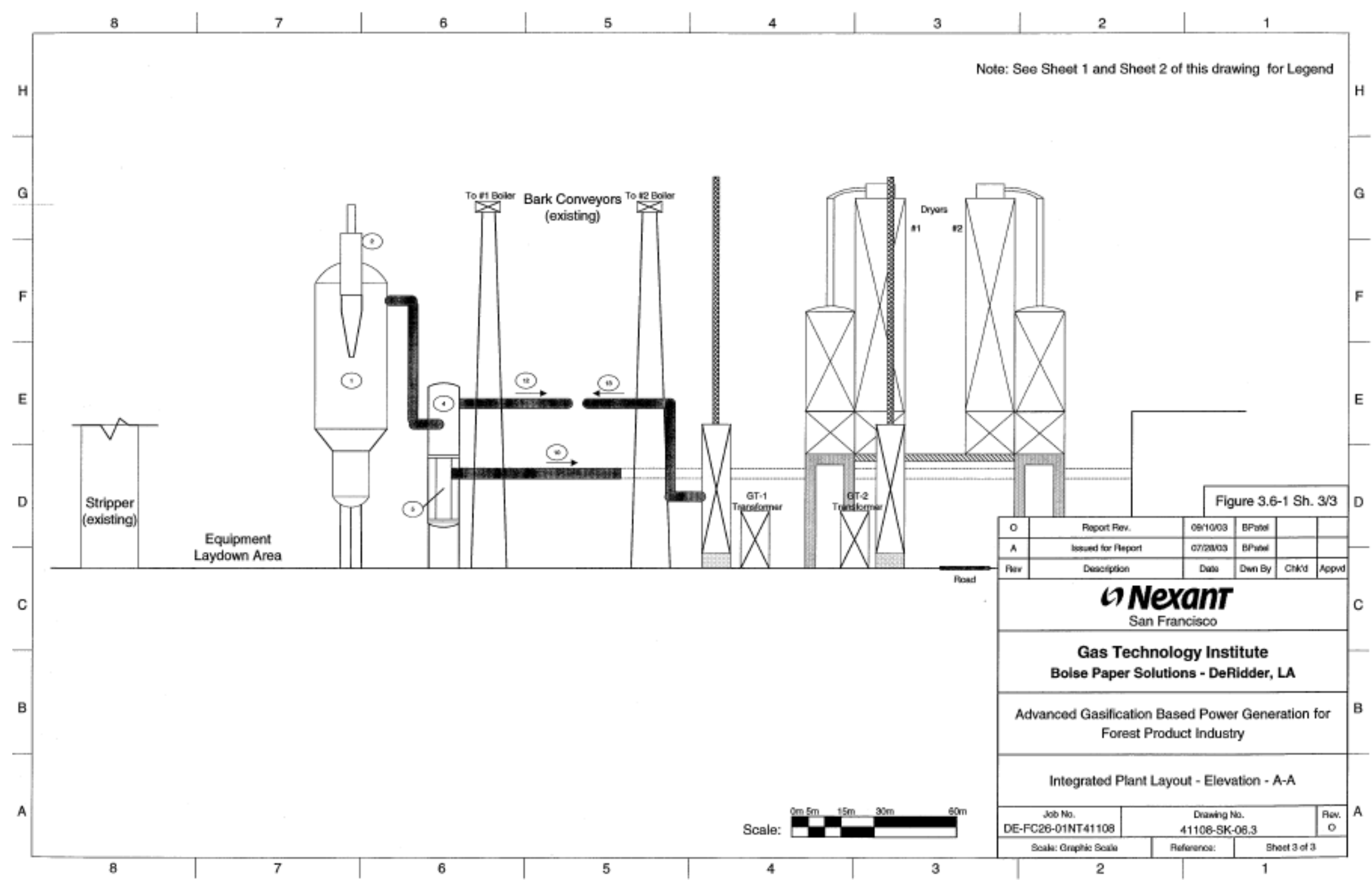

Figure 3.6-1 Integrated Plant Layout - Sheet 3 


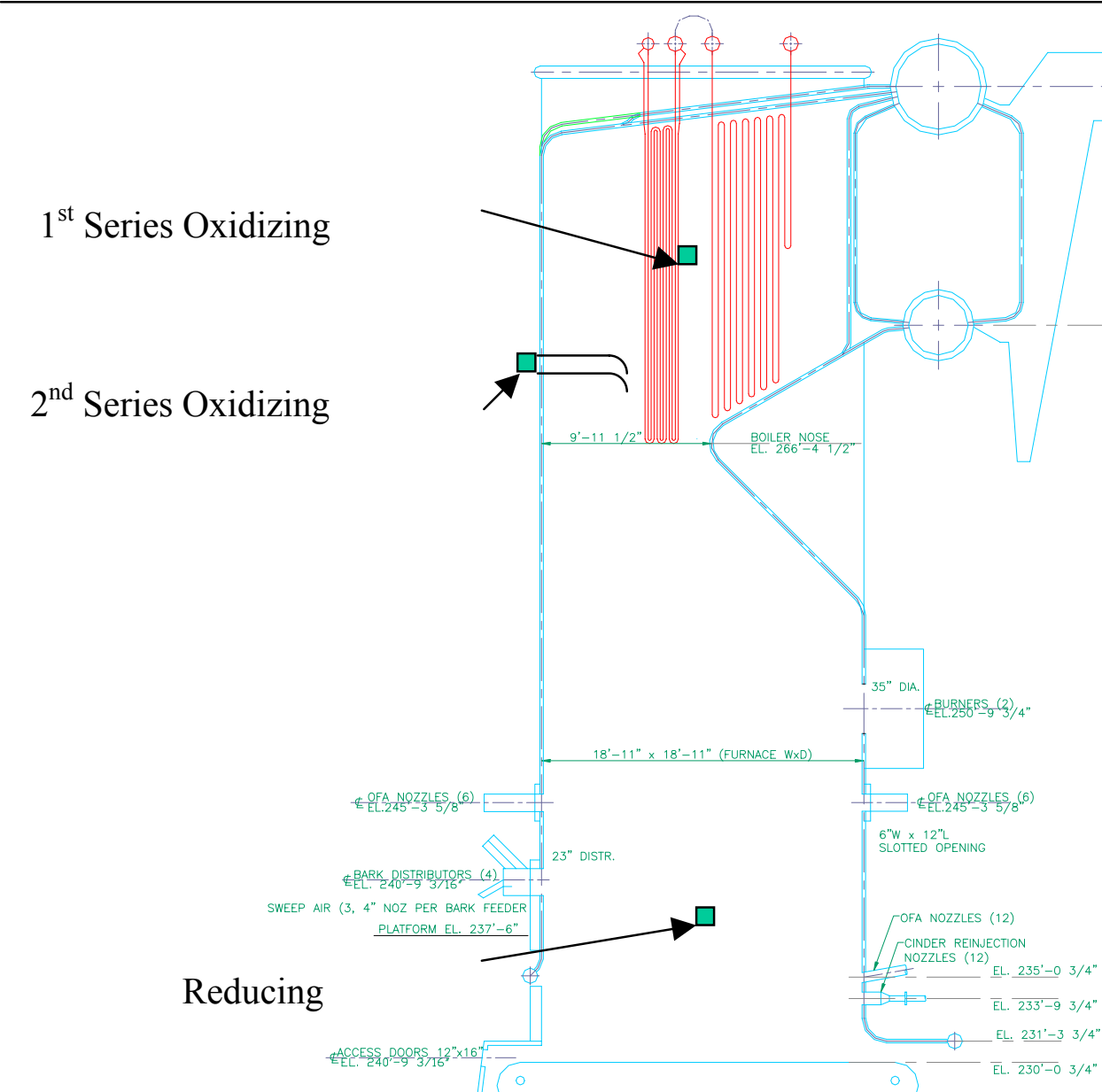

Figure 4.2-1. Locations of Tube Samples in No. 2 Bark Boiler at Boise DeRidder

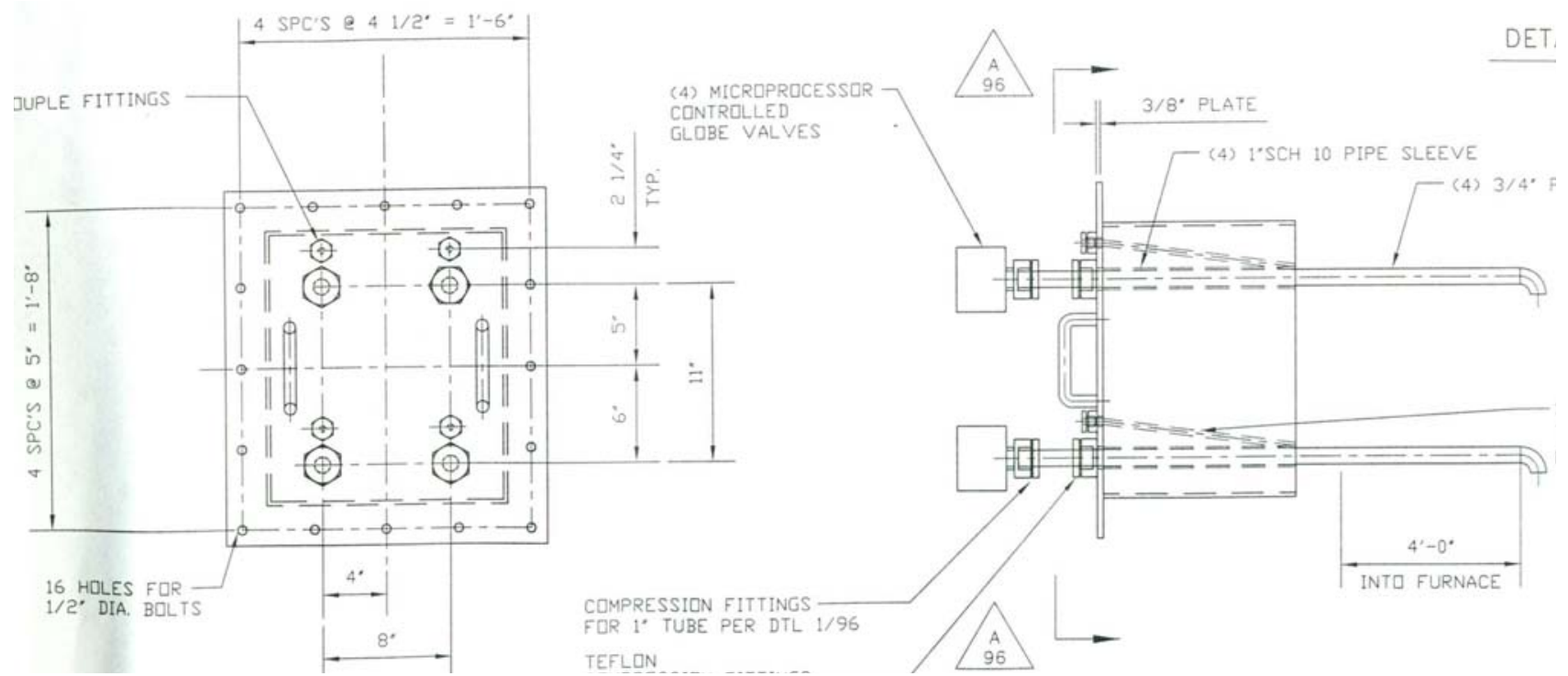

Figure 4.2-2 Test Assemblies for Tube Testing in No. 2 Bark Boiler DeRidder 
DeRidder, LA March 20, $2003 \quad$ Lower Door 800H
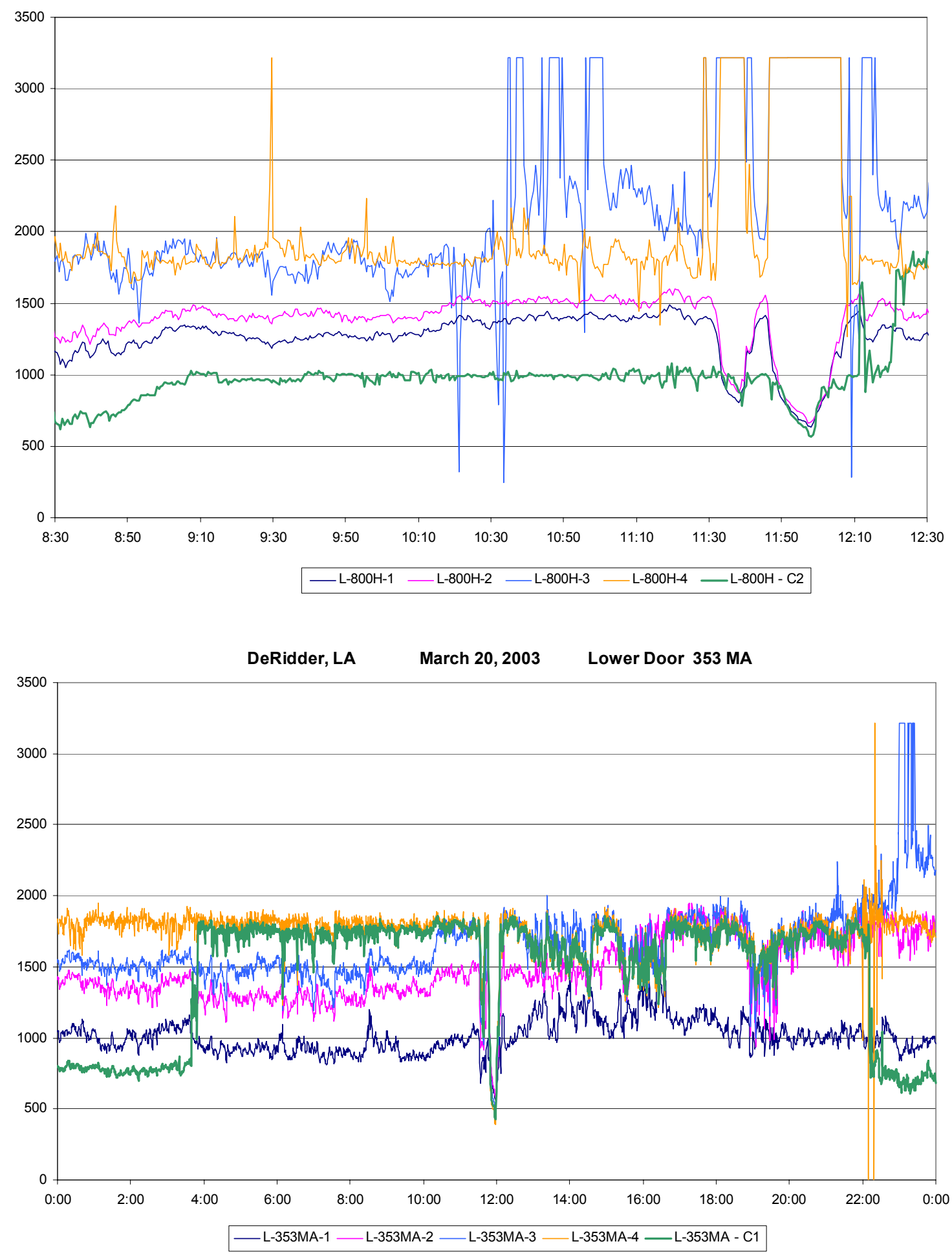

Figure 4.2-3. Typical Temperature Profile for Test Tube Coupons with air temperature control (800 H) and skin temperature control (353 MA) 


\section{APPENDIX A EQUIPMENT LIST}

This appendix lists the major equipment and the associated physical and capacity/rating parameters. The operating and performance parameters are presented in the respective descriptive sections in Sections 3.1 through 3.5. 


\section{APPENDIX A: PLANT EQUIPMENT LIST}

\section{Equipment}

\subsection{Gasification Plant}

Manufacturer

Gasifier Output

Gasifier Input

Cyclone

Start-up Heater Burner

Start-up Heater Furnace

Fuel Feeder (2 trains)

Limestone Feeder

Gas Feeder Steam Trap

Process Air Compressor

Ash Discharge Equipment

Nitrogen Generation Equipment

- Nitrogen Generator

- Air Compressor

Flare Equipment - Burner \& Stack

\section{Capacity/Rating}

Carbona Corp., Finland

$146 \mathrm{MMBtu} / \mathrm{hr}$

$180 \mathrm{MMBtu} / \mathrm{hr}$

1.57 MMBtu/hr

$65.8 \mathrm{~m}^{3} / \mathrm{hr}$, each train

$1.2 \mathrm{~m}^{3} / \mathrm{hr}$

$7.2 \mathrm{~kg} / \mathrm{hr}$ air

$1.1 \mathrm{~m}^{3} / \mathrm{hr}$

$65 \mathrm{~g} / \mathrm{sec}$

$0.21 \mathrm{~kg} / \mathrm{sec}$

$9.8 \mathrm{~kg} / \mathrm{sec}$

\subsection{Bark Dryer}

Manufacturer

MEC Company, USA

No. of Dryers

2

Drying Capacity

$24,500 \mathrm{~kg} / \mathrm{hr}$, each

Other Equipment include Wet Bark Feed Valve, Inlet Air Damper, Flue Gas Inlet

Damper, Natural Gas Burner, Drying Drum, Drop-out Box, Bark Discharge Valve

Overall Dimensions

36.9m Lx10.2m Wx20.1m H

\subsection{External Air Heater (AH-1)}

Type

No. of Heater

Heat Transfer Area

Type

Tube Outside Diameter

Overall Dimensions
Shell and U-Tube

1

$743 \mathrm{~m}^{2}$

Pure Counter Flow

$63.5 \mathrm{~mm}$

$2.9 \mathrm{~m}$ int. dia. $\mathrm{x} 11.9 \mathrm{~m}$ high 


\section{APPENDIX A: PLANT EQUIPMENT LIST (Cont'd)}

\section{Equipment}

\subsection{Boiler Modification}

Internal HT HP Air Heater

Manufacturer

No. of Heater

Heat Transfer Area

Type

Tube Outside Diameter

Tube Materials

Location

Syngas Injection Nozzles

No. and size of Nozzles

Location

\section{Capacity/Rating}

Babcock Power Services, USA

1

$437 \mathrm{~m}^{2}$

Parallel Cross Flow, Radiant

$70 \mathrm{~mm}$

SB-407, 800 HT and

Haynes 230

Boiler Rear Wall Below Present HMZ OFA nozzles

5.0 Gas Turbine Generator

Manufacturer

No. of Turbines

Standard Rating

Generators
12; $152.4 \mathrm{~mm}$ OD, each

Above the Top of Auxiliary Natural Gas Burners and Below the Furnace Arch Tip

Accessories

Include Air Compressor, Lube Oil Cooler, Control Panel, Intake Air Filter, External Combustor

\subsection{Natural Gas Compressor for Gas Turbines}

No. of compressors

Type of compressor

Rating

Motor
2 , one for each gas turbine

ARIEL JGH4 four throw double acting 6,000 std. cu. m per hr, $890 \mathrm{rpm}$, each $350 \mathrm{~kW}, 4000 \mathrm{~V}$, each 


\section{APPENDIX A: PLANT EQUIPMENT LIST (Cont'd)}

\section{Equipment}

\subsection{Heat Recovery Steam Generator (HRSG)}

No. of HRSGs

Type

Stack

Deaerator

Accessories

\section{Capacity/Rating}

2

unfired, two pressure, non-reheat, natural circulation, drum type with horizontal gas flow 2 Nos., 6m D, 42.7m H

1

Feed Pumps, Feedwater stop and check valves, relief valves, continuous and intermittent blowdown system, and economizer bypass, chemical treatment equipment

\subsection{Electrical Distribution}

Step-up Transformer

2, Oil-filled, 20 MVA

Station Service Transformer

1, Oil-filled, 5 MVA

Low Voltage Load Center Transformer

2, 500/750 kVA

Other Equipment include: 4.1 kV Switchgear; 400 V MCCs; 400 V Load Switchgear, Protective Relay Panel, Cathodic Protection, Lightning Protection

\subsection{Balance-of-Plant}

\subsection{Cooling Water System}

Cooling tower and fan

Circulating Water Pumps

1 Cell, Mechanical Draft $4.5 \times 10^{6} \mathrm{~kJ} / \mathrm{hr}$

Cooling Water Pumps (Closed Loop) $2-100 \% ; 22,500 \mathrm{~kg} / \mathrm{hr}$ each Motor $-5 \mathrm{~kW}, 1,500 \mathrm{RPM}$ $2-100 \% ; 22,500 \mathrm{~kg} / \mathrm{hr}$ each Motor - $10 \mathrm{~kW}, 1,500 \mathrm{RPM}$

Other Equipment include: 2-100\% Cooling Water Heat Exchangers and 1Surge Tank

\subsection{Compressed Air System}

Air compressor

$$
\begin{aligned}
& 2-100 \% \text { capacity } \\
& 1,700 \mathrm{scfm} / \mathrm{hr}, 7.0 \text { bar each } \\
& 200 \mathrm{~kW}, 380 \mathrm{~V} \text { Motor each }
\end{aligned}
$$

Other Equipment includes: air receiver; accumulator; pre-filter; after-filter; dryer

\subsection{Fire Protection System}

Fire Suppression and Extinguishing System $\quad$ FM-200 total system or fire extinguisher High pressure $\mathrm{CO}_{2}$ system

Other Equipment includes: Stand pipes, fire hydrants, fire hose, sprinklers 


\section{APPENDIX A: PLANT EQUIPMENT LIST (Cont'd)}

\section{Equipment}

\subsection{Conveying, Air Piping, Ducting}

\section{Bark Conveying}

Screening/Sizing Machine

From Junction Box \#14 to Dryers

From Dryers to Junction Box \#15

From Junction Box \#15 to Screening Machine

From Screening Machine to Gasifier

From Screening Machine to Existing Conveyor

\section{External Air Heater (AH-1) Piping}

Air piping from GT-1 to AH-1

Air piping from $\mathrm{AH}-1$ to $\mathrm{GT}-1$

\section{Internal Air Heater (AH-2) Piping}

Air piping from GT-2 to AH-2

Air piping from $\mathrm{AH}-2$ to $\mathrm{GT}-2$

Product gas piping from gasifier plant to boiler

\section{Flue gas ducting}

From boiler to dryers

From dryers to boiler

From HRSGs to boiler

\section{Capacity/Rating}

$145 \mathrm{~m}^{3} / \mathrm{hr}$

$1.2 \mathrm{~m} \mathrm{~W} \times 110 \mathrm{~m} \mathrm{~L}$

$1.2 \mathrm{~m} \times 91 \mathrm{~m} \mathrm{~L}$

$1.0 \mathrm{~m} \times 37 \mathrm{~m} \mathrm{~L}$

$1.0 \mathrm{~m} \mathrm{~W} \times 30 \mathrm{~m} \mathrm{~L}$

$0.5 \mathrm{~m} \times 60 \mathrm{~m} \mathrm{~L}$

$250 \mathrm{~mm}$ ID; $45 \mathrm{~m}$ long

300mm ID; 50m long

250mm ID; $28 \mathrm{~m}$ long

$300 \mathrm{~mm}$ ID; 33m long

$122 \mathrm{~m}$ long

$55 \mathrm{~m}$

$91 \mathrm{~m}$

$137 \mathrm{~m}$ 
APPENDIX B

SOLAR TURBINES INCORPORATED

FINAL REPORT 


\title{
Advanced Gasification Based Fuel Conversion and Electricity Production System for Forest Product Industry Power Island Pre-design Study
}

\author{
GTI Subcontract: PF 13524 \\ DOE/GTI Contract: $\quad$ DE-FC26-01NT41108
}

Final Report

October 31, 2003

Submitted To:

GAS TECHNOLOGY INSTITUTE

\author{
Submitted By: \\ SOLAR TURBINES INCORPORATED \\ 2200 Pacific Hwy, \\ San Diego, CA 92101
}

Solar Principal Investigator: Dr. Vivek Khanna

Phone:

(619) 5445166

E-mail:

khanna_vivek_k@solarturbines.com 
Contract Number

PF 13524
Project Title

Advanced Gasification Based Fuel Conversion and

Electricity Production System for Forest Product Industry

\section{Table of Contents}

Executive Summary

Project Background

Introduction

Technical Summary

Conclusions and Recommendations

Introduction

2 Project Approach

3 Project Outcomes

3.1 Design Information Definition and Inquiry 4

3.1.1 Proposed Cycle Concepts 4

3.1.2 Cycle Selection 8

3.1.3 Standard Titan 130 Cycle Data $\quad 8$

3.1.4 Parameters for ERGT Cycle study 9

3.2 Cycle Analysis for ERGT cycle 9

3.2.1 Comparison of Option 1 and Option 2 to Baseline 10

3.2.2 Performance of ERGT based on Option 1

$\begin{array}{lll}3.2 .3 & \text { ERGT with Steam Cooled Turbines } & 16\end{array}$

3.2.4 Effects of Humidification of Inlet Air 19

3.3 Conclusions 25

3.4 Arrangement Drawings, PFD and PI\&D for Recommended Gas Turbine System 28

$\begin{array}{lll}\text { 3.4.1 Titan } 130 \text { Package } & 28\end{array}$

$\begin{array}{ll}3.5 & \text { Equipment Modifications Design Study } \\ 32\end{array}$

$\begin{array}{lll}\text { 3.5.1 Combustor } & 32\end{array}$

3.5.2 HP/HT Air Heater $\quad 32$

3.5.3 Steam Cooled Turbine $\quad 32$

3.6 Market Potential Estimate 33

4 Conclusions and Recommendations 33 


\section{Table of Figures}

Figure 3.1

Figure 3.2

Figure 3.3

Figure 3.4

Figure 3.5

Figure 3.6

Figure 3.7

Figure 3.8

Figure 3.9

Figure 3.10

Figure 3.11

Figure 3.12

Figure 3.13

Figure 3.14

Figure 3.15

Figure 3.16

Figure 3.17

Figure 3.18

Figure 3.19

Figure 3.20

Figure 3.21

Figure 3.22

ERGT With Boost Combustor in Series With The Heat Exchanger ................. 5

ERGT With Boost Combustor in Parallel With The Heat Exchanger............... 5

System of Two ERGT With Single Boost Combustor in Series With The

Heat Exchanger. 6

System of Two ERGT With Single Boost Combustor in Parallel With The Heat Exchanger.....

System of Two ERGT With Two Boost Combustors in Series With a

Single Heat Exchanger. 7

System of Two ERGT With Two Boost Combustors in Parallel With a

Single Heat Exchanger. 7

Net Turbine Output as a Function of HP/HT Air Heater Exit Temperature for Option 1 and Options $2 \mathrm{a} \& 2 \mathrm{~b}$ 11

Natural Gas Consumption as a Function of HP/HT Air Heater Exit

Temperature for Option 1 and Option 2a \& 2b.

Fuel Cost as a Function of HP/HT Air Heater Exit Temperature for Option 1 and Option 2a \& 2b.

Percentage Fuel Cost Savings using the Standard Engine Fuel Costs as a

Baseline 12

Net Turbine output as a Function of HP/HT Air Heater Pressure Drop and HP/HT Air Heater Exit Temperature.

Natural Gas Consumption as a Function of HP/HT Air Heater Exit

Temperature. 14

Fuel Cost as a Function of HP/HT Air Heater Pressure Drop and HP/HT

Air Heater Exit Temperature 14

Gas Turbine Exhaust Temperature as a Function of HP/HT Air Heater Pressure Drop. 15

Percentage Fuel Cost Savings while Operating an ERGT Using the

Standard Engine Fuel Costs as a Baseline 15

Net Turbine Output as a Function of HP/HT Air Heater Pressure Drop and $\mathrm{HP} / \mathrm{HT}$ Air Heater Exit Temperature $\left(\mathrm{TRIT}=2100^{\circ} \mathrm{F}\right)$.. 16

Natural Gas Consumption as a Function of HP/HT Air Heater Exit Temperature $\left(\right.$ TRIT $\left.=2100^{\circ} \mathrm{F}\right)$. 17

Fuel Cost as a Function of HP/HT Air Heater Pressure Drop and HP/HT Air Heater Exit Temperature $\left(\mathrm{TRIT}=2100^{\circ} \mathrm{F}\right)$....

Gas Turbine Exhaust Temperature as a Function of HP/HT Air Heater Pressure Drop $\left(\mathrm{TRIT}=2100^{\circ} \mathrm{F}\right)$ 18

Percentage Fuel Cost Savings while Operating an ERGT Using the Standard Engine Fuel Costs as a Baseline

Net Turbine Output as a Function of HP/HT Air Heater Pressure Drop and HP/HT Air Heater Exit Temperature for Air-Cooled Turbine with and without a Humidifier at Inlet of Compressor.

Natural Gas Consumption as a Function of HP/HT Air Heater Exit Temperature for Air-cooled Turbine with and without a Humidifier at inlet of Compressor. 
Figure 3.23 Fuel Cost as a Function of HP/HT Air Heater Pressure Drop and HP/HT Air Heater Exit Temperature for Air-Cooled Turbine with and without a Humidifier at Inlet of Compressor.

Figure 3.24 Gas Turbine Exhaust Temperature as a Function of HP/HT Air Heater Pressure Drop for Air-Cooled Turbine with and without a Humidifier at Inlet of Compressor.

Figure 3.25 Percentage Fuel Cost Savings while Operating an ERGT using the Standard Engine Fuel Costs as a Baseline

Figure 3.26

Net Turbine Output as a Function of HP/HT Air Heater Pressure Drop and HP/HT Air Heater Exit Temperature for Steam-Cooled Turbine with a Humidifier at Inlet of Compressor Compared to Baseline Cycle using Air-Cooled Turbine without a Humidifier at Inlet of Compressor.

Figure 3.27

Natural Gas Consumption as a Function of HP/HT Air Heater Exit Temperature for Steam-Cooled Turbine with a Humidifier at Inlet of Compressor Compared to Baseline Cycle using Air-Cooled Turbine without a Humidifier at Inlet of Compressor 22

Figure 3.28 Fuel Cost as a Function of HP/HT Air Heater Pressure Drop and HP/HT Air Heater Exit Temperature for Steam-Cooled Turbine with a Humidifier at Inlet of Compressor compared to Baseline Cycle using AirCooled Turbine without a Humidifier at Inlet of Compressor...

Figure 3.29

Gas Turbine Exhaust Temperature as a Function of HP/HT Air Heater Pressure Drop for Steam-Cooled Turbine with a Humidifier at Inlet of Compressor Compared to Baseline Cycle using Air-Cooled Turbine without a Humidifier at Inlet of Compressor....

Figure 3.30

Percentage Fuel Cost Savings while Operating an ERGT using the Standard Engine Fuel Costs as a Baseline

Figure 3.31

Figure 3.32

Percentage Increase in Electrical Output (with a Standard Engine as the Baseline) for various ERGT Cycles using a HP/HT Heat Exchanger that has a 10psi Pressure Drop....

Percentage Increase in Electrical Output (with a Standard Engine as the Baseline) for various ERGT Cycles using a HP/HT Heat Exchanger that has a 20psi Pressure Drop.

Figure 3.33

Percentage Increase in Electrical Output (with a Standard Engine as the Baseline) for various ERGT Cycles using a HP/HT Heat Exchanger that has a 30psi pressure drop

Figure 3.34 Fuel Cost Savings as a Percentage of the Fuel Costs of a Standard Engine for Various ERGT Cycles Using a HP/HT Heat Exchanger that has a 10psi Pressure Drop....

Figure 3.35

Fuel Cost Savings as a Percentage of the Fuel Costs of a Standard Engine for Various ERGT Cycles Using a HP/HT Heat Exchanger that has a 20psi Pressure Drop.

Figure 3.36 Fuel Cost Savings as a Percentage of the Fuel Costs of a Standard Engine for various ERGT Cycles using a HP/HT Heat Exchanger that has a 30psi Pressure Drop .................................................................................. 27

Figure 3.37 Titan 130 IPG Turbine/Gen Set .............................................................. 28

Figure 3.38 Equipment Layout - Titan 130 Turbine /Gen Set...................................... 29 
Figure 3.39 Typical plant Layout of Three Titan 130 Turbine/Gen Set ......................... 29

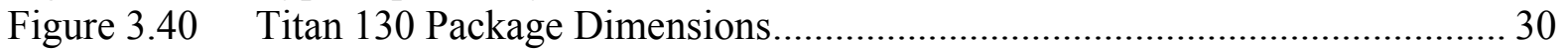

Figure 3.41 Gas Turbine with a Side Mounted Can Configuration ................................ 30

Figure 3.42 A Gas Turbine with a Silo-Combustor and a Hot Scroll .............................. 31

Figure 3.43 A Recuperated Gas Turbine................................................................. 31

\section{List of Tables}

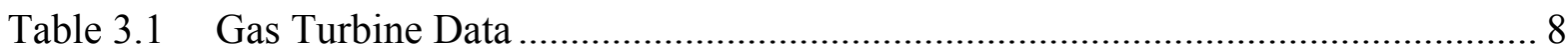

Table 3.2 Fuel Composition.................................................................................. 8

Table 3.3 The ranges of parameters being considered for this study.............................. 9

Table 3.4 Inlet Conditions for which the code was benchmarked ..................................... 9

Table 3.5 The parameters ranges used in the evaluation of Option 2 ........................... 10

Table 3.6 Percentage of air allowed to pass through the air heater ................................ 10 
Contract Number

PF 13524
Advanced Gasification Based Fuel Conversion and Electricity Production System for Forest Product Industry

\section{Executive Summary}

\section{Project Background}

Boise Paper Solutions (Boise) and the Gas Technology Institute (GTI) have teamed to develop, demonstrate, and place in continuous operation an advanced biomass gasificationbased, power generation system suitable for near-term commercial deployment in the forest products industry. The program aims to develop and install a system that will be used in conjunction with, rather than in place of, existing wood waste fired boilers and flue gas cleanup systems. The main objective of the initial development phase of this program is to define a system that avoids the major hurdles of high-pressure gasification (i.e., highpressure fuel feeding, ash removal, and hot gas cleaning) that are typical for conventional IGCC power generation. The specific system under study uses an atmospheric pressure biomass gasifier and an externally recuperated gas turbine.

\section{Introduction}

As part of the pre-design evaluation study, Solar Turbines Incorporated (Solar) completed the following tasks using a Titan 130 gas turbine as a baseline:

i. Propose and analyze different candidate cycles for an Externally Recuperated Gas Turbine (ERGT)

ii. Assess the viability of modifying existing Solar gas turbine designs to the ERGT cycle.

iii. Provide GTI with information required to install and commission a standard Titan 130 package so as to enable GTI to assess the viability of installing an ERGT in an existing forest products industrial site.

iv. Support an assessment of the market potential for an ERGT in the forest products industry.

\section{Technical Summary}

Solar considered six different ERGT cycles for an ERGT system comprised of two Titan 130 sized turbines. Of these six options two were selected as the most suitable based on the practical operational constraints. These two options were thermodynamically analyzed over a range of operating parameters. Potential operating cost savings and mechanical design feasibility was also evaluated.

Three different ERGT development parameters were considered in defining system configuration. The scenarios reflected three potential development strategies

- Development for a near-term application and requiring only moderate modification

- A long-term engine development program requiring a significant developmental effort and considerable modification to the present engine designs.

- Modifications and developmental effort required specifically for Solar engines to operate in the ERGT configuration with current operating constraints (temperatures and material considerations). 
Solar provided information on the layout, installation and commissioning of Solar's standard Titan 130 gas turbine package. This data included the arrangement and layout drawing of a standard T130 package and information regarding the various pumps, compression systems and cooling systems. This information was provided to help GTI assess the feasibility and the economics of modifying an existing facility at the Boise DeRidder paper mill to accommodate an ERGT.

Finally Solar assessed the market potential for an ERGT from a gas turbine manufacturer's perspective.

\section{Conclusions and Recommendations}

Based on the results of the thermodynamic analyses it is concluded that increasing the high pressure/high temp (HP/HT) heat exchanger exit temperature and reducing the pressure drop across the heat exchanger will help maximize the fuel cost savings. Of the various options considered, the most beneficial one in terms of fuel cost savings and the net power output was the ERGT cycle that used steam as the cooling medium for its turbine and had a humidifier installed at its inlet. However, in view of the major redesign effort required to develop a steam cooled turbine it is recommended that presently available air-cooled turbines be used with an inlet fogger/humidifier when the ambient conditions warrant its use.

Based on an analysis of the current operating constraints on the various components of an ERGT, it is recommended that an ERGT be developed by modifying existing gas turbines to accommodate a heat exchanger outlet temperature (combustor inlet temperature) of no more than $1450^{\circ} \mathrm{F}$. In addition, an $\mathrm{HP} / \mathrm{HT}$ air heater that works with a pressure drop at or below $15 \mathrm{psi}$ is recommended so as to minimize changes to present gas turbine designs and keep development costs low.

From a long-term perspective, the ERGT cycle potential can be realized if significant improvements can be made to effectively sustain air temperatures of up to $1800^{\circ} \mathrm{F}$. Critical components of the cycle include: high-pressure air heater (having a low pressure-drop), boost combustor, scroll and engine casings. 
Contract Number

PF 13524
Advanced Gasification Based Fuel Conversion and Electricity Production System for Forest Product Industry

\section{Introduction}

Boise Paper Solutions (Boise) and the Gas Technology Institute (GTI) have teamed up to develop, demonstrate, and place in continuous operation an advanced biomass gasificationbased power generation system suitable for near-term commercial deployment in the forest products industry. The program is being funded by the US Department of Energy and Gas Research Institute. The program aims to develop and install a system that will be used in conjunction with, rather than in place of, existing wood waste fired boilers and flue gas cleanup systems. The novel system is expected to include three advanced technological components based on GTI's RENUGAS ${ }^{\circledR}$ and METHANE de-NOX ${ }^{\circledR}$ technologies, and a concept used in the HIPPS program. The main objective of the development phase of this program is to design a system that avoids the major hurdles of high-pressure gasification (i.e., high-pressure fuel feeding and ash removal, and hot gas cleaning) that are typical for conventional IGCC power generation. It aims to also minimize capital intensity and technology risks. The system shall meet the immediate needs of the forest products industry for highly efficient and environmentally friendly electricity and steam generation systems utilizing existing wood waste as fuel resources.

As part of the pre-design evaluation study phase, Solar Turbines Incorporated (Solar) accepted a sub-contract from GTI (contract number PF13524) to propose and analyze different possible cycles for the operation of an Externally Recuperated Gas Turbine (ERGT) and then assess the viability of modifying existing gas turbine designs to suit the ERGT cycle. It was mutually agreed that the analysis be based on a Titan 130 size gas turbine.

As part of the subcontract, Solar agreed to provide GTI with information required to install and commission a standard Titan 130 package so as to enable GTI to assess the viability of installing an ERGT in an existing forest products industrial site. Finally Solar also agreed to participate (from a gas turbine manufacturer's perspective), in an estimate of the market potential for an ERGT in the forest product industry.

\section{Project Approach}

For this study Solar evaluated the Titan 130 turbine since GTI, required a power generation system that provides $27 \mathrm{MW}$ of electrical energy output. Two Titan 130 size gas turbines are required to meet the electrical demand. Based on these evaluations Solar proposed various cycle options.

In the next stage Solar, with inputs from GTI, narrowed the proposed cycle options to the two most promising ones and conducted thermodynamic cycle analyses of these two options for various engine parameters including but not limited to turbine rotor inlet temperature (TRIT), inlet air humidity and different turbine cooling scenarios.

Based on the results of these cycle analyses, Solar has provided recommendations on

- The feasible operating conditions with respect to

$>$ Thermodynamic performance

$>$ Engine design 
- Engine layout and configuration

Solar has also classified the range of parameters, which are thermodynamically feasible, as

- Appropriate for the near-term application and will require moderate modification,

- Appropriate for a long-term engine development program that would require a significant developmental effort and considerable modification to the present engine designs,

- Modifications and developmental effort required on Solar engines to achieve the parametric ranges that are feasible from both thermodynamic and mechanical design aspects.

In a parallel effort Solar provided GTI with information regarding Solar's existing Titan 130 package layout and installation and commissioning. Included were the arrangement and layout drawing of a Standard T130 package and information regarding the various pumps, compression systems and cooling systems. This information was intended to help GTI assess the feasibility and the economics of modifying an existing facility at one of Boise's paper mills to accommodate an ERGT.

Finally, Solar assessed the market potential of an ERGT from the gas turbine manufacturer's perspective.

\section{Project Outcomes}

\subsection{Design Information Definition and Inquiry}

\subsubsection{Proposed Cycle Concepts}

In the initial phase of this study Solar evaluated the gas turbine requirements of the program with an understanding that GTI required a power generation turbine system that provides 27 MW of electrical energy output. Configurations based on two Titan 130 size gas turbines were studied. Based on the information provided, Solar with input from GTI proposed the different cycle options detailed below.

\section{Option 1}

Option 1 consists of two independent ERGTs, each having the heat exchanger and boost combustor in series. A schematic layout of the cycle is shown in Figure 3.1. 
Contract Number

PF 13524

\section{Gas Technology Institute}

Advanced Gasification Based Fuel Conversion and Electricity Production System for Forest Product Industry

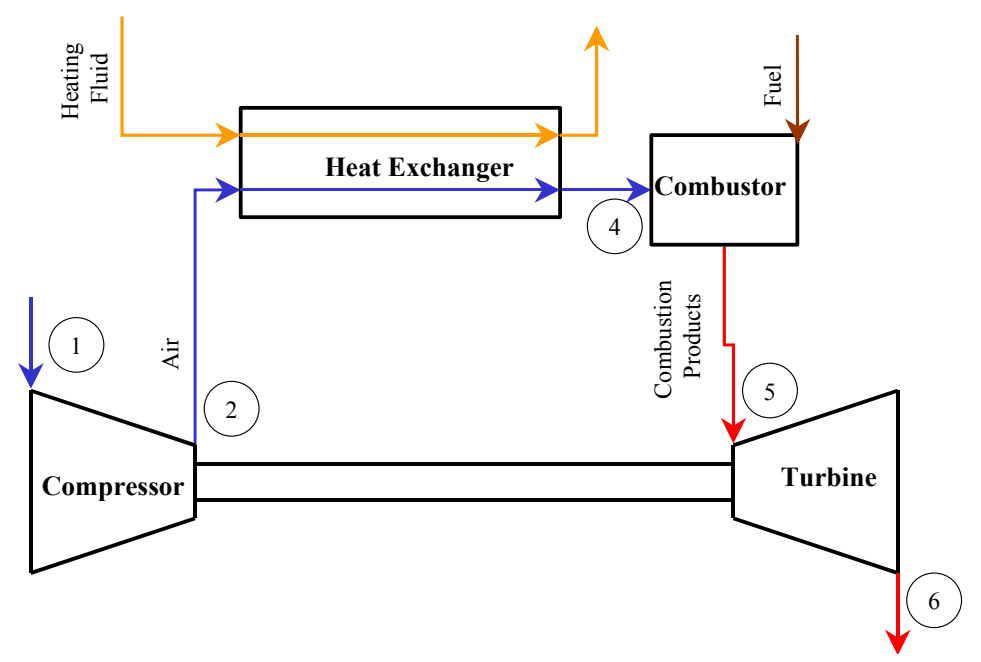

Figure 3.1 ERGT With Boost Combustor in Series With The Heat Exchanger

\section{Option 2}

Option 2 consists of two independent ERGTs, each having the heat exchanger and boost combustor in parallel. Figure 3.2 shows a schematic layout of the cycle.

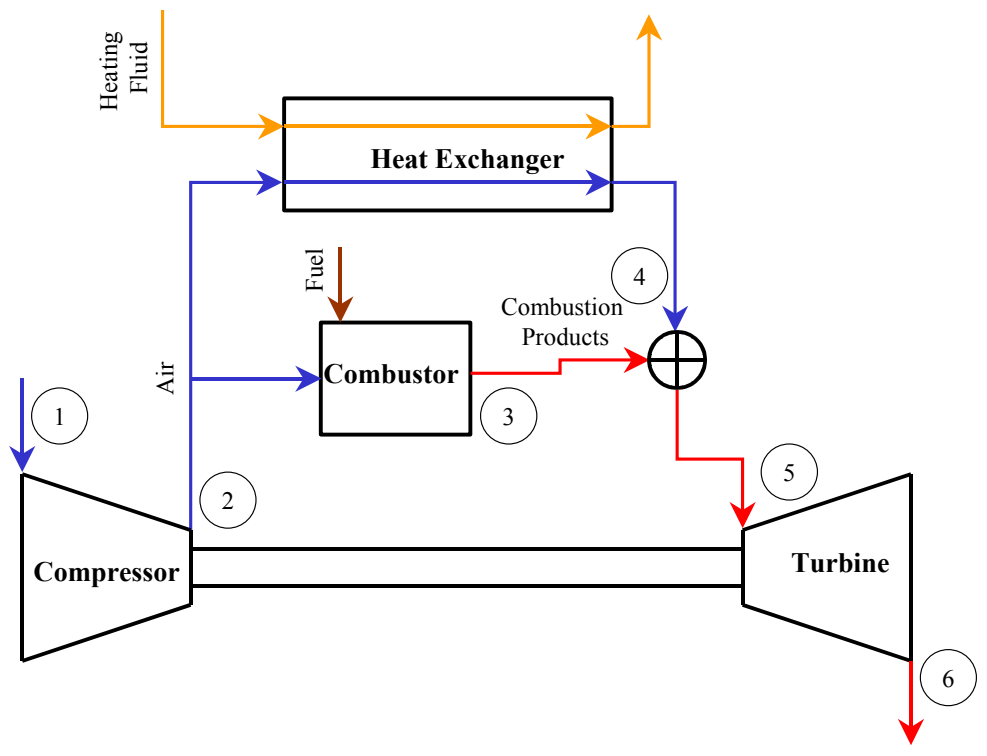

Figure 3.2 ERGT With Boost Combustor in Parallel With The Heat Exchanger

\section{Option 3}

This option consists of two ERGTs, each of which is connected to an independent generator. However, the compressed air flow from the compressors of the two ERGTs is combined into a single flow stream and fed through a single heat exchanger and boost combustor (in series). The products of combustion are then split into two streams and fed to the respective turbines of the two ERGTs. A schematic layout of this cycle is shown in Figure 3.3. 
Contract Number

PF 13524

\section{Gas Technology Institute}

Advanced Gasification Based Fuel Conversion and Electricity Production System for Forest Product Industry

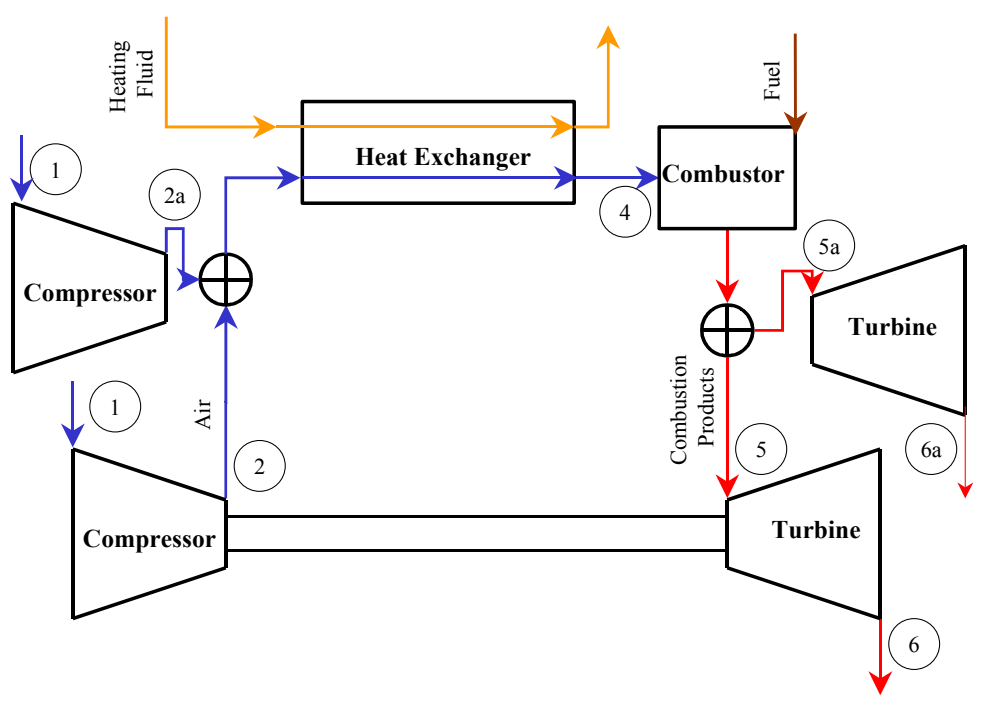

Figure 3.3 System of Two ERGT With Single Boost Combustor in Series With The Heat Exchanger

\section{Option 4}

Option 4 is similar to Option 3 with the only difference being the layout of the common heat exchanger and the boost combustor. Here the common heat exchanger and the boost combustor are piped in parallel as opposed to being in series. A schematic layout of this cycle is shown in Figure 3.4.

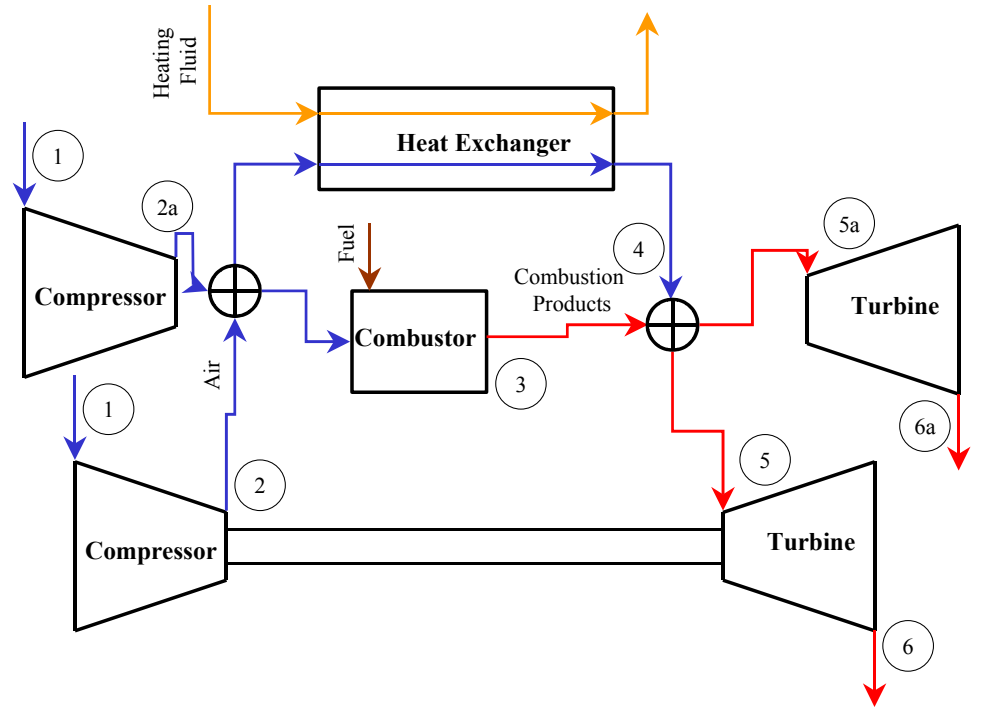

Figure 3.4 System of Two ERGT With Single Boost Combustor in Parallel With The Heat Exchanger

\section{Option 5}

This option consists of two ERGTs, each of which is connected to an independent generator. Each ERGT has its own compressor, boost combustor and turbine. The compressed air flow from the individual compressors is combined into a single flow stream and fed through a 
Contract Number

PF 13524

\section{Gas Technology Institute}

Advanced Gasification Based Fuel Conversion and Electricity Production System for Forest Product Industry

single heat exchanger. Downstream of the heat exchanger the air stream is split into two streams, each of which feeds into the boost combustor of the two turbines. A schematic layout of this cycle is shown in Figure 3.5.

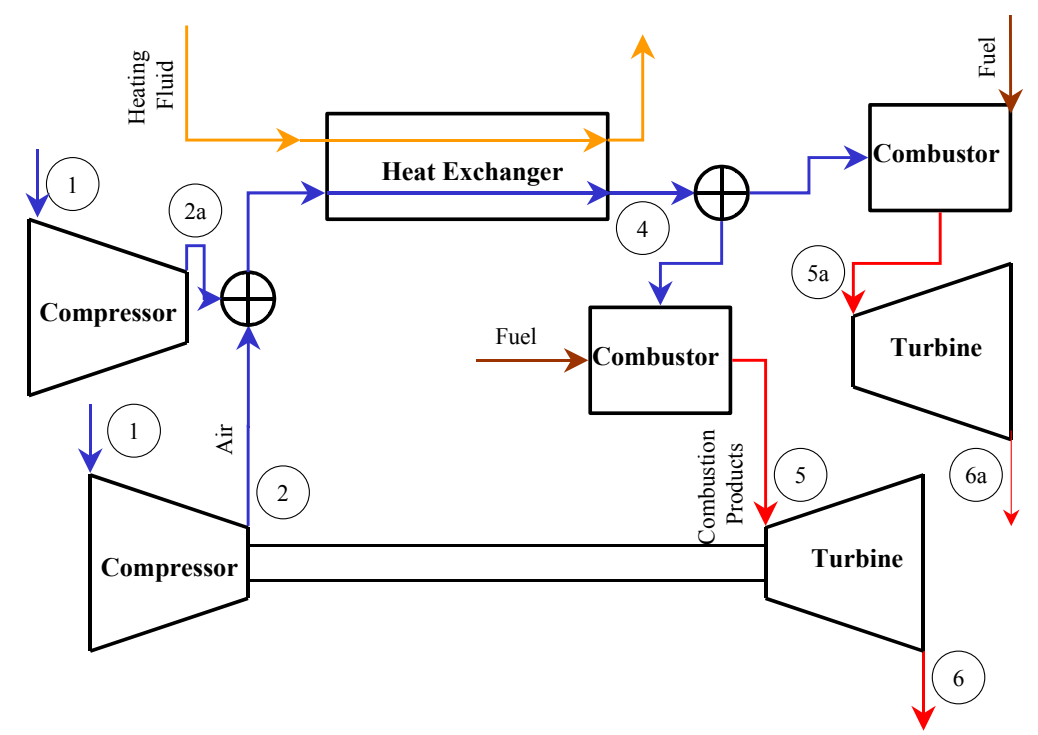

Figure 3.5 System of Two ERGT With Two Boost Combustors in Series With a Single Heat Exchanger

\section{Option 6}

Option 6 is similar to Option 5 with the only difference being the layout of the boost combustors. Here the boost combustors are piped in parallel to the heat exchanger, as opposed to being in series. A schematic layout of this cycle is shown in Figure 3.6.

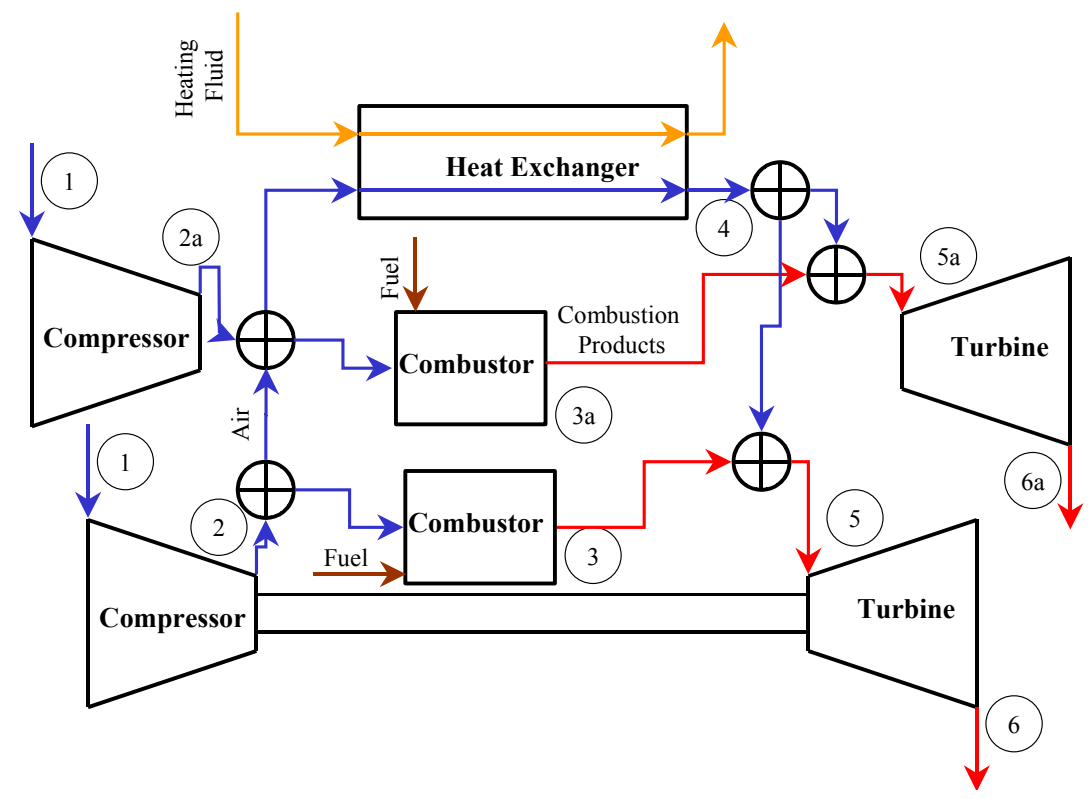

Figure 3.6 System of Two ERGT With Two Boost Combustors in Parallel With a Single Heat Exchanger 
Contract Number

PF 13524

\section{Gas Technology Institute}

Advanced Gasification Based Fuel Conversion and Electricity Production System for Forest Product Industry

\subsubsection{Cycle Selection}

Based upon the desire for system and controls simplicity, Option 3 through Option 6 were discarded. These options add controls and synchronization complexities that would increase the capital and operating cost of the equipment. Based on the space available at the pilot plant test site at DeRidder Paper Mill, DeRidder, Louisiana, it was determined that it would be possible to install two independent ERGT units of Titan 130 size. Therefore it was decided to limit the cycle analysis for this feasibility study to Option 1 and Option 2.

\subsubsection{Standard Titan 130 Cycle Data}

The cycle analysis and the design study presented in this report used the Titan 130 engine performance as the baseline. The performance data for this baseline single shaft Titan 130 gas turbine under ISO conditions is detailed in Table 3.1, while the composition of Natural gas used for the cycle analysis is detailed in Table 3.2.

Table 3.1 Gas Turbine Data

\begin{tabular}{|l|l|}
\hline Parameter & Units \\
\hline Number of compressor stages & 14 \\
\hline Number of turbine stages & 3 \\
\hline Pressure at compressor inlet & $14.7 \mathrm{psia}$ \\
\hline Pressure at compressor outlet pressure & $230.25 \mathrm{psig}$ \\
\hline Pressure ratio (outlet/inlet) & 16.663 \\
\hline Ambient air temperature & $60^{\circ} \mathrm{F}$ \\
\hline Air flow rate through the compressor & $6478.9 \mathrm{lb} / \mathrm{min}$ \\
\hline Gas composition & Natural Gas* \\
\hline Fuel flow rate & $112.02 \mathrm{lb} / \mathrm{min}$ \\
\hline Temperature at turbine outlet & $908.34^{\circ} \mathrm{F}$ \\
\hline Pressure at turbine outlet & $14.7 \mathrm{psia}$ \\
\hline Flow rate out the turbine & $6590.92 \mathrm{lb} / \mathrm{min}$ \\
\hline
\end{tabular}

*Note 1: The composition of natural gas assumed is detailed in Table 4

${ }^{\ddagger}$ Note 2: The lower heating value of the fuel is $20167.86 \mathrm{Btu} / \mathrm{lb}$

Table $3.2 \quad$ Fuel Composition

\begin{tabular}{|l|l|}
\hline Parameter & Volume Percent \\
\hline $\mathrm{CH}_{4}$ & 92.7899 \\
\hline $\mathrm{C}_{2} \mathrm{H}_{6}$ & 4.16 \\
\hline $\mathrm{C}_{3} \mathrm{H}_{8}$ & 0.84 \\
\hline $\mathrm{C}_{4}$ & 0.18 \\
\hline $\mathrm{C}_{5}$ & 0.04 \\
\hline $\mathrm{C}_{6}$ & 0.04 \\
\hline $\mathrm{CO}_{2}$ & 0.44 \\
\hline $\mathrm{N}_{2}$ & 1.51 \\
\hline $\mathrm{H}_{2} \mathrm{~S}$ & 0.0001 \\
\hline
\end{tabular}


Contract Number

PF 13524
Gas Technology Institute

Advanced Gasification Based Fuel Conversion and Electricity Production System for Forest Product Industry

\subsubsection{Parameters for ERGT Cycle study}

After discussions with GTI, it was decided to conduct the cycle analysis for a range of parameters that is broader than those acceptable for on the current Titan 130 designs. The ranges of parameters being considered for this are detailed in Table 3.3

Table 3.3 Ranges of Parameters Considered for this Study

\begin{tabular}{|l|l|}
\hline Turbine rotor inlet temperature & $1900^{\circ} \mathrm{F}, 2100^{\circ} \mathrm{F}$ \\
\hline Pressure drop across the HP/HT air heater & $10,20,30 \mathrm{psi}$ \\
\hline Exit temperature of the HP/HT air heater: & $1300^{\circ} \mathrm{F}$ through $1800^{\circ} \mathrm{F}$ in increments of $50^{\circ} \mathrm{F}$ \\
\hline HP/HT air heater leakage & $0 \%$ \\
\hline Pressure drop across the combustor & $3.5 \%$ of compressor outlet \\
\hline Ambient air temperature & $80^{\circ} \mathrm{F}$ \\
\hline Ambient air RH & $60 \%$, humidified using a fogger at inlet \\
\hline Combustor and turbine cooling & $\begin{array}{l}\text { Air, Steam to replace air wherever feasible } \\
\text { (no steam injection) }\end{array}$ \\
\hline Engine Load Conditions & Full Load \\
\hline
\end{tabular}

\subsection{Cycle Analysis for ERGT cycle}

Table 3.4 Inlet Conditions for Performance Code Benchmarking

\begin{tabular}{|c|l|}
\hline Inlet Air Temperature & $60^{\circ} \mathrm{F}, 80^{\circ} \mathrm{F}$ \\
\hline Relative Humidity & $60 \%$ \\
\hline Inlet Air Pressure & Sea level \\
\hline Pressure Ratio & 16.6 \\
\hline Nominal Net Turbine Output & $14 \mathrm{MW}$ \\
\hline Turbine Exhaust Pressure & $14.7 \mathrm{psia}$ \\
\hline
\end{tabular}

A computer code was developed for the purpose of thermodynamic cycle analysis of the various ERGT configurations. The code was benchmarked with results from an in-house proprietary code (simple cycle GT) for inlet conditions detailed in Table 3.4. The comparison was made for a standard gas turbine cycle. Based on the comparison it was concluded that the newly developed code could be considered reasonably accurate for purpose of this study. Using this new code, parametric thermodynamic simulations were conducted to map out all of the parametric variations detailed in Table 3.3. The results of the analyses were used to assess the cycle configurations and assist in identifying the most cost effective one. The evaluation presented here includes the effects of the various parameters on system performance and fuel costs.

Simulations were performed at full load conditions for fixed TRIT, and ambient conditions, and a fixed turbine-cooling scheme. The pressure drop across the HP/HT air heater was varied between $10 \mathrm{psi}$ and $30 \mathrm{psi}$ in increments of $10 \mathrm{psi}$, while the exit temperature of the $\mathrm{HP} / \mathrm{HT}$ air heater was varied between $1300^{\circ} \mathrm{F}$ and $1800^{\circ} \mathrm{F}$ in increments of $50^{\circ} \mathrm{F}$ 
For the purpose of evaluating the fuel cost (per KW-hr) the following assumptions were made

i. Full load operation for 8000 hours per year

ii. Natural gas price of $\$ 4 / \mathrm{MBTU}$

iii. Wood waste price of $\$ 1.78 / \mathrm{MBTU}$

iv. Only $50 \%$ of the wood waste used is purchased. The other $50 \%$ is generated from an in-house paper manufacturing process so is considered free.

v. Efficiency of the boiler that uses wood waste as fuel and houses the HP/HT heat exchanger is $80 \%$.

\subsubsection{Comparison of Option 1 and Option 2 to Baseline}

Detailed thermodynamic analyses of Option 1 and Option 2 (schematically shown in Figure 3.1 and Figure 3.2) were conducted for the parameters detailed in Table 3.5. Two cycle variants were investigated based on Option 2. Option 2a employs a combustor that is cooled using compressed air at the compressor discharge temperature. Option $2 \mathrm{~b}$ reflects a combustor cooled using either heated air from the air heater or steam, assuming there is no leakage of the steam into the combustor. For Option 1, the combustor cooling was achieved using heated air from the air heater

Table 3.5 The Parameters Ranges used in the Evaluation of Option 2

\begin{tabular}{|c|c|}
\hline Turbine rotor inlet temperature & $2100^{\circ} \mathrm{F}$ \\
\hline System pressure drop & $10 \mathrm{psi}$ \\
\hline HP/HT air heater exit temperature & $1300^{\circ} \mathrm{F}$ to $1800^{\circ} \mathrm{F}$ in increments of $50^{\circ} \mathrm{F}$ \\
\hline HP/HT air heater leakage & $0 \%$ \\
\hline Ambient air temperature & $80^{\circ} \mathrm{F}$ \\
\hline Ambient air RH & $60 \%$ \\
\hline $\begin{array}{r}\text { Combustor cooling (Option 1) } \\
\text { (Option 2a) } \\
\text { (Option 2b) }\end{array}$ & $\begin{array}{l}\text { Air from HP/HT air heater } \\
\text { Air at compressor discharge temperature } \\
\text { Steam (no steam injection) or air from HP/HT air heater }\end{array}$ \\
\hline Turbine cooling & Air at compressor discharge temperature \\
\hline
\end{tabular}

While conducting the analyses, the flame temperature was restricted to levels at which current gas turbines can operate in a low emissions mode. This restriction defined the amount of air that could bypass the combustor and be heated by the air heater in Option 2 . The percentage of air that can be allowed to pass through the HP/HT air heater for the various conditions used in the evaluation of Option 2 is detailed in Table 3.6.

Table 3.6 Percentage of Air Allowed to Pass Through the Air Heater as a Function of Air Heater Exit Temperature

\begin{tabular}{|l|l|l|l|l|l|l|}
\hline Configuration & \multicolumn{7}{|c|}{ Percentage of air passed through the air heater for different } \\
& Heater Exit Temperatures \\
\hline & $\mathbf{1 3 0 0}^{\circ} \mathbf{F}$ & $\mathbf{1 4 0 0}^{\circ} \mathbf{F}$ & $\mathbf{1 5 0 0}^{\circ} \mathbf{F}$ & $\mathbf{1 6 0 0}^{\circ} \mathbf{F}$ & $\mathbf{1 7 0 0}^{\circ} \mathbf{F}$ & $\mathbf{1 8 0 0}^{\circ} \mathbf{F}$ \\
\hline Option 2a & 7.57 & 8.33 & 9.27 & 10.48 & 12.07 & 14.25 \\
\hline Option 2b & 35.88 & 38.1 & 40.64 & 43.58 & 47.01 & 51.06 \\
\hline
\end{tabular}


Contract Number

PF 13524
Gas Technology Institute

Advanced Gasification Based Fuel Conversion and Electricity Production System for Forest Product Industry

The results of the cycle analyses are shown in Figure 3.7 through Figure 3.9. Figure 3.7 compares the net electrical power output of the three cases with that of the baseline standard gas turbine (no heat exchanger and directly fired). Figure 3.8 compares the natural gas consumption for the three cases with that of the baseline standard gas turbine, and Figure 3.9 compares the fuel costs $(\$ / \mathrm{KW}-\mathrm{hr})$ of operating an ERGT based on the three cases with that of a baseline gas turbine. Figure 3.10 shows the percentage of fuel cost savings achieved while operating an ERGT in comparison with a standard engine.

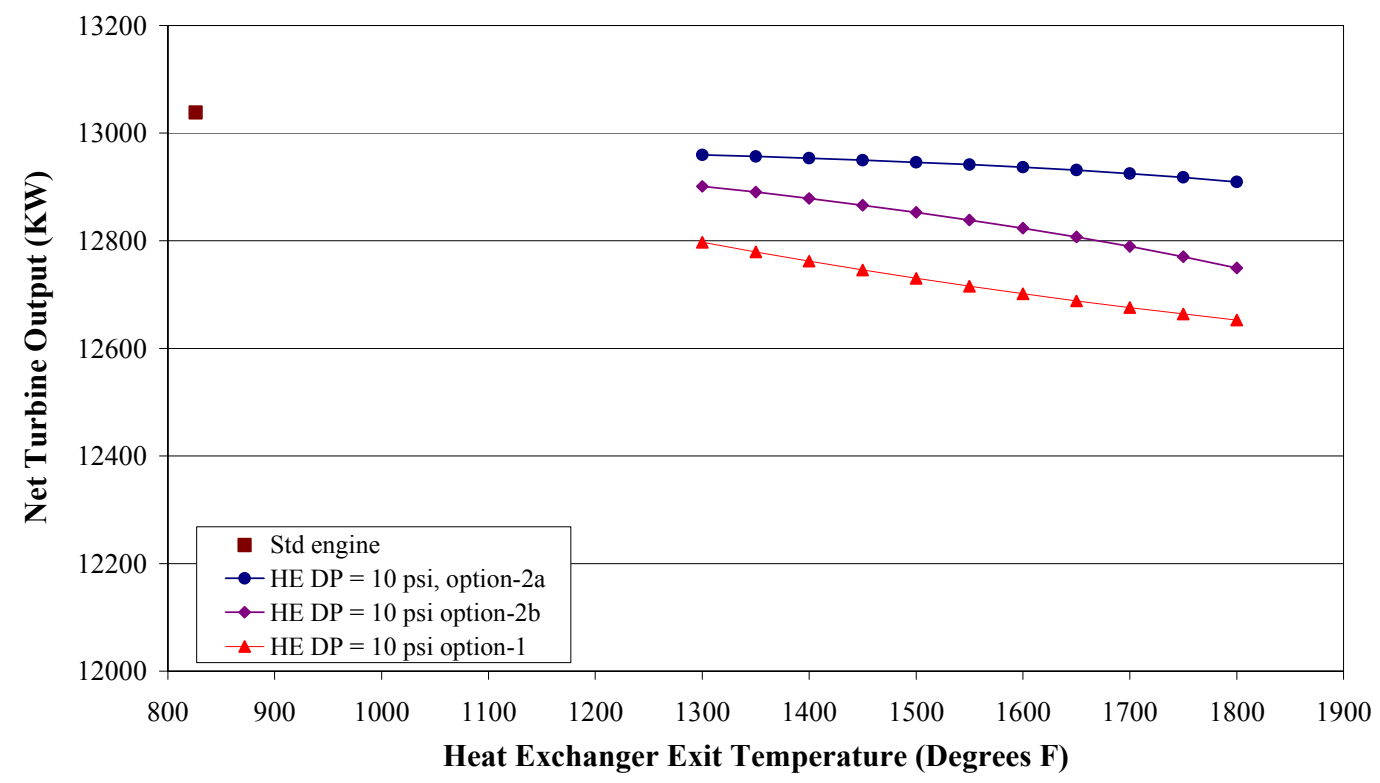

Figure 3.7 Net Turbine Output as a Function of HP/HT Air Heater Exit Temperature for Option 1 and Options $2 a \& 2 b$

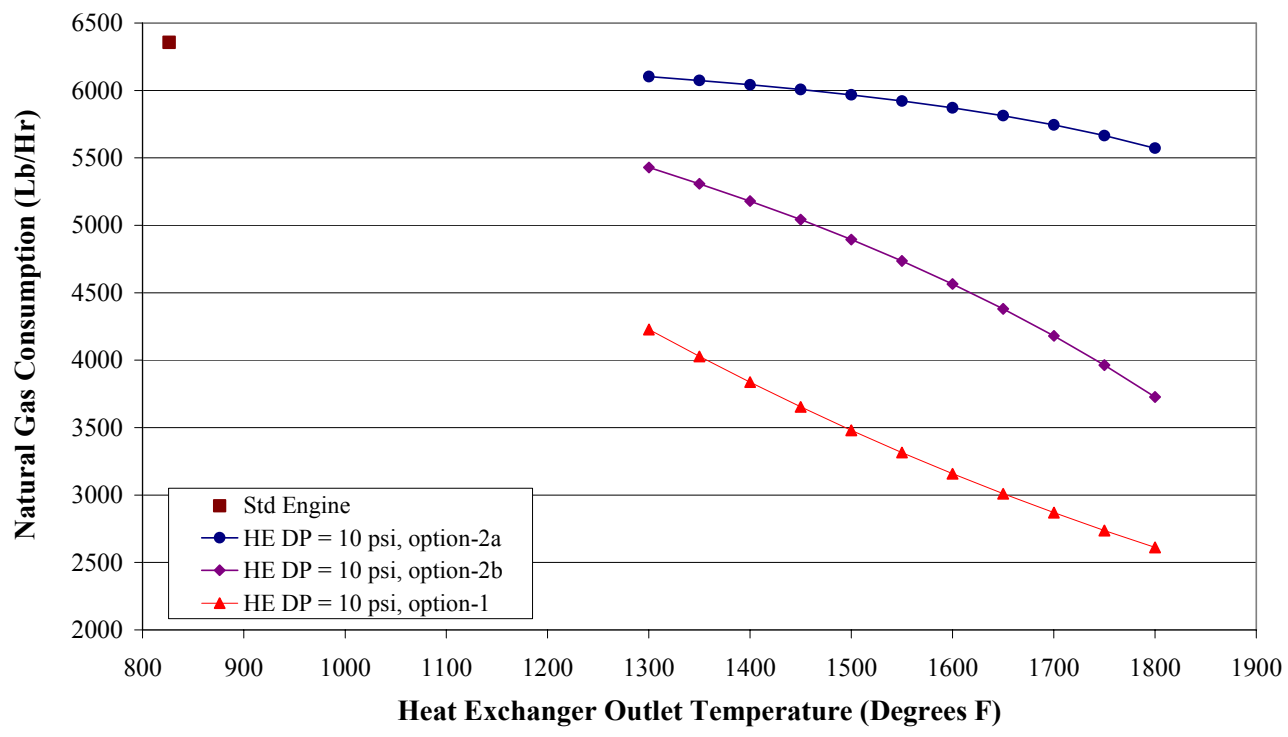

Figure 3.8 Natural Gas Consumption as a Function of HP/HT Air Heater Exit Temperature for Option 1 and Option $2 a \& 2 b$ 
Contract Number

PF 13524
Gas Technology Institute

Advanced Gasification Based Fuel Conversion and Electricity Production System for Forest Product Industry

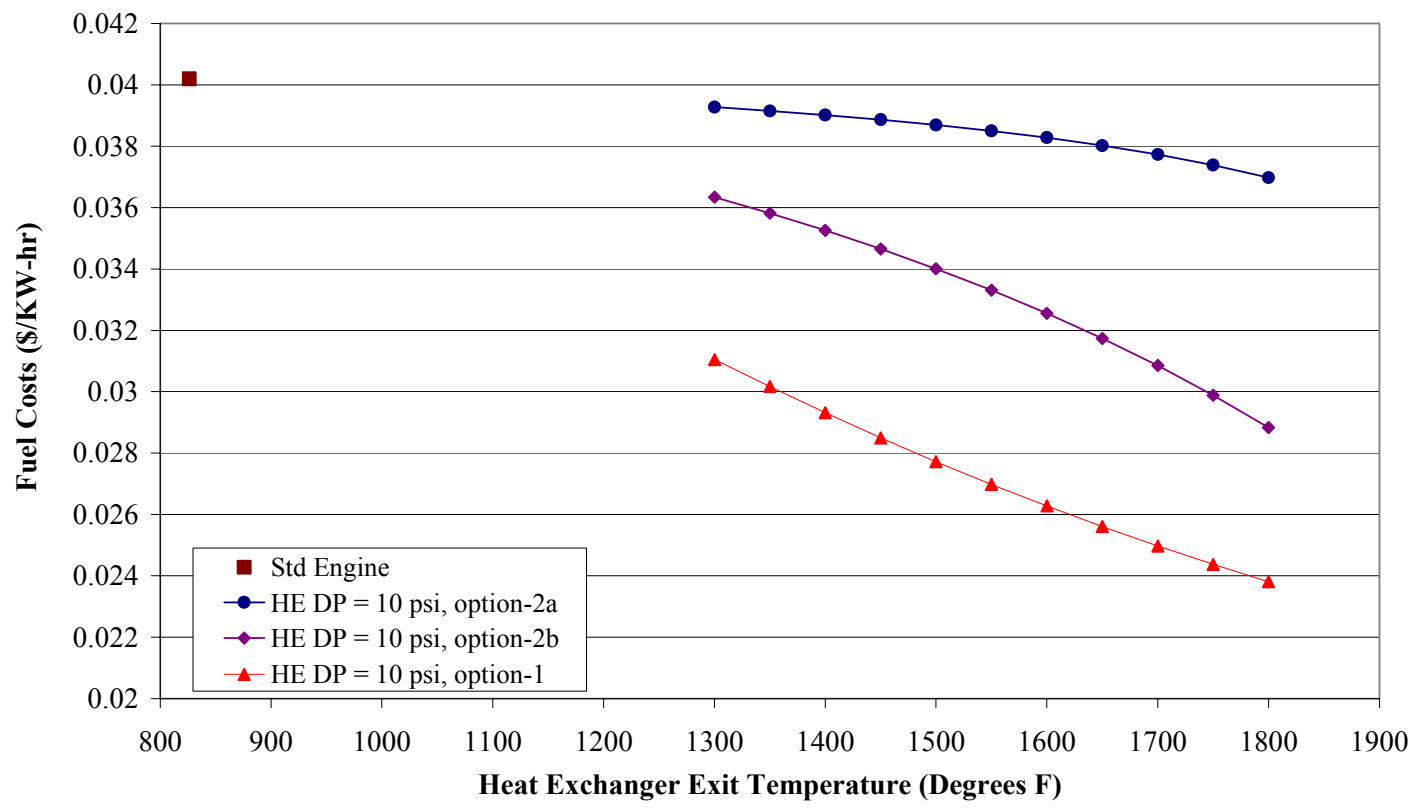

Figure $3.9 \quad$ Fuel Cost as a Function of HP/HT Air Heater Exit Temperature for Option 1 and Option $2 a \& 2 b$

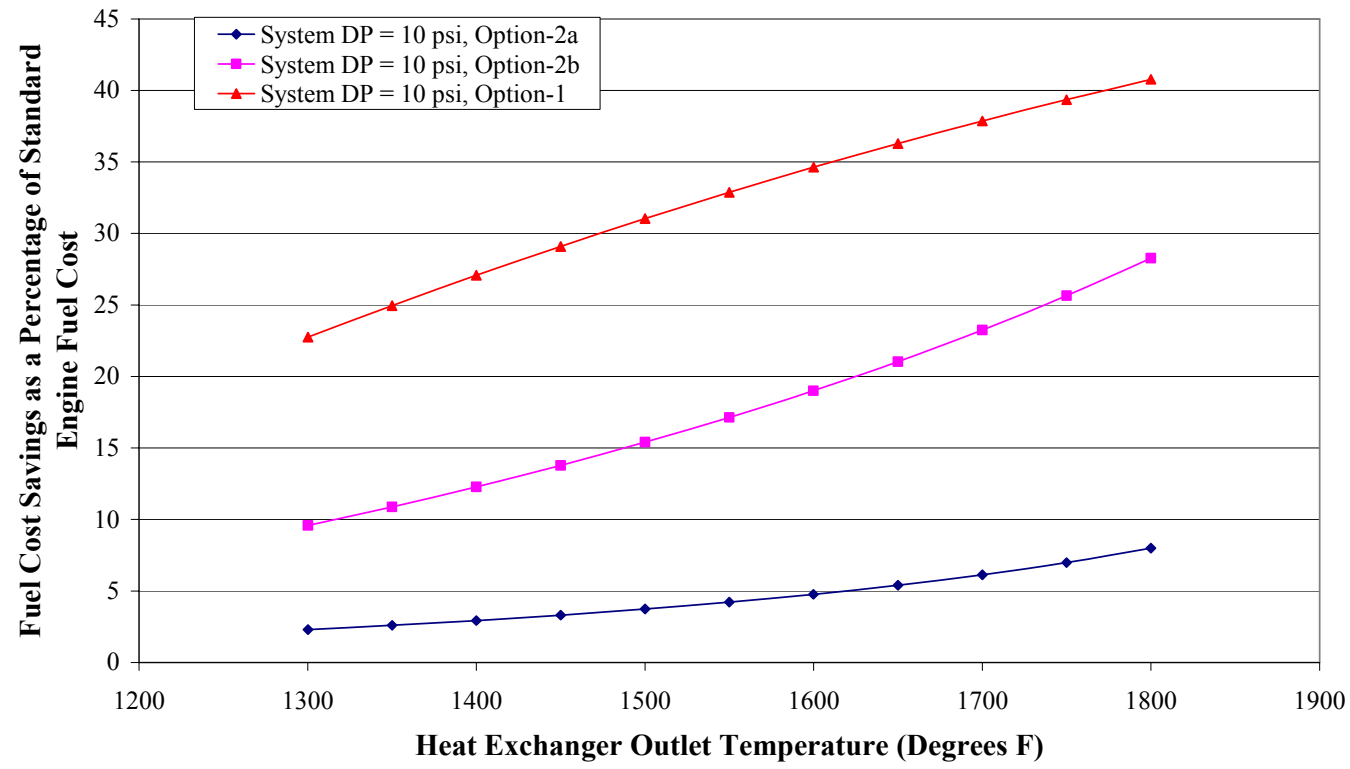

Figure 3.10 Percentage Fuel Cost Savings using the Standard Engine Fuel Costs as a Baseline

Evaluating these results, it is seen that both Option $2 \mathrm{a}$ and Option $2 \mathrm{~b}$ provide a slightly more power than Option 1. However, their savings in fuel cost is small when compared to a standard gas turbine and much smaller than that of Option 1. Since the initial pilot installation will most likely be with air heater exhaust temperatures in the range of $1400^{\circ} \mathrm{F}$ to $1500^{\circ} \mathrm{F}$, Option 2 does not provide significant fuel cost savings to warrant development. 
Contract Number

PF 13524
Gas Technology Institute

Advanced Gasification Based Fuel Conversion and Electricity Production System for Forest Product Industry

Therefore, it was recommended that Option 1 be the preferred cycle for this study and the rest of the analysis presented on this report is based on Option 1.

\subsubsection{Performance of ERGT based on Option 1}

Detailed parametric, thermodynamic analyses of Option 1, Figure 3.1, were conducted for two TRITs, to determine the effect of HP/HT air heater pressure drop and exit temperature on the net turbine power output, natural gas consumption, turbine exhaust temperature and fuel cost. In these simulations, compressed air was used as the cooling medium for the turbine. The results of these analyses were compared with those of the baseline engine and are graphically shown in Figure 3.11 through Figure 3.14, while Figure 3.15 shows the fuel savings while operating an ERGT as a percentage of the fuel cost needed to run a standard engine.

The TRITs chosen for comparison were $2100^{\circ} \mathrm{F}$ and $1900^{\circ} \mathrm{F}$. The TRIT of $2100^{\circ} \mathrm{F}$ is currently state of the art for small industrial turbines. The lower TRIT was adopted based on the assumptions that mechanical design of some of the ERGT components (such as the scroll) might force the system to run at a lower TRIT and that operation at lower TIRT could be cost effective when natural gas costs rise.

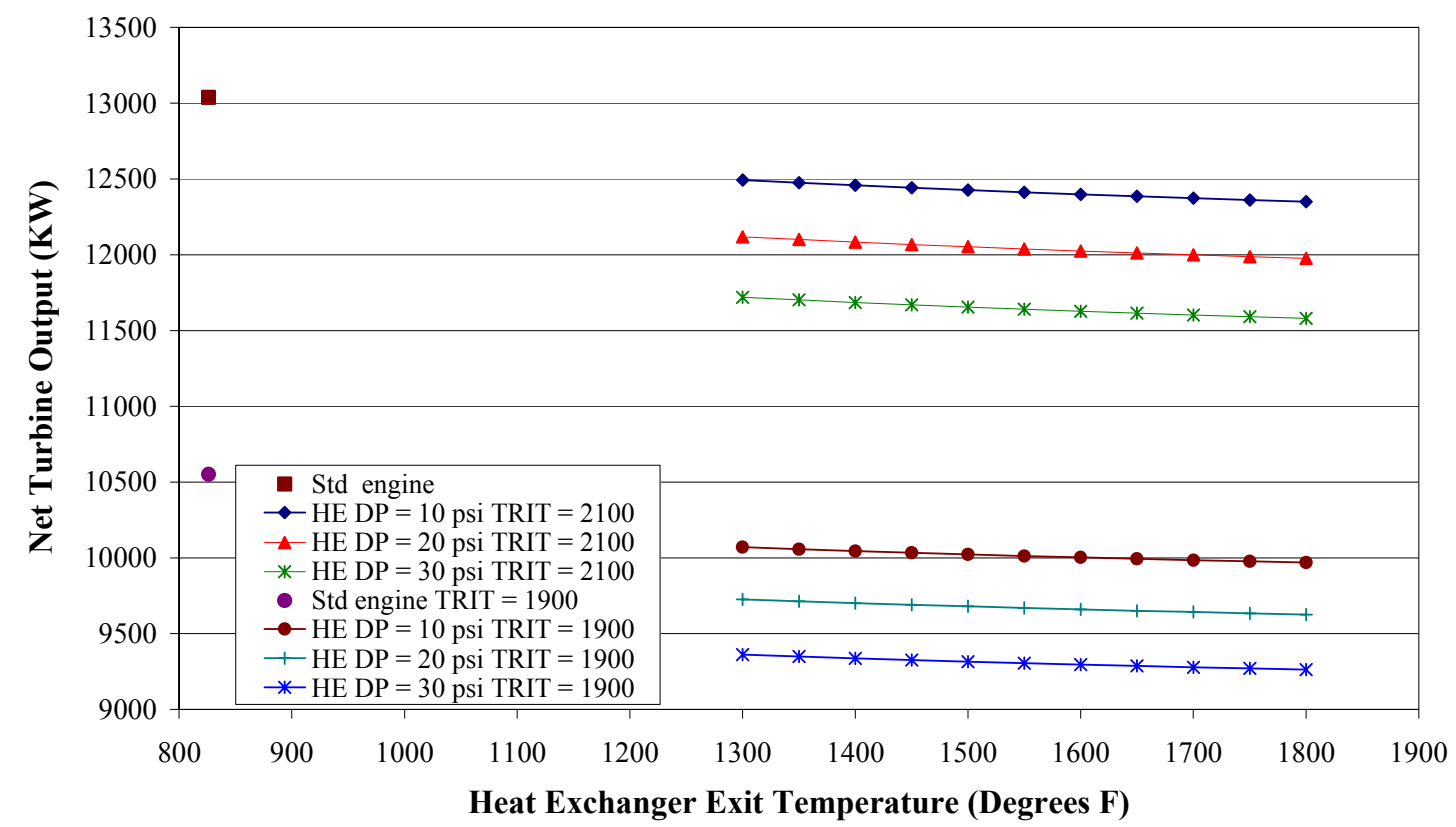

Figure $3.11 \quad$ Net Turbine output as a Function of HP/HT Air Heater Pressure Drop and HP/HT Air Heater Exit Temperature 
Contract Number

PF 13524

\section{Gas Technology Institute}

Advanced Gasification Based Fuel Conversion and Electricity Production System for Forest Product Industry

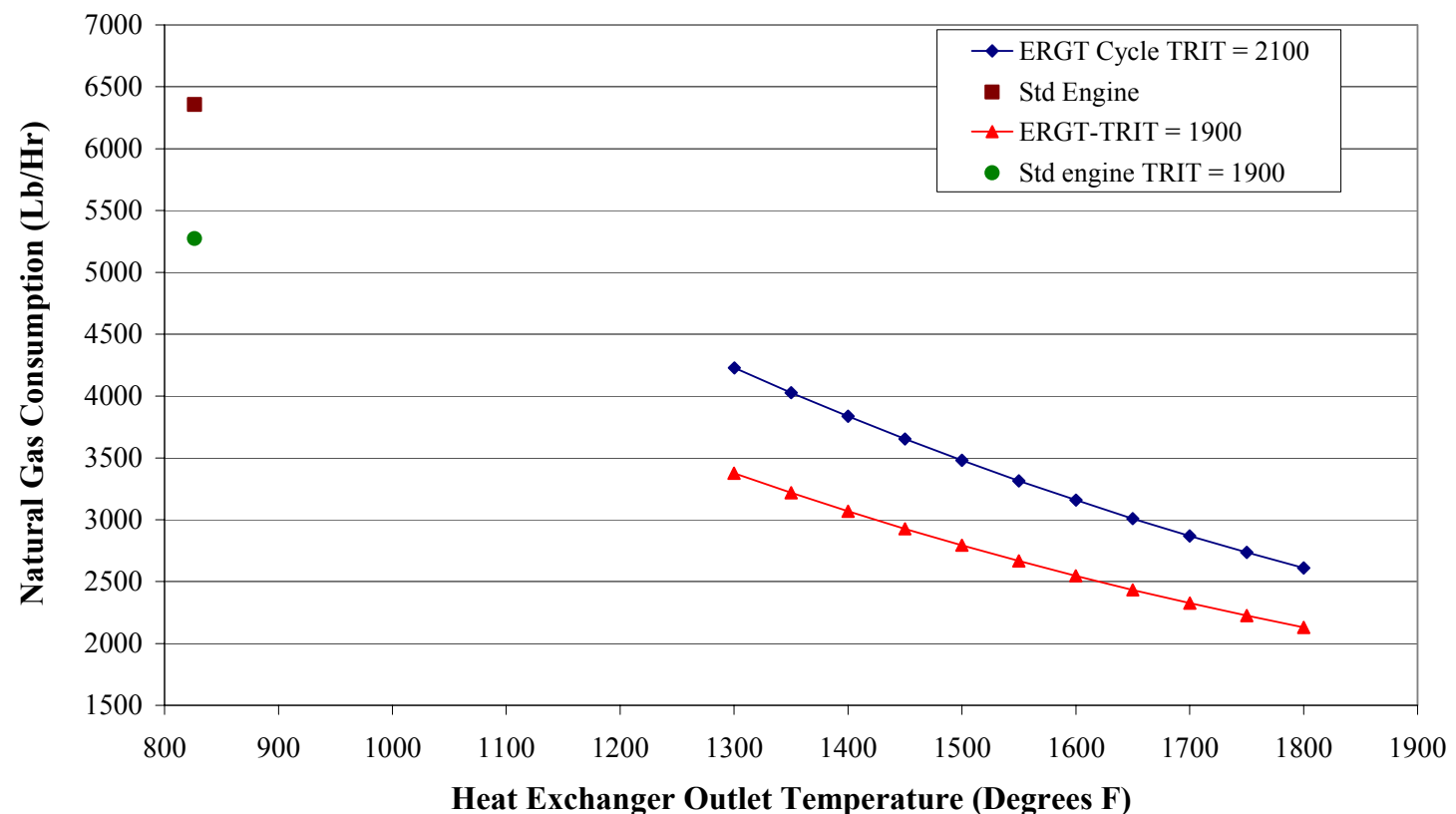

Figure 3.12 Natural Gas Consumption as a Function of HP/HT Air Heater Exit Temperature

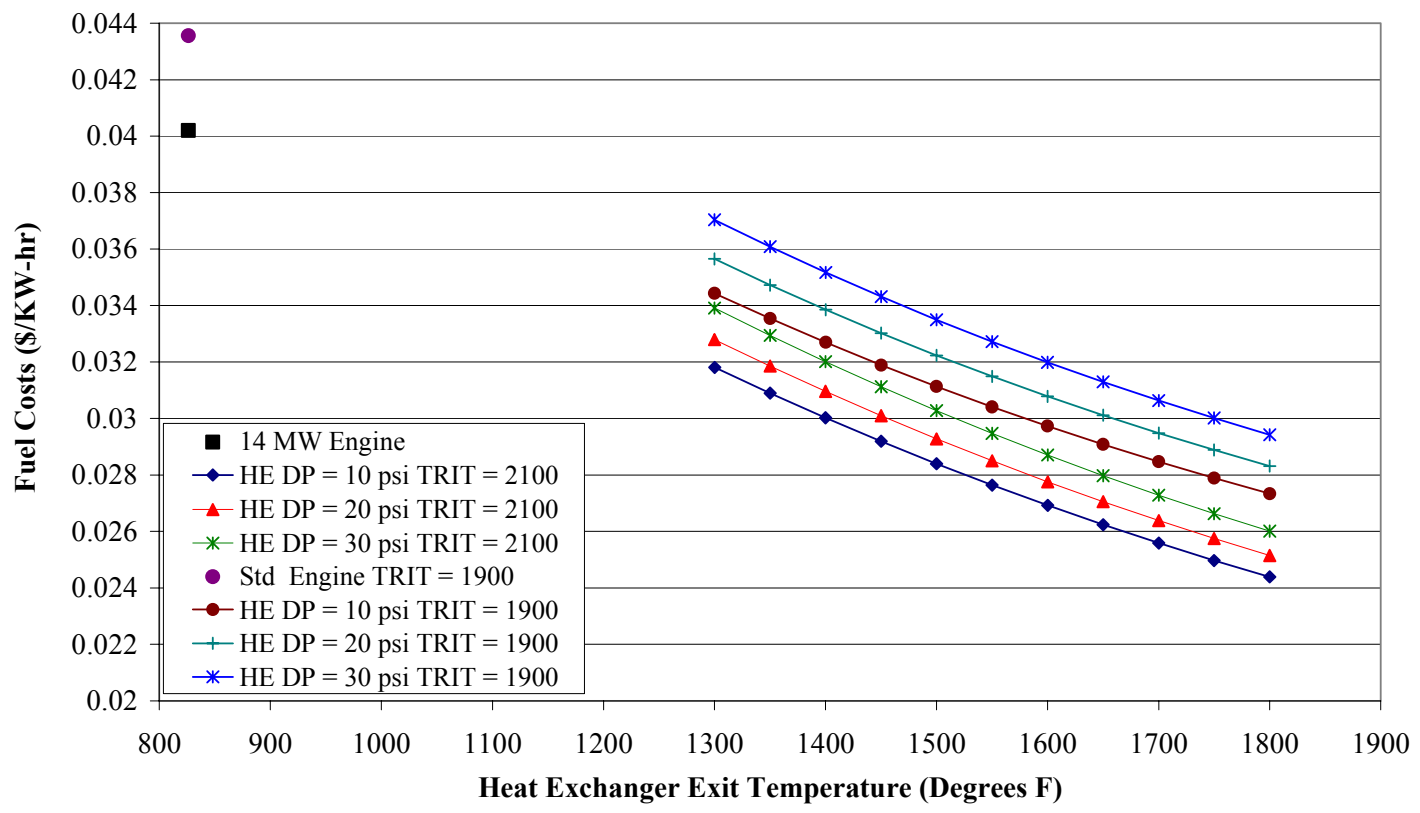

Figure 3.13 Fuel Cost as a Function of HP/HT Air Heater Pressure Drop and HP/HT Air Heater Exit Temperature 
Contract Number

PF 13524
Gas Technology Institute

Project Title

Advanced Gasification Based Fuel Conversion and

Electricity Production System for Forest Product Industry

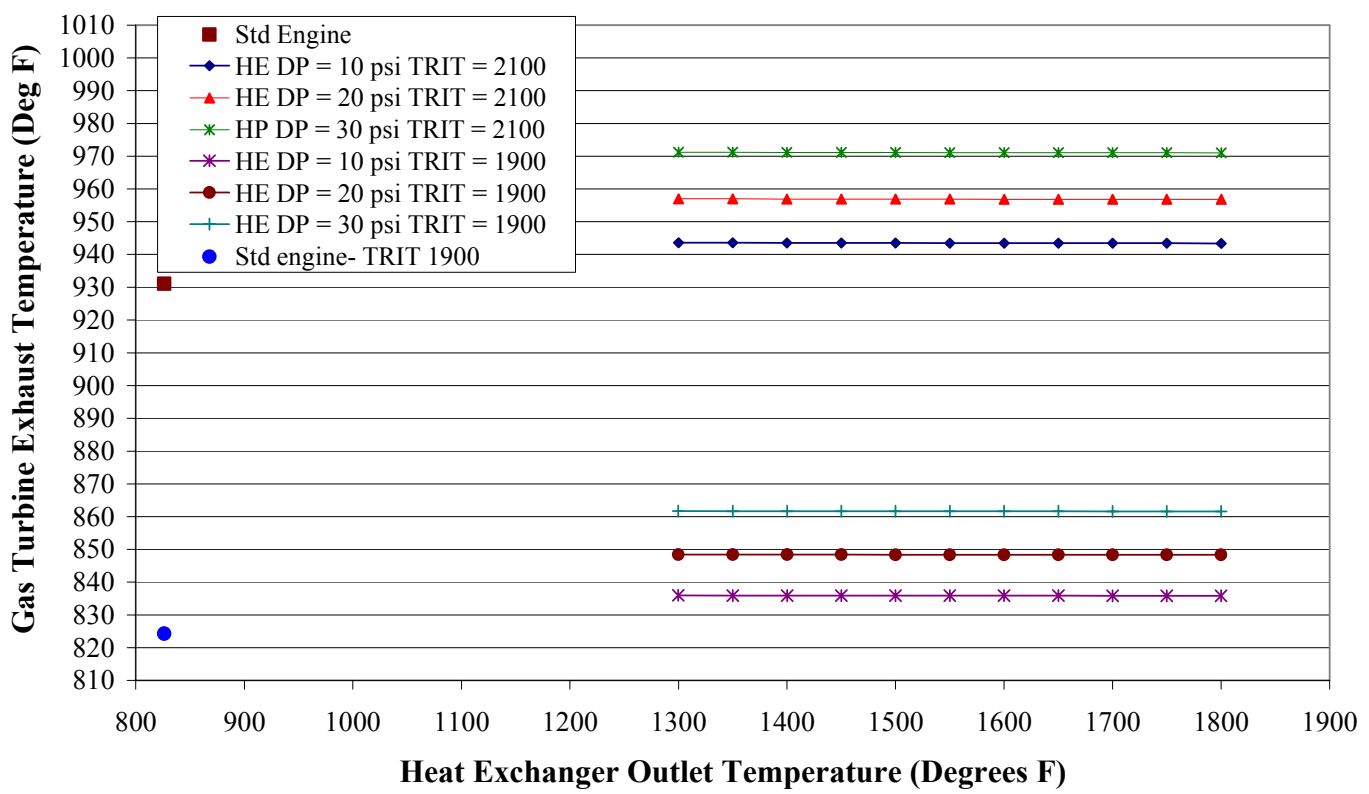

Figure 3.14 Gas Turbine Exhaust Temperature as a Function of HP/HT Air Heater Pressure Drop

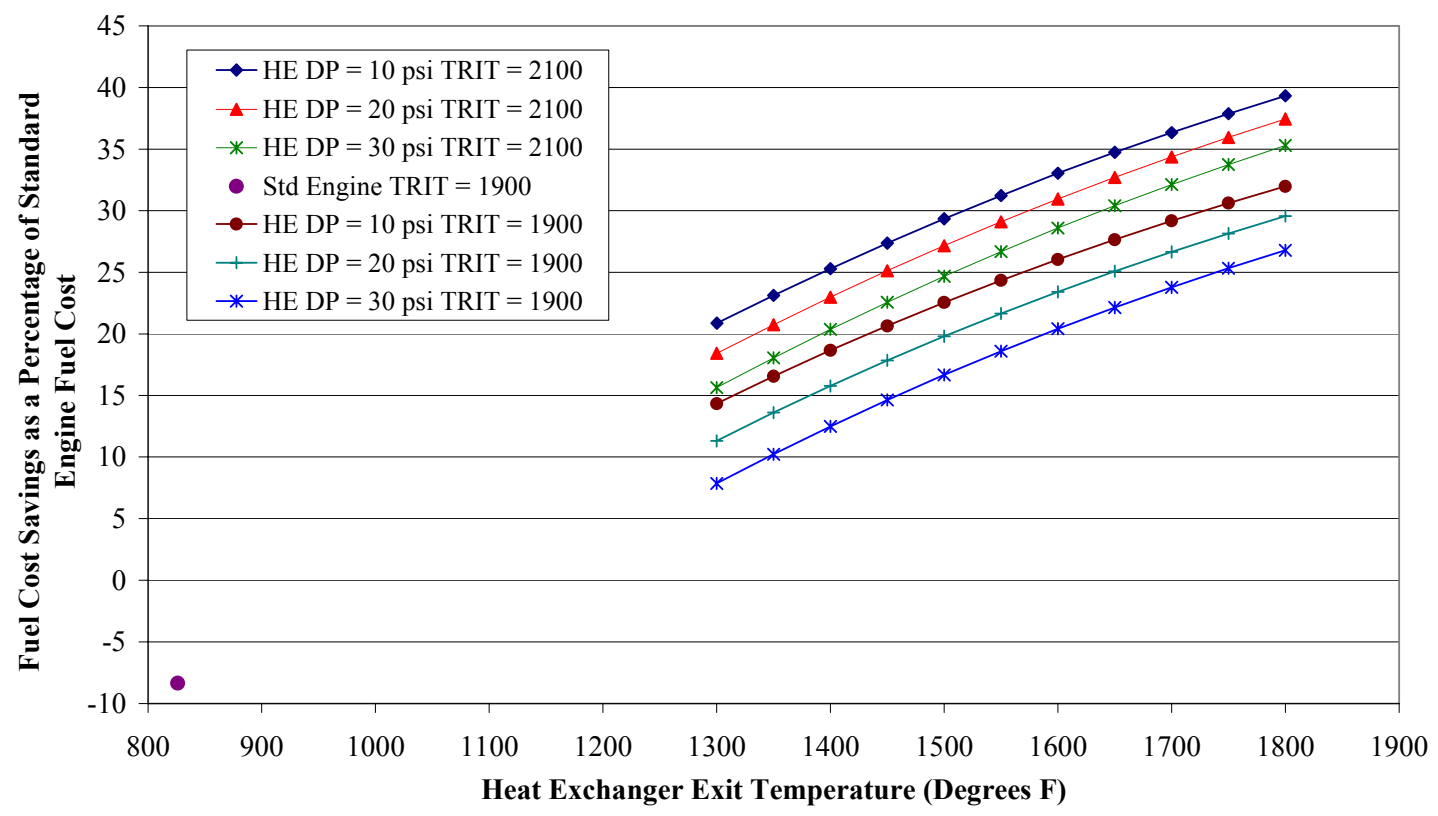

Figure 3.15 Percentage Fuel Cost Savings while Operating an ERGT Using the Standard Engine Fuel Costs as a Baseline

These results indicate that increasing the heat exchanger exit temperature and lowering its pressure drop, while increasing the TRIT, will maximize the ERGT savings and make the cycle more attractive. Note that unless the TRIT is increased beyond $2100^{\circ} \mathrm{F}$, there will always be a small penalty on the net turbine KW by using an ERGT. However, the ERGT will provide higher exhaust heat relative to the standard gas turbine when both are compared 
Contract Number

PF 13524

\section{Gas Technology Institute}

Advanced Gasification Based Fuel Conversion and Electricity Production System for Forest Product Industry

at the same TRIT.

\subsubsection{ERGT with Steam Cooled Turbines}

Additional thermodynamic analysis of Option 1 was conducted to evaluate the effect of using steam as the cooling medium for the turbine. Using steam allows more air to flow through the power turbine, increasing output. These simulations were performed for a TRIT of $2100^{\circ} \mathrm{F}$. The variables involved in this analysis were the HP/HT air heater pressure drop and exit temperature, while the parameters used for the comparison were the net turbine power output, natural gas consumption, turbine exhaust temperature, cost of fuel per KW-hr and the percentage of savings in fuel cost. The results of this analysis are graphically shown in Figure 3.16 through Figure 3.19, while Figure 3.20 shows the percentage of fuel cost saved when operating an ERGT. The basis of the cost savings is taken to be the fuel cost needed to run a standard engine.

This analysis assumes that no steam enters the turbine flow stream and that the steam is available in abundance. In addition the analysis is not evaluating a combined cycle. Therefore some leakage of steam can be permitted in the actual design. Thus the design constraints on the turbine cooling circuit leakage can be made less restrictive.

Due to the pressure drop across the HP/HT heat exchanger, an ERGT with an air-cooled turbine will always have a net electrical output lower than a standard gas turbine. However an ERGT with a steam-cooled turbine can provide an electrical output greater than that of a standard gas turbine for an added pressure drop of up to 20 psi. The results further show that an ERGT can produce an increase in electrical output of about $8 \%$ by switching the cooling medium of the turbine from compressed air to steam (comparisons being made for the same pressure drop across the HP/HT heat exchanger).

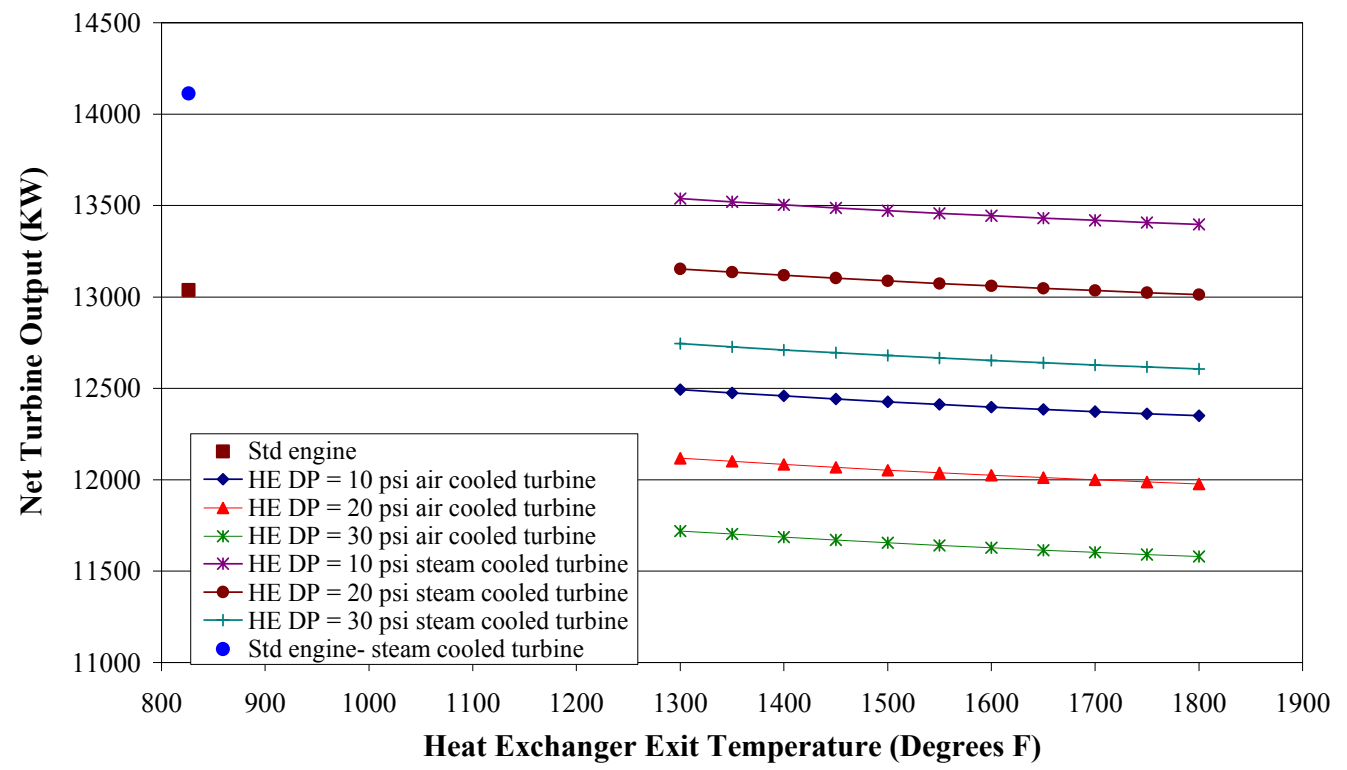

Figure 3.16 Net Turbine Output as a Function of HP/HT Air Heater Pressure Drop and HP/HT Air Heater Exit Temperature $\left(\right.$ TRIT $\left.=2100^{\circ} \mathrm{F}\right)$ 
Contract Number

PF 13524

\section{Gas Technology Institute}

Advanced Gasification Based Fuel Conversion and Electricity Production System for Forest Product Industry

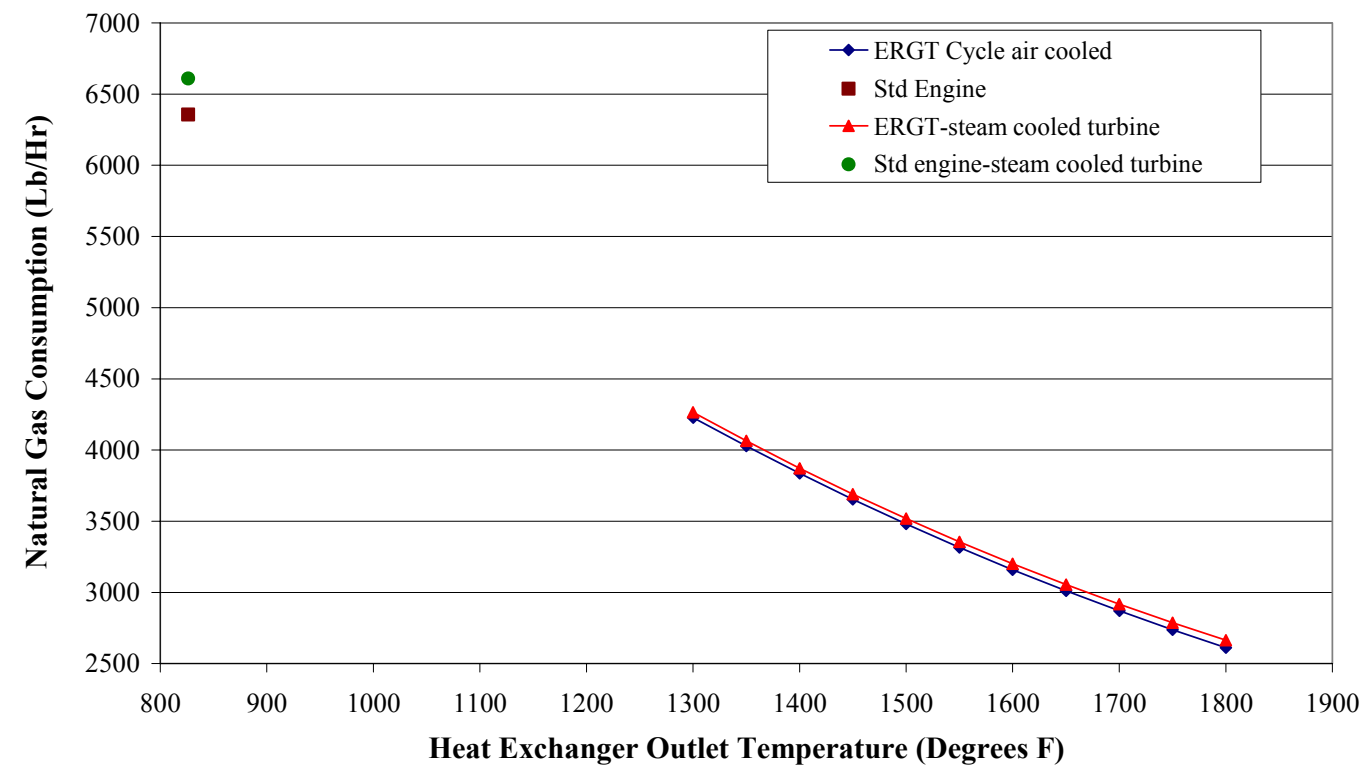

Figure 3.17 Natural Gas Consumption as a Function of HP/HT Air Heater Exit Temperature $\left(T R I T=2100^{\circ} \mathrm{F}\right)$

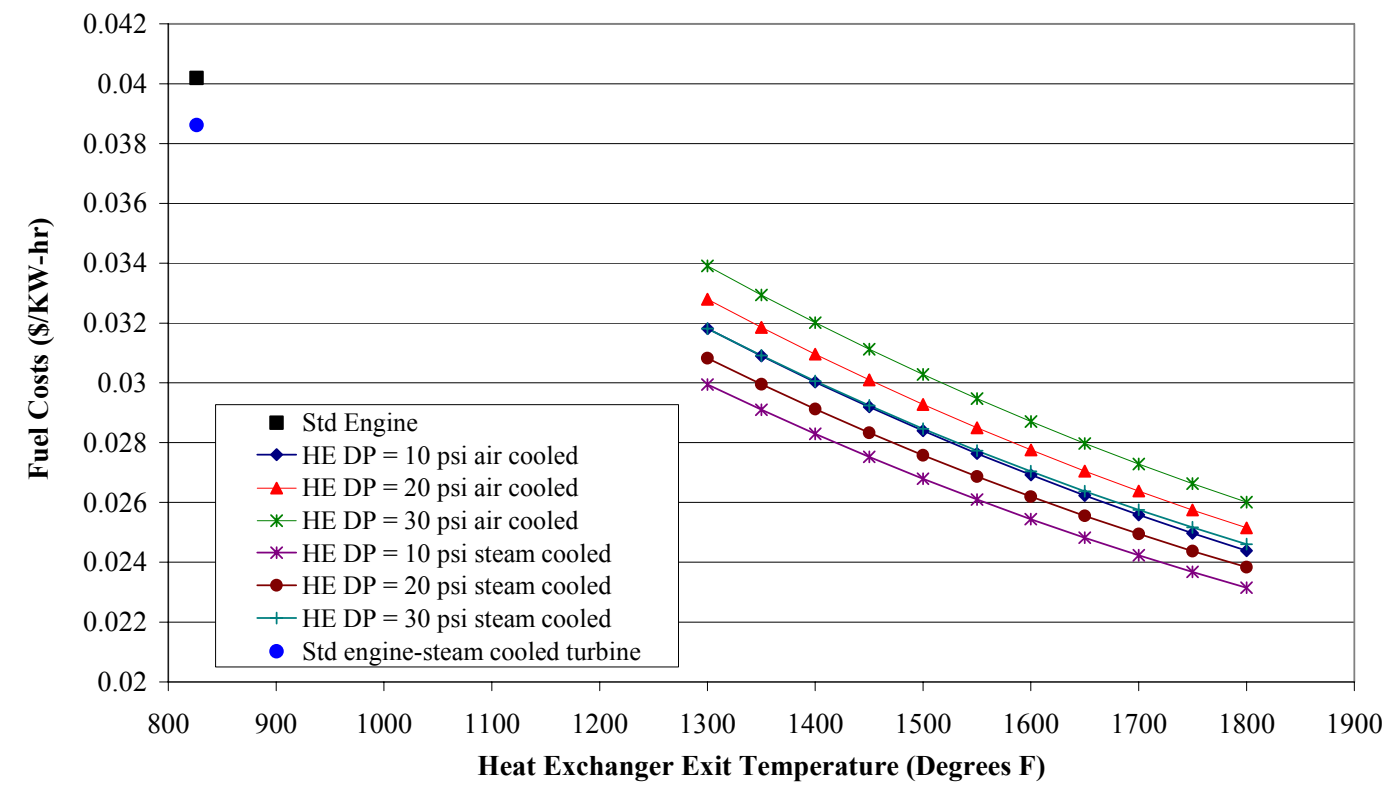

Figure 3.18 Fuel Cost as a Function of HP/HT Air Heater Pressure Drop and HP/HT Air Heater Exit Temperature $\left(\right.$ TRIT $\left.=2100^{\circ} \mathrm{F}\right)$ 
Contract Number

PF 13524

\section{Gas Technology Institute}

Advanced Gasification Based Fuel Conversion and Electricity Production System for Forest Product Industry

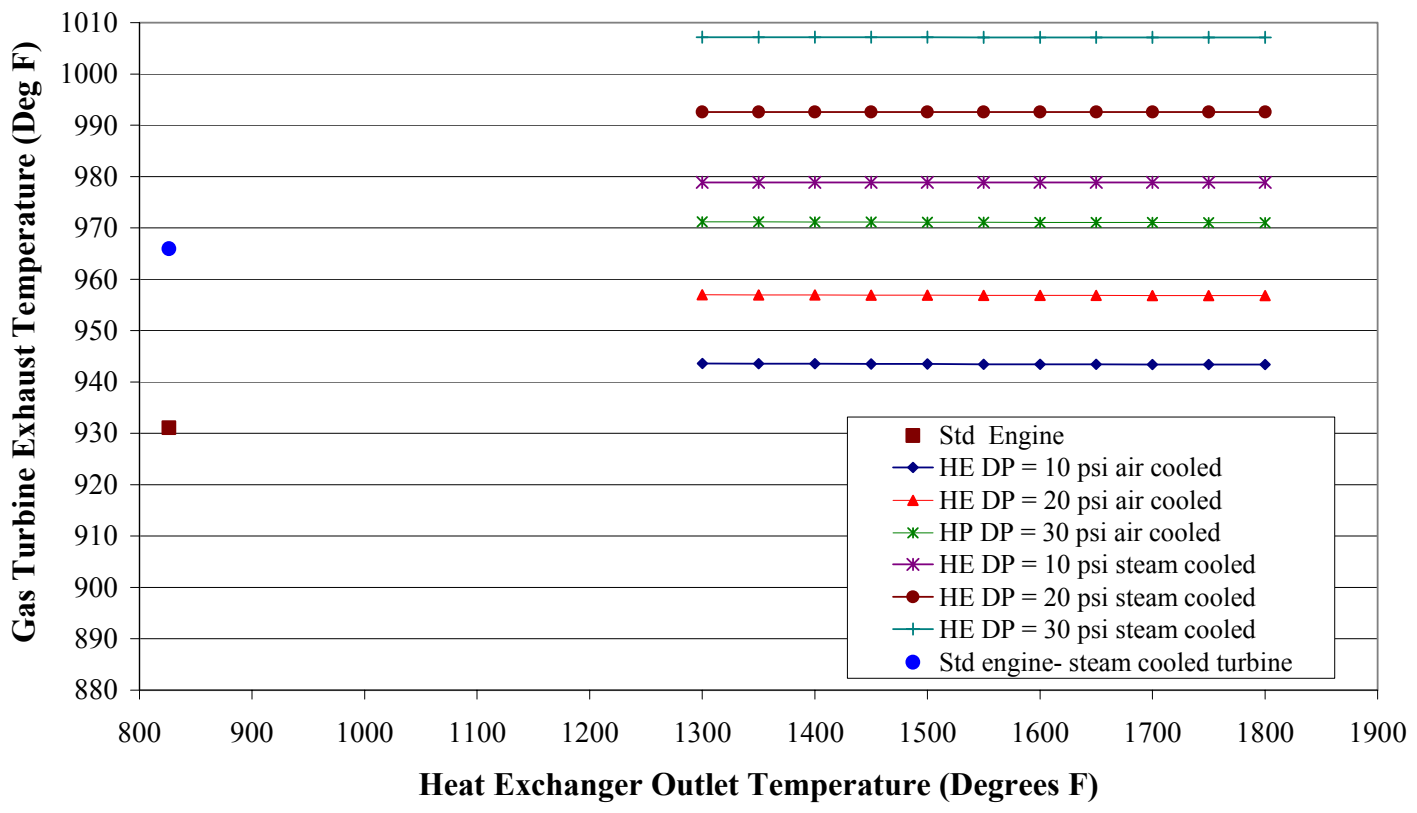

Figure 3.19 Gas Turbine Exhaust Temperature as a Function of HP/HT Air Heater Pressure Drop $\left(T R I T=2100^{\circ} \mathrm{F}\right)$

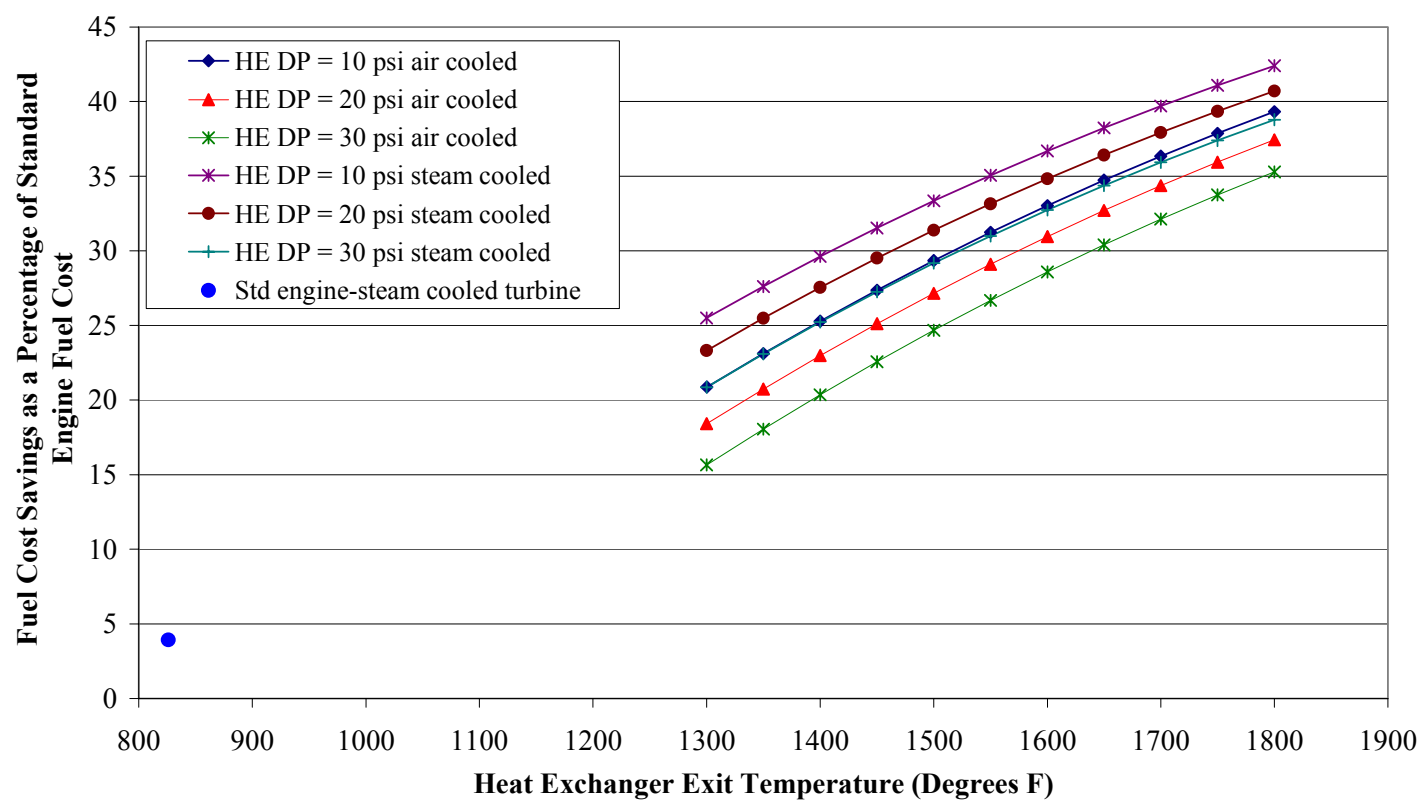

Figure 3.20 Percentage Fuel Cost Savings while Operating an ERGT Using the Standard Engine Fuel Costs as a Baseline 
Along with a higher electrical output, the ERGT with steam-cooled turbine also provides a higher exhaust temperature than an ERGT with air-cooled turbine. This aids in cogeneration. Further, the ERGT with steam cooled turbine generates a fuel cost savings of at least $23 \%$ over a standard gas turbine, while an ERGT with compressed air cooled turbine blades generates a fuel cost savings of at least $15 \%$. Thus using steam as a turbine cooling medium results in an additional $8 \%$ of fuel cost savings.

Based on the above discussion, it can therefore be concluded that thermodynamically an ERGT with a steam-cooled turbine is a preferred option.

\subsubsection{Effects of Humidification of Inlet Air}

Thermodynamic analysis of Option 1 was extended to encompass the effects of using a fogger/humidifier at the inlet of the gas turbine. The use of the humidifier changed the inlet air condition from a temperature of $80^{\circ} \mathrm{F}$ and a $\mathrm{RH}$ of $60 \%$ to a temperature of $70^{\circ} \mathrm{F}$ and a $\mathrm{RH}$ of $100 \%$. The analysis was conducted to study the effect of the humidifier on an ERGT with an air-cooled turbine (Option 1a) and an ERGT with a steam-cooled turbine (Option 1b). Figure 3.21 through Figure 3.25 detail the results of the simulations of Option 1a, while Figure 3.26 through Figure 3.30 detail the results of the simulations of Option $1 \mathrm{~b}$. The analysis of Option $1 \mathrm{~b}$ assumes that there is no steam flow into the turbine flow stream and the discussion with respect to steam cooling that is detailed in Section 3.2.3 is valid.

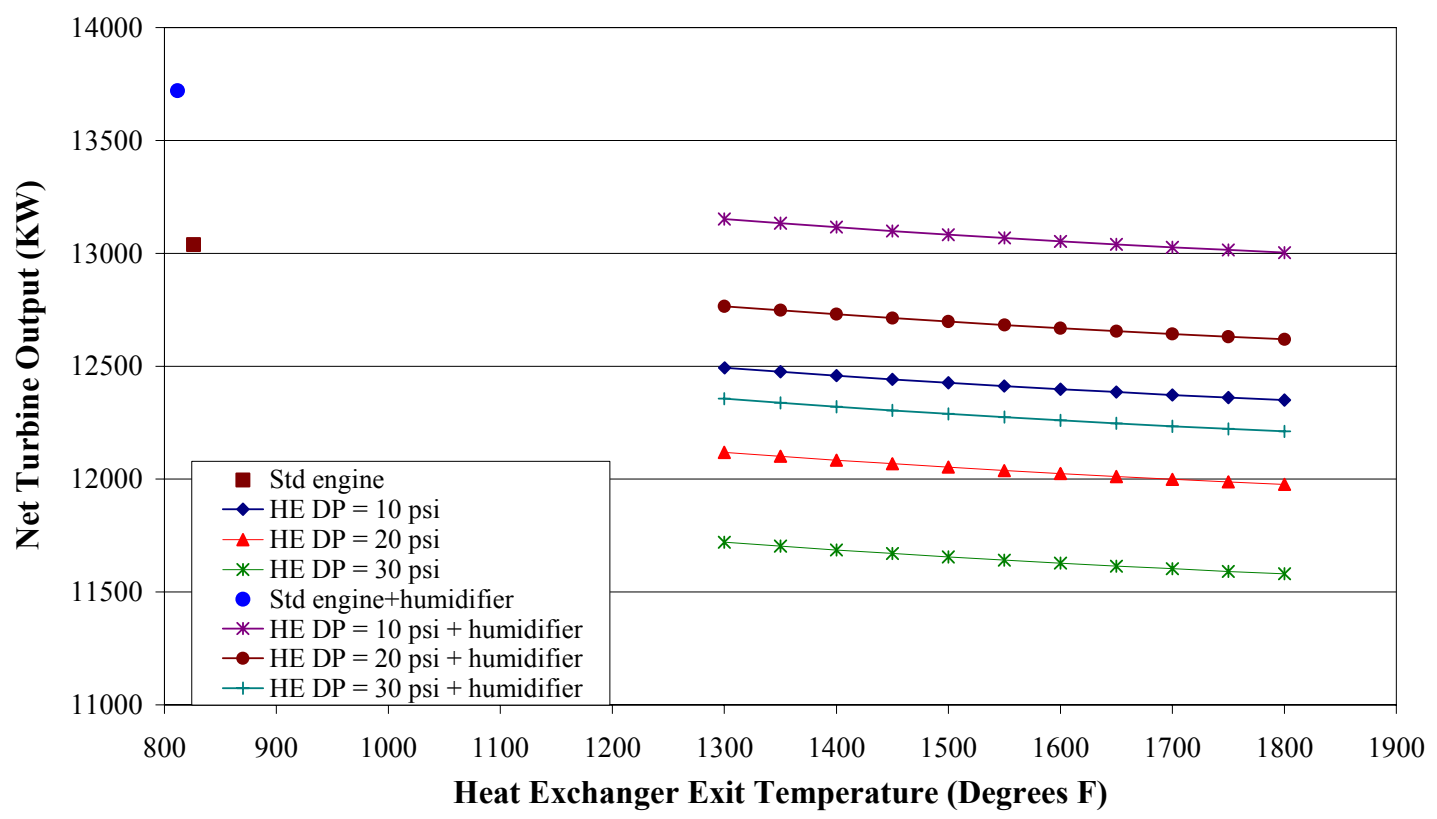

Figure 3.21 Net Turbine Output as a Function of HP/HT Air Heater Pressure Drop and HP/HT Air Heater Exit Temperature for Air-Cooled Turbine with and without a Humidifier at Inlet of Compressor 
Contract Number

PF 13524

\section{Gas Technology Institute}

Advanced Gasification Based Fuel Conversion and

Electricity Production System for Forest Product Industry

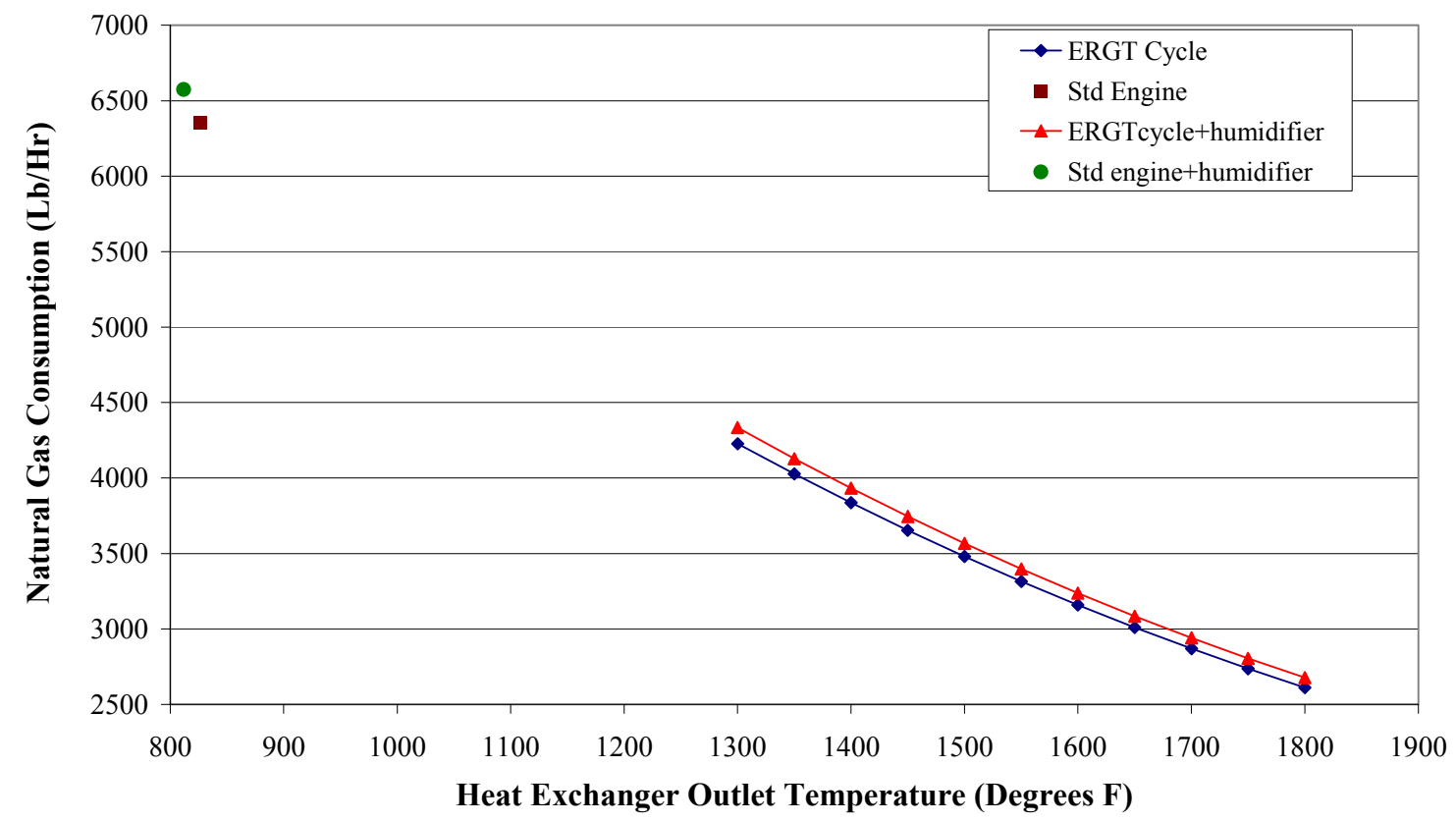

Figure 3.22 Natural Gas Consumption as a Function of HP/HT Air Heater Exit Temperature for Air-cooled Turbine with and without a Humidifier at inlet of Compressor

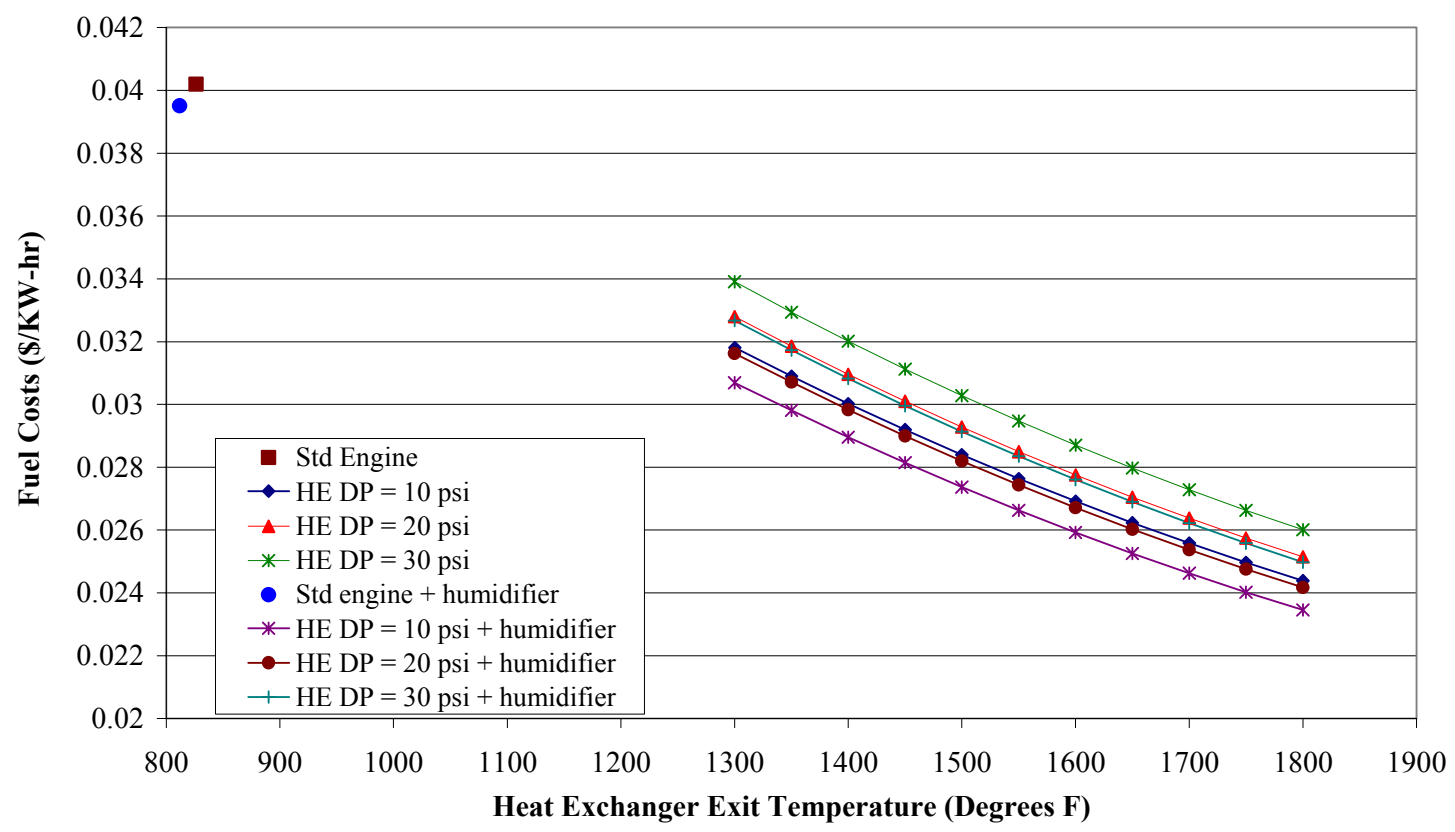

Figure 3.23 Fuel Cost as a Function of HP/HT Air Heater Pressure Drop and HP/HT Air Heater Exit Temperature for Air-Cooled Turbine with and without a Humidifier at Inlet of Compressor 
Contract Number

PF 13524

\section{Gas Technology Institute}

Advanced Gasification Based Fuel Conversion and

Electricity Production System for Forest Product Industry

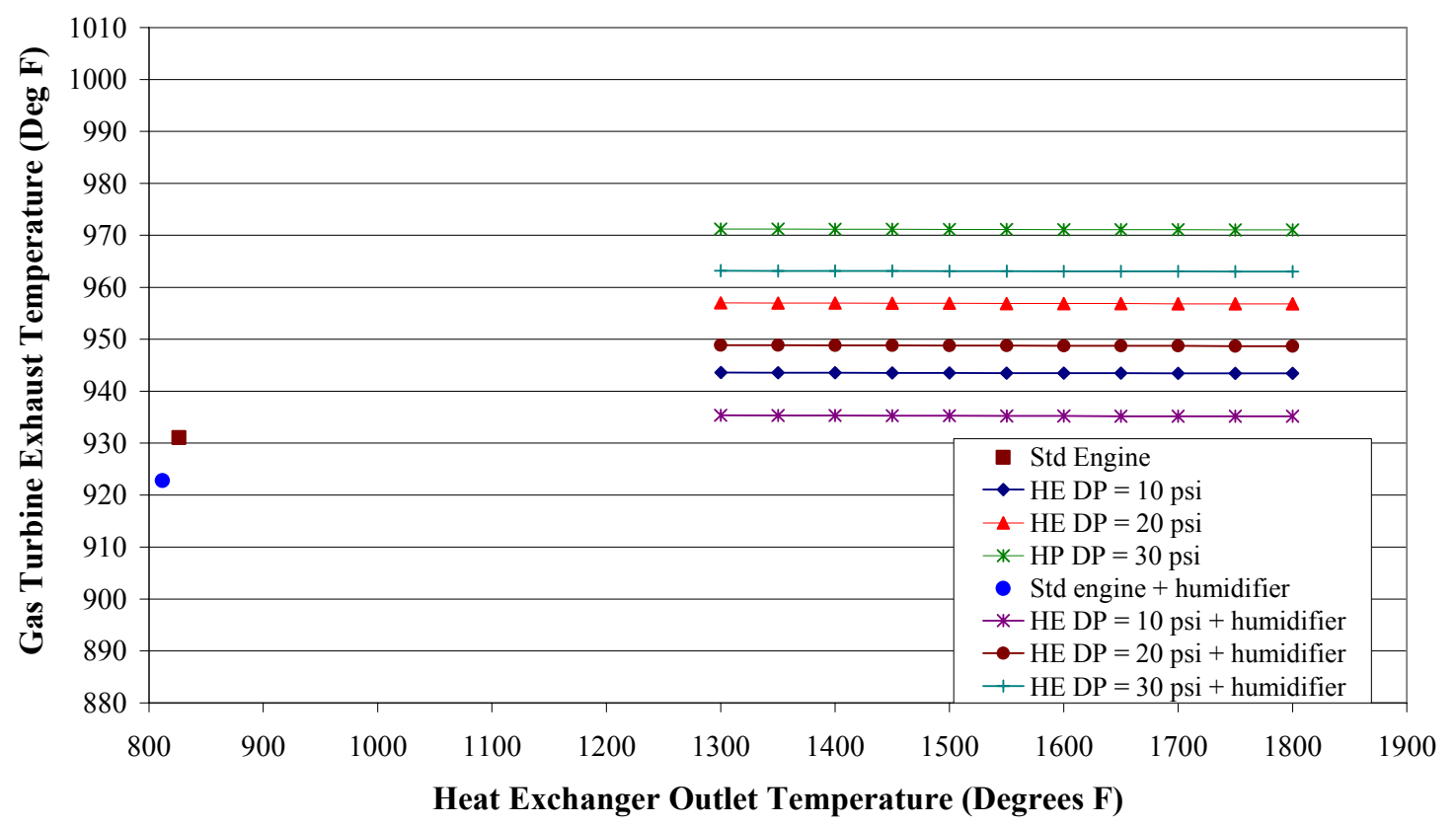

Figure 3.24 Gas Turbine Exhaust Temperature as a Function of HP/HT Air Heater Pressure Drop for Air-Cooled Turbine with and without a Humidifier at Inlet of Compressor

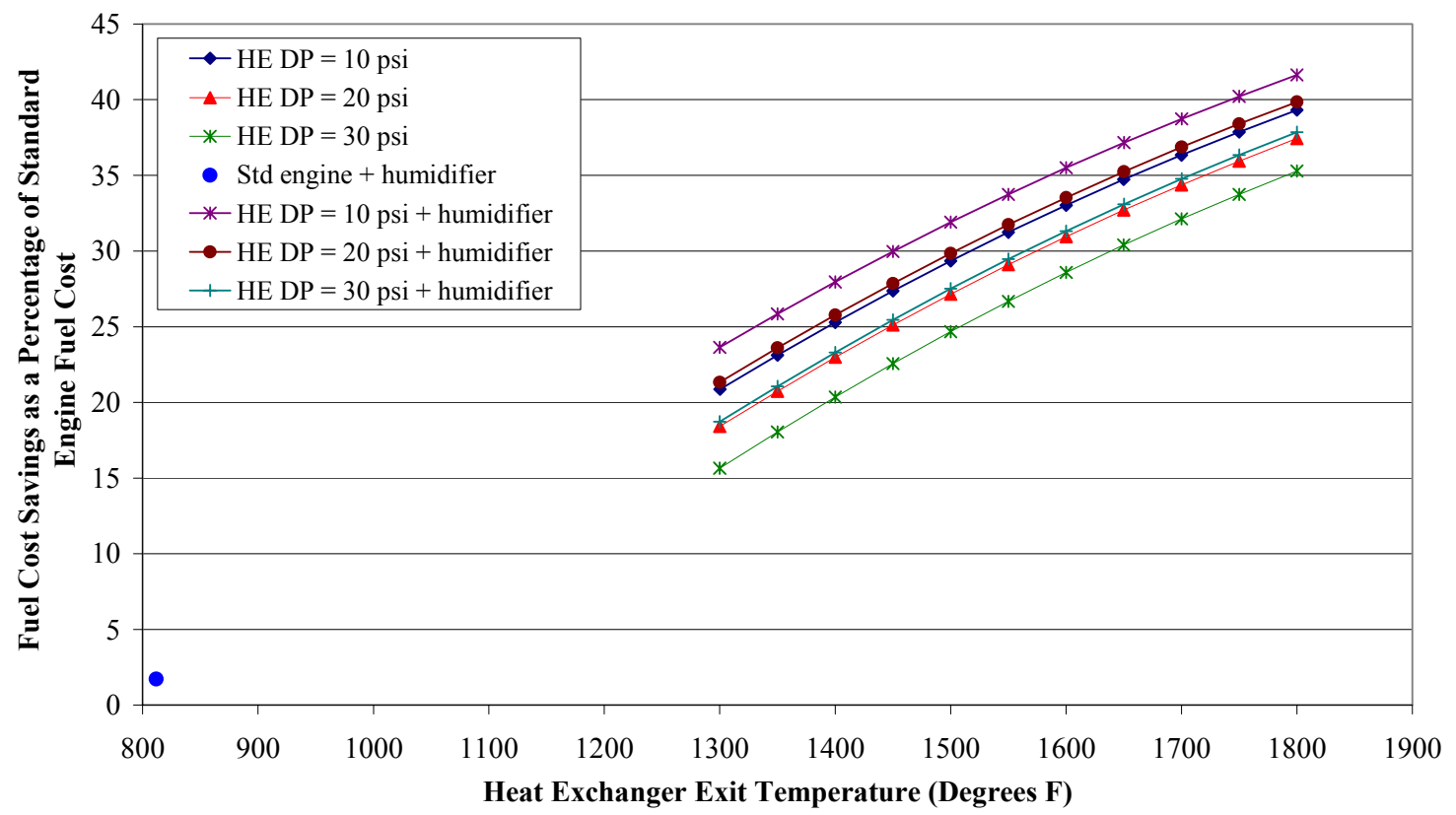

Figure 3.25 Percentage Fuel Cost Savings while Operating an ERGT using the Standard Engine Fuel Costs as a Baseline 
Contract Number

PF 13524

\section{Gas Technology Institute}

Advanced Gasification Based Fuel Conversion and Electricity Production System for Forest Product Industry

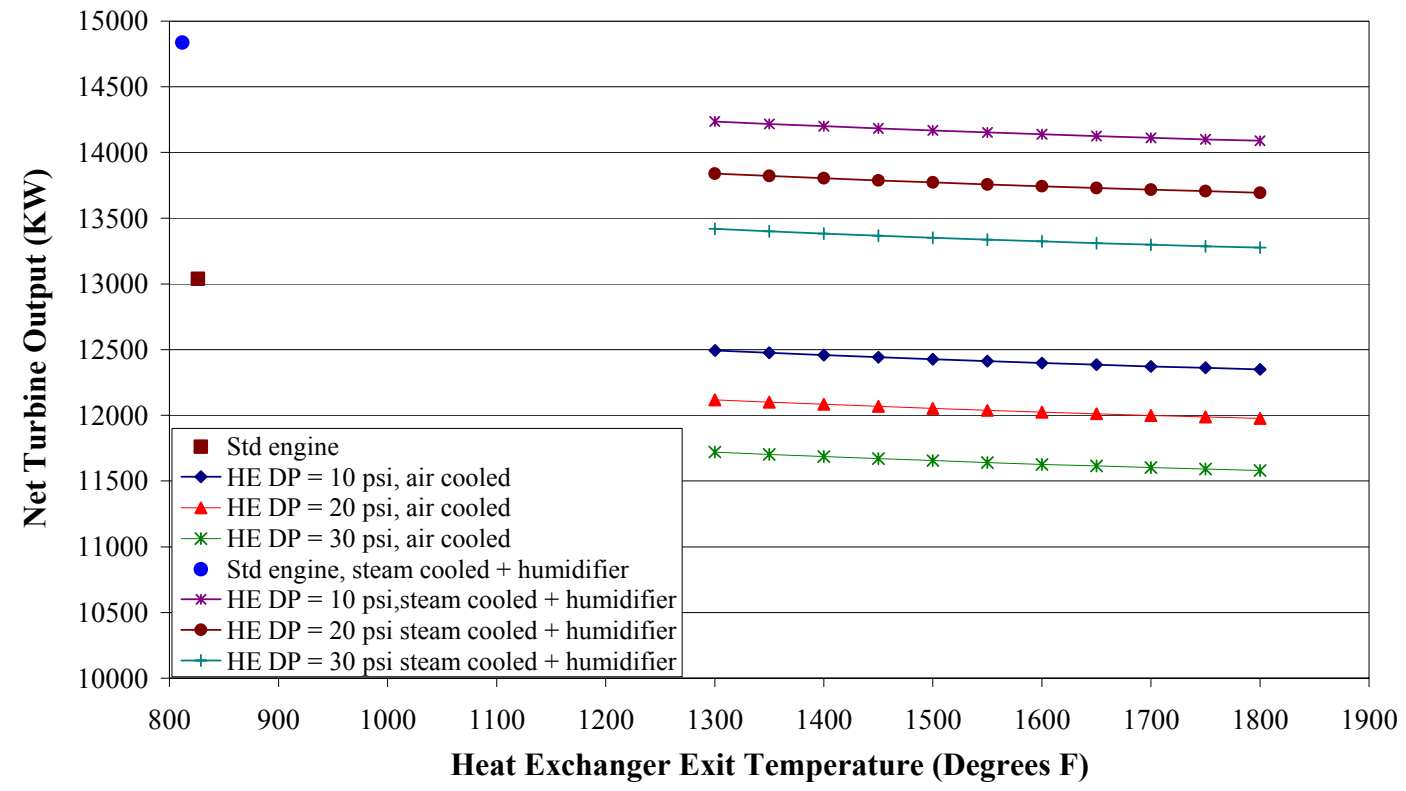

Figure 3.26 Net Turbine Output as a Function of HP/HT Air Heater Pressure Drop and HP/HT Air Heater Exit Temperature for Steam-Cooled Turbine with a Humidifier at Inlet of Compressor Compared to Baseline Cycle using Air-Cooled Turbine without a Humidifier at Inlet of Compressor

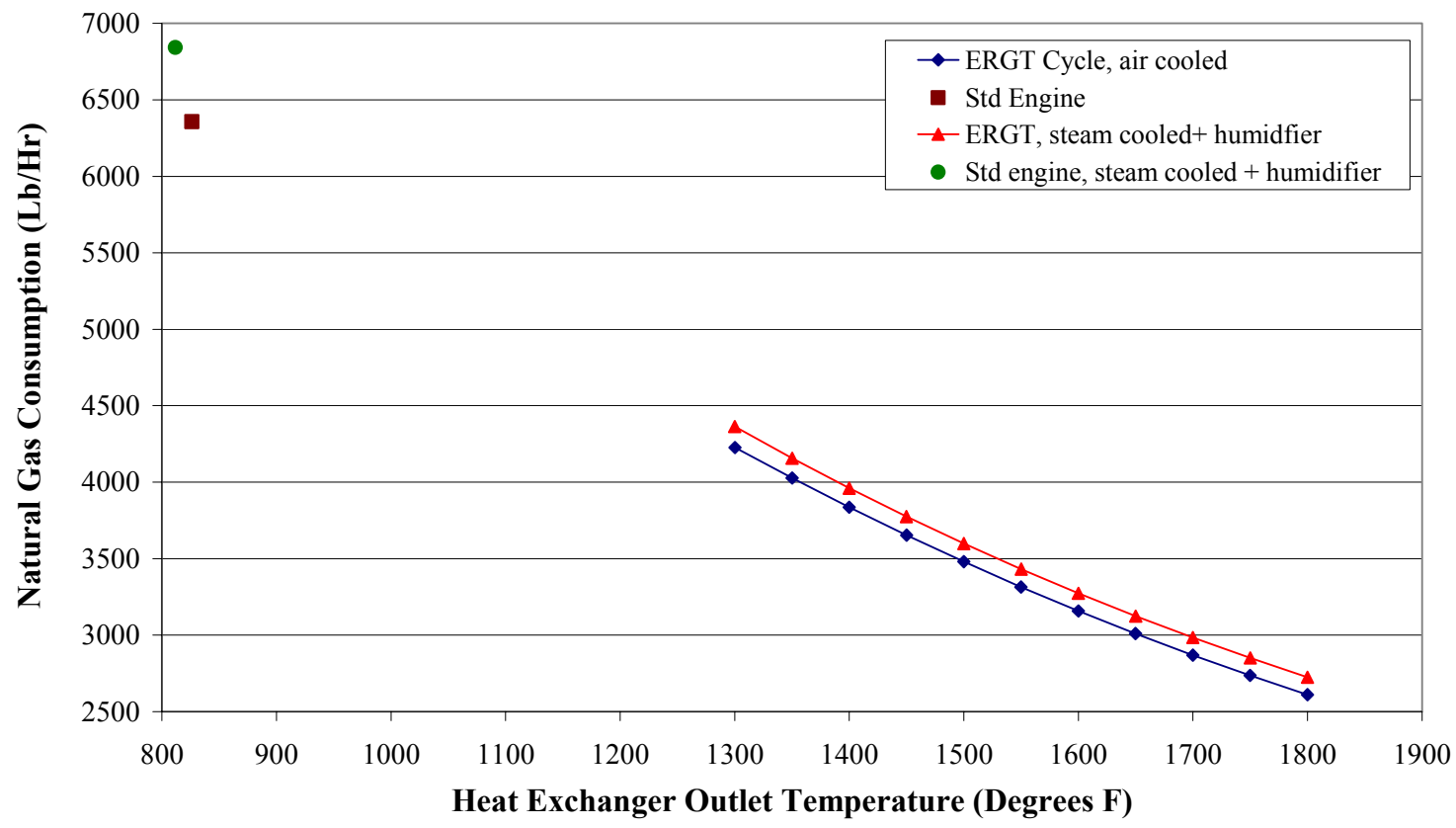

Figure 3.27 Natural Gas Consumption as a Function of HP/HT Air Heater Exit Temperature for Steam-Cooled Turbine with a Humidifier at Inlet of Compressor Compared to Baseline Cycle using Air-Cooled Turbine without a Humidifier at Inlet of Compressor 
Contract Number

PF 13524

\section{Gas Technology Institute}

Advanced Gasification Based Fuel Conversion and Electricity Production System for Forest Product Industry

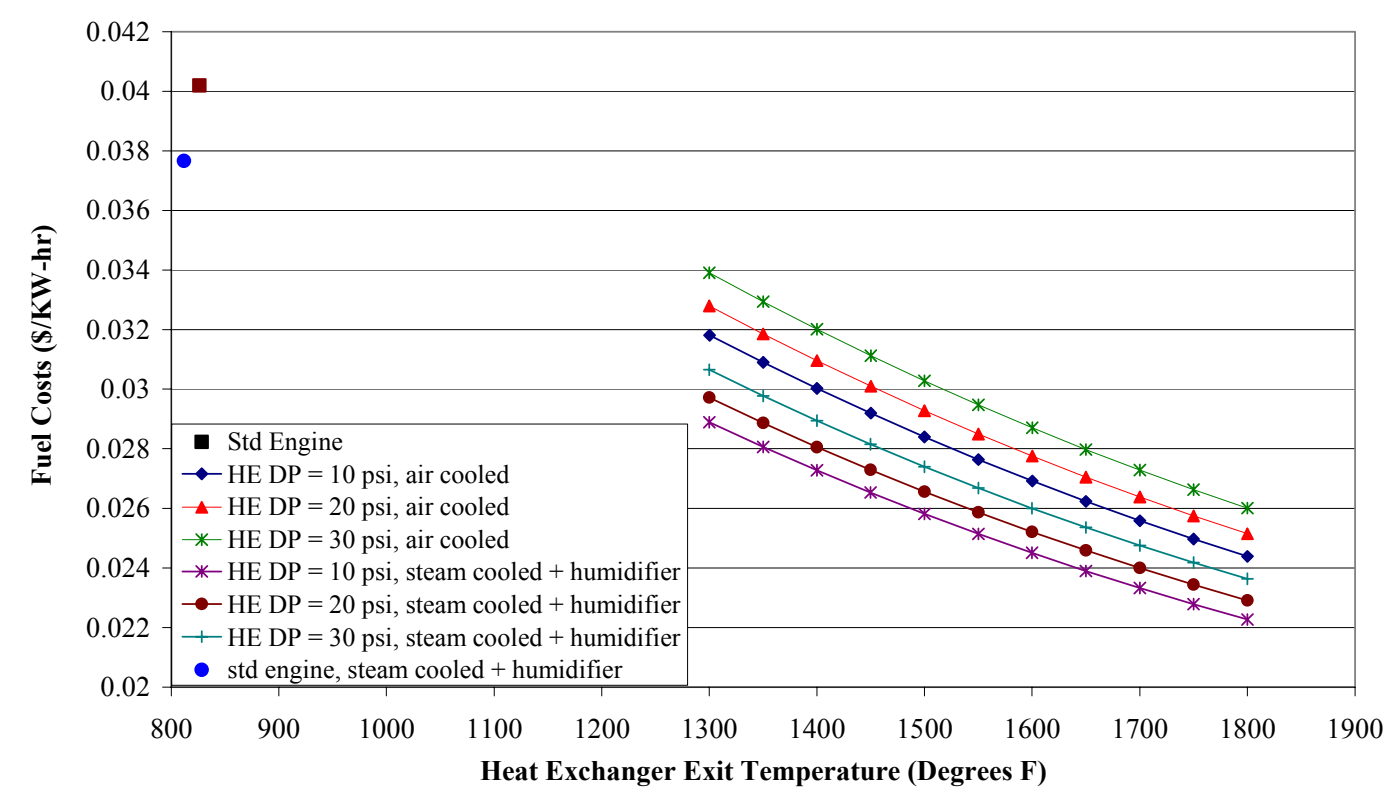

Figure 3.28 Fuel Cost as a Function of HP/HT Air Heater Pressure Drop and HP/HT Air Heater Exit Temperature for Steam-Cooled Turbine with a Humidifier at Inlet of Compressor compared to Baseline Cycle using Air-Cooled Turbine without a Humidifier at Inlet of Compressor

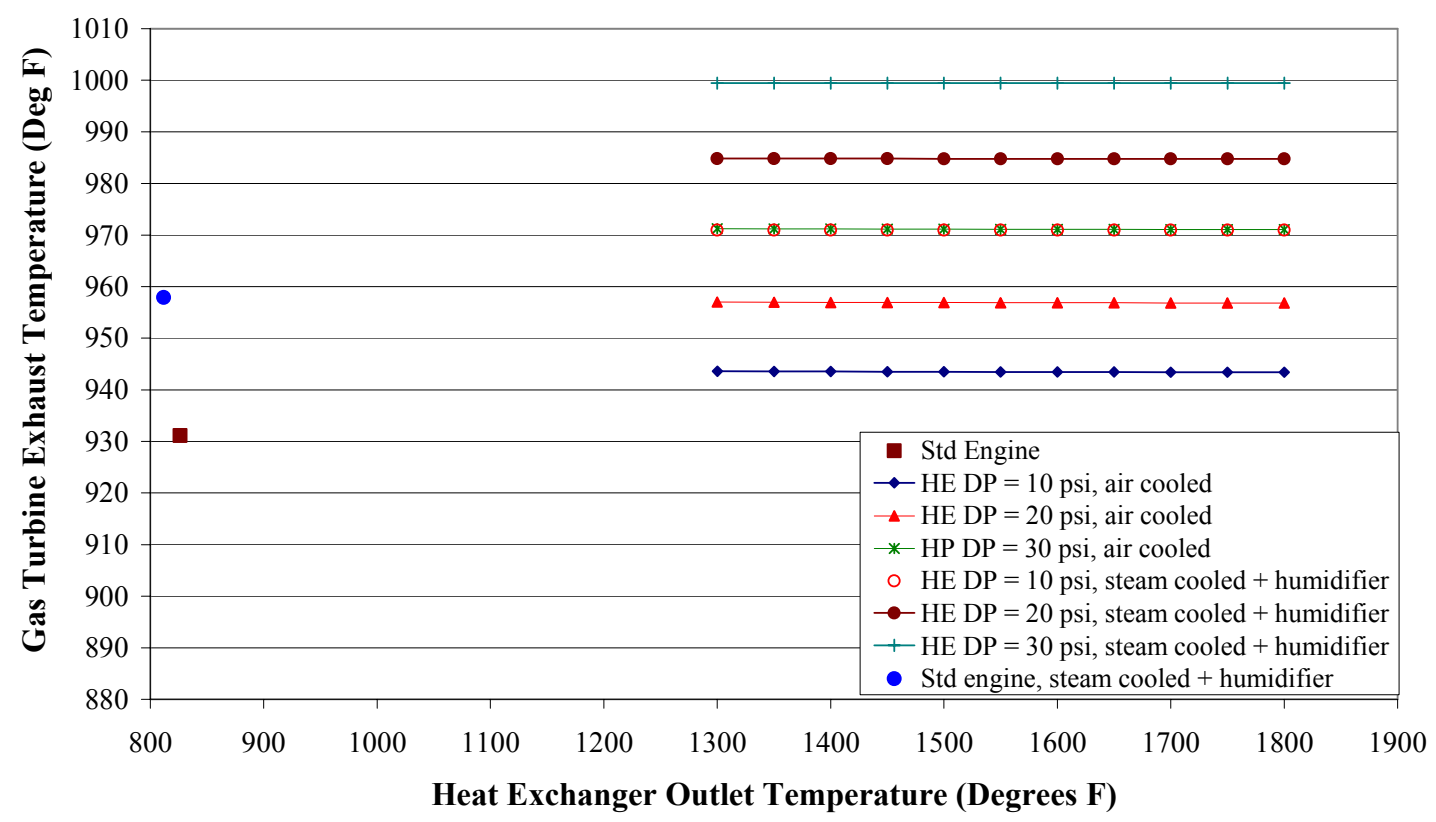

Figure 3.29 Gas Turbine Exhaust Temperature as a Function of HP/HT Air Heater Pressure Drop for Steam-Cooled Turbine with a Humidifier at Inlet of Compressor Compared to Baseline Cycle using Air-Cooled Turbine without a Humidifier at Inlet of Compressor 


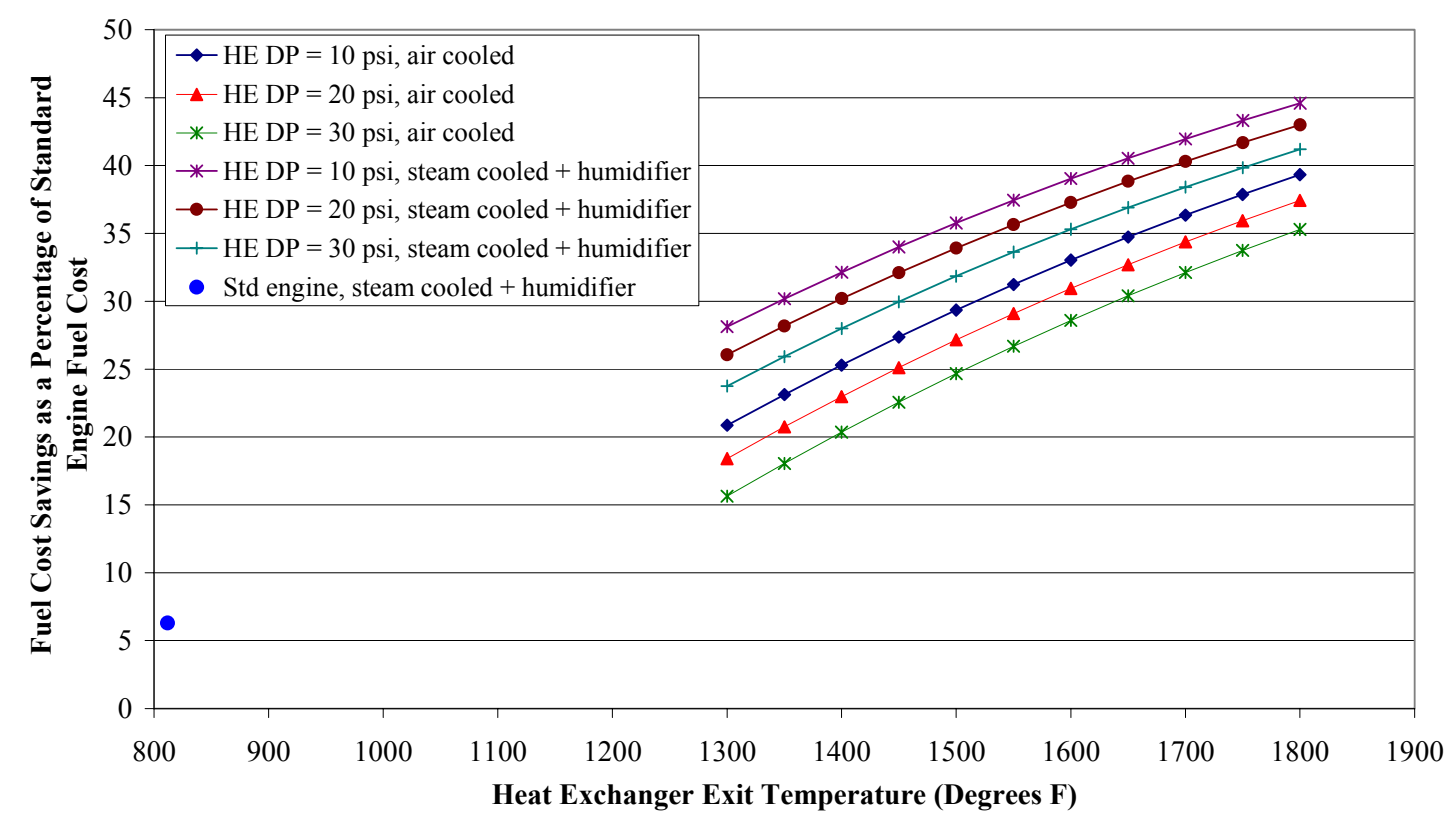

Figure $3.30 \quad$ Percentage Fuel Cost Savings while Operating an ERGT using the Standard Engine Fuel Costs as a Baseline

The results shown above indicate that installation of the humidifier at the inlet of the ERGT using an air-cooled turbine increases the electrical output by about $5 \%$ while the exhaust temperature is decreased by less than $1 \%$. In addition, the installation of the humidifier also increases the savings in fuel cost by about 3\%. All these comparisons are made for the same HP/HT heat exchanger pressure drop.

Similar comparisons made for an ERGT using a steam cooled turbine reveal that using a humidifier at the inlet of the ERGT increases the electrical output by 5\%, while the exhaust temperature drops by less than $1 \%$ and the fuel cost savings is increased by about $3 \%$.

Thus over all, installing a humidifier at the inlet of an ERGT and using steam as the turbine cooling medium increases the electrical output by at least $14 \%$ and the fuel cost savings by at least $8 \%$ when compared to an ERGT that uses air as a turbine cooling medium and does not have humidification equipment installed at the inlet.

When compared to a standard engine, an ERGT that uses air as a turbine cooling medium and does not have humidification equipment installed at the inlet, saves approximately 18\% in fuel cost. A similar comparison between the standard engine and an ERGT that has a humidifier installed at the inlet and uses steam as the turbine cooling medium results in a fuel cost saving of approximately $26 \%$

Based on the above discussion, it can therefore be concluded that thermodynamically an ERGT with a steam-cooled turbine and a humidifier at the compressor inlet is a preferred option. 
Contract Number

PF 13524

\section{Gas Technology Institute}

Advanced Gasification Based Fuel Conversion and

Electricity Production System for Forest Product Industry

\subsection{Conclusions}

The results of the cycle analysis in terms of percentage increase in electrical output and percentage increase in fuel cost savings are summarized in Figure 3.31 through Figure 3.36.

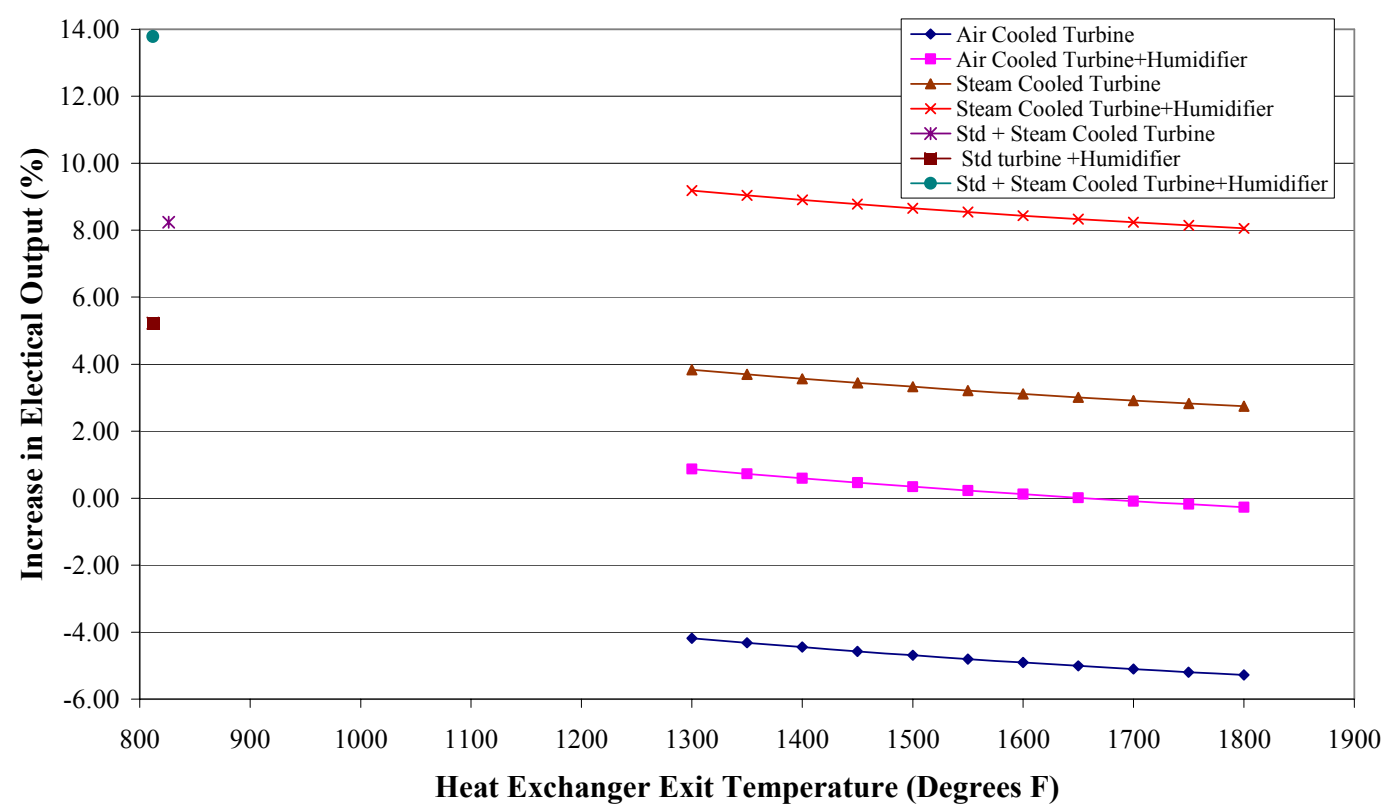

Figure 3.31 Percentage Increase in Electrical Output (with a Standard Engine as the Baseline) for various ERGT Cycles using a HP/HT Heat Exchanger that has a 10psi Pressure Drop

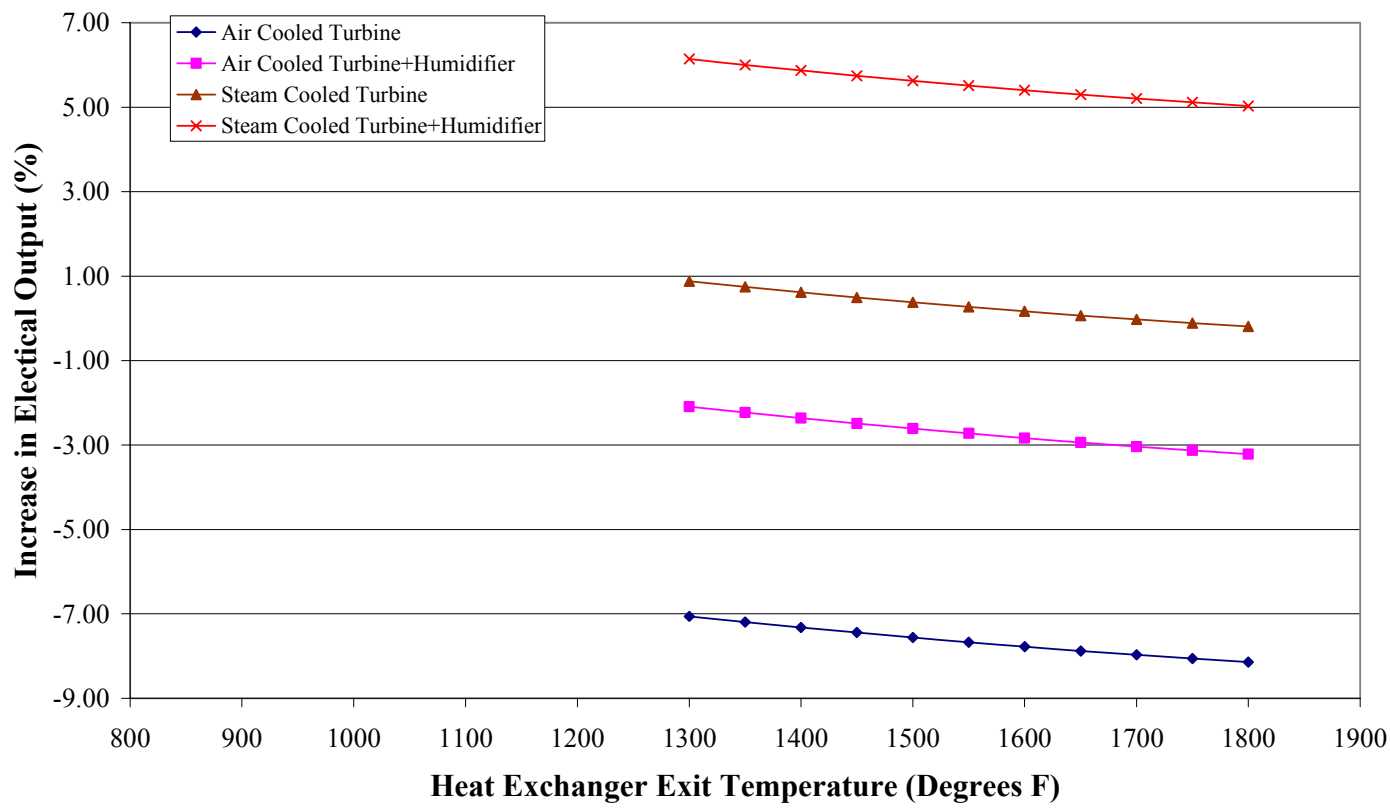

Figure 3.32 Percentage Increase in Electrical Output (with a Standard Engine as the Baseline) for various ERGT Cycles using a HP/HT Heat Exchanger that has a 20psi Pressure Drop 
Contract Number

PF 13524

\section{Gas Technology Institute}

Advanced Gasification Based Fuel Conversion and

Electricity Production System for Forest Product Industry

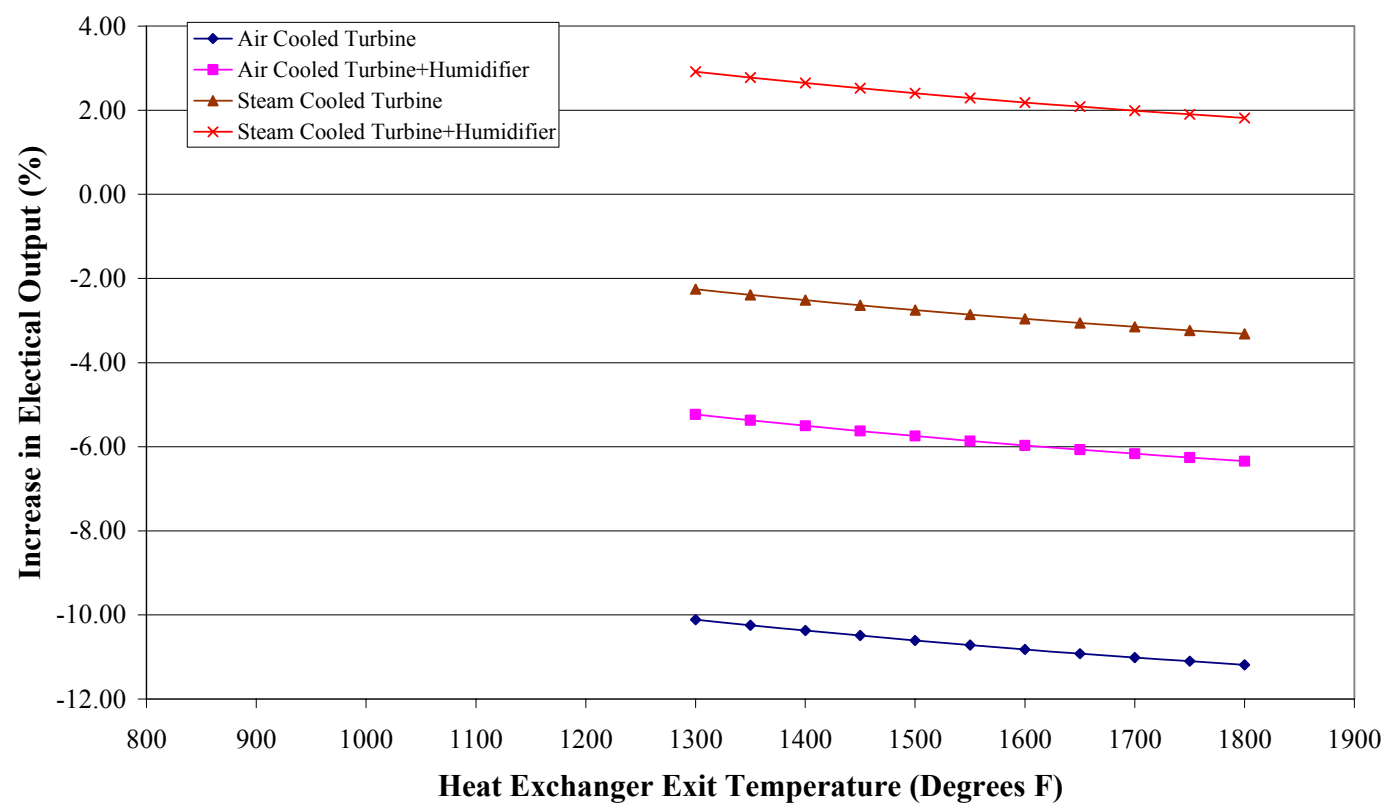

Figure 3.33 Percentage Increase in Electrical Output (with a Standard Engine as the Baseline) for various ERGT Cycles using a HP/HT Heat Exchanger that has a 30psi Pressure Drop

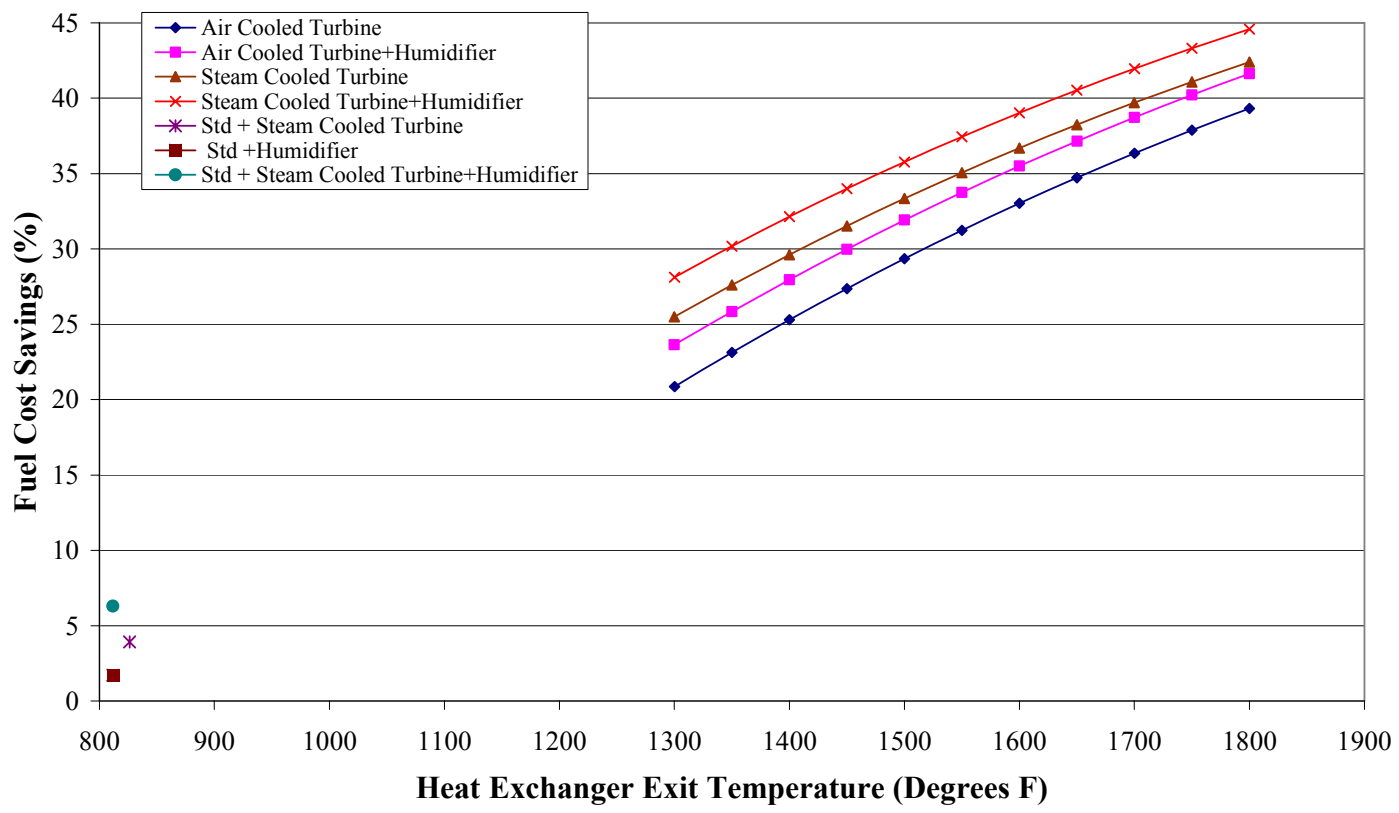

Figure 3.34 Fuel Cost Savings as a Percentage of the Fuel Costs of a Standard Engine for various ERGT Cycles Using a HP/HT Heat Exchanger that has a 10psi Pressure Drop 
Contract Number

PF 13524

\section{Gas Technology Institute}

Advanced Gasification Based Fuel Conversion and

Electricity Production System for Forest Product Industry

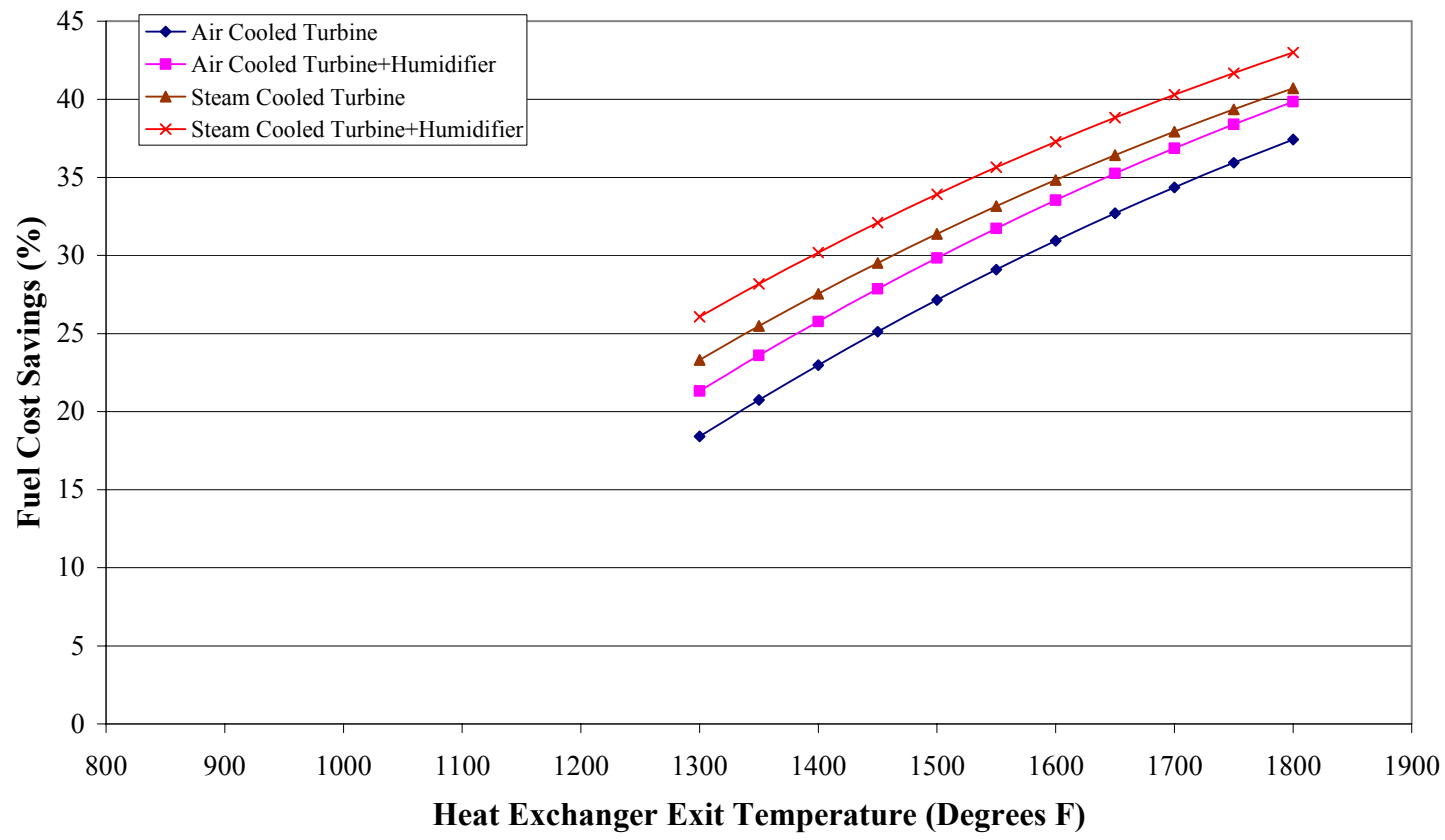

Figure 3.35 Fuel Cost Savings as a Percentage of the Fuel Costs of a Standard Engine for various ERGT Cycles Using a HP/HT Heat Exchanger that has a 20psi Pressure Drop

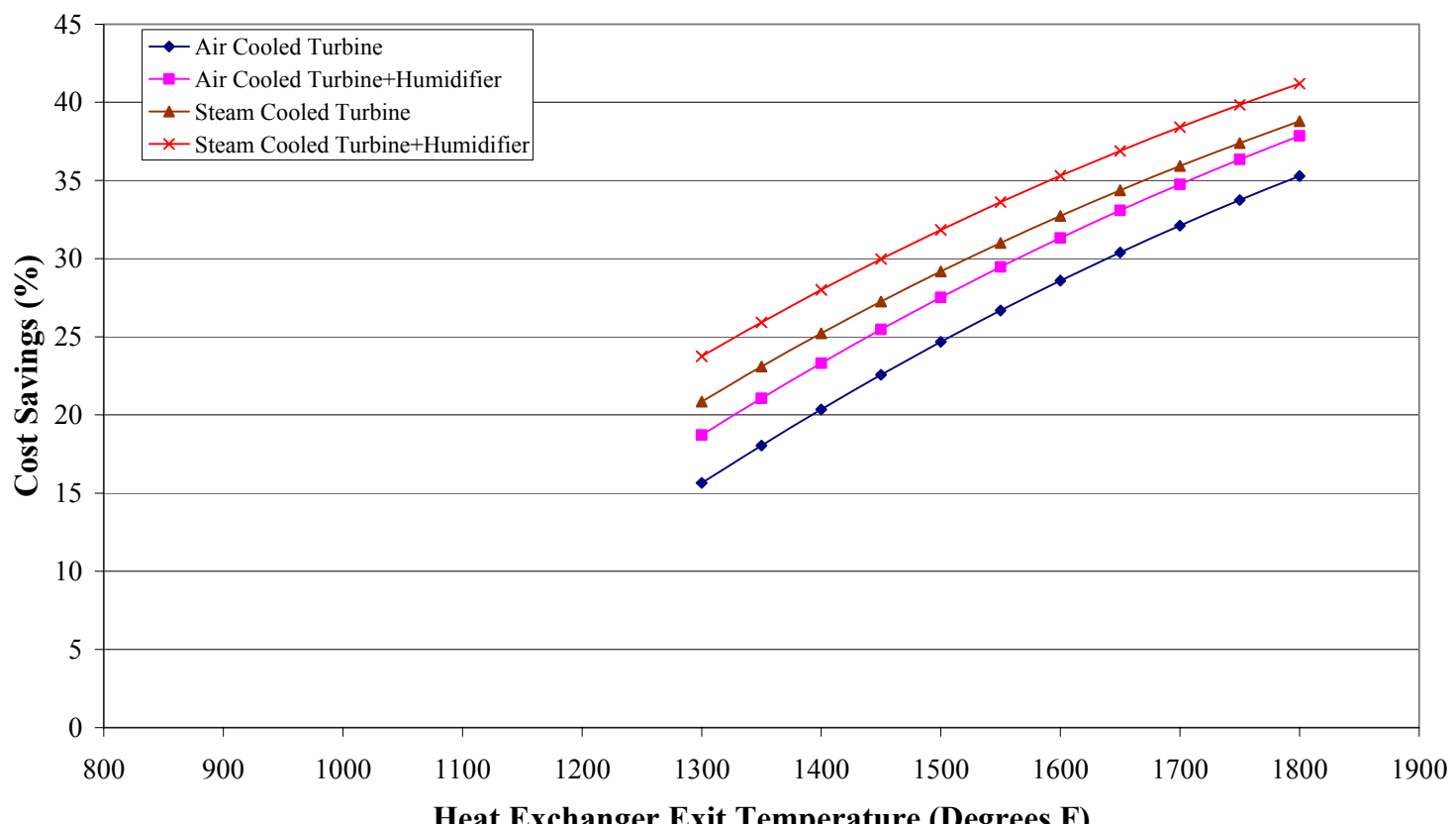

Figure $3.36 \quad$ Fuel Cost Savings as a Percentage of the Fuel Costs of a Standard Engine for various ERGT Cycles using a HP/HT Heat Exchanger that has a 30psi Pressure Drop 
Contract Number

PF 13524
Gas Technology Institute

Advanced Gasification Based Fuel Conversion and Electricity Production System for Forest Product Industry

Based on the results of the thermodynamic analysis summarized above, it is noted that increasing the HP/HT Heat Exchanger exit temperature and reducing the pressure drop across the heat exchanger will help maximize the fuel cost savings. The reduction in pressure drop also increases the net electrical output, but an increase in the heat exchanger exit temperature causes the power output to reduce slightly. Of the various options considered, the most beneficial in terms of fuel cost savings and the net power output is the ERGT cycle that uses steam as the cooling medium for its turbine and has a humidifier installed at the inlet. However, there are physical design constraints for the present gas turbine design that will limit the extent of savings that can be derived from this ERGT cycle. Potential limits for various ERGT cycles are discussed in Section 3.5.

\subsection{Arrangement Drawings, PFD and PI\&D for Recommended Gas Turbine System}

\subsubsection{Titan 130 Package}

Solar has provided information regarding the package layout and installation and commissioning. This includes the arrangement and layout drawings of a standard T130 package (Figure 3.37 through Figure 3.40), and information regarding the various pumps, compression systems and cooling systems used on a standard Titan 130 package. It should be noted that all data provided relate to Solar's present Titan 130 package and do not reflect modifications engineered for the ERGT program.

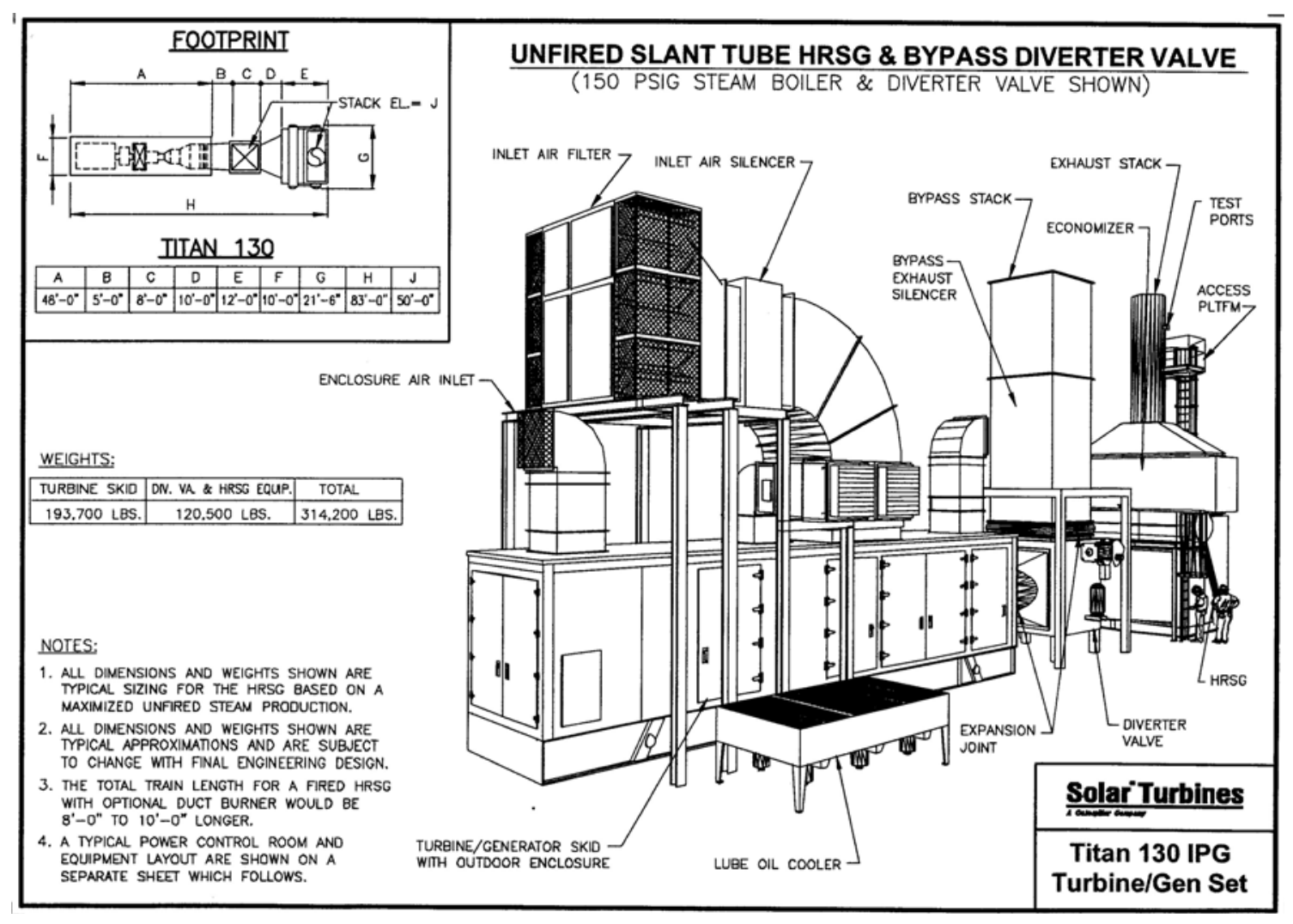

Figure 3.37 Titan 130 IPG Turbine/Gen Set 
Contract Number

PF 13524

\section{Gas Technology Institute}

Electricity Production System for Forest Product Industry

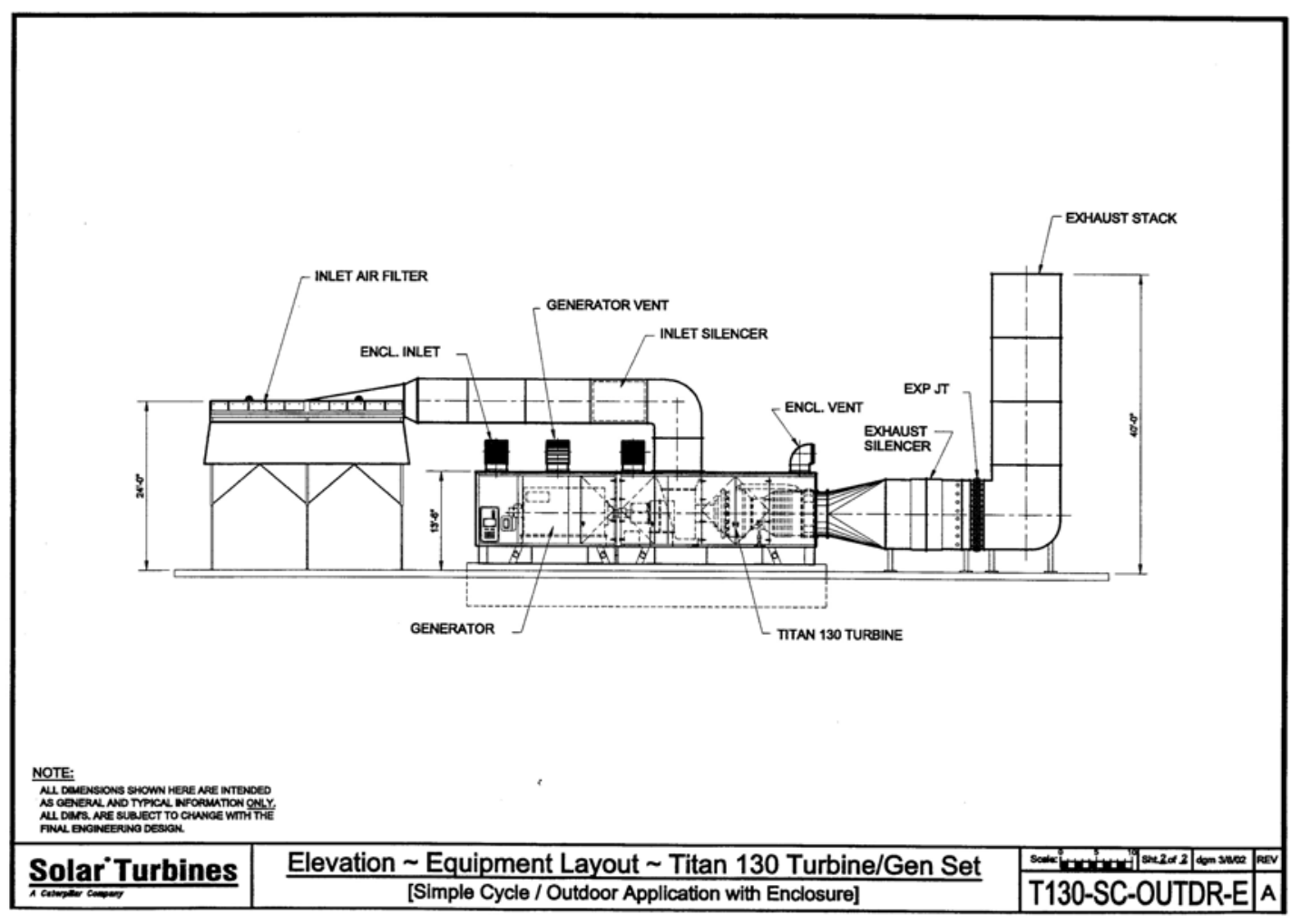

Figure 3.38 Equipment Layout-Titan 130 Turbine /Gen Set

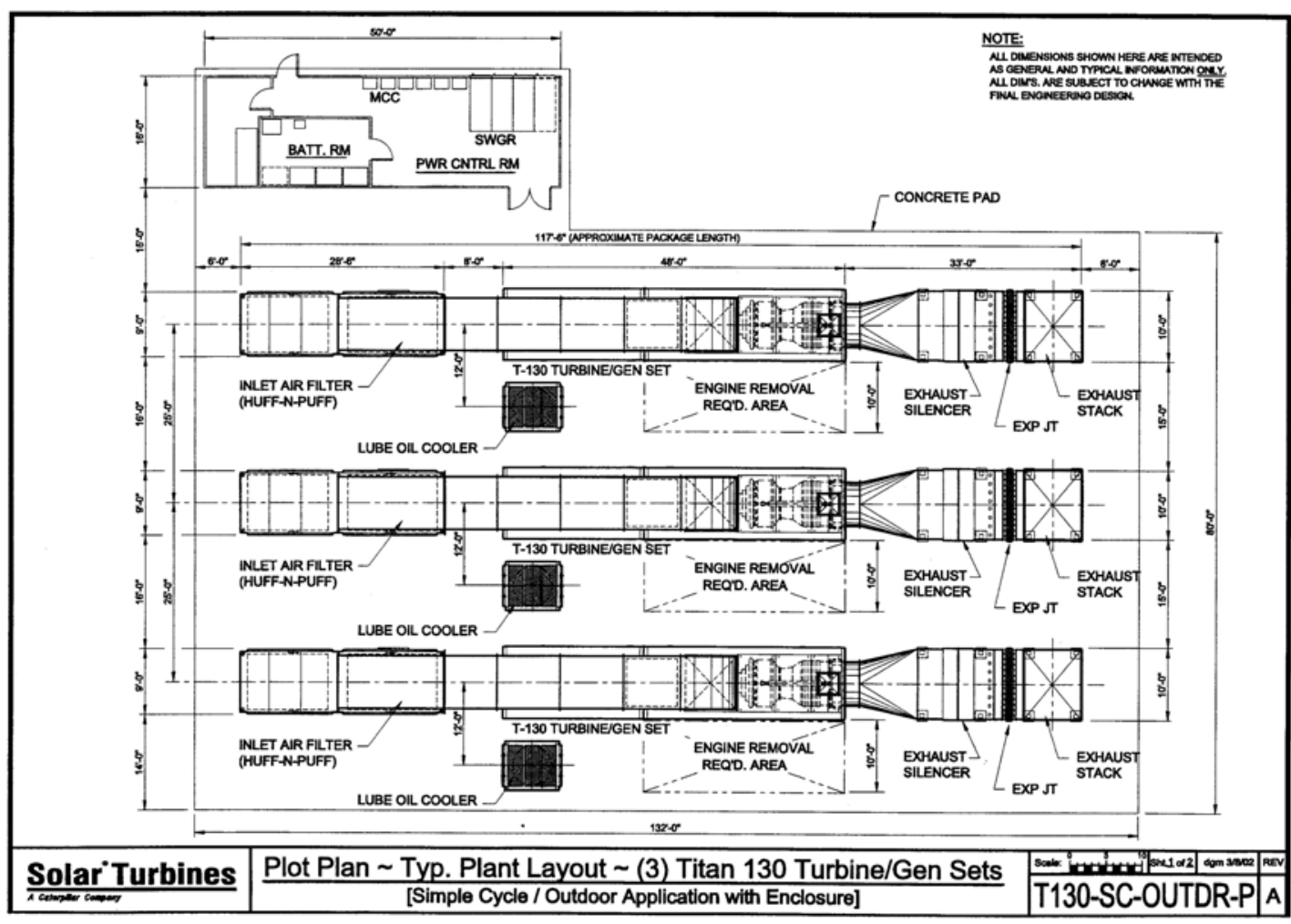

Figure 3.39

Typical plant Layout of Three Titan 130 Turbine/Gen Set 
Contract Number

PF 13524

\section{Gas Technology Institute}

Advanced Gasification Based Fuel Conversion and Electricity Production System for Forest Product Industry

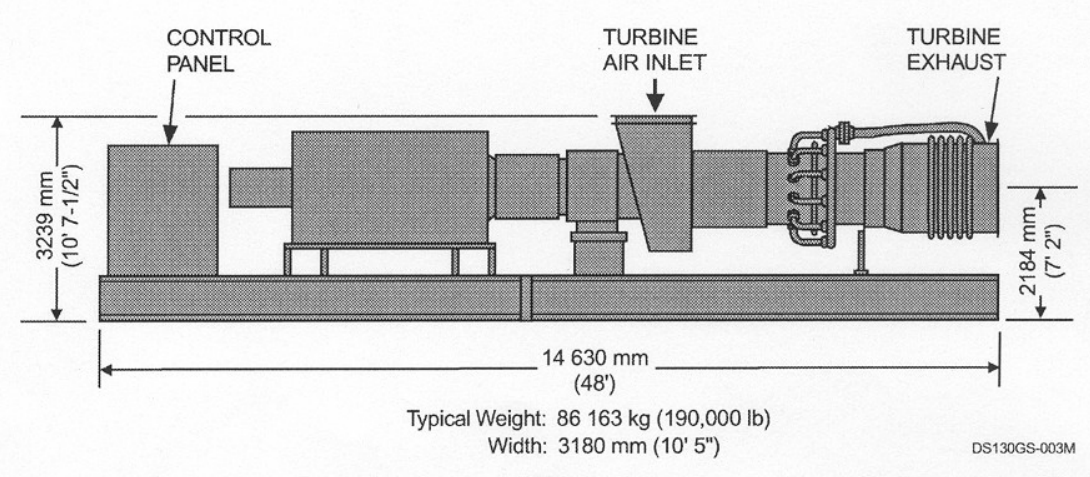

Figure $3.40 \quad$ Titan 130 Package Dimensions

To minimize the development cost of an ERGT based on one of the cycles discussed in Section 3.1, it is recommended that an ERGT be developed by modifying an existing gas turbine. Minimum modifications would include modifying the combustor and providing a passage for the airflow to and from the HP/HT heat exchanger. The possible candidates for such a modification are:

i. A gas turbine that has a side mounted can combustor as shown in Figure 3.41

ii. A gas turbine that has a silo combustor, similar to the one shown in Figure 3.42

iii. A gas turbine that has been designed to run on a recuperated cycle, similar to the one shown in Figure 3.43

Each of these three configurations can accommodate airflows to and from the HP/HT heat exchanger.

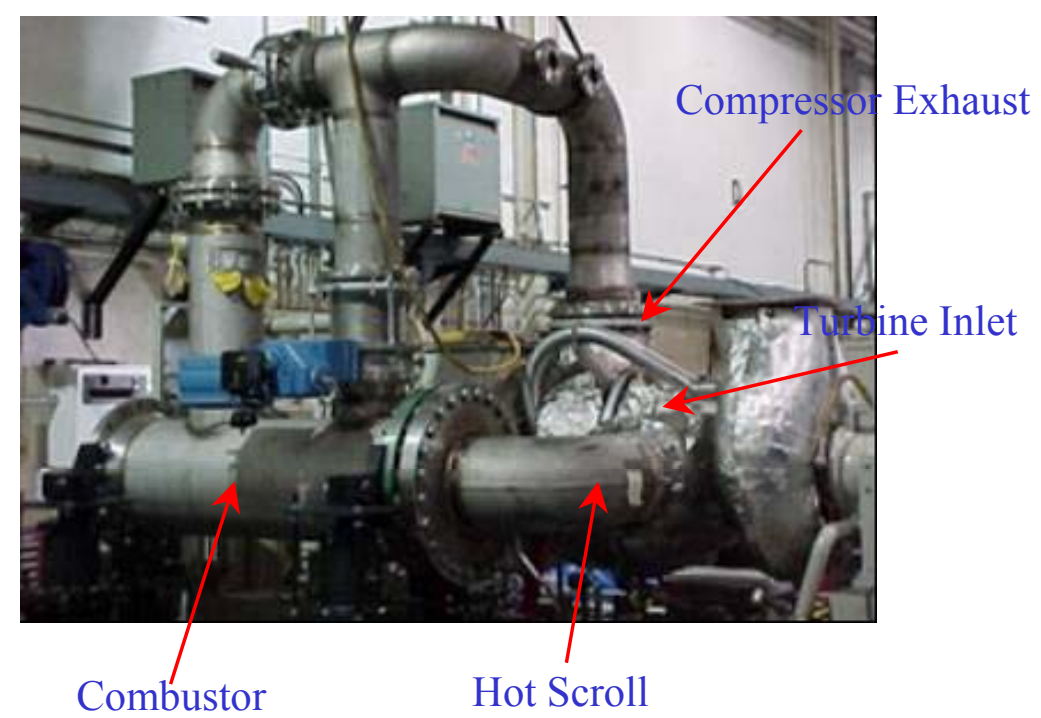

Figure 3.41 Gas Turbine with a Side Mounted Can Configuration 
Contract Number PF 13524

\section{Gas Technology Institute}

Advanced Gasification Based Fuel Conversion and Electricity Production System for Forest Product Industry

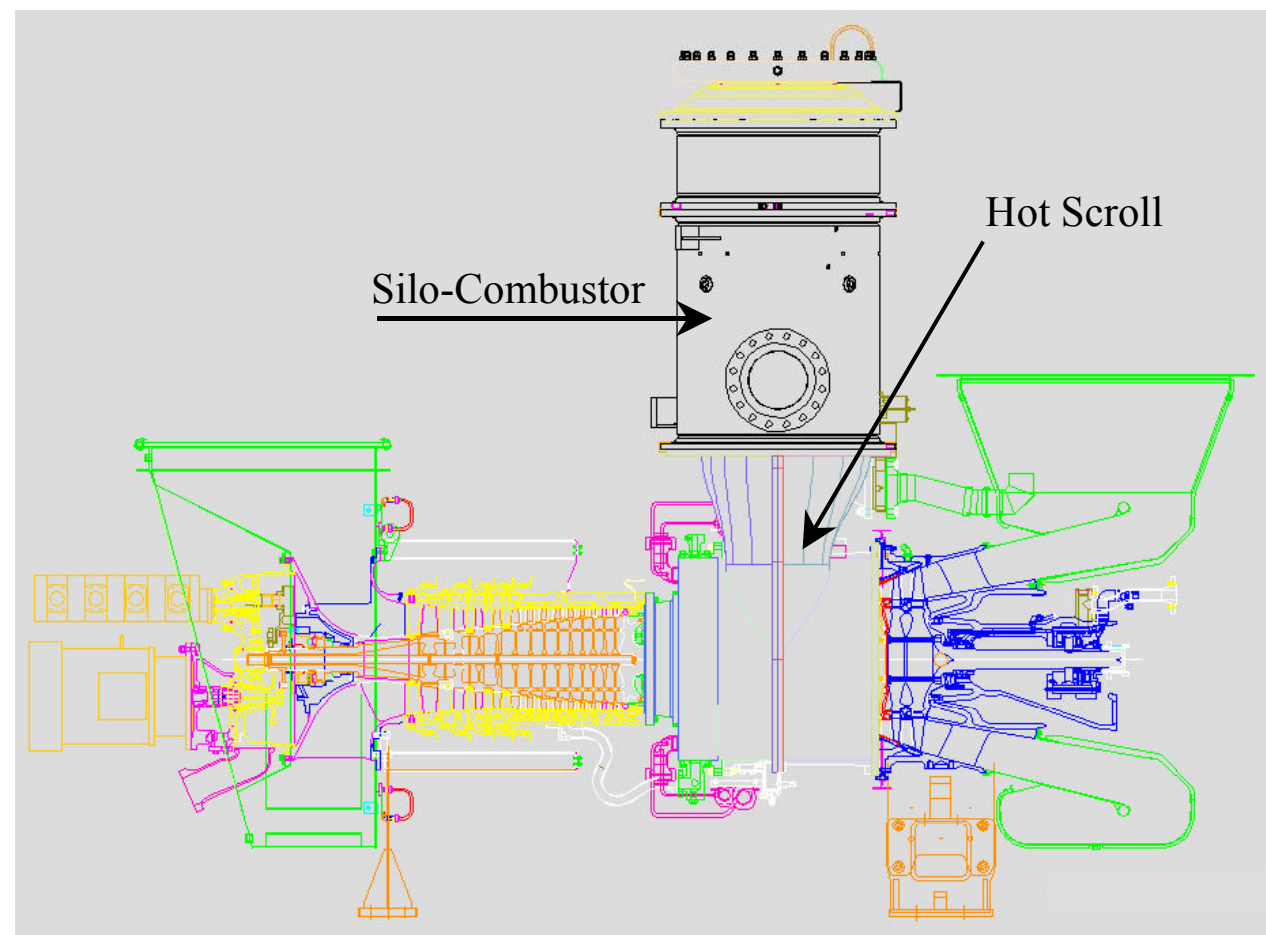

Figure 3.42 A Gas Turbine with a Silo-Combustor and a Hot Scroll

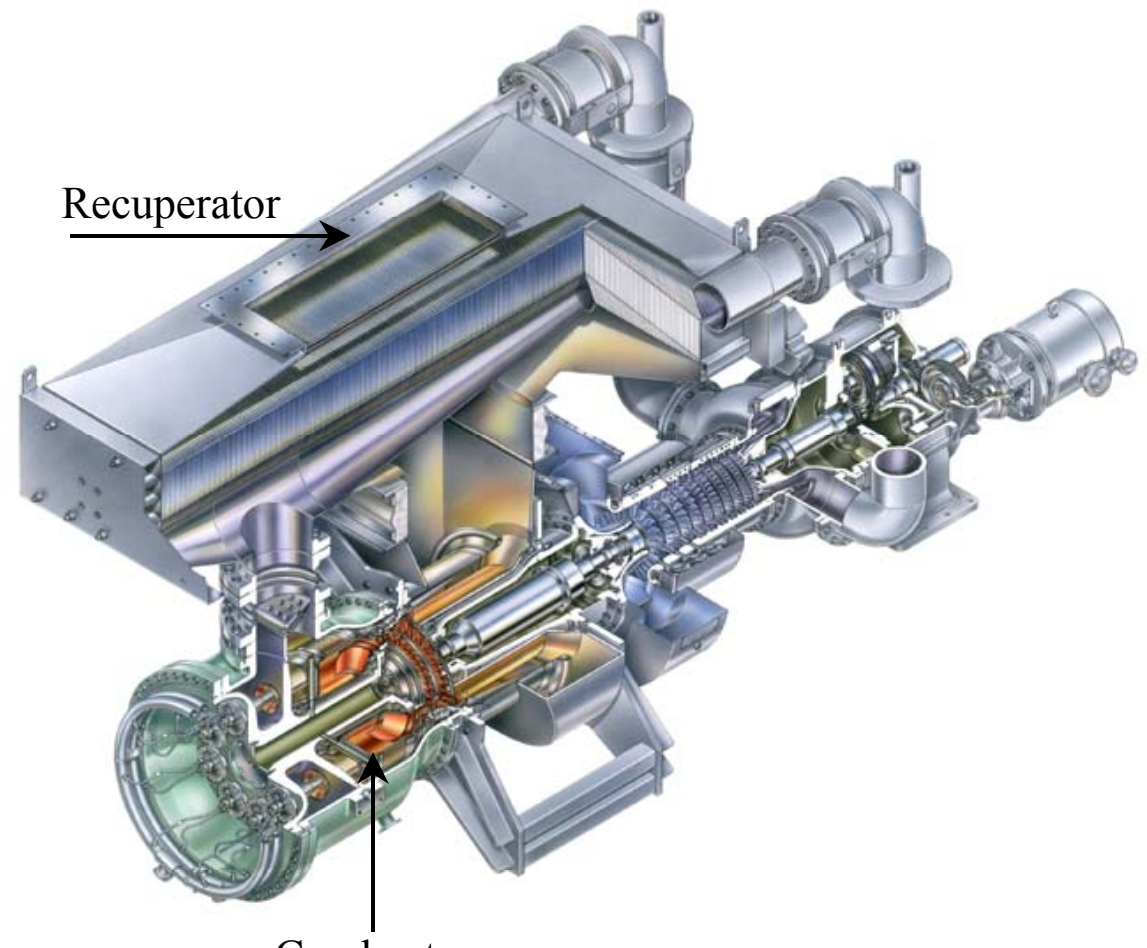

Combustor

Figure 3.43 A Recuperated Gas Turbine 
The production Titan 130 gas turbine that Solar currently offers does not reflect any of the above geometries and is unsuitable for the ERGT application. The effort required to modify this gas turbine to the preferred ERGT cycle is equivalent to developing a new gas turbine. Further, given the present heat exchanger exit temperature limit of $1450^{\circ} \mathrm{F}$ (see Section 3.5), the developmental cost will more than offset any fuel cost savings unless there is a significant market for the ERGT.

\subsection{Equipment Modifications Design Study}

Within the program an assessment was made of the technologies reflected in the ERGT cycle to define near-term improvements. The conclusions drawn from these assessments are presented here.

\subsubsection{Combustor}

For production engines at Solar combustor inlet temperatures range from approximately $690^{\circ} \mathrm{F}$ to $1250^{\circ} \mathrm{F}$. Present materials and premixed combustion technology limitations hinder the design of gas turbine combustors with inlet temperatures greater than $1450^{\circ} \mathrm{F}$. Further, the design effort required to modify present gas turbines to accommodate combustor inlet temperatures of $1450^{\circ} \mathrm{F}$ will be considerable.

\subsubsection{HP/HT Air Heater}

The present study has assumed that the HP/HT air heater will be operated at a pressure drop of $30 \mathrm{psi}$ and an exit air temperature of $1400^{\circ} \mathrm{F}$. With future materials advancement the exit temperature most likely can be increased to $1500^{\circ} \mathrm{F}$. However, the high-pressure drop (30 psi) is incompatible with most small to medium industrial gas turbines. A high-pressure drop will increase the risk of compressor surge. To overcome this hurdle either

i. A new compressor and turbine need to be designed and developed,

Or

ii. The heat exchanger pressure drop has to be reduced below 15 psi.

Reduction of the heat exchanger pressure drop poses technical, cost and practical difficulties as such a reduction would require increased surface area and volume of the air heater (while there is normally a limited space within the furnaces to fit an air heater). Further, this reduction in pressure drop will adversely affect the convective heat transfer coefficient, causing the heat exchanger temperatures to rise. Higher metal temperatures may reduce the life and operational safety of the heat exchanger.

\subsubsection{Steam Cooled Turbine}

Although the ERGT using a steam cooled turbine looks attractive, developing such a turbine cooling system is prohibitively expensive for Solar. This issue will effect most smaller gas turbines where first cost is a critical buying criterion. If such a turbine was developed its capital cost will be substantially higher than current air-cooled gas turbines due to the complexities of the cooling circuits and control systems. It is expected that the high development and manufacturing cost of such a system will nullify the fuel cost savings seen in the cycle analysis, especially as the combustor and heat exchanger designs limit the combustor inlet temperature to $1450^{\circ} \mathrm{F}$. 


\subsection{Market Potential Estimate}

After evaluating the present technologies and the cycle requirements for ERGT in the forest products industry (FPI) applications, it was concluded that on a long-term basis, the FPI could be a potential market. However, to realize this potential the present technologies related to critical components of the cycle including high-pressure air heaters (with low pressure-drop) need significant development. Further materials for gas turbine components such as boost combustor, scroll, etc., need to be developed to effectively sustain air temperatures of up to $1800^{\circ} \mathrm{F}$ without any significant rise in component cost from present levels.

It was also concluded that Solar's present range of products is unsuitable both in size and configuration for the FPI application. However, this conclusion may warrant re-evaluation if in the future Solar adds to its product family an engine configuration that is more adaptable to the FPI application.

\section{Conclusions and Recommendations}

Based on the results of the thermodynamic analysis, it is concluded that increasing the $\mathrm{HP} / \mathrm{HT}$ heat exchanger exit temperature and reducing the pressure drop across the heat exchanger will help maximize the fuel cost savings. The reduction in pressure drop also increases the net electrical output, but increase in heat exchanger exit temperature causes the power output to reduce slightly and raises material durability issues for the ERGT engine casings. Of the various options considered, the most beneficial one in terms of fuel cost savings and net power output is the ERGT cycle that uses steam as the cooling medium for its turbine and has a humidifier installed at its inlet. However, in view of the major redesign effort required for Solar to develop a steam-cooled turbine, it is recommended that presently available air-cooled turbines be used with an inlet fogger/humidifier (when the ambient conditions warrant its use).

Based on the analysis of the present physical design constraints on the various components of an ERGT, it is recommended that an ERGT be developed by modifying existing gas turbines to accommodate a heat exchanger outlet temperature (combustor inlet temperature) of up to $1450^{\circ} \mathrm{F}$. Efforts need to be made to develop an HP/HT air heater that works with a maximum pressure drop of 15 psi so as to minimize changes to present gas turbine designs and keep development costs low.

From a long-term perspective, the ERGT cycle potential can be realized in the coming years if significant improvements can be made to the present technologies related to critical components of the cycle including high-pressure air heaters (having a low pressure-drop). Further materials for gas turbine components such as boost combustor, scroll, etc., need to be developed to effectively sustain air temperatures of up to $1800^{\circ} \mathrm{F}$ without any significant rise in component cost from present levels. 